\title{
Protective Clothing Based on Permselective Membrane and Carbon Adsorption
}

\author{
Phase II Final Report \\ Contract Period: \\ October 25, 1997-September 24, 2001 \\ prepared for \\ U.S. Department of Energy \\ Morgantown Energy Technology Center \\ Morgantown, West Virginia \\ Contract Number DE-AC21-93MC30179 \\ by \\ Membrane Technology and Research, Inc. \\ 1360 Willow Road \\ Menlo Park, CA 94025 \\ November 7, 2001 \\ Contributors to this Report: \\ J.G. Wijmans \\ J.O. Stull (International Personnel Protection, Inc.)
}




\section{DISCLAIMER}

This report was prepared as an account of work sponsored by an agency of the United States Government. Neither the United States Government nor any agency thereof, nor any of their employees, makes any warranty, express or implied, or assumes any legal liability or responsibility for the accuracy, completeness, or usefulness of any information, apparatus, product, or process disclosed, or represents that its use would not infringe privately owned rights.

Reference herein to any specific name, trademark, manufacturer, or otherwise does not necessarily constitute or imply its endorsement, recommendation, or favoring by the United States Government or any agency thereof. The views and opinions of authors expressed herein do not necessarily state or reflect those of the United States Government or any agency thereof.

Available to the public from the National Technical Information Service, U.S. Department of Commerce, 5285 Port Royal Road, Springfield, VA 22161; phone orders accepted at (703) 4874650 . 


\section{ABSTRACT}

The goal of this project was to develop chemical protective clothing for use by DOE decontamination and decommissioning workers that is sufficiently water vapor permeable to keep the workers cool, thereby enhancing their productivity. This report describes the results of Phase II of a two-phase project to complete development of the novel permselective material and to test protective clothing made from the fabric.

In Phase I a novel material incorporating a nonporous hydrophilic polyvinylacohol (PVA) layer, which is water vapor permeable but relatively impermeable to organic vapors, was developed. The results of the Phase I tests showed that the chemical resistance of the MTR material is comparable to that of Saranex/Tyvek materials, and that the comfort properties are closer to those of Tyvek (as measured in terms of CLO and permeability). Chemical resistance was measured using permeation tests against liquid dichloromethane. Comfort properties were ascertained by measuring the water vapor transmission of the material and by sweating manikin tests on whole protective suits. In addition, a cost/benefit analysis demonstrated that use of MTR's material technology could result in significant improvements in work productivity and cost savings if protective clothing items made from the new material were used more than once.

In Phase II, MTR undertook a program to optimize the performance and production engineering for the new material technology. A partnership was formed with Kimberly-Clark Corporation to assist with a detailed evaluation of the MTR technology, and MTR used the services of Mr. Jeff Stull, President of the consulting firm International Personnel Protection, Inc., who conducted a detailed economic and application analysis for the developed fabric. The protective fabric manufacturing steps were simplified significantly, resulting in a 30\% reduction in manufacturing costs and eliminating the necessity for capital investment in production equipment. Protective suits were prepared in collaboration with Kimberly-Clark Corporation and heat stress testing with human test subjects was carried out by the International Union of Operating Engineers (IUOE). The tests confirmed that the MTR protective fabric is significantly more comfortable than non-breathable materials.

A cost analysis was developed from the properties of the optimized protective fabric and the results of the of the IUOE field study to determine the potential for the MTR material technology within the chemical protective clothing market. A detailed assessment of the specific chemical protective clothing applications for which the material can be used and its competitiveness with existing material technology, based both on expected performance and material/end item costs, was prepared. Three specific market opportunities identified for the novel protective fabric are: (1) liquid splash protective clothing for hazardous waste site operations, (2) liquid splash protective clothing for emergency response, and (3) Class 3 NFPA 1994-compliant protective clothing for civilian use during chemical terrorism incidents. 
DISCLAIMER $\ldots \ldots \ldots \ldots \ldots \ldots \ldots \ldots \ldots \ldots \ldots \ldots \ldots \ldots \ldots \ldots \ldots \ldots$

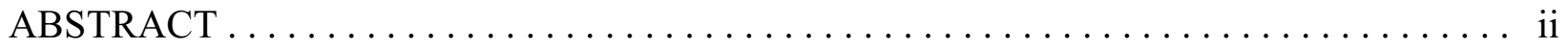

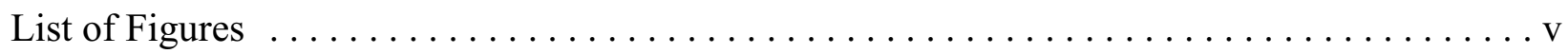

List of Tables $\ldots \ldots \ldots \ldots \ldots \ldots \ldots \ldots \ldots \ldots \ldots \ldots \ldots \ldots \ldots \ldots \ldots \ldots \ldots$

EXECUTIVE SUMMARY $\ldots \ldots \ldots \ldots \ldots \ldots \ldots \ldots \ldots \ldots \ldots \ldots \ldots \ldots$

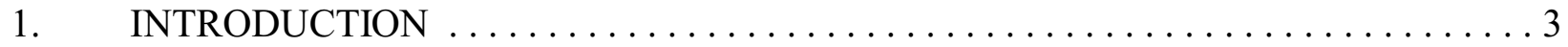

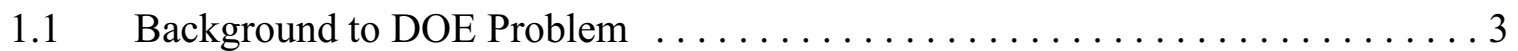

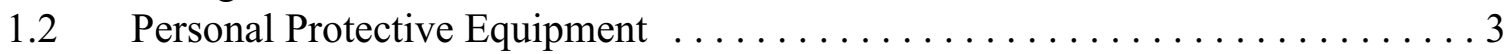

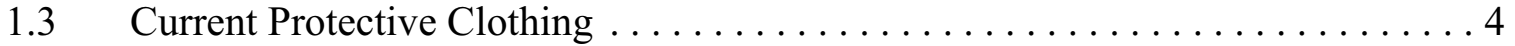

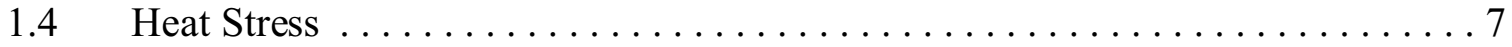

2. PHASE I SUMMARY AND PHASE II GOALS $\ldots \ldots \ldots \ldots \ldots \ldots \ldots \ldots \ldots \ldots 1$

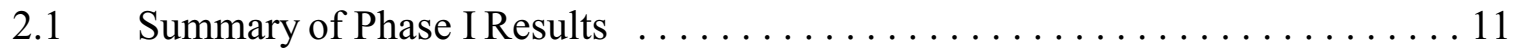

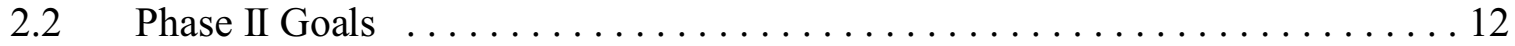

3. IDENTIFY COMMERCIAL PARTNERS $\ldots \ldots \ldots \ldots \ldots \ldots \ldots \ldots \ldots \ldots \ldots$

4. MODIFY PROTECTIVE FABRIC / PRODUCE PROTECTIVE FABRIC . . . . . . . . 14

5. PREPARE PROTECTIVE SUITS AND TEST AT IUOE FACILITIES $\ldots \ldots \ldots \ldots$

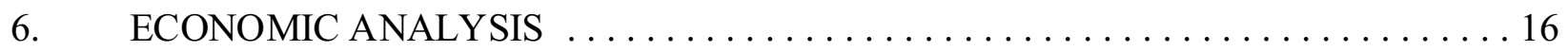

$6.1 \quad$ Estimate of Fabric Production Costs $\ldots \ldots \ldots \ldots \ldots \ldots \ldots \ldots \ldots \ldots$

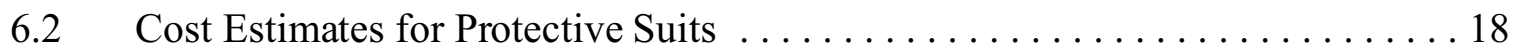

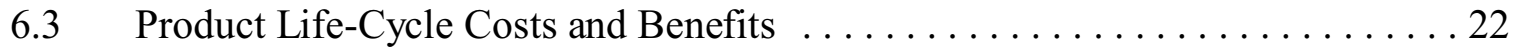

7. CHEMICAL PROTECTIVE CLOTHING MARKET ANALYSIS $\ldots \ldots \ldots \ldots \ldots$

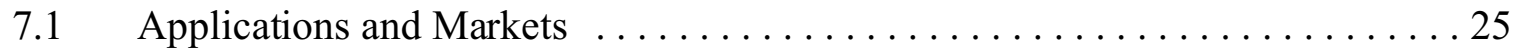

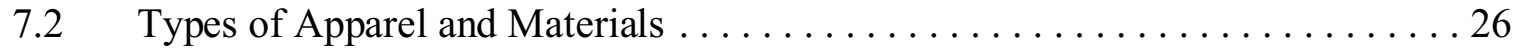

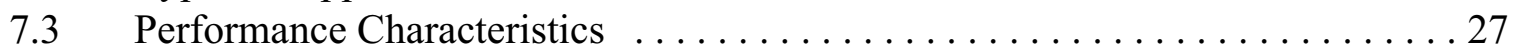

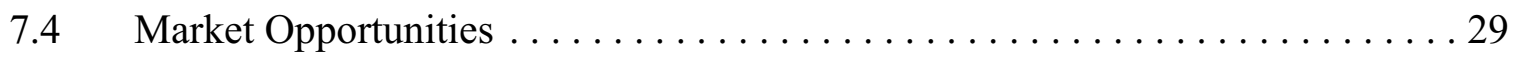

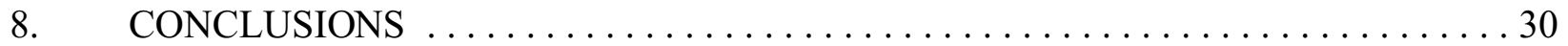

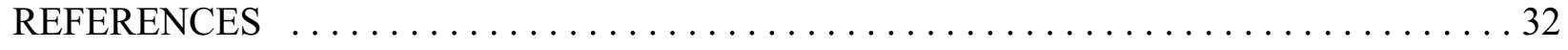


PROJECT REPORTS:

APPENDIX A: Chemical Protective Clothing Standards Organizations and Trade Groups A-1 APPENDIX B: Full IUOE Report ( 74 pages). . . . . . . . . . . . . . . . . . B-1 


\section{List of Figures}

Figure 1. Water vapor permeability and protective characteristics of commercially available clothing $[\mathrm{PE}=$ polyethylene $] . \ldots \ldots \ldots \ldots \ldots$

Figure 2. Heat stress exposure limits recommended by the American Conference of Government Industrial Hygienists (ACGIH) $\ldots \ldots \ldots \ldots \ldots$

Figure 3. Effect of clothing type on heat stress exposure limits

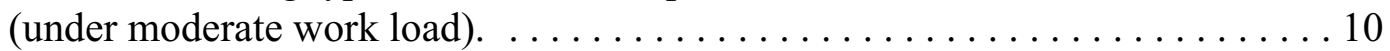

Figure 4. Structure of the MTR-X protective fabric developed in Phase II. . . . . . . . 15

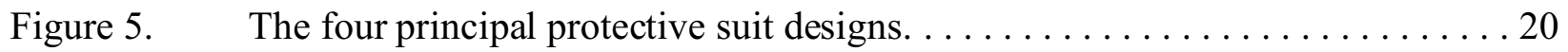




\section{List of Tables}

Table 1. EPA Levels of Chemical Protective Clothing. $\ldots \ldots \ldots \ldots \ldots \ldots$

Table 2. Properties of MTR and Commercially Available Protective Fabrics

Determined in Phase I. . . . . . . . . . . . . . . . . . . . . . 11

Table 3. Chemical Permeation Resistance of MTR-2 Protective Fabric Compared

with Saranex-Coated Tyvek. . . . . . . . . . . . . . . . . . . . 12

Table 4. Fabrication Cost Estimates for the MTR-X Fabric Compared with the Lowest Estimate Arrived at in Phase I. . . . . . . . . . . . . . . . 17

Table 5. Representative Costs of Available Chemical Protective Clothing Fabrics. . . . 18

Table 6. Rules of Thumb for Calculating the Cost Elements for the Four Principal Protective Suit Designs Shown in Figure 5. . . . . . . . . . 21

Table 7. Cost Estimates for Protective Suits Made from the MTR-X Fabric for the Four Protective Suit Designs Shown in Figure $5 . \quad \ldots \ldots \ldots \ldots \ldots \ldots 21$

Table 8. Comparison of Cost to End User of the MTR-X Protective Suits (see Table 7) with Existing Industry Products. . . . . . . . . . . . . 22

Table 9. Life-Cycle Cost Estimates for Three Types of Chemical Protective Coveralls. ............................ 23

Table 10. Comparison of Cost-Benefit Calculations for the MTR-X Coveralls with Those for Saranex/Tyvek and PVC Coveralls. . . . . . . . . . . 24

Table 11. Key Characteristics of Applications for Chemical Protective Clothing. . . . . . 26

Table 12. Comparison of Market Segment Opportunities for Permselective/Adsorptive Material Technologies. . . . . . . . . . . . . . 30 


\section{EXECUTIVE SUMMARY}

The goal of this project was to develop chemical protective clothing for use by DOE decontamination and decommissioning workers that is sufficiently water vapor permeable to keep the workers cool, thereby enhancing their productivity. This report describes the results of Phase II of a two-phase project to complete development of the novel permselective material and test protective clothing made from the fabric.

In Phase I a novel material incorporating a nonporous hydrophilic polyvinylacohol (PVA) layer, which is water vapor permeable but relatively impermeable to organic vapors, was developed. The results of the Phase I tests showed that the chemical resistance of the MTR material is comparable to that of Saranex/Tyvek materials, and the comfort properties are closer to those of Tyvek (as measured in terms of CLO and permeability). Chemical resistance was measured using permeation tests against liquid dichloromethane. Comfort properties were ascertained by measuring the water vapor transmission of the material and by sweating manikin tests on whole protective suits. In addition, a cost/benefit analysis demonstrated that use of MTR's material technology could result in significant improvements in work productivity and cost savings if protective clothing items made from the new material were used more than once.

In Phase II, MTR undertook a program to optimize the performance and production engineering for the new material technology. A partnership was formed with Kimberly-Clark Corporation to assist with a detailed evaluation of the MTR technology, and MTR used the services of Mr. Jeff Stull, President of the consulting firm International Personnel Protection, Inc., who conducted a detailed economic and application analysis for the developed fabric.

In Phase II the structure of the fabric was modified without modifying its function. The microporous support produced by MTR was replaced with a commercially available material consisting of a microporous polyethylene layer supported by a nylon substrate. This material was laminated back-to-back with the PVA layer, which provides the resulting fabric with its protective properties. As a result, the fabric manufacturing steps were simplified significantly, which resulted in a $30 \%$ reduction in manufacturing costs compared to those calculated in Phase I. Additionally, the need for capital investment in production equipment was completely eliminated because the lamination step can be carried out by third-party laminators.

Protective suits were prepared in collaboration with Kimberly-Clark Corporation using the modified fabric developed in Phase II. The International Union of Operating Engineers (IUOE) conducted a field evaluation to determine how well the MTR-fabric-based coveralls performed compared to currently available products of this type. In addition to the MTR coveralls, the evaluation involved coveralls constructed of polyvinyl chloride (PVC), which offers comparable liquid splash protection, and Tyvek, which is considered to offer less chemical protection but greater breathability. The IUOE study entailed a thoroughly validated human study involving 15 human subjects for each material type and the measurement of body-core temperature during specific work tasks representing hazardous materials remediation activity, including: 
- A confined space task involving crawling and manipulation of tools

- A pit task where test subjects climbed into a pit and simulated nuclear rod removal

- A wheelbarrow task entailing the shoveling and transport of sand from one location to another.

All coveralls were similarly designed and used in the same manner for these evaluations. Data were subjected to an analysis of variance to determine if statistically significant differences were found between garment materials during the various tasks. Significant differences were found between the three types of coveralls, notably that the MTR coveralls allowed body-core temperature to dissipate more thoroughly than the PVC coveralls. Qualitative results based on subjective questionnaires also rated the MTR coveralls as more comfortable than similar coveralls constructed of PVC. Although Tyvek coveralls demonstrated lower rises in body-core temperature and better overall test subject perception of comfort, the barrier properties of such garments would be considered unacceptable for most operations involving the potential for liquid chemical exposure.

The cost information developed for the optimized protective fabric was combined with the results of IUOE field study to determine the potential for the MTR material technology within the chemical protective clothing market. A cost-benefit analysis showed that the predicted increase in productive time per work cycle achieved by the newly developed fabric reduces the cost per productive hour worked compared to PVC or Saranex/Tyvek coveralls.

The report provides a detailed assessment of the specific chemical protective clothing applications for which the material can be used and its competitiveness with existing material technology, based both on expected performance and on material/end item costs. Three specific market opportunities identified for the novel protective fabric are: (1) liquid splash protective clothing for hazardous waste site operations, (2) liquid splash protective clothing for emergency response, and (3) Class 3 NFPA 1994-compliant protective clothing for civilian use during chemical terrorism incidents. 


\section{INTRODUCTION}

The goal of this project was to develop chemical protective clothing for use by DOE decontamination and decommissioning workers that will increase worker productivity—because it is cooler and more comfortable than conventional protective clothing - while maintaining protection against chemical liquids and vapors.

This report describes the results obtained in Phase II of a two-phase project to develop the protective fabric and to demonstrate its utility in field trials. A detailed description of the results obtained in Phase I is given in the Phase I Final Report submitted to the Department of Energy (1). In Phase II, the protective fabric developed in Phase I was modified to allow for more economical production. A small number of prototype suits were made by Kimberly-Clark Corporation, and a preliminary suit evaluation was conducted at the test facility of the International Union of Operating Engineers (IUOE). An economic analysis was performed to identify the potential markets for this novel type of protective suit.

\subsection{Background to DOE Problem}

Over the next three decades, the Department of Energy faces an enormous decontamination and decommissioning task as facilities associated with research, development, and production of atomic weapons are closed. This task is complex and expensive because many sites are contaminated with a variety of hazardous compounds ranging from asbestos, mercury and other heavy metals, to toxic organic compounds, such as PCB and chlorinated solvents, and radioactive metals and salts. Because of the hazards of exposure to these materials, workers must frequently wear completely encapsulating protective protective suits. These protective suits are impermeable to particulates, aerosols, and organic vapors and provide good protection from toxic contaminants. However, the suits are heavy, time consuming to don and remove, and most importantly, are impermeable to water vapor. Because the suits are water vapor impermeable, body heat cannot readily escape. As a result, workers easily become heat stressed and must rest frequently.

\subsection{Personal Protective Equipment}

When performing decontamination and decommissioning tasks at hazardous or radioactive facilities, the equipment and procedures used to protect the workers also lower worker efficiency and productivity. Depending on the hazards present, workers may be required to wear respiratory protection; particle, liquid, or vapor resistant clothing; layered boots and gloves; and a even selfcontained breathing apparatus (SCBA). These items of personal protective equipment (PPE) reduce worker efficiency and productivity for several reasons, including:

- $\quad$ Restricted mobility, vision, and communication.

- Increased fatigue due to their weight and restrictiveness. 
- $\quad$ Reduced working time because of the non-working time required for donning and doffing PPE, decontamination, equipment changes (for example, air tanks), and special training and inspection.

- Increased heat stress due to impermeability to water vapor (sweating cannot effectively cool the body if water vapor cannot escape from the suit), requiring more frequent breaks and reducing efficiency while working.

The degree to which these factors affect worker productivity depends on the seriousness of the hazard present at the site.

The EPA has categorized four levels of chemical protective clothing; the level required for a given situation depends on the amount and toxicity of the chemicals present, the duration of exposure, and the physical environment. In extreme (or unknown) conditions, the highest level of skin and respiratory protection (Level A) is required. Level A protection requires a gas-tight, fully encapsulating suit with gas-tight closures to boots and gloves. Breathing air must be supplied by an SCBA or an airline respirator. To protect against many chemical agents found at hazardous sites, the suit must be gas-tight, and the fabric must not allow significant permeation of the chemical. To achieve this high degree of protection, the worker must contend with heavy/bulky equipment, thick/stiff fabrics, and hot/water-impermeable suits.

Less hazardous situations require less protective equipment. Level B protection is used when the skin-absorption hazard of the chemical is not as severe as at Level A. Level B protection includes the same respiratory protection as Level A (SCBA), but non-gas-tight suits are acceptable. Level C requires the same protective clothing as Level $\mathrm{B}$, but a respirator is used instead of an SCBA. The lowest level of protection defined by the EPA, Level D, consists of essentially standard work clothing. Depending on the site, all levels may require use of a hard hat, protective gloves, hearing protection, and foot protection.

These EPA standards are not the only guidelines available to users of PPE.(2) The National Fire Protection Association has a set of very specific standards for protective guidelines; OSHA also has standards that, although not very specific, are enforceable by law. Manufacturers of protective equipment also provide advice on the suitability of their equipment for use under various conditions. In the end, the user must determine which type of PPE is appropriate for the specific conditions of the particular site being worked on; these decisions require individuals with expertise in health and safety issues, an understanding of the types of PPE available, and knowledge of the hazards to be encountered at the site.

\subsection{Current Protective Clothing}

As with PPE in general, different levels of personal protective clothing (PPC) are used under different hazardous conditions. The types of PPC that correspond approximately to the EPA's levels 
of protection are shown in Table $1 .^{1}$ Typically the protective clothing used at DOE sites is of the Level B or $\mathrm{C}$ variety. Although these suits are light and relatively inexpensive, they are impermeable to water and therefore hot, increasing the potential for heat stress and reduced productivity.

Another way to look at the current state of chemical protective clothing is to compare the protection characteristics and the comfort characteristics of commercially available clothing. Figure 1 shows a qualitative comparison of these characteristics for several commercial suits. Clothing worn against particulate hazards ranges from permeable to impermeable; typically clothing worn to protect against volatile organic compounds (VOCs) is completely impermeable to water vapor.

1 The EPA does not describe specific standards for clothing to meet their guidelines for protective levels, so these clothing types are MTR's interpretation of the PPC appropriate for a particular level of protection. 
Table 1. EPA Levels of Chemical Protective Clothing.

\begin{tabular}{|c|c|c|c|}
\hline Protection Level & Hazards & Fabric & Construction \\
\hline $\begin{array}{l}\text { Level A: } \\
\text { Extreme }\end{array}$ & $\begin{array}{l}\text { Respiratory, } \\
\text { Skin } \\
\text { (vapor and liquid) }\end{array}$ & $\begin{array}{l}\text { Extremely resistant to } \\
\text { chemical permeation and } \\
\text { degradation }\end{array}$ & $\begin{array}{l}\text { One-piece, } \\
\text { gas-tight, } \\
\text { sealed seams }\end{array}$ \\
\hline $\begin{array}{l}\text { Level B: } \\
\text { Moderate }\end{array}$ & $\begin{array}{l}\text { Respiratory, } \\
\text { Skin } \\
\text { (vapor and liquid) }\end{array}$ & $\begin{array}{l}\text { Moderately resistant to } \\
\text { chemical permeation and } \\
\text { degradation }\end{array}$ & Sealed seams \\
\hline $\begin{array}{l}\text { Level C: } \\
\text { Low }\end{array}$ & $\begin{array}{l}\text { Respiratory, } \\
\text { Skin (liquid) }\end{array}$ & $\begin{array}{l}\text { Resistant to chemical } \\
\text { degradation and penetration } \\
\text { by liquids; no permeation } \\
\text { resistance }\end{array}$ & $\begin{array}{l}\text { Cheap, breathable (cool), light } \\
\text { and flexible, no chemical } \\
\text { protection Sewn seams }\end{array}$ \\
\hline $\begin{array}{l}\text { Level D: } \\
\text { Very low }\end{array}$ & & No chemical protection & Sewn seams \\
\hline Protection Level & \multicolumn{2}{|c|}{ Commercial Examples } & Characteristics \\
\hline $\begin{array}{l}\text { Level A: } \\
\text { Extreme }\end{array}$ & \multicolumn{2}{|c|}{$\begin{array}{l}\text { Challenge } 6400(R, M, v E) \\
\text { Responder }(D, M, E) \\
\text { Chemrel Max (D, M, E) } \\
\text { Trellchem Extra (R, S, vE) }\end{array}$} & $\begin{array}{l}\text { Expensive, impermeable to water } \\
\text { vapor (very hot), thick and stiff, } \\
\text { cumbersome }\end{array}$ \\
\hline $\begin{array}{l}\text { Level B: } \\
\text { Moderate }\end{array}$ & \multicolumn{2}{|c|}{$\begin{array}{l}\text { Tyvek/Saranex-coated Tyvek Haz-Mat Response } \\
\text { Suit (D, M, I) } \\
\text { Tychem } 9400 \text { Splash Suit (D, M, E) } \\
\text { Kappler CPF IV Splash Suit (D, M, E) }\end{array}$} & $\begin{array}{l}\text { Moderate cost, impermeable to } \\
\text { water vapor (very hot), } \\
\text { cumbersome, only moderate } \\
\text { chemical protection }\end{array}$ \\
\hline $\begin{array}{l}\text { Level C: } \\
\text { Low }\end{array}$ & \multicolumn{2}{|c|}{$\begin{array}{l}\text { Coveralls made from variety of fabrics including } \\
\text { Tyvek, Tyvek/Saranex-coated Tyvek, Tyche, } \\
\text { Kappler CPF, Chemrel, PVC, Neoprene, } \\
\text { Comfort-Gard (D or R, S or M, I or C) }\end{array}$} & $\begin{array}{l}\text { Cheap, low water vapor } \\
\text { permeation (hot), light and } \\
\text { flexible, little chemical protection }\end{array}$ \\
\hline $\begin{array}{l}\text { Level D: } \\
\text { Very low }\end{array}$ & \multicolumn{2}{|c|}{$\begin{array}{l}\text { Clothing made from variety of fabrics including } \\
\text { Tyvek, Cotton, Polyester, etc. } \\
\text { (D or } \mathrm{R}, \mathrm{S} \text { or } \mathrm{M}, \mathrm{I} \text { or } \mathrm{C} \text { ) }\end{array}$} & $\begin{array}{l}\text { Cheap, breathable (cool), light } \\
\text { and flexible, no chemical } \\
\text { protection }\end{array}$ \\
\hline
\end{tabular}

$\mathrm{D}, \mathrm{R} \quad=$ disposable, reusable

$\mathrm{S}, \mathrm{M} \quad=$ single layer fabric, multilayer composite fabric

$\mathrm{VE}, \mathrm{E}, \mathrm{I}, \mathrm{C}=$ very expensive $(>\$ 1,000)$, expensive $(>\$ 100-\$ 1,000)$, moderate price $(>\$ 20-100)$, inexpensive $<\$ 20)$ 


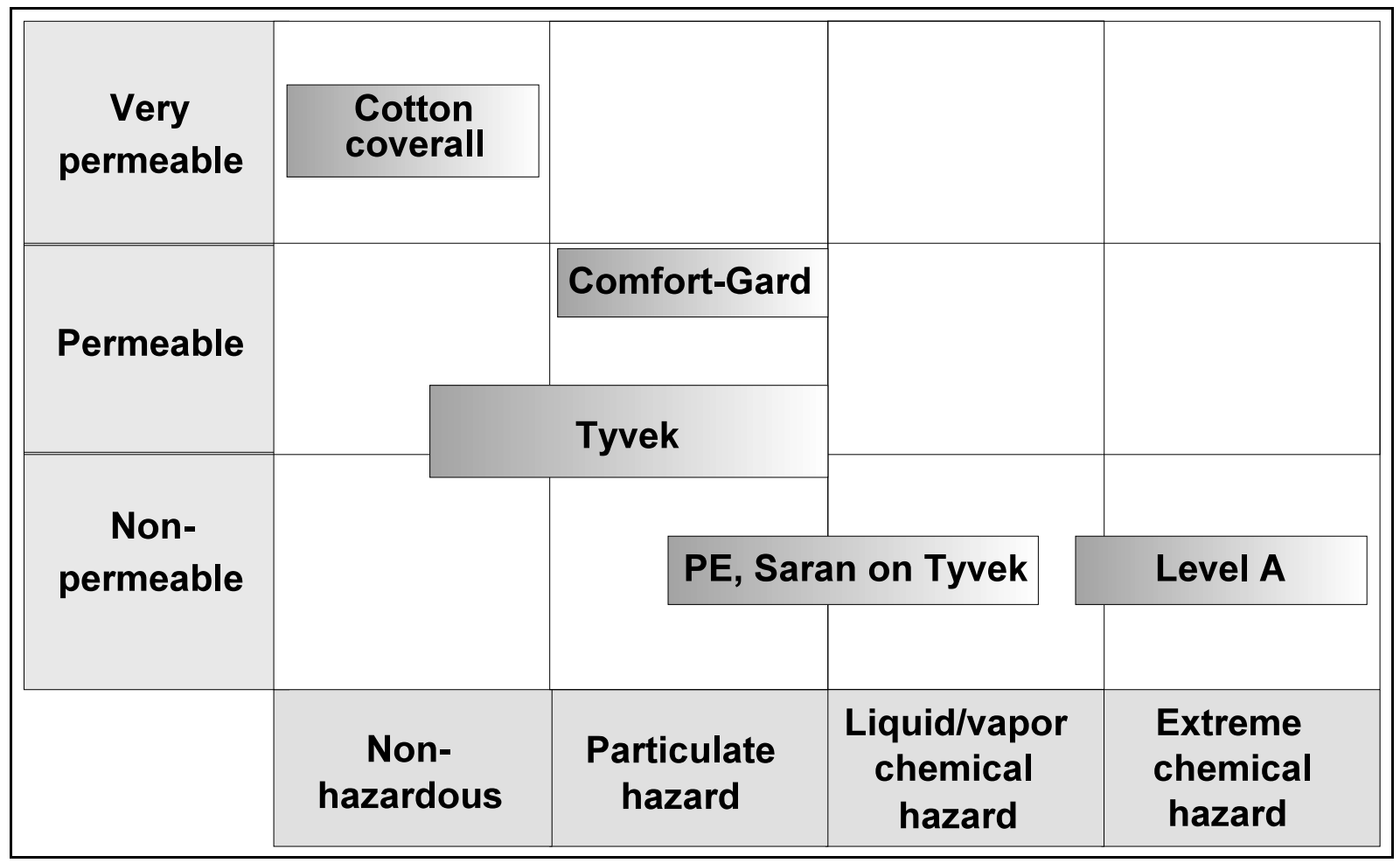

Figure 1. Water vapor permeability and protective characteristics of commercially available clothing $[\mathrm{PE}=$ polyethylene].

\section{$1.4 \quad$ Heat Stress}

Heat stress, which refers to a number of illnesses resulting from overheating, is one of the primary drawbacks of wearing protective clothing.(3-6) As the body's core temperature rises above $98.6^{\circ} \mathrm{F}$, motor and mental skills become sluggish. Cramps, heat fatigue and exhaustion, dizziness, collapse, or even stroke may follow. These problems are known under a variety of names including heat rash, heat fatigue, heat cramp, heat exhaustion, heat collapse, and heat stroke.

The potential for heat stress depends on two factors: the rate at which the body generates heat and the rate at which the body can dissipate heat to the environment. The body naturally generates heat through metabolism; as metabolism increases (for example, through strenuous activity), the amount of heat generated also increases.

To maintain a constant temperature, the body must get rid of this metabolic heat by dissipating it to the environment. If the body cannot dissipate enough heat, body temperature begins to rise, resulting in heat stress. Heat dissipation occurs by a number of mechanisms including conduction, convection, 
radiation, and evaporation. The environmental conditions (temperature, humidity, air movement) determine how much heat can be dissipated by each mechanism. For example, on cold, windy days, heat is easily lost through convection; on high humidity days, very little heat can be lost through evaporation. The human body has two mechanisms to actively control heat dissipation. The first is regulation of blood flow near the skin; as body temperature increases, the blood flow is increased to the skin, from which heat is dissipated to the air by conduction. The closer the surrounding air temperature is to the body temperature, the less effective is this mechanism at dissipating heat and cooling the body. As the air temperature rises, more and more heat is dissipated by the second mechanism-evaporation. At air temperatures above $95^{\circ} \mathrm{F}$, almost all heat is lost through evaporation. The body exploits the evaporation mechanism through sweating; as sweat evaporates, it carries heat with it and cools the body. If the surrounding air is saturated with water, sweat will not evaporate, and this cooling mechanism is not effective.

From the proceeding discussion, it is apparent that the potential for heat stress rises when:

- The rate of metabolic heat generation is high (from strenuous activity).

- The rate of convective heat dissipation is low (due to either high ambient temperature or to clothing that insulates the body or prevents air flow to the body).

- The rate of evaporative heat transfer is low (because ambient humidity is high or because impermeable clothing prevents the escape of water vapor, resulting in saturated air immediately adjacent to the skin).

The American Conference of Government Industrial Hygienists (ACGIH) has issued "Permissible Heat Exposure Threshold Limit Values." (7) These limits, summarized in Figure 2, depend on the wet bulb globe temperature (WBGT: a combination of ambient temperature, humidity, and radiation), the work load, and the type of clothing being worn. For example, if the WBGT at the worksite is $85^{\circ} \mathrm{F}\left(29^{\circ} \mathrm{C}\right)$ and the level of work is moderate, the worker can work for only $50 \%$ of each hour. The remaining portion of each hour must be used for resting in a cooler environment. 


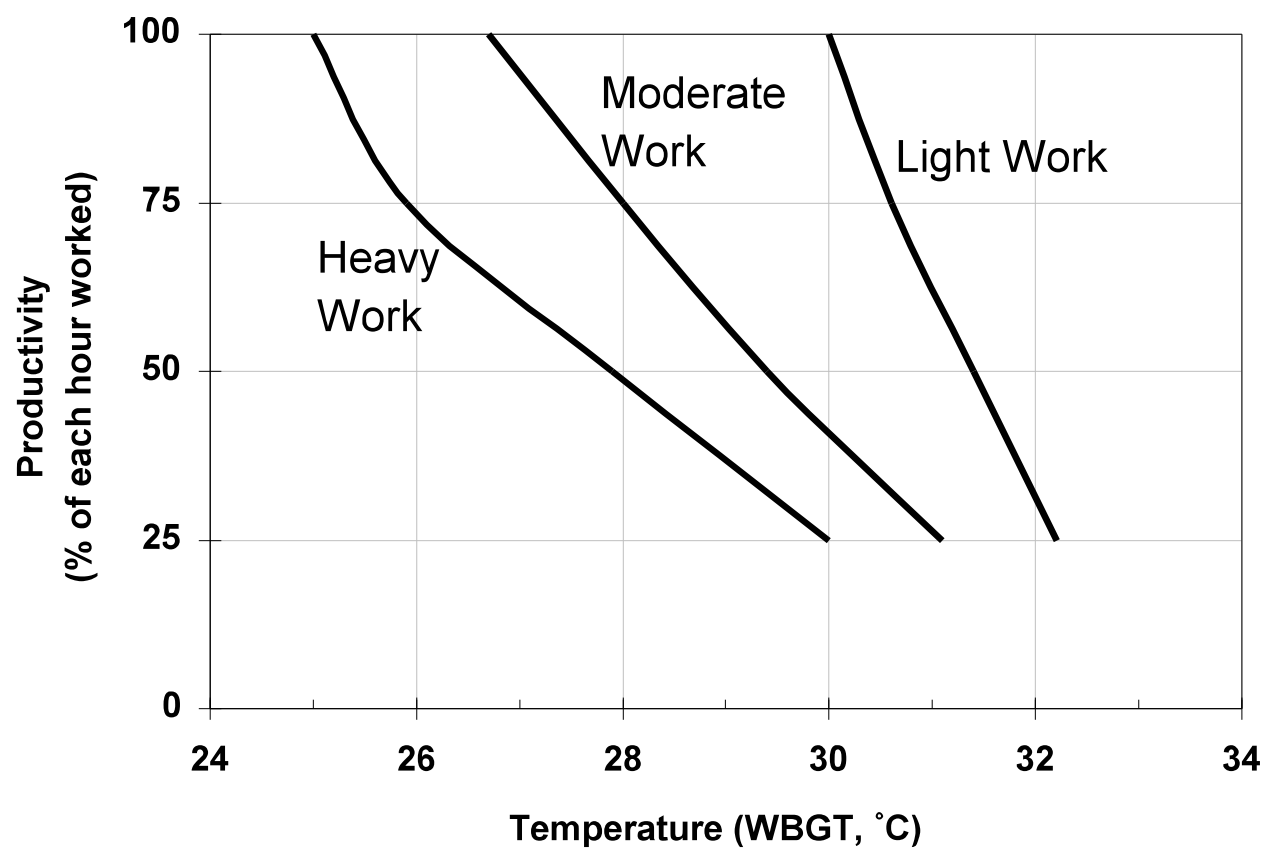

Figure 2. Heat stress exposure limits recommended by the American Conference of Government Industrial Hygienists (ACGIH). (Worker is assumed to be wearing summer-weight work clothes.)

The type of clothing plays an important role in determining susceptibility to heat stress and the length of time a worker can work before the ACGIH heat stress limits are reached. Figure 3 shows the ACGIH limits for a worker performing moderate work with different types of clothing. Using the example of a slightly cooler worksite than above $\left(80^{\circ} \mathrm{F}, 27^{\circ} \mathrm{C}\right)$, the worker can spend $100 \%$ of each hour working in summer-weight clothing, but only $25 \%$ in a winter work uniform. Wearing a suit that is impermeable to water vapor limits working time even further. 


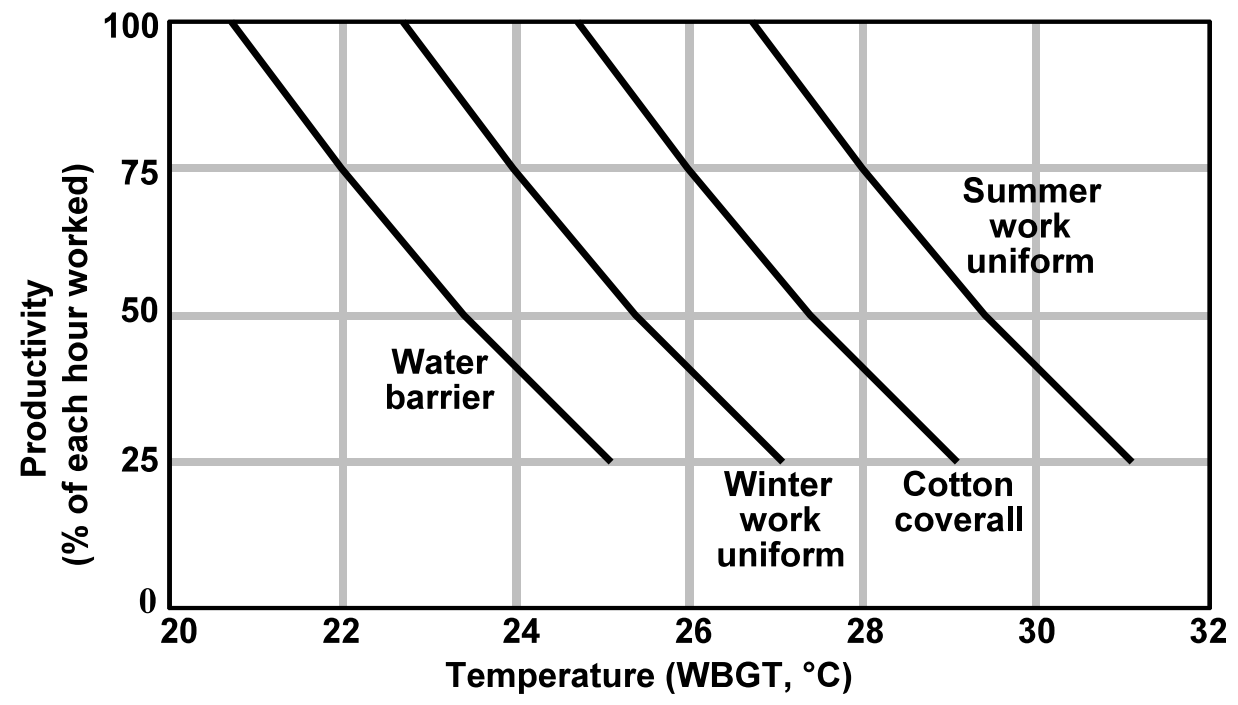

Figure 3. Effect of clothing type on heat stress exposure limits (under moderate work load).

The ACGIH heat exposure limits demonstrate the restrictions that heat stress and protective clothing place on worker productivity, and indicate the need for ways to keep workers cool while still protecting them from chemical hazards. To keep workers cool, one of two approaches (other than frequent rests and working during cool parts of the day) is used: either cooling vests or lightweight, water-vapor-permeable clothing.

The simplest form of cooling vest contains ice packs; the more sophisticated form contains tubes through which cool water can be pumped. Cooling vests are commercially available, but they have several drawbacks. The vests are heavy and cumbersome, they have a limited life before they need to be regenerated, and health problems have been reported due to uneven cooling supplied by some models.

Over the past 10 years, protective clothing has become lighter weight and more flexible with the introduction of multilayer, polymer fabrics such as Saranex-coated Tyvek. The lighter weight reduces the heat insulating characteristics of the fabrics, and the flexibility reduces the effort required to move around in them. However, these fabrics are still impermeable to water vapor, so workers are still exposed to heat stress. A second advance is the development of protective clothing that allows permeation of water vapor, but still protects against chemical hazards. Some water-vapor-permeable fabrics provide limited protection against liquid chemicals, but not against chemical vapors. The goal of this project was to develop water-vapor-permeable fabrics that also provide chemical protection against both liquid and vapor hazards. 


\section{PHASE I SUMMARY AND PHASE II GOALS}

\subsection{Summary of Phase I Results}

A detailed description of all results obtained under the Phase I project can be found in the Phase I Final Report submitted to the Department of Energy. (1) In summary, MTR used its membrane production equipment to produce multilayer fabrics that incorporate polyvinylalcohol (PVA) as the protective layer. The PVA layer is permeable to water vapor but is much less permeable to organic vapors. The fabric may also contain a sorbent layer for additional protection. The Phase I work focused on the three areas described below.

Fabric Optimization: Two steps were involved: optimization of the individual layers included in the final protective fabric, and optimization of the way these layers were combined. The fabric components studied during the optimization process were (i) the support fabric, (ii) the sorbent layer (including the sorbent used, the polymer used, and the ratio of the two), and (iii) the selective layer (including the polymer and post-treatment methods). We also studied the geometry used to combine the individual layers into the final protective fabric.

Commercial-Scale Fabric Production: The production of fabric was scaled-up from the 12-inchwide rolls used during fabric optimization to 40-inch-wide rolls made on MTR's commercial-scale equipment. Outside suppliers of techniques and methods not available within MTR were identified as necessary. Rolls of 40-inch-wide fabric at least $100 \mathrm{~m}$ long were required for use in prototype suit fabrication; a reliable method was developed for use in future commercial production. Two variations of the fabric (MTR-1 and MTR-2) were prepared and tested for water vapor and methylene chloride transmission rates. Table 2 compares the properties of the MTR-1 and MTR-2 materials with those of Tyvek, Saranex-coated Tyvek, and Barricade. The data show that the MTR materials achieve the objective of providing a reasonable amount of chemical protection while providing a water vapor transmission rate that is at least $50 \%$ of the transmission rate of Tyvek.

Table 2. Properties of MTR and Commercially Available Protective Fabrics Determined in Phase I.

\begin{tabular}{||l|c|c|c|c|c||}
\hline \multicolumn{1}{|c|}{ Property } & MTR-1 & MTR-2 & Tyvek & $\begin{array}{c}\text { Saranex-Coated } \\
\text { Tyvek }\end{array}$ & Barricade \\
\hline $\begin{array}{l}\text { Chemical Permeation } \\
\text { (dichloromethane) }\left(\mu \mathrm{g} / \mathrm{cm}^{2} \cdot \mathrm{min}\right)\end{array}$ & 440 & 165 & High & 120 & $<0.1$ \\
\hline $\begin{array}{l}\text { Water Vapor Transmission Rate } \\
\left(\text { MVTR) }\left(\mathrm{g} / \mathrm{m}^{2} \cdot \mathrm{min}\right)\right.\end{array}$ & $800-1,200$ & $800-1,300$ & $1,200-2,000$ & 0 & 0 \\
\hline Thickness $(\mathrm{mils})$ & 10 & 8 & 8 & 10 & 21 \\
\hline Weight $\left(\mathrm{oz} / \mathrm{yd}^{2}\right)$ & 6 & 6 & 1 & 4 & 5 \\
\hline \hline
\end{tabular}


During Phase I, a sample of the MTR-2 material was supplied for evaluation to a manufacturer of protective clothing, which measured the permeation resistance of the material to six different chemicals. The results of the evaluation, given in Table 3, confirm that the MTR material provides chemical protection comparable to that of Saranex-coated Tyvek, which is not breathable. MTR received these evaluation results after the Phase I Final Report had been submitted to DOE; therefore, these results were not included in the Phase I Final Report and are reported for the first time here.

Table 3. Chemical Permeation Resistance of MTR-2 Protective Fabric Compared with SaranexCoated Tyvek. Data Obtained by a Protective Fabric Producer.

\begin{tabular}{||l|c|c|c|c||}
\hline \multirow{2}{*}{\multicolumn{1}{|c|}{ Chemical }} & \multicolumn{2}{c|}{$\begin{array}{c}\text { Normalized Breakthrough Time } \\
\text { (minutes) }\end{array}$} & \multicolumn{2}{c|}{$\begin{array}{c}\text { Steady-State Permeation Rate } \\
\left(\mu \mathrm{g} / \mathrm{cm}^{2} \cdot \mathrm{min}\right)\end{array}$} \\
\cline { 2 - 5 } & MTR-2 & Tyvek/Saranex & MTR-2 & Tyvek/Saranex \\
\hline Ammonia (gas) & 277 & 32 & 24 & 0.15 \\
\hline Dichloromethane & 1 & 4 & 164 & 119 \\
\hline Diethylamine & $>480$ & 12 & $\mathrm{ND}^{*}$ & $>50$ \\
\hline Dimethylacetamide & 13 & 64 & 33 & 2 \\
\hline Hexane & $>480$ & 146 & $\mathrm{ND}^{*}$ & 0.48 \\
\hline Methanol & $>480$ & $>480$ & $\mathrm{ND}^{*}$ & $\mathrm{ND}^{*}$ \\
\hline
\end{tabular}

"No steady-state achieved in a 480-minute (8-hour) test period.

Prototype Suit Production and Evaluation: A commercial protective clothing manufacturer (Kappler Safety Group, Gantesville, AL) fabricated 10 to 15 prototype suits, to demonstrate the manufacturability of protective clothing made with our fabric. These prototype suits were evaluated under laboratory conditions for their comfort, durability, and protective characteristics. Finally, an economic evaluation was performed to compare the value of increased worker productivity versus the cost of the suit. An estimate of the commercial potential of the fabric was made from the economic analysis and market estimates. It was recognized that the cost of the MTR fabrics were too high and that the membrane production techniques used by MTR would not lend themselves to substantial cost savings, even if the fabrics were to be produced in large quantities. The need for different production techniques was to be addressed in Phase II.

\subsection{Phase II Goals}

Based on the Phase I results, the following components were identified for the subsequent Phase II effort:

Task 11. Identify a commercial partner to participate in the Phase II project.

Task 12. Optimize the fabric production techniques to reduce fabric costs. 
Task 13. Fabricate suits from the optimized fabric and perform user tests at the test facility of the International Union of Operating Engineers (IUOE).

Task 14. Perform a protective suit cost analysis, identify potential uses, and estimate the market potential.

The results obtained in the Phase II project are described in detail in the following sections.

\section{IDENTIFY COMMERCIAL PARTNERS}

A project consultant, Jeffrey O. Stull of International Personnel Protection, Inc., was used by MTR to solicit commercial partners to participate in Phase II of the project. Mr. Stull has extensive knowledge of the marketplace and is well connected with several potential partners through his participation in the chemical protective clothing industry and standards development organization.

Candidates for further development/commercialization of the material technology included companies that manufacture protective clothing materials and companies that fabricate clothing, either from their own materials or from other sources. These candidate partners and information related to their interest in MTR's technology are described below.

1. Kimberly-Clark Corporation. Kimberly-Clark recently entered the chemical protective apparel market, having already established itself as a major manufacturer in the general work-wear market. Kimberly-Clark is one of the few manufacturers that is vertically integrated, producing protective clothing material, using the material to manufacture protective suits, and selling these suits directly to the marketplace. The major focus of Kimberly-Clark's market entry has been on comfort and other human-factor-related properties. It also has an extensive background in nonwoven material technology. In addition, Kimberly-Clark has recently indicated some interest in MTR's permselective material technology.

2. W. L. Gore \& Associates. W. L. Gore is well known for its Gore-Tex products. It also manufacturers a series of materials for chemical protective apparel, which have fared somewhat disappointingly because of their relatively high cost. Competitive pressures are forcing W. L. Gore to seek out new material technologies in the chemical protection area. The company has extensive laminating expertise and have prototyping capability, but it generally participates in the industry as a material supplier, relying on outside suit fabrication. The company also has strong ties to the military market for protective gear against chemical and biological warfare agents.

3. Fabrene. Fabrene produces coated and laminated materials for a variety of applications, including chemical protective clothing, and is quickly becoming one of the industry leaders for extruding materials for apparel. The company intends to expand its capabilities for fabricating a wider range of materials and is specifically interested in apparel applications. 
4. Du Pont. Du Pont is the leading supplier of materials, but does not actually make or sell suits. Instead, it uses Lakeland Industries and Mar-Mac Manufacturing. Du Pont has expressed interest in new technologies, but has focused principally on Tyvek and film-based products. It has not introduced microporous film materials or any other material with comfort-related properties, but is positioning itself to offer a wider selection of materials. Therefore, Du Pont remains a logical choice for a partner. However, it would have to coordinate with one its existing contractors for the fabrication of prototype suits.

5. 3M. $3 \mathrm{M}$ has indicated a potential interest in the chemical protective clothing market. The company recently entered the healthcare apparel market and was able to quickly establish a significant market share for disposable gowns and drapes. Some of this technology has been based on a microporous film which is purportedly the best-performing product of its type in its class (polypropylene-based). 3M has made arrangements with Kappler (see below) for supplying a new high grade of microporous material.

6. Kappler. Although Kappler is the leading manufacturer of chemical protective apparel, it tends to pride itself on using internally-developed material technology. During Phase I, the company indicated some receptiveness but required the material to be further along in its final optimization. Kappler is also undertaking several material research and development projects and would be constrained to contribute resources to this project.

The efforts of Mr. Stull resulted in an agreement between Kimberly-Clark and MTR to work together in Phase II. Kimberly-Clark assisted MTR in the effort to lower production costs of the protective fabric and manufactured the protective suits used in the heat stress evaluation performed at the test facility of the International Union of Operating Engineers.

\section{MODIFY PROTECTIVE FABRIC / PRODUCE PROTECTIVE FABRIC}

The protective fabrics developed in Phase I consist of two layers laminated together by a polyvinylalcohol (PVA) layer, which gives the fabric its selective properties. In one variation (the MTR-2 material), the two layers were identical and consisted of a microporous polyurethane layer, which was solution cast onto a woven cloth. In the other variation (the MTR-1 material), the two layers were different: one was the same polyurethane/cloth material used in the MTR-2 material and the second layer was a commercially available nonwoven fabric (Medifilm, Bertek, St. Albans, Vermont).

During Phase I the polyurethane/cloth layer was prepared with MTR's existing membrane production equipment. This equipment, while suitable for the production of high-value selective membranes, is not suitable for economical fabric production. The minimum production cost (including capital charges) estimated in Phase I for the finished protective fabric was $\$ 4.54 / \mathrm{yd}^{2}$, which adjusted to 2001 levels is $\$ 5.29 / \mathrm{yd}^{2}$. This cost is high compared to other chemical protective fabrics, as discussed later in Section 6.2, and reduces the commercial potential of protective suits prepared with the MTR fabric. 
The approach pursued in Phase II was to find suitable commercially available fabrics that could be laminated together by the PVA-based lamination technique developed by MTR in Phase I. The commercial fabric must be finely microporous to allow a defect-free nonporous PVA layer to be formed and must have sufficient mechanical strength to allow the manufacture of protective suits. Working with Kimberly-Clark, MTR identified a suitable commercial fabric consisting of a microporous polyethylene (PE) layer supported by a spun-bonded nylon layer. The nylon layer makes this fabric extremely tough and tear resistant.

Trial experiments at MTR showed that the PE layer can be laminated to itself using MTR's PVA lamination procedure. A trial lamination run at a third-party laminating company was also successful, and subsequently about 300 linear yards of protective fabric were produced. The structure of the fabric (MTR-X) is shown in Figure 4. As will be discussed in Section 6.2, this fabric is much cheaper to produce than those developed in Phase I.

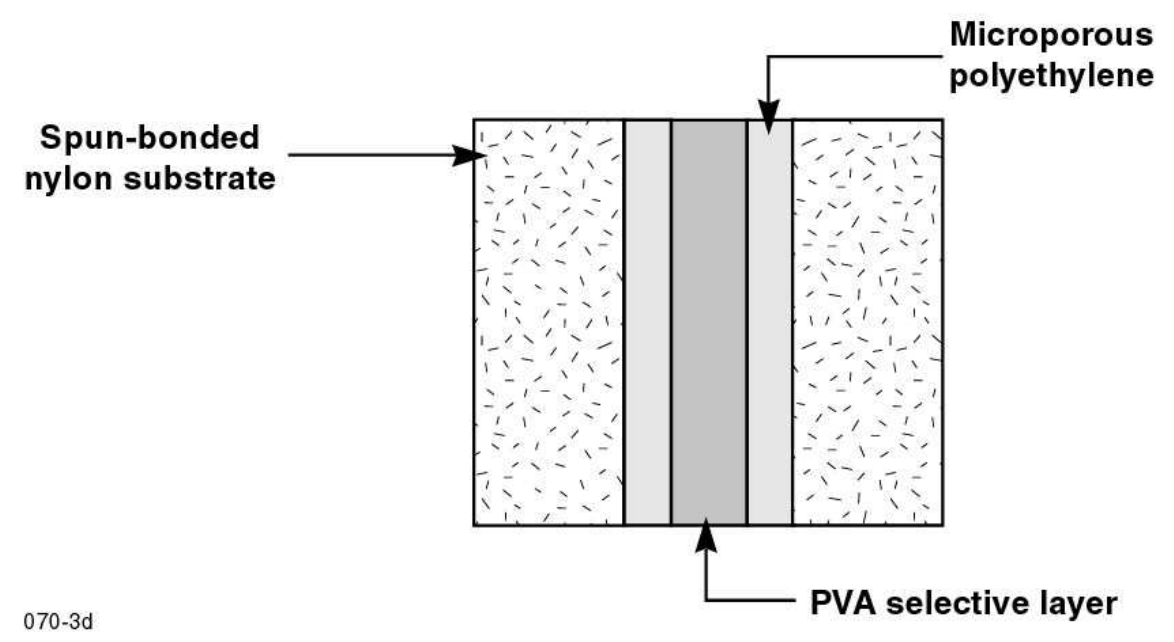

Figure 4. Structure of the MTR-X protective fabric developed in Phase II. The PVA layer in the middle provides the selective properties of the material, whereas the nylon layers on the outside provide mechanical strength. Protective suits made from the MTR-X material were successfully tested by IUOE.

\section{PREPARE PROTECTIVE SUITS AND TEST AT IUOE FACILITIES}

Kimberly-Clark manufactured 50 protective suits using MTR-X protective fabric provided by MTR and produced as described in Section 4. The suits were of Kimberly-Clark's REFLEX coverall design. The suits were used in a heat stress evaluation carried out at the Beaver, West Virginia test facility of the International Union of Operating Engineers (IUOE). The full report submitted by IUOE is attached to this report as an Appendix. A summary of the IUOE Study follows. 
The IUOE conducted a field evaluation to determine how well the MTR-based coveralls performed compared with other industry products. In addition to the MTR coveralls, the evaluation included coveralls constructed of polyvinyl chloride (PVC), which offers comparable liquid splash protection, and Tyvek, which is considered to offer less chemical protection but greater breathability. The IUOE Study entailed a thoroughly validated human study involving 15 human subjects for each material type and the measurement of body core temperature during specific work tasks representing hazardous materials remediation activities. These activities included:

- A confined space task involving crawling and manipulation of tools

- A pit task in which test subjects climbed into a pit and simulated nuclear rod removal

- A wheelbarrow task entailing shoveling and transporting sand from one location to another

All of the coveralls were similarly designed and used in the same manner for these evaluations. Data were subjected to an analysis of variance (ANOVA) to identify any statistically significant differences between protective suit materials during the various tasks.

Based on the results of this work, significant differences were found between the three types of coveralls, notably that the MTR coveralls allowed body-core temperature to dissipate more thoroughly than the PVC coveralls. Qualitative results based on subjective questionnaires also rated the MTR coveralls as more comfortable than similar coveralls constructed of PVC. Although Tyvek coveralls demonstrated lower rises in body-core temperature and better overall test-subject perception of comfort, the barrier properties of such protective suits would be considered unacceptable for most operations having the potential for liquid chemical exposure. In fact, Du Pont, as a supplier of this fabric, recommends against the use of Tyvek protective suits in environments where liquid protection is required. Hence, the IUOE field study showed the MTR coveralls to have advantages over nonpermeable protective suits, in terms of improved worker comfort and higher productivity. The IUOE analysis showed that workers wearing the MTR coveralls would be able to continue to perform tasks for nearly two hours without reaching the American Conference of Governmental Industrial Hygienists' body-core temperature limit of $40^{\circ} \mathrm{C}$. In contrast, workers in the similarly designed PVC coveralls would have trouble working for more than one hour.

\section{ECONOMIC ANALYSIS}

The assessment of the market potential of the developed fabric as a protective suit material consisted of three steps:

1. Estimation of costs associated with production of the material and its fabrication into protective suits.

2. Estimation of protective suit life-cycle costs, using the impact of worker productivity to demonstrate cost per use advantages for permselective/adsorptive material technology. 
3. Analysis of the existing chemical protective clothing market to identify the most promising applications for which permselective/adsorptive material would offer key benefits to promote end-user and industry acceptance.

Each step is described in detail in the following sections.

\subsection{Estimate of Fabric Production Costs}

Estimating the fabrication cost for the MTR-X material is straightforward because the PE/nylon layer can be acquired and the lamination step is performed by a third party. This means that a prospective producer does not need to invest in equipment and that no in-house production labor is required. The fabrication costs listed in Table 4 are based on a cost for the PE/nylon layer of $\$ 1.80 / \mathrm{m}^{2}$ (which translates to $\$ 3.60 / \mathrm{m}^{2}$ of fabric because the fabric consists of two PE/nylon layers) and lamination costs of $\$ 0.45 / \mathrm{m}^{2}$.

As shown by the costs of other protective clothing fabrics given in Table 5, the cost of the MTR-X fabric is still at the high end of the majority of materials used in liquid splash operations. However, these costs do not take into account any benefits achieved by the stress-relief properties of the fabric.

Table 4. Fabrication Cost Estimates for the MTR-X Fabric Compared with the Lowest Estimate Arrived at in Phase I. Estimates are based on production of 250,000 $\mathrm{yd}^{2}$ of protective fabric, which yields 50,000 protective suits. Phase I estimates are those given in the Phase I Final Report (i), adjusted to 2001 Levels.

\begin{tabular}{||l|c|c||}
\hline \multirow{2}{*}{\multicolumn{1}{|c|}{ Component Cost }} & \multicolumn{2}{c|}{ Total Fabric Manufacturing Cost } \\
\cline { 2 - 3 } & $\begin{array}{c}\text { Phase I } \\
\text { (lowest estimate) }\end{array}$ & $\begin{array}{c}\text { Phase II } \\
\text { (MTR-X) }\end{array}$ \\
\hline Capital Equipment $\left(\$ / \mathrm{m}^{2}\right)$ & 2.65 & None \\
\hline Materials $\left(\$ / \mathrm{m}^{2}\right)$ & 2.60 & 3.60 \\
\hline Labor $\left(\$ / \mathrm{m}^{2}\right)$ & 1.10 & None \\
\hline Third party Lamination Services $\left(\$ / \mathrm{m}^{2}\right)$ & None & 0.90 \\
\hline Total $\left(\$ / \mathrm{m}^{2}\right)$ & 6.35 & 4.50 \\
$\left(\$ / \mathrm{yd}^{2}\right)$ & 5.30 & 3.75 \\
\hline
\end{tabular}


Table 5. Representative Costs of Available Chemical Protective Clothing Fabrics.

\begin{tabular}{|c|c|c|}
\hline Fabric & Supplier & $\begin{array}{l}\text { Unit Cost } \\
\left(\$ / y d^{2}\right)\end{array}$ \\
\hline Tyvek (uncoated) & Du Pont & 1.00 \\
\hline PE coated Tyvek & Du Pont & 1.25 \\
\hline Saranex laminated Tyvek & Du Pont & 1.50 \\
\hline Barricade (multi-plastic laminate) & Du Pont & 3.90 \\
\hline CPF2 (multi-plastic laminate) & Kappler & 2.25 \\
\hline CPF3 (multi-plastic laminate) & Kappler & 3.25 \\
\hline Proshield 2 (breathable laminate) & Kappler & 1.30 \\
\hline Series 3000 (PVC/Nylon) & Tingley & 1.75 \\
\hline Series 3500 (PVC/Nylon/PVC) & Tingley & 2.75 \\
\hline
\end{tabular}

\subsection{Cost Estimates for Protective Suits}

The fabrication cost of protective suits does not depend solely on the fabric costs, but also depends on the style of suit produced and the choices made for the construction of seams. At the low end, protective suits have serged seams in which the seam is made on interior, adjacent plies of fabric and the protective suit is turned inside out. However, for liquid-chemical protective suits, the combination of sewing and taping (sometimes referred to as "strapping") is generally used to provide consistent performance of the seams.

Representative designs for liquid-chemical protective suits generally include features such as:

- One-piece coverall design

- Attached hood with elasticized face openings

- Bootie extension of protective suit legs

- Elasticized openings at wrists and ankles

- Front closure zipper with storm flaps, often provided with adhesive tapes

The four principal protective suit designs shown in Figure 5 illustrate the hierarchy for increasing levels of protection: 
Design (a) represents the minimum liquid-splash protective suit design common in the chemical protective clothing industry, The coverall is designed to be used with separate gloves, footwear, and a respirator to provide total body protection. Seams in such protective suits are generally "bound" by sewing a separate material over the serged edge of a seam; however, suits incorporating higher performing material use strapped seams. Components include a zipper and elasticized trouser and sleeve ends.

Design (b) provides increased protection with the attachment of booties with splash covers for outer boots and a protective flap over the front closure. Seams are strapped, and the closure flap uses either double-sided tape or a hook/loop closure. Both Designs (a) and (b) are commonly used in many hazardous material remediation applications.

Design (c) represents a protective suit configuration in which the respirator is encapsulated with the wearer. While this suit is not gas-tight in that the gloves are freely attached to the sleeves, it does completely cover the wearer's body except for the hands. A visor is incorporated into a more integrated hood, and a more robust zipper with a protective cover is used for closure. Suits of this type are generally used in Level B emergency response activities or for situations where liquid contact with a hazardous material is very likely.

Design (d) is known as a Level A suit. Use of a permselective/adsorptive fabric is less likely in this configuration. Nevertheless, this fabric could be useful in applications requiring a fully gas-tight, totally encapsulating suit. Like design (c), design (d) fully encloses the wearer and the breathing apparatus. The gas-tight envelope is completed around the wearer and their respirator with gloves that are attached to the suit. Because the suit is gas-tight, a special sealing zipper must be used and exhaust valves must be provided for the escape of respirator exhalation air. 


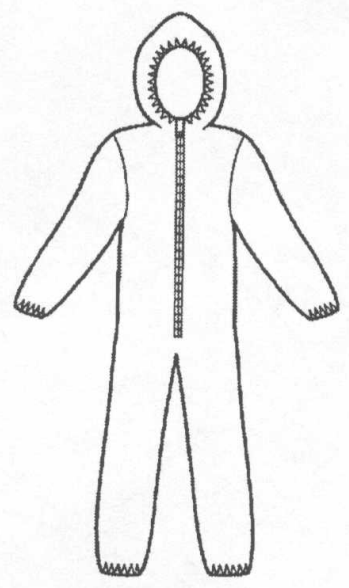

(a) One-piece coverall with attached hood and elasticized wrists and ankles

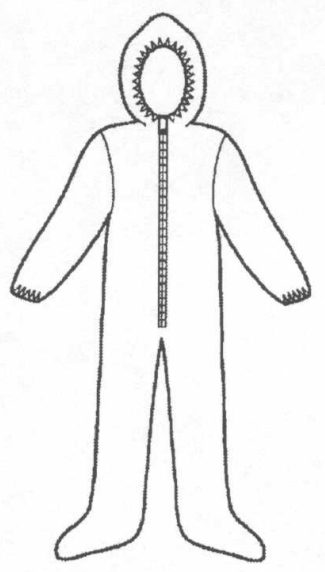

(b) One-piece coverall with attached hood, elasticized wrists, bootie feet, and storm flap

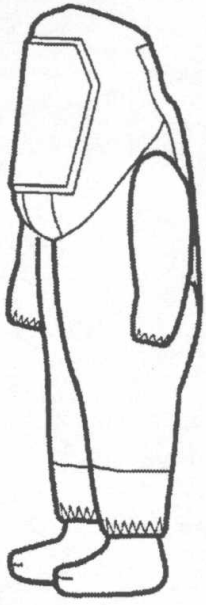

(c) Encapsulating suit with elasticized wrists and bootie feet

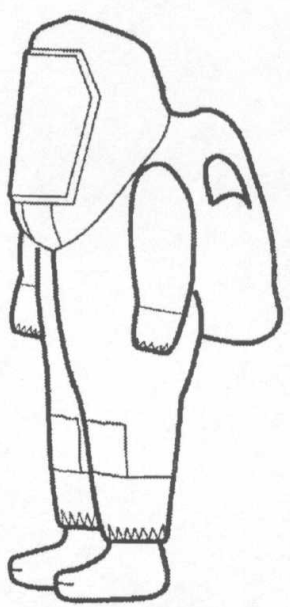

(d) Encapsulating suit with expanded back (for respirator), elasticized wrists, reinforcements and bootie feet

Figure 5. The four principal protective suit designs.

The range in the cost of these protective suit designs is considerable. Cost differences are due to the relative amounts of fabric used, the expense of suit components and other materials, and the type and amount of labor needed for fabrication. Noteworthy is that the simpler protective suits are mostly constructed outside the United States at low labor rates, whereas more complicated protective suits are still produced domestically. Thus, the sales price of protective suits includes the following cost elements:

- cost and amount of the primary protective fabric,

- other suit components (zippers, hardware, seam materials),

- fabrication labor,

- labor rate, and

- distributor mark-up.

Table 6 shows the rules of thumb used to calculate these cost elements. These rules are the basis for Table 7, which gives cost estimates for the four suit types made from the MTR-X protective fabric. The "cost to end user" data listed in Table 7 are compared in Table 8 with estimates for existing, commercially available products. Table 8 shows that the cost of MTR-X protective suits is in the mid-range of existing products. To determine the competitiveness of the MTR-X protective suits, a product-life-cycle costs and benefits analysis was performed, as described in Section 6.3. 
Table 6. Rules of Thumb for Calculating the Cost Elements for the Four Principal Protective Suit Designs Shown in Figure 5.

\begin{tabular}{||l|c|c|c|c||}
\hline \multicolumn{1}{|c|}{ Cost Element } & \multicolumn{5}{c||}{ Protective Suit Design } \\
\cline { 2 - 7 } & (a) & (b) & (c) & (d) \\
\hline Estimated Material Quantity $\left(\$ / \mathrm{yd}^{2}\right)$ & 4.0 & 4.25 & 6.5 & 8.0 \\
\hline Other Material/Component Costs (\$) & 3.75 & 5.50 & 12.50 & 30.00 \\
\hline Labor for Construction (\# hours) & 1.5 & 1.75 & 4.0 & 6.5 \\
\hline Average Labor Cost (\$/hour) & 10.00 & 10.00 & 18.00 & 20.00 \\
\hline Typical Distributor Mark-Up (\%) & 10 & 10 & 15 & 25 \\
\hline
\end{tabular}

*Average labor loaded with overhead, general \& administrative expenses and profit

Table 7. Cost Estimates for Protective Suits Made from the MTR-X Fabric for the Four Protective Suit Designs Shown in Figure 5.

\begin{tabular}{||l|c|c|c|c||}
\hline \multicolumn{1}{|c|}{ Cost Element } & \multicolumn{5}{|c||}{ Protective Suit Design } \\
\cline { 2 - 6 } & (a) & (b) & (c) & (d) \\
\hline Total Material Costs (\$) & 19.00 & 21.00 & 44.00 & 155.00 \\
\hline Total Labor Costs (\$) & 15.00 & 18.00 & 60.00 & 146.00 \\
\hline Cost to Distributor (\$) & 34.00 & 39.00 & 104.00 & 301.00 \\
\hline Cost to End-User (\$) & 37.40 & 42.90 & 120.00 & 376.00 \\
\hline
\end{tabular}


Table 8. Comparison of Cost to End User of the MTR-X Protective Suits (see Table 7) with Existing Industry Products.

\begin{tabular}{||l|c|c|c|c||}
\hline \multirow{2}{*}{\multicolumn{1}{|c|}{ Fabric }} & \multicolumn{3}{c||}{ Protective Suit Cost to End-User (\$) } \\
\cline { 2 - 5 } & (a) & (b) & (c) & (d) \\
\hline Polyethelene/Tyvek & 11.00 & 12.00 & & \\
\hline Saranex laminated Tyvek & 20.00 & 21.00 & & 95.00 \\
\hline PVC/Nylon & 37.00 & & & \\
\hline CPF2 (plastic laminate) & & 38.00 & & \\
\hline CPF3 (plastic laminate) & & 52.00 & 115.00 & \\
\hline Barricade (plastic laminate) & 51.00 & 68.00 & 198.00 & \\
\hline PVC/Nylon/PVC & 81.00 & & & \\
\hline Tychem TK (plastic laminate) & 82.00 & 86.00 & & 697.00 \\
\hline MTR-X Protective Fabric & $\mathbf{3 7 . 4 0}$ & $\mathbf{4 2 . 9 0}$ & $\mathbf{1 2 0 . 0 0}$ & $\mathbf{3 7 6 . 0 0}$ \\
\hline
\end{tabular}

\subsection{Product Life-Cycle Costs and Benefits}

Life-cycle costs are the costs associated with the entire life cycle of the protective suit; these comprise the acquisition cost plus the costs associated with decontamination, maintenance, storage and disposal. For a single-use product, life-cycle cost would include only the purchase price, any labor or consumables used in decontamination, and the cost of disposal (if applicable). Reusable clothing, however, must account for maintenance and storage costs. Life-cycle costs are compared by determining the cost per use. A clothing item that can be used several times can be much more expensive to purchase than the analogous single-use item. However, if the cost per use is taken into account, the relative expense can be quite different.

A key consideration in the life-cycle cost estimate is the disposal cost. Both reusable and limited use/disposable products are subject to disposal costs, which depend on whether the clothing is contaminated and, if so, the nature of the contaminant. Clearly, in many cases disposal costs (especially for large, bulky chemical protective suits) can be a significant factor in the overall cost per use. On the other hand, disposable suits may command higher disposal costs due to the quantity generated because they are not intended to last as long as reusable suits.

Another key parameter in assessing life-cycle cost is the number of expected uses. Concerns for product durability and ease of decontamination can further affect the decision to reuse chemical protective suits. Both are difficult to assess. Product durability measures the time a material or clothing item can maintain its new or near-new performance after a specified period of use in a given environment. Lack of product durability manifests itself in seams that pull apart, fabrics that crack from flex fatigue, abraded surfaces, and cloudy or cracked visors. The dual substrate configuration 
of the MTR material is expected to provide improved durability. Relatively favorable physical property values were found for MTR-1 and MTR-2 prototype materials in Phase I testing. Furthermore, no complaints were made about the durability of the MTR coveralls during the IUOE field evaluation.

Other than cost and durability, the other important issue in determining whether to reuse chemical protective suits is confidence that the suit is contaminant-free. Disposable clothing has become popular, not only because it is less expensive, but also because it obviates the difficult decision of determining if the clothing is clean enough for reuse. However, suits providing greater levels of chemical resistance are more likely to resist contamination and retain chemicals on the surface. Limited studies in the past have shown that some materials are easily decontaminated without losing any chemical barrier performance.

Accounting for all of these considerations permits an estimation of life-cycle cost. Table 9 shows life-cycle cost estimates for three coveralls, including one reusable type (PVC/nylon/PVC), a relatively inexpensive disposable type (Saranex/Tyvek), and a coverall made from the MTR-X fabric. The MTR material has intentionally been represented as a limited-use material allowing two uses.

Table 9. Life-Cycle Cost Estimates for Three Types of Chemical Protective Coveralls.

\begin{tabular}{||l|c|c|c||}
\hline \multicolumn{1}{|c|}{ Cost Element } & $\begin{array}{c}\text { PVC/Nylon/PVC } \\
\text { Coverall }\end{array}$ & $\begin{array}{c}\text { Saranex/Tyvek } \\
\text { Coverall }\end{array}$ & $\begin{array}{c}\text { MTR-X } \\
\text { Coverall }\end{array}$ \\
\hline Purchase $(\$)$ & 80.80 & 20.10 & 37.12 \\
\hline Decontamination $(\$)$ & 50.00 (five uses) & 10.00 & 20.00 (two uses) \\
\hline Maintenance $(\$)$ & 12.50 (five uses) & 2.50 & 5.00 (two uses) \\
\hline Storage $(\$)$ & 10.00 & 10.00 & 10.00 \\
\hline Disposal $(\$)$ & 5.00 & 2.50 & 2.50 \\
\hline Subtotal $(\$)$ & 158.30 & 45.10 & 74.62 \\
\hline Number of Uses & 5 & 1 & 2 \\
\hline Cost per Use $(\$)$ & 31.66 & 45.10 & 37.31 \\
\hline
\end{tabular}

* A detailed method for estimating chemical protective clothing life-cycle cost is provided in Schwope and Renard, "Estimation of the Cost of Using Chemical Protective Clothing," Performance of Protective Clothing: Fourth Volume, ASTM STP 1133, James P. McBriarty and Norman W. Henry (eds.), ASTM, Philadelphia, 1992, pp. $972-981$.

This sample analysis shows that the cost per use of the PVC overall is the lowest of the three chemical protective suits considered. However, these estimates can change depending on the type of care and user conditions to which each suit is subjected. Also, the analysis does not cover specific benefits that may be achieved with a specific protective suit material or design. 
A cost-benefit analysis can show whether higher costs are justified on the basis of product attributes that improve worker productivity. The objective of the MTR fabric development has been to provide a material that provides greater comfort at the levels of work activity associated with decontamination and decommissioning of DOE facilities. These improvements come at the expense of protective suit cost and chemical resistance performance.

In Phase I, cost-benefit calculations were made on the basis of predictions from laboratory evaluations of protective suit fabrics. For the cost-benefit analysis given here, findings from the IUOE evaluation were used to determine productivity improvements. Tyvek would not normally be used in the same applications as protective suits based on either PVC-coated or permselective/adsorptive materials, so some assumptions were made about the performance of a comparable Saranex/Tyvek- base d coverall. Table 10 incorporates the IUOE field study findings and these assumptions.

Table 10. Comparison of Cost-Benefit Calculations for the MTR-X Coveralls with Those for Saranex/Tyvek and PVC Coveralls.

\begin{tabular}{|c|c|c|c|}
\hline Parameter & $\begin{array}{c}\text { PVC/Nylon/PVC } \\
\text { Coverall }\end{array}$ & $\begin{array}{c}\text { Saranex/Tyvek } \\
\text { Coverall }\end{array}$ & $\begin{array}{l}\text { MTR-X } \\
\text { Coverall }\end{array}$ \\
\hline Productive time per work cycle (hr) & 1.0 & 1.25 & 2.0 \\
\hline Work-rest cycles per 8-hour day ${ }^{*}$ & 5.33 & 4.57 & 3.5 \\
\hline Productive time per 8-hour day (hr) & 5.33 & 5.71 & 7.0 \\
\hline Productive time per week (hr) & 26.6 & 28.6 & 35.0 \\
\hline Total labor cost per week $(\$)$ & 720 & 720 & 720 \\
\hline Coveralls used per week $^{* *}$ & 1 & 5 & 2.5 \\
\hline Coverall life-cycle cost per week $(\$)^{* * *}$ & 158.30 & 225.50 & 186.55 \\
\hline Total cost per week $(\$)$ & 878.30 & 945.50 & 906.55 \\
\hline Total cost per productive hour $(\$)$ & 33.02 & 33.06 & 25.90 \\
\hline
\end{tabular}

*Includes rest period of 30 minutes following each work period; assumes midday break of 1 hour.

${ }^{* *}$ Assumes one suit use per day

${ }^{\star * *}$ From previous calculations

Presuming that the conditions under which the assumptions hold true, a significant benefit can be achieved with coveralls using the permselective/adsorptive material over those made from either a disposable Saranex/Tyvek fabric or from the more durable PVC-coated nylon. For the reusable PVC coverall to obtain a comparable cost per productive hour, it would have to be used 7.6 times or approximately $1 \frac{1}{2}$ weeks. 


\section{CHEMICAL PROTECTIVE CLOTHING MARKET ANALYSIS}

The market for chemical protective clothing is large but extremely diverse. Excluding gloves, boots and other non-protective suit apparel, chemical protective clothing constitutes a total market size of approximately $\$ 450$ million. However, the chemical protective clothing industry is extremely fragmented into a variety of applications, product types, and material technology. Furthermore, the industry has been characterized by rapid change over the last two decades. Most market segments are now strongly affected by industry tests of chemical protective clothing performance developed by key standards organizations and by trade groups. Opportunities in the chemical protective clothing industry generally exist in "niche" markets, requiring a clear understanding of the particular market segment's current practices and needs.

\subsection{Applications and Markets}

Chemical protective clothing is best characterized as apparel that prevents chemicals, in one form or another, from reaching the wearer's skin. In other words, the clothing protects the wearer from a hostile (chemically contaminated) environment. In some cases, the chemical protective clothing may actually protect the environment from the wearer, as in cleanrooms where human particles and other contamination can destroy ultrasensitive manufacturing operations, such as the production of semiconductors and pharmaceuticals. The use of chemical protective clothing is often an alternative to establishing administrative or engineering controls, to limit worker contact with chemicals. Therefore, against hazardous chemicals, chemical protective clothing is often referred to as the "last line of defense."

In the industrial market, chemical protective clothing is used for numerous applications (or market segments) including:

- chemical manufacturing and process industries,

- hazardous waste site clean up and disposal,

- pharmaceuticals production,

- asbestos removal and other particulate operations,

- agricultural application of pesticides,

- cleanroom operations, and

- emergency response.

Chemical protective clothing is also used extensively by the government in many operations analogous to these commercial activities and to protect military personnel against chemical warfare agents.

The properties of the various protective clothing types are important for any specific application, yet some types are appropriate for more than one application. Thus, the choice depends strongly on the specific application; Table 11 provides an overview of the key characteristics of various applications. 
Table 11. Key Characteristics of Applications for Chemical Protective Clothing.

\begin{tabular}{|c|c|c|c|}
\hline Application & Clothing Types & Material Technology & Performance Areas \\
\hline $\begin{array}{l}\text { Chemical manufacturing } \\
\text { and process industries }\end{array}$ & $\begin{array}{l}\text { All types, depending on } \\
\text { specific chemical hazards }\end{array}$ & Full range of materials & $\begin{array}{l}\text { Permeation resistance, } \\
\text { liquid penetration } \\
\text { resistance, strength, } \\
\text { durability }\end{array}$ \\
\hline $\begin{array}{l}\text { Hazardous waste site } \\
\text { clean up and disposal }\end{array}$ & $\begin{array}{l}\text { One- or two-piece splash } \\
\text { suits with hoods, } \\
\text { glove/boot interfaces, and } \\
\text { liquid-resistant closures; } \\
\text { coveralls, aprons, sleeve } \\
\text { protectors }\end{array}$ & $\begin{array}{l}\text { Light-weight, breathable, } \\
\text { but liquid-splash- } \\
\text { resistant, non-woven } \\
\text { based materials or } \\
\text { rubber/plastic-coated } \\
\text { woven materials }\end{array}$ & $\begin{array}{l}\text { Liquid penetration } \\
\text { resistance, comfort, } \\
\text { overall product integrity }\end{array}$ \\
\hline $\begin{array}{l}\text { Pharmaceutical } \\
\text { production, asbestos } \\
\text { removal; other particulate } \\
\text { operations }\end{array}$ & $\begin{array}{l}\text { Full-body, hooded } \\
\text { coveralls }\end{array}$ & $\begin{array}{l}\text { Light-weight, breathable, } \\
\text { non-woven based } \\
\text { materials }\end{array}$ & $\begin{array}{l}\text { Particulate penetration } \\
\text { resistance, comfort }\end{array}$ \\
\hline Cleanroom operations & $\begin{array}{l}\text { Full-body, hooded } \\
\text { coveralls }\end{array}$ & $\begin{array}{l}\text { Light-weight, breathable, } \\
\text { non-woven based } \\
\text { materials }\end{array}$ & $\begin{array}{l}\text { Particulate penetration } \\
\text { resistance, comfort, non- } \\
\text { linting }\end{array}$ \\
\hline $\begin{array}{l}\text { Agricultural application of } \\
\text { pesticides }\end{array}$ & $\begin{array}{l}\text { Coveralls, aprons, sleeve } \\
\text { protectors }\end{array}$ & $\begin{array}{l}\text { Light-weight, breathable, } \\
\text { but liquid splash resistant } \\
\text { non-woven based } \\
\text { materials }\end{array}$ & $\begin{array}{l}\text { Liquid penetration } \\
\text { resistance, comfort }\end{array}$ \\
\hline Emergency response & $\begin{array}{l}\text { Complex encapsulating } \\
\text { suits; one or two piece } \\
\text { splash suits with hoods, } \\
\text { glove/boot interfaces, and } \\
\text { liquid-resistant closures }\end{array}$ & $\begin{array}{l}\text { High chemical resistance, } \\
\text { durable coated fabrics } \\
\text { and specialized plastic/ } \\
\text { non-woven laminates }\end{array}$ & $\begin{array}{l}\text { Permeation resistance, } \\
\text { liquid penetration } \\
\text { resistance, strength, } \\
\text { physical hazard } \\
\text { resistance, overall } \\
\text { integrity }\end{array}$ \\
\hline
\end{tabular}

\subsection{Types of Apparel and Materials}

Chemical protective apparel ranges from simple aprons to coveralls to full-body suits that totally encapsulate wearers and their self-contained breathing apparatus(see Section 6.2). The extent of body coverage and the specific design are chosen to meet the needs of the particular application, the nature and potential for chemical exposure, and the consequences of that exposure.

Except in low-hazard applications, where chemical exposure risks are low, most chemical protective clothing covers the entire body except for the face, hands, and feet. Typical chemical protective clothing designs are one- or two-piece splash suits or coveralls, which have features in common with everyday apparel. The complexity of the clothing increases as the protection needs for the specific application escalate. High-exposure risks to the more hazardous chemicals require the design to include special seams, closures, respirator interfaces, and other features to isolate the wearer from the chemical environment. As a result, most low-end market clothing is manufactured overseas using 
simple sewing operations, whereas high-end clothing requiring special machinery is fabricated domestically.

Materials available for the protective clothing market have changed considerably over the years. Until the late-1970s most chemical protective clothing materials were elastomer-coated fabrics. At that time, most commercial protective clothing developments followed the lead of the U.S. military, which spent considerable resources in providing chemical warfare agent protection. Elastomers were used to establish barrier performance, while substrates offered material strength. Common elastomers included Neoprene and butyl rubber; substrates included nylon and polyester, and poly(vinyl chloride) was also used extensively. These materials are still used extensively today, but early in the 1980s more exotic elastomers such as Viton and Teflon were developed. Combinations of elastomers were used to improve chemical resistance and other important material characteristics. However, these new materials often involved certain tradeoffs, such as increased stiffness and higher roll-good costs.

In the mid- to late-1980s, a complete shift in the chemical protective clothing marketplace occurred through the introduction of lightweight, plastic-based, nonwoven substrates. Low-end products involved materials composed of polypropylene and polyethylene. By combining polyethylene with other plastics, chemical resistance performance increased. Another advantage of plastics included ease of manufacturing because seam-joining techniques, based on sewing and heat sealing, replaced adhesives. Because of the low cost, clothing made from these materials is considered disposable.

The chemical protective clothing market today offers many choices of materials. Plastic nonwoven fabric laminates dominate some segments of the market, but other new materials have been developed. These include microporous fabrics, which allow air and moisture but not liquids to transfer through the material, and adsorbent-based fabric technology, which is used extensively by the military, such as in air-purifying respirators. This diversity of materials results in part from the different performance characteristics important to each application.

\subsection{Performance Characteristics}

Few tests exist for evaluating entire protective clothing products, so fabric properties are most often used to judge performance characteristics. The most significant properties of chemical protective clothing fabrics are barrier properties, namely chemical resistance. Since chemicals occur in three states - solid, liquid, and gas - tests for material barrier performance determine protection levels for gases or vapors, liquids, solids, particulates, and aerosols.

Protection against gases and vapors represents the highest level of protection. The level is assessed through permeation resistance testing, which measures the rate of chemical diffusion through the protective clothing fabric and seams. Testing in this area is highly standardized, and many manufacturers report performance in terms of both breakthrough time and steady-state or maximum chemical permeation rates. Breakthrough times measure how soon after exposure a chemical passes through the protective material at a detectable level, and permeation rates indicate how quickly 
chemical diffusion occurs. This high level of chemical resistance requires continuous elastomer and plastic barrier layers in protective clothing materials. Protective clothing that provides a barrier to vapors or gases will also offer liquid or solid protection.

Liquid protection involves barrier materials that prevent the bulk passage or flow of a liquid through the clothing. Effective liquid barriers are those that prevent liquids from penetrating protective clothing and reaching the wearer's skin or underclothing. The result of an industry standard test for measuring liquid penetration resistance of this type of protective clothing is usually reported as pass/fail for specific liquid chemicals or mixtures. Film-coated or laminated fabrics as well as microporous fabrics and special surface-treated textiles are generally used for liquid protection. Usually, protective clothing demonstrating liquid hold-out will also prevent penetration of solids.

Particulate protection requires protective clothing that limits the passage of particles or other solid matter onto the wearer's skin or, conversely, particles from the wearer into the environment. A number of industry-accepted tests are used for protective suits worn in cleanrooms, but no industry consensus exists on methods to evaluate particulate penetration. Techniques commonly applied measure filtration efficiency using surrogate particulates of known sizes. Most fabrics for this type of protection are porous woven or nonwoven textiles.

One of the areas not traditionally addressed is vapor penetration resistance of protective materials. Whereas this area has been addressed in military application for chemical agent protection, the concept has not found much acceptance for industrial chemical protective clothing. This performance area has particular relevance to permselective/adsorptive materials because such materials will repel most liquids and prevent permeation by vapors, but have lower permeation resistance compared to high-end impermeable materials.

Other general properties measured for chemical protective clothing materials include those for strength, physical hazard resistance, and durability. Common strength tests are tensile, burst, and tear strength. Physical hazard resistance is evaluated through tests for cut, puncture, abrasion, and snag resistance. Durability is more difficult to assess, but generally involves measurement of chemical resistance following conditioning of the material to simulate wear and use.

In addition, chemical protective clothing must afford maximum function and comfort, particularly when wearing chemical protective clothing is a routine part of the worker's role. Tests that measure air permeability, water vapor transmission rate, stiffness, and water absorption are often used to supplement field tests of clothing performance. However, many of these properties become moot in all applications except those for which porous or microporous materials can be used. Most materials for vapor and liquid-splash protection prevent evaporation of sweat as a means of body cooling as well as retaining heat, increasing the potential for thermal discomfort and heat stress. 


\subsection{Market Opportunities}

To succeed, potential manufacturers and suppliers of new materials in the protective clothing industry need to study carefully the particular merits of new clothing concepts or novel materials before entering the market. Performance features considered important in one segment may be meaningless in a related, but different market application. End-users are becoming more sophisticated, and the industry as a whole depends more on product information as chemical protective clothing becomes more specialized and less of a commodity item.

Specific market opportunities that are available for protective clothing based on the MTR-X fabric are:

- Liquid splash protective clothing for hazardous waste site operations

- Liquid splash protective clothing for emergency response

- Class 3 NFPA 1994-compliant protective clothing for civilian use during chemical terrorism incidents

Each application has specific requirements for chemical holdout, but all are likely to involve lower levels of exposure. Liquid contact would not usually occur in many of these situations, but some residual vapor contact could occur. The relatively long wearing times for these applications would also be best served by clothing that offers some water vapor transport with a sacrifice in barrier protection. Table 12 gives a comparison of these applications.

The chemical terrorism protective clothing is understood to be one of the more promising applications, because of the establishment of a new standard (NFPA 1994) and an increased awareness for domestic preparedness. Federal funds are now being made available through grant programs to many moderate to large municipalities for outfitting response teams and related personnel. In the event of a terrorism incident, the majority of persons wearing protective clothing would typically wear clothing fitting the NFPA 1994 Class 3 configuration. 
Table 12. Comparison of Market Segment Opportunities for Permselective/Adsorptive Material Technologies.

\begin{tabular}{||l|l|l|l|c||}
\hline \multicolumn{1}{|c|}{ Market Segment } & Current Products & \multicolumn{1}{|c||}{$\begin{array}{l}\text { Leading } \\
\text { Manufacturers }\end{array}$} & $\begin{array}{l}\text { Applicable } \\
\text { Standards }\end{array}$ & $\begin{array}{c}\text { Expected } \\
\text { Growth }\end{array}$ \\
\hline $\begin{array}{l}\text { Liquid splash protective clothing for } \\
\text { hazardous waste site operations }\end{array}$ & $\begin{array}{l}\text { Polyethylene/Tyvek } \\
\text { Saranex/Tyvek } \\
\text { PVC/Nylon }\end{array}$ & $\begin{array}{l}\text { Du Pont/MarMac } \\
\text { Kappler } \\
\text { Lakeland } \\
\text { Rainfair } \\
\text { Tingley }\end{array}$ & NFPA 1992 & Low \\
\hline $\begin{array}{l}\text { Liquid splash protective clothing for } \\
\text { emergency response }\end{array}$ & $\begin{array}{l}\text { Barricade } \\
\text { Tychem 10K } \\
\text { CPF3/CPF4 } \\
\text { Responder } \\
\text { Trellchem }\end{array}$ & $\begin{array}{l}\text { Du Pont/MarMac } \\
\text { Kappler } \\
\text { Lakeland } \\
\text { Trelleborg }\end{array}$ & NFPA 1992 & Low \\
\hline $\begin{array}{l}\text { Class 3 NFPA 1994-compliant } \\
\text { protective clothing for civilian use } \\
\text { during chemical terrorism incidents }\end{array}$ & $\begin{array}{l}\text { Barricade } \\
\text { Tychem 10K } \\
\text { CPF3/CPF4 } \\
\text { Responder } \\
\text { Trellchem }\end{array}$ & $\begin{array}{l}\text { Du Pont/MarMac } \\
\text { Kappler } \\
\text { Lakeland } \\
\text { Trelleborg }\end{array}$ & NFPA 1994 & High \\
\hline
\end{tabular}

\section{CONCLUSIONS}

The following conclusions were drawn from the results of the Phase II effort:

- In Phase II, the structure of the protective fabric was modified without modifying its function. The microporous support produced by MTR was replaced with a commercially available material consisting of a microporous polyethylene layer supported by a nylon substrate. This material was laminated back-to-back with the PVA layer which provides the resulting fabric with its protective properties. As a result, the fabric manufacturing steps were significantly simplified which resulted in a $30 \%$ reduction in manufacturing costs and eliminating the need for capital investment in production equipment.

- $\quad$ Protective suits were prepared in collaboration with Kimberly-Clark Corporation using the modified fabric developed in Phase II. The International Union of Operating Engineers (IUOE) compared the performance of the MTR-fabric-based coveralls with that of PVC and Tyvek coveralls. Significant differences were found between the three types of coveralls, notably that the MTR coveralls allowed body-core temperature to dissipate more thoroughly than the PVC coveralls. Qualitative results based on subjective questionnaires also rated the MTR coveralls as more comfortable than similar coveralls constructed of PVC. Although Tyvek coveralls demonstrated lower rises in body-core temperature and better overall test subject perception of comfort, the barrier properties of such garments would be considered unacceptable for most operations involving the potential for liquid chemical exposure 
- The cost information developed for the optimized protective fabric was combined with the results of the IUOE field study to determine the potential for the MTR material technology within the chemical protective clothing market. A cost-benefit analysis showed that the predicted increase in productive time per work cycle achieved by the newly developed fabric reduces the cost per productive hour worked compared to PVC or Saranex/Tyvek coveralls.

- $\quad$ The report provides a detailed assessment of the specific chemical protective clothing applications for which the material can be used and its competitiveness with existing material technology, based both on expected performance and on material/end item costs. Three specific market opportunities identified for the novel protective fabric are: (1) liquid splash protective clothing for hazardous waste site operations, (2) liquid splash protective clothing for emergency response, and (3) Class 3 NFPA 1994-compliant protective clothing for civilian use during chemical terrorism incidents. 


\section{REFERENCES}

1. D.L. Gottschlich, et al., "Protective Clothing Based on Permselective Membrane and Carbon Adsorption," Final Topical Report on Phase I, Contract Number DE-AC21-93MC30179 (July 1996)

2. J.O. Stull, "Full-Body Protection and Standards," in Guidelines for the Selection of Chemical Protective Clothing, 3rd ed., American Conference of Governmental Industrial Hygienists, Inc., Cincinnati, OH (February 1987).

3. J.F. Rekus, "Can You Take The Heat," Occupational Health and Safety.

4. $\quad$ S. Minter, "Cooling Off Heat Stress," Occupational Hazards, (June 1994).

5. M. Hans, "Wage War Against Heat Stress," Safety and Health, (June 1994).

6. J. Huck, "The Physiology of Heat Stress," Safety and Protective Fabrics, (August 1993).

7. American Conference of Government Industrial Hygienists, "1994-1995 Threshold Limit Value for Chemical Substances and Physical Agents and Biological Exposure Indices," ACGIH, Cincinnati, OH (1994).

\section{PROJECT REPORTS:}

1. "Protective Clothing Based on Permselective Membrane and Carbon Adsorption," presented at Opportunities '95 - Environmental Technology Through Small Businesses, Morgantown, WV (November 16-17, 1994).

2. "Protective Clothing Based on Permselective Membrane and Carbon Adsorption," presented at Environmental Technology Through Industry Participation, Morgantown, WV (October $3-5,1995)$.

3. "Protective Clothing Based on Permselective Membrane and Carbon Adsorption," presented at Sixth International Symposium on Performance of Protective Clothing, sponsored by ASTM, Orlando, FL (June 18-19, 1996). 


\section{APPENDIX A: Chemical Protective Clothing Standards of Organizations and Trade Groups}

Although a number of driving forces are responsible for changes in the chemical protective clothing industry, one of the primary reasons for its rapid growth can be attributed to the introduction of new standards. Consensus group standards such as those established by the American Society for Testing and Materials (ASTM) and the National Fire Protection Association (NFPA) influence both manufacturers and end-users significantly.

The ASTM F23 Committee on Protective Clothing was formed to develop standards to measure the properties of materials used in protective clothing and the performance of complete protective suits. This committee has focused on development of specific test methods, many of which address tests of chemical protective clothing. Key ASTM standards in this area include:

ASTM F 739 Test Method for Resistance of Protective Clothing Materials to Permeation by Liquids and Gases

ASTM F 903 Test Method for Resistance of Protective Clothing Materials to Penetration by Liquids

ASTM F $1001 \quad$ Guide For Test Chemicals to Evaluate Protective Clothing Materials

ASTM F 1052 Practice for Pressure Testing of Totally Encapsulating Chemical Protective Suits

ASTM F $1359 \quad$ Practice for Determining the Liquid-Tight Integrity of Chemical Protective Suits or Ensembles under Static Conditions.

Other ASTM standards related to specific types of materials, such as textiles, plastics, and rubber, are also routinely used to evaluate chemical protective clothing materials.

The NFPA Technical Committee on Protective Clothing for Fire and Emergency Services has developed three standards that apply to chemical protective clothing:

NFPA 1991

NFPA 1992

NFPA 1994
Standard on Vapor-Protective Ensembles for Hazardous Materials Response Standard on Liquid Splash-Protective Ensembles for Hazardous Materials Response

Standard on Protective Ensembles for Chemical/Biological Terrorism Incidents

Each standard provides a comprehensive set of performance criteria and requires independent, thirdparty certification. These standards are primarily aimed at emergency response, but are often cited in specifications for chemical industry and hazardous waste cleanup, in the absence of standards for those applications. 
APPENDIX B: Full IUOE Report (74 pages).

B-1 
International Union of Operating

Engineers National Hazmat Program

\author{
International Environmental Technology \\ \& Training Center
}

\title{
Membrane Technologies Research MTR Protective Garment
}
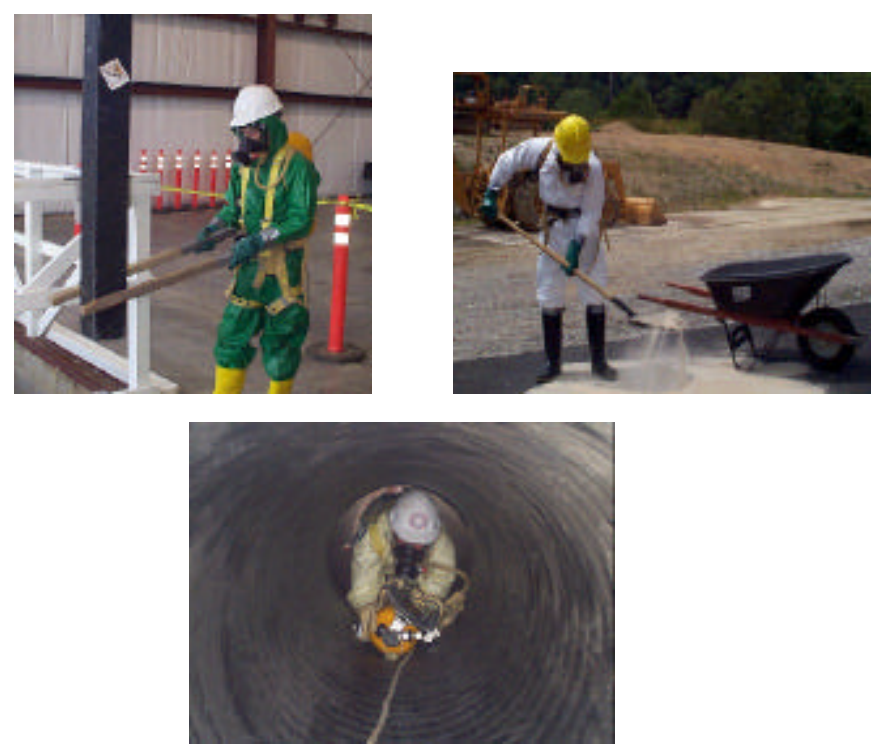

HUMAN FACTORS

ASSESSMENT

REPORT

FEBRUARY 2001 
Research supported by the U.S. Department of Energy's

National Energy Technology Laboratory under cooperative agreement DE-FC21-95MC32260 with the Operating Engineers National Hazmat Program,

1293 Airport Road, Beaver, WV 25813, Phone: 304-253-8674, Fax (304) 253-7758.

Email: hazmat@iuoeiettc.org

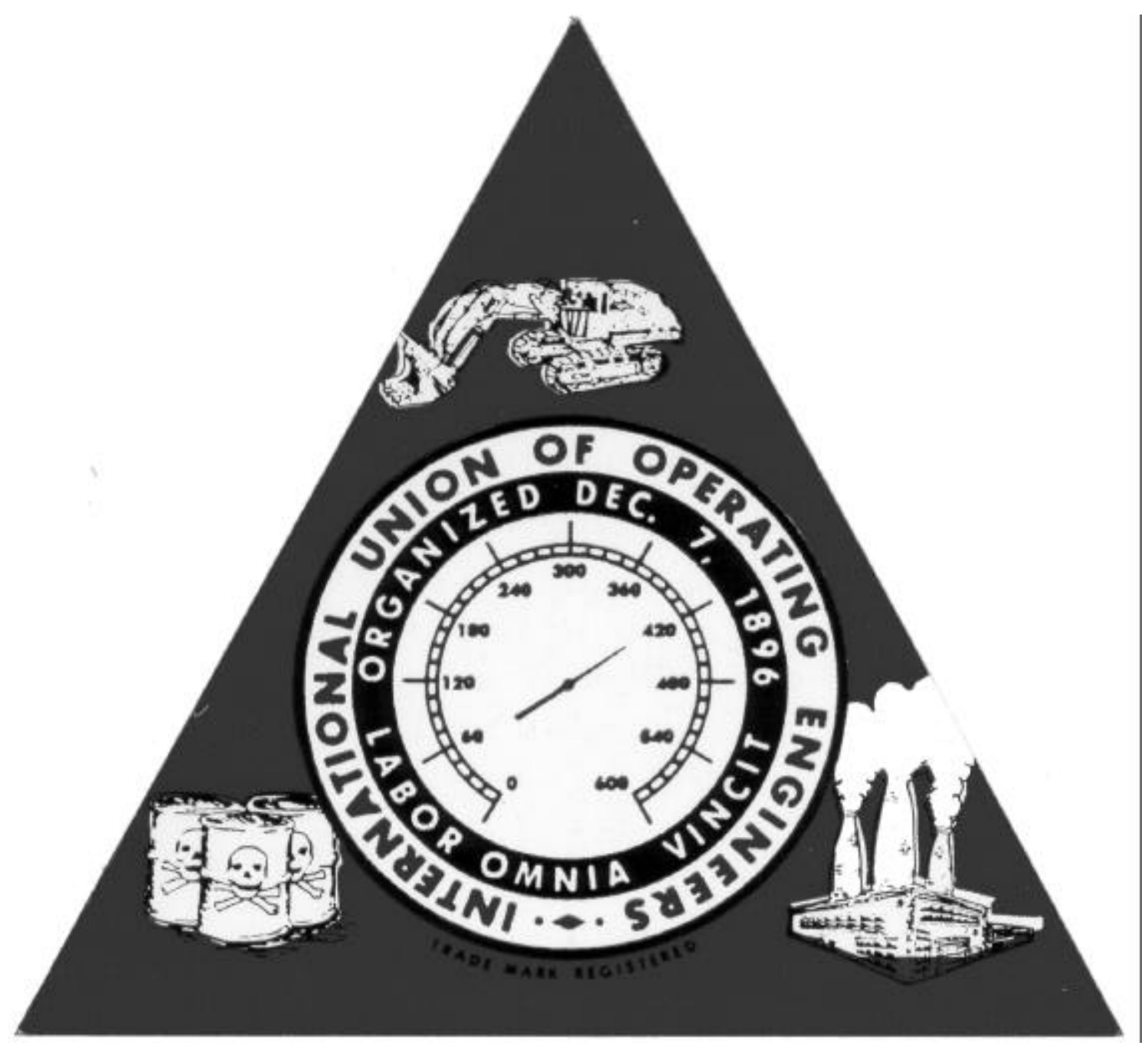

Frank Hanley, General President

This report was prepared with the support of the U.S. Department of Energy. However, any opinions, findings, conclusions, or recommendations expressed herein are those of the author(s) and do not necessarily reflect the views of the DOE. 


\section{TABLE OF CONTENTS}

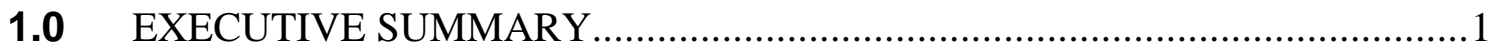

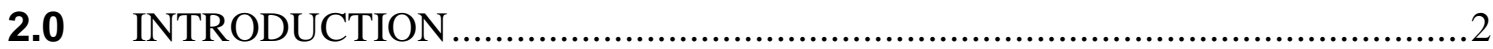

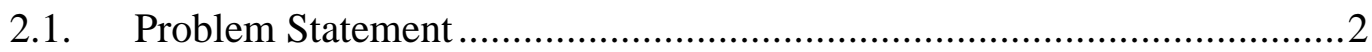

2.2. Objective of the Assessment ………………….......................................

2.3. Background on the Operating Engineers National Hazmat Program...................3

2.4. Description of the Protective Garments ……………...............................

2.4.1. Background on protective garments ........................................... 4

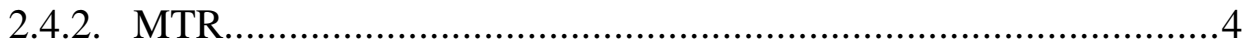

2.4.3. Poly Vinyl Chloride (PVC).....................................................5

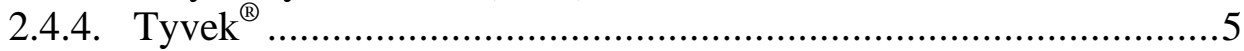

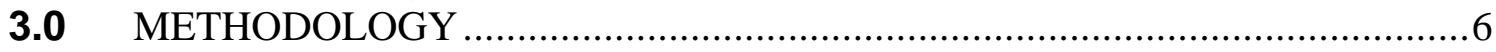

3.1. Test Subject Selection .....................................................................6

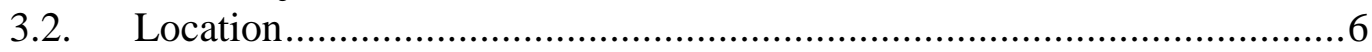

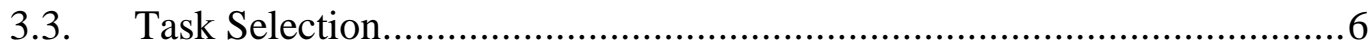

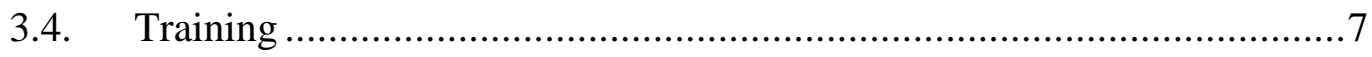

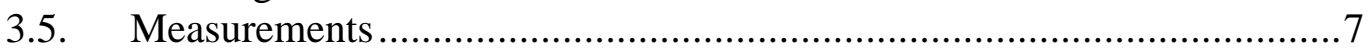

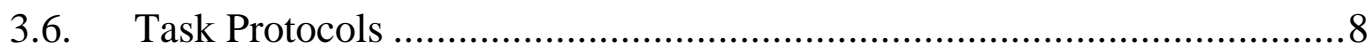

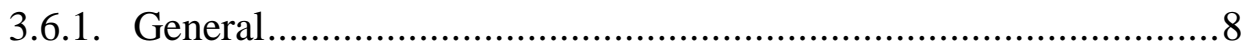

3.6.2. Confined Space Task ............................................................

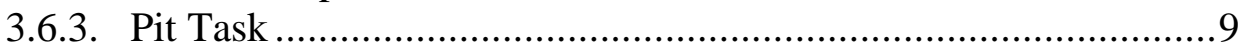

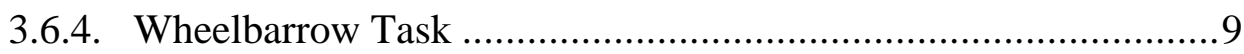

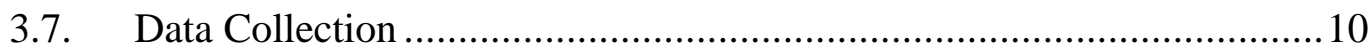

3.7.1. Quantitative .......................................................................... 10

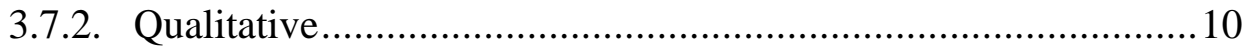

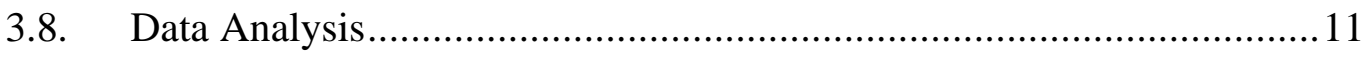

3.8.1. Quantitative........................................................................ 11

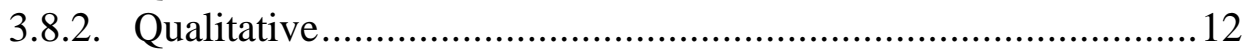

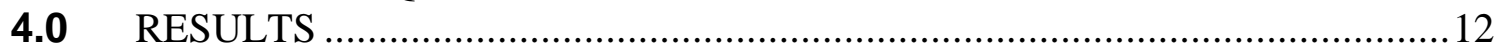

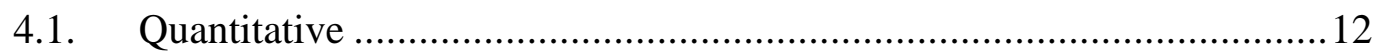

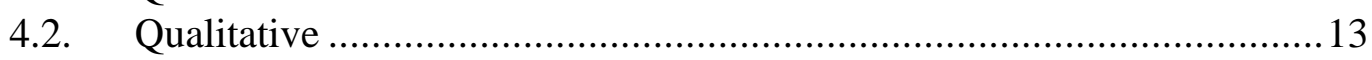

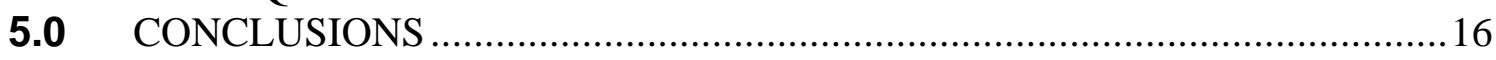

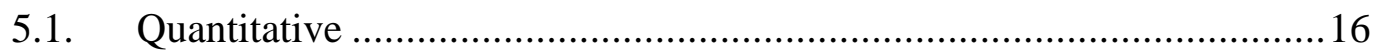

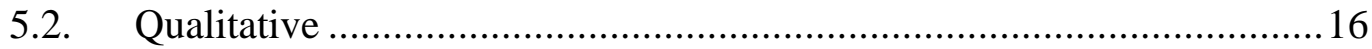

6.0 RECOMMENDATIONS FOR FUTURE STUDIES ........................................

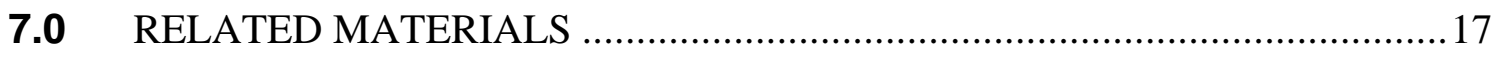

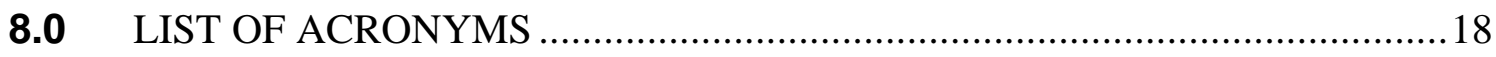

9.0 APPENDICES

9.1. Appendix A - Charts E - S ...................................................... 1

9.2. Appendix B - Tables A - S ......................................................... B - 1 


\subsection{EXECUTIVE SUMMARY}

The objective of this assessment was to determine, using a thoroughly validated method for measuring core body temperature, how well the MTR suit designed by Kimberly Clark maintained internal body temperatures of workers performing tasks common to hazardous waste work. ${ }^{1,2}$ The MTR suit was compared to a polyvinyl chloride (PVC) suit that offers comparable chemical protection and a Tyvek $^{\circledR}$ suit, which offers much lower chemical protection but improved evaporative cooling through the fabric. A total of 147 different subject-suit-task combinations were tested using sixteen subjects, three suits, and three tasks: confined space, pit, and wheelbarrow.

The quantitative results indicated that there was a significant difference among the core temperature readings for the three suits when 6000 data points for all tasks were combined. The F-statistic for Table-D-MPT is greater than 24 with a p-value of less than $3.6 \times 10^{-11}$, an indication of strong significance. Additional ANOVA tests showed that there were significant differences in core temperatures among the three tasks for each suit.

Regression analysis of the quantitative data indicated that the MTR suit, for most subjects and tasks, allowed core body heat to dissipate more thoroughly than the impermeable PVC suit. The regression equations predict that the test subjects would have been able to wear the MTR suit and continue the tasks for two hours without reaching the ACGIH heat stroke temperature of 40 degrees Celsius, while they would have been close to or above 40 degrees Celsius wearing the PVC suit within an hour in most cases.

Qualitative results of all the MTR questionnaires, on the average, show the subjects rated the MTR suit to be generally in the range of less than adequate to adequate. The results, however, represent a small test sample. The results of the "user satisfaction" questionnaire rated the MTR suit lower than the Tyvek ${ }^{\circledR}$ suit and higher than the PVC suit but adequate in most categories.

The quantitative core temperature results from this assessment are significant and indicate that workers wearing the MTR suit are definitely able to dissipate body heat better than when wearing the PVC suit. As one would expect, the Tyvek ${ }^{\circledR}$ suit provided the greatest overall core temperature dissipation but in several of the tests the MTR suit had comparable results.

The qualitative results show that the operators perceived the MTR suit to be an acceptable protective garment. If the MTR suit provides protection against chemicals comparable to impermeable protective garments, it represents a significant improvement because of its advantage in the prevention of heat-related illnesses.

\subsection{INTRODUCTION}

\subsection{Problem Statement}

1 Leonard Keilson. An Analysis of the Accuracy and Stability of Temperature Telemetry Capsules. Department of Health and Human Services. 2-3. (April 12, 1988).

2 Mittal BB, Sathiaseelan V, Rademaker AW, Pierce MC, Johnson PM, Brand WN. Evaluation of an ingestible telemetric temperature sensor for deep hyperthermia applications. Int. J. Radiation Oncology Biol. Phys. 21: 13531361. 1991. 
Heat stress is one of the greatest and most overlooked threats to workers cleaning up hazardous environments across the Department of Energy (DOE) complex. This threat is greatly increased for workers wearing chemical and/or radiation protective suits, a situation which is becoming much more common as DOE steps up deactivation and decommissioning (D\&D) activities.

Several innovative heat stress technologies have been developed to measure or manage this increased risk to workers. The problem is that these technologies are typically evaluated for effectiveness in an environmental chamber with healthy, nonsmoking, young male subjects performing very limited activities on a treadmill, typically walking or crawling. This approach provides strong internal validity and reliability but very little external validity. The test routines that subjects perform in laboratory settings bear little resemblance to the real tasks that workers execute in D\&D activities. Consequently, the results from lab tests may be reproducible but they aren't very applicable to the real world.

Studies conducted in the field, on the other hand, lack the controls possible in the lab but provide data much more representative of the environment that workers actually face. Field studies also allow for meaningful qualitative feedback from the test subjects, which can be more important than quantitative data. The evaporative capacity of a new protective garment is of little importance if workers find it too uncomfortable or inflexible to wear. Field studies are particularly valuable if the test subjects are real workers taken from the work environments of interest who have a direct, working knowledge of protective garments. The seasoned hazardous waste workers who were the subjects of this present field study by the Operating Engineers National Hazmat Program (OENHP) had all routinely worked in protective garments prior to the test.

Heat stress is the net heat load to which a worker may be exposed from the combined contributions of metabolic cost of work, environmental factors (such as air temperature, humidity, and air movement) and clothing requirements. The wet-bulb globe temperature index (WBGT) recommended by the American Conference of Governmental Industrial Hygienists (ACGIH) has been the most widely practiced field method for monitoring the environmental conditions that lead to heat stress.

Under the ACGIH standard, the environmental measurements are integrated with an estimate of the physical exertion required for the task to determine a work-rest schedule that should repeatedly protect "all adequately hydrated, non-medicated, healthy workers." 3 The schedule, however, may limit the crew to 15 minutes of work and 45 minutes of rest, which significantly reduces productivity. Of great importance to this study, the ACGIH admits the difficulty of applying their standard when workers are wearing impermeable garments. This buttresses the need for good studies on the effects of these garments.

Heat strain is the response of the human body to heat stress. The risk and severity of excessive heat strain will vary widely among people, even under identical heat stress conditions. ${ }^{4}$ This is the major reason that the Occupational Safety and Health Administration (OSHA) has never promulgated a standard on heat exposure. These individual differences mean that some workers will be at an elevated risk of heat stroke

3 American Conference of Governmental Industrial Hygienists. 2000 TLVs and BEIs. Cincinnati, OH: ACGIH. 180. (2000). 
while their coworkers are adequately coping with the heat. This raises the importance of any protective garment that offers protection from chemicals while allowing much better evaporative cooling.

\subsection{Objective of the Assessment}

The objective of this assessment was to determine, using a thoroughly validated method for measuring core body temperature, how well the MTR suit designed by Kimberly Clark maintained internal body temperatures of workers performing tasks common to hazardous waste work. ${ }^{5,6}$ The suit was compared to a polyvinyl chloride (PVC) suit that offers comparable chemical protection and a Tyvek ${ }^{\circledR}$ suit, which offers much lower chemical protection but improved evaporative cooling through the fabric. The main null hypothesis for this assessment was that there would be no significant difference in the mean core temperature of workers wearing the MTR and PVC suits. The second null hypothesis was that the difference between the mean core temperatures for the MTR and Tyvek ${ }^{\circledR}$ suits would be as great as the difference between the PVC and Tyvek ${ }^{\circledR}$.

\subsection{Background on the Operating Engineers National Hazmat Program}

The OENHP has a cooperative agreement with the National Energy Technology Laboratory (NETL) of the Department of Energy to assess the health and safety risks faced by workers who operate and maintain innovative environmental technologies. The OENHP has conducted over 50 assessments in four years. Each human factors assessment has been conducted using a team of safety and health professionals and operating engineers. The main objective of the assessments has been to provide the technology developer with data from field tests early enough in the process to reduce hazards through redesign, rather than through retrofit of technologies already deployed in the field.

OENHP also evaluates technologies designed to protect the worker, such as the Kimberly-Clark MTR suit. When assessing these technologies a protocol is developed to ensure the safety and health of the participants and also to define the testing methods. When, as in the case of the MTR suit, test subjects are required, OENHP draws upon the 400,000 members of the International Union of Operating Engineers (IUOE).

The protocols created by the OENHP for heat stress testing comply with OSHA's requirement for a heat stress management plan under the Hazardous Waste Operations and Emergency Response standard (HAZWOPER) found in 29 CFR 1910.120. Consequently, the OENHP has determined that a human subjects review board is not necessary for the heat stress testing. To ensure the safety of test subjects, emergency medical personnel and an ambulance are on hand whenever testing is conducted.

\subsection{Description of the Protective Garments}

5 Keilson. 1-2.

6 Mittal BB. 1353-1361. 


\subsubsection{Background on protective garments}

Protective garments are available in a broad range of materials and can protect against chemical, physical, biological, and radiological hazards. As OSHA points out, however, most materials will protect well against some hazardous substances and poorly, or not at all, against others. ${ }^{7}$ A general rule of thumb is that impermeable suits provide greater protection against more agents but they also prevent the evaporation of sweat, creating a much greater risk of heat stress illness. The ideal suit would allow water vapor to evaporate from the body to the atmosphere while maintaining a barrier against chemical permeation.

\subsubsection{MTR}

Kimberly Clark's suit is designed to fulfill this important role: lower the risks from chemical permeation without increasing the risk of heat stress illness. The MTR suit's outer fabric that contacts the contaminated atmosphere is a nonporous, but permselective, polymer membrane. It permits the permeation of water vapor, but is essentially impermeable to toxic organic compounds. Since the membrane is nonporous, it also acts as a complete barrier to penetration by particulates, aerosols, and liquids. Because penetration of the hazardous compound is greatly reduced by the permselective membrane, the sorptive layer can be relatively thin. The sorptive layer consists of carbon adsorbent dispersed in a microporous support membrane. The membrane layers are supported on a woven fabric that provides mechanical strength. A protective layer covering the outer surface of the permselective layer makes the fabric water repellent, seals any defects, and protects the permselective layer from abrasion. ${ }^{8}$

This suit design has a reduced potential for heat stress due to the very-high water vapor transmission rate of the new fabric (up to $1,000 \mathrm{~g} / \mathrm{m}^{2}-$ day or more). ${ }^{9}$ The suit was, at the time of the assessment, still in the design/testing phase. The yellow MTR suit was significantly thinner than the impermeable suit chosen for comparison. See Figure 1 for suit example.

7 OSHA. (1998). Hazardous Waste Operations and Emergency Response. 1910.120, Appendix B. 8 Membrane Technology \& Research Inc. Protective Clothing Based on Permselective Membrane and Carbon Adsorption. Federal Energy Technology Center. 1-2. (October 1997).

9 MTRI. 1-2. 


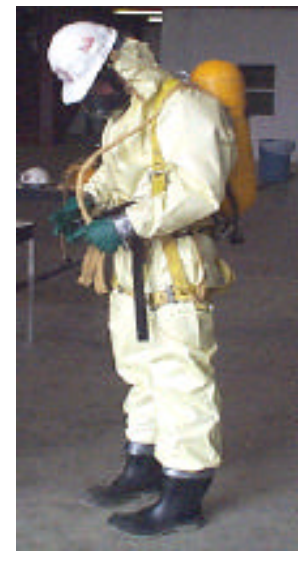

Figure 1. MTR Suit

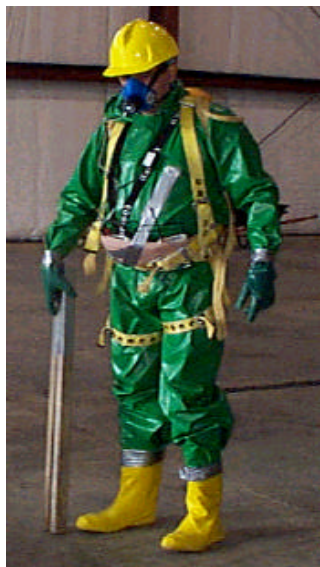

Figure 2. PVC Suit

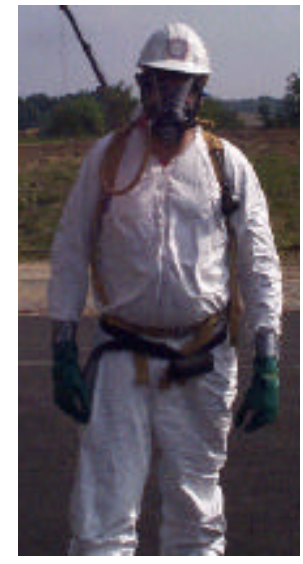

Figure 3. Tyvek ${ }^{\circledR}$ Suit

\subsubsection{Poly Vinyl Chloride (PVC)}

The PVC suit was the impermeable suit used in the assessment. The PVC suit prevented the transfer of any water vapor through the suit material; consequently any perspiration created by the wearer of this type of suit would be contained within the suit until removed. The green PVC suit was chosen because it represents the suit typically used in an OSHA level B ensemble and currently worn on many hazardous waste sites. See Figure 2 for suit example.

\subsubsection{Tyvek $^{\circledR}$}

The Tyvek ${ }^{\circledR}$ suit was chosen for comparison because it is not considered to be chemically impermeable and cannot be used in a Level B ensemble. If the MTR suit can approach the "breathability" of Tyvek ${ }^{\circledR}$ while delivering Level B chemical protection, the product is filling an important niche. Tyvek ${ }^{\circledR}$ suits are typically used in Level C ensembles on hazardous waste sites, although the major use of the garment has been in the asbestos and lead abatement business, where the material protects against dusts rather than chemicals. Other applications include use in clean rooms for the protection of product rather than the worker. See Figure 3 for suit example.

\subsection{METHODOLOGY}

\subsection{Test Subject Selection}

Test subjects were non-randomly selected using the following criteria:

1. Current certification under OSHA 29 CFR 1910.120 as a hazardous waste worker;

2. Workplace experience wearing protective clothing;

3. Successful completion of a medical examination in accordance with 29 CFR 1910.120 HAZWOPER, the NIOSH/OSHA/USCG/EPA Occupational Safety and Health Guidance Manual for Hazardous Waste Site Activities, and ANSI Z88.6-1984- American National 
Standard for Respiratory Protection Respirator Use - Physical Qualifications for Personnel;

4. Medical clearance to use the CorTemp ${ }^{\mathrm{TM}}$ pill system.

At least fifteen field-experienced operating engineers or safety professionals served as test subjects for each heat stress technology. Prior to inclusion in the assessment, each test subject completed a current health questionnaire and was examined by a licensed physician. If the same subject was used within 6 months of their initial physical examination, a new examination was not required unless there had been a change in health status. Each subject was asked to sign a form stating that no changes had occurred.

\subsection{Location}

All heat stress testing was conducted at the International Environmental Technology and Training Center in Beaver, West Virginia.

\subsection{Task Selection}

Tasks were chosen that represented real work on hazardous waste sites and required moderate to heavy exertion. Prior to the use of a task for the assessment, the average oxygen consumption level for the task was determined by having four test subjects perform each task while wearing a telemetric oxygen consumption monitor and a PVC suit. This allowed each task to be rated as light, moderate, heavy, or very heavy work. Using the ACGIH guidelines, the oxygen consumption data allowed OENHP to rate the confined space task rated as heavy, the pit task as moderate, and the wheelbarrow task as heavy to very heavy. This testing was conducted in conjunction with the National Institute for Occupational Safety and Health (NIOSH). Figure 4 below exhibits the field measurements of energy expenditure during six simulated hazardous waste site work activities.

\begin{tabular}{|c|c|c|c|c|c|c|c|c|c|}
\hline Task & $n$ & $\begin{array}{c}\mathrm{VO}_{2} \\
(\mathrm{~L} / \mathrm{min})\end{array}$ & $\begin{array}{c}\mathrm{VO}_{2} \\
\text { (kcal/hr) }\end{array}$ & $\begin{array}{l}\mathrm{VCO}_{2} \\
(\mathrm{~L} / \mathrm{min})\end{array}$ & RQ & $\begin{array}{c}\mathrm{HR} \\
\text { (beats } / \mathrm{min} \text { ) }\end{array}$ & $\begin{array}{c}V E \\
(L / m i n)\end{array}$ & $\begin{array}{c}\mathrm{f} \\
\text { (breaths/ } \\
\text { min) }\end{array}$ & $\begin{array}{l}\text { ACGIH } \\
\text { Rating }\end{array}$ \\
\hline Bulldozer & 4 & $1.0 \pm 0.1$ & 300 & $0.8 \pm 0.1$ & $0.83 \pm 0.05$ & $119 \pm 12$ & $23.0 \pm 2.6$ & $25.8 \pm 3.0$ & Moderate \\
\hline Backhoe & 4 & $1.0 \pm 0.1$ & 300 & $0.9 \pm 0.1$ & $0.89 \pm 0.03$ & $133 \pm 13$ & $24.1 \pm 1.4$ & $26.7 \pm 1.5$ & Moderate \\
\hline $\begin{array}{l}\text { Climb/ } \\
\text { Rod Removal }\end{array}$ & 5 & $1.1 \pm 0.2$ & 330 & $1.0 \pm 0.2$ & $0.88 \pm 0.07$ & $120 \pm 24$ & $26.4 \pm 4.5$ & $27.8 \pm 4.1$ & Moderate \\
\hline Water Carry & 4 & $1.4 \pm 0.4 *$ & 420 & $1.3 \pm 0.3^{*}$ & $0.88 \pm 0.02$ & $134 \pm 20$ & $31.1 \pm 8.1 *$ & $30.5 \pm 4.2^{*}$ & Heavy \\
\hline \begin{tabular}{|l} 
Confined- \\
space \\
Crawl
\end{tabular} & 4 & $1.4 \pm 0.3^{*}$ & 420 & $1.4 \pm 0.4 *$ & $0.96 \pm 0.08$ & $139 \pm 31$ & $38.0 \pm 9.8^{*}$ & $34.1 \pm 2.5^{*}$ & Heavy \\
\hline $\begin{array}{l}\text { Shovel/ } \\
\text { Wheelbarrow } \\
\text { Push }\end{array}$ & 4 & $1.7 \pm 0.2 *$ & 510 & $1.5 \pm 0.3^{*}$ & $0.91 \pm 0.05$ & $140 \pm 13$ & $36.6 \pm 5.9 *$ & $32.0 \pm 5.7 *$ & $\begin{array}{l}\text { Heavy - } \\
\text { Very Heavy }\end{array}$ \\
\hline
\end{tabular}




\subsection{Training}

Prior to the assessment each test subject was trained on the suits and educated on heat stress, including signs and symptoms, and actions to take if they experienced any of these signs and symptoms. The test subject donned the heat stress technology (suit) and appropriate PPE, with assistance. The test subject then performed the task and physiological measurements were taken.

\subsection{Measurements}

Each test subject's core body temperature was measured using a CorTemp ${ }^{\mathrm{TM}}$ pill, which is swallowed and ingested by the test subject and remains in the body until passed in the stool. The CorTemp ${ }^{\mathrm{TM}}$ pill was chosen as the basis for all core body temperature measurements due to its ease of use and reliability. ${ }^{10,11}$ The CorTemp ${ }^{\mathrm{TM}}$ pill contains a microchip that transmits a signal to a data logging devise worn on the belt of the test subject. The data-logging devise can then be connected to a computer and the electronic data can be transferred. CorTemp ${ }^{\mathrm{TM}}$ pill data were collected for all three suits.

Additionally, a WBGT index was recorded during every task at 30 (thirty) second intervals to document the environmental conditions during the assessment. The Quest wet bulb globe thermometer was used for the measurements.

\subsection{Task Protocols}

\subsubsection{General}

Three different tasks were used in this assessment and were repeated for each of the three suits for a total of nine different task/suit combinations. The tasks did not change from one suit to another. Before each task the test subject donned a suit, gloves, boots, hardhat, and SCBA. Additionally, a harness was used for the pit task. After each task the test subjects doffed the above-mentioned PPE. The three tasks involved different challenges.

The test subjects were asked to perform each task for twenty minutes or until one of three criteria was met:

1. Core body temperature reached $38.75^{\circ} \mathrm{C}\left(101.75^{\circ} \mathrm{F}\right)$

2. $90 \%$ of maximum heart rate (maximum heart rate is 220 minus age) was attained

3. Test subject experienced serious fatigue

If fatigue was the reason for stopping, the task was restarted if the subject expressed a willingness to restart. If either of the other two conditions occurred, the subject was removed to a cool area and allowed to rest until the temperature or heart rate returned to normal. Each test subject rested for a minimum of thirty minutes between the 
performance of each task.

\subsubsection{Confined Space Task}

The confined space task consisted of the test subject crawling through a 24-inch diameter culvert that led into a ten foot square wooden confined space. Once inside the wooden structure the test subject opened a door on the side of the structure and exited. The test subject would proceed to manipulate a tool for three minutes. The test subject would then return to the wooden structure through the door and then proceed to crawl through the culvert to the beginning point. This was repeated for the remainder of the task time. See Figures 5 and 6 for task examples.

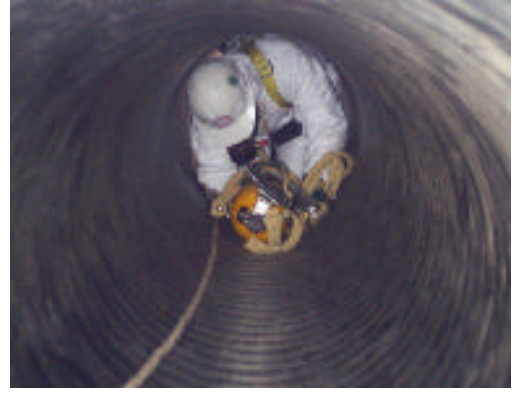

Figure 5. Confined Space Task (Culvert)

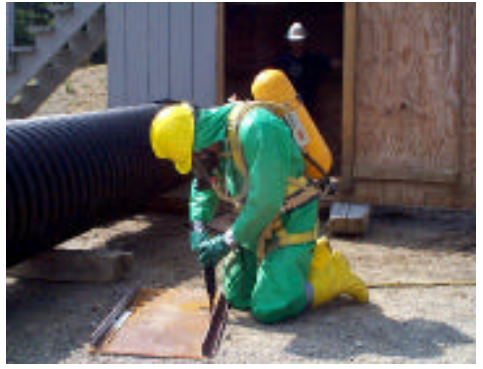

Figure 6. Confined Space Task (Tool)

\subsubsection{Pit Task}

The pit task consisted of the test subject walking a short distance to a vertical ladder. Once at the ladder the test subject's full body harness was attached to a fall protection device that was attached to a tripod. The test subject climbed down the twelve-foot vertical ladder into the pit. Once in the pit a ten-foot hallway was negotiated until the opening of the pit was reached. The test subject would then proceed to simulate a spent nuclear fuel rod removal. Another person assisted the test subject in removing the spent nuclear fuel rod by operating an overhead crane. The test subject in the pit had to attach the crane hook to the attachment point on the steel beam. Guide wands were used to guide the fuel rod as the overhead crane operator picked it out of the pit. The test subject returned to the ladder and climbed out of the pit. Once at the top of the ladder the test subject was unhooked from the tripod. The test subject walked fifteen feet and again used guide wands to guide the spent rod into a containment vessel. This was repeated for the remainder of the task time. See Figures 7 and 8 for task examples. 


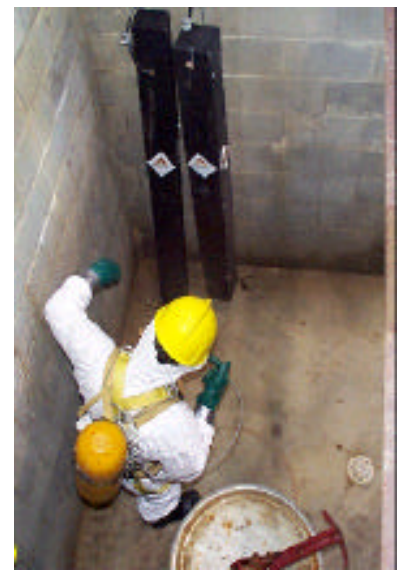

Figure 7. Pit Task (Removal)

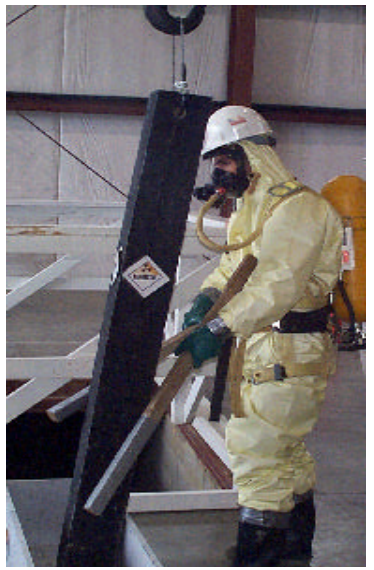

Figure 8. Pit Task (Guiding)

\subsubsection{Wheelbarrow Task}

The wheelbarrow task consisted of the test subject moving sand between two locations seventy-five feet apart. The test subject used a flat scoop shovel to move the sand from a pile to the wheelbarrow. A load limit line located on the inside walls of the wheelbarrow limited the amount of sand shoveled into the wheelbarrow. The test subject would push the wheelbarrow seventy-five feet to another location and then proceed to dump the sand out of the wheelbarrow. The test subject returned to the pile of sand and proceed to fill the wheelbarrow with sand again. This was repeated for the remainder of the task time. See Figures 9 and 10 for task examples.

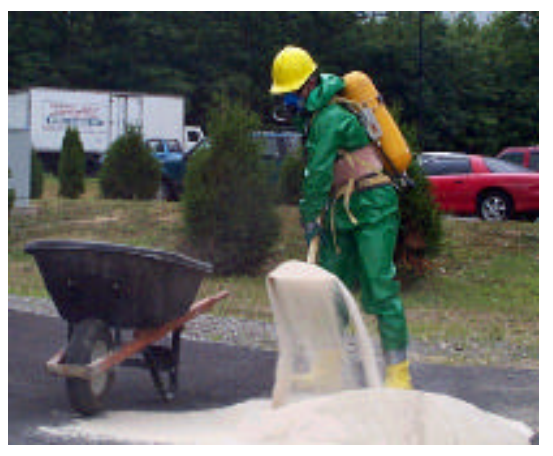

Figure 9. Wheelbarrow (Shovel)

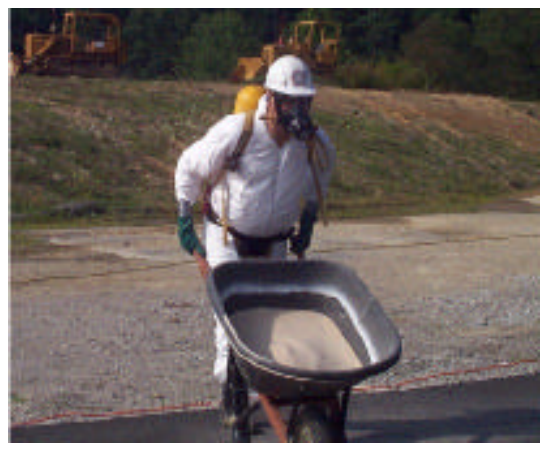

Figure 10. Wheelbarrow (Push) 


\subsection{Data Collection}

\subsubsection{Quantitative}

Core temperature measurements were collected for each task. Each task set was assigned a file name and the corresponding CorTemp ${ }^{\mathrm{TM}}$ pill data for that task set was stored within that file. Each file was then assigned a task set number (T-x) that was used as the reference number for that task set.

\subsubsection{Qualitative}

The test subjects completed five questionnaires before and after using the MTR suit. The subject matter for the five questionnaires:

- Visual Assessment,

- Fit Assessment,

- Before Exercise,

- After Task Performance, and

- After Removing Coverall.

These questionnaires asked about the user's perception of the comfort and flexibility of the suit, for instance. The visual analog scale was used for recording the results of several of the questionnaires. The other questionnaires relied on the more traditional five-point Likert scale.

For comparison purposes, the users completed a User Satisfaction Questionnaire for all three suits. The User Satisfaction Questionnaire was completed after each task.

\subsection{Data Analysis}

\subsubsection{Quantitative}

The CorTemp ${ }^{\mathrm{TM}}$ pill data were logged for each test subject during each task set. The electronic data were imported into Microsoft Excel ${ }^{\circledR}$. The source of the data was confirmed using the CorTemp ${ }^{\mathrm{TM}}$ pill serial number. The data sets were then grouped according to the subject, task, and suit used. The data were then cleaned by excluding outliers that fell above forty-one (41) degrees Celsius or below thirty-three (33) degrees Celsius. The upper constraint was derived from the ACGIH value for heat stroke $\left(40^{\circ} \mathrm{C}\right.$ to $41^{\circ} \mathrm{C}$ ). This limit is four $(4)$ degrees above normal body temperature $\left(37^{\circ} \mathrm{C}\right)$. The lower limit was chosen at four (4) degrees Celsius below normal, or thirty-three (33) degrees Celsius.

Statistical analysis was performed on the data in each task set to determine: number of data points (n), average (Avg.), population standard deviation (SD), and coefficient of variation (CV). These values sorted by suit, task, and subject can be found in Appendix B Tables: S-MTR, SPVC, and S-Tyvek ${ }^{\circledR}$. The combined values can be found in the previously mentioned tables and in Table A that follows. 
Table A: Subjects' core body temperature while wearing suit as indicated.

\begin{tabular}{|c|c|c|c|c|c|c|c|c|c|c|c|c|c|c|c|c|}
\hline \multirow[t]{2}{*}{ Suit } & \multicolumn{4}{|c|}{$\begin{array}{c}\text { Table SMTR } \\
\text { MIR }\end{array}$} & \multicolumn{4}{|c|}{$\begin{array}{c}\text { Table SPVC } \\
\text { PVC }\end{array}$} & \multicolumn{4}{|c|}{$\begin{array}{c}\text { Table S-Tyvek® } \\
\text { Tyvekß }\end{array}$} & \multicolumn{4}{|c|}{$\begin{array}{c}\text { Table S(MTR,PVC, and Tyvek®) } \\
\text { All } 3\end{array}$} \\
\hline & $\mathrm{n}$ & Avg. & Stdev & CV\% & $\mathbf{n}$ & Avg. & Stdev & CV\% & $\mathbf{n}$ & Avg. & Stdev & CV\% & $n$ & Avg. & Stdev & CV\% \\
\hline CS & 16 & 37.37 & 0.46 & 1.22 & 16 & 37.36 & 0.54 & 1.46 & 16 & 37.40 & 0.48 & 1.30 & 48 & 37.38 & 0.50 & 1.33 \\
\hline PIT & 16 & 37.31 & 0.26 & 0.69 & 15 & 37.19 & 0.43 & 1.15 & 18 & 37.01 & 0.46 & 1.24 & 49 & 37.16 & 0.41 & 1.11 \\
\hline WB & 17 & 37.27 & 0.36 & 0.97 & 17 & 37.22 & 0.47 & 1.27 & 16 & 37.34 & 0.28 & 0.75 & 50 & 37.28 & 0.38 & 1.03 \\
\hline All 3 & 49 & 37.31 & 0.37 & 0.99 & 48 & 37.26 & 0.49 & 1.32 & 50 & 37.24 & 0.45 & 1.22 & 147 & 37.27 & 0.44 & 1.19 \\
\hline
\end{tabular}

An analysis of variance (ANOVA) was performed on the suit and task groups to see if any significant differences existed. The data from each suit and task grouping were randomly sampled to achieve three task sets for each suit containing 2000 data points. The ANOVA's were then calculated from these randomly sampled data sets. The ANOVA results can be found in Appendix B Tables: D-MPT, D-MTR, D-PVC, D-Tyvek ${ }^{\circledR}$, and D-TF.

Regression analyses were then performed on the data to estimate the best linear fit between the core temperature data and the elapsed time for each subject wearing a particular suit during a particular task. The lines depicting the regression equations were then graphed to better evaluate the relationship of the three suits. This can be seen in Appendix A with charts bearing the " $\mathrm{S}$ " heading (the subject number and task follow S-2-CS).

\subsubsection{Qualitative}

Questionnaires completed by the test subjects consisted of visual analog scales and Likert scales. The visual analog scale required that a line marked by the subjects be measured and the value recorded. On the Likert scale, the subject checked a box representing the ordinal value they felt most closely matched their opinion. The results were statistically evaluated for the number of answers ( $n$ ) and average (Avg.). The results from all of the questionnaires can be found in Appendix B Tables E-K. The averages from all the questionnaires were charted and can be found in Appendix $A$ Charts E-K. The questions asked on the questionnaires appear below each of the corresponding charts.

\subsection{RESULTS}

\subsection{Quantitative}

The core temperature results from this assessment are significant and indicate that workers wearing the MTR suit are definitely able to dissipate body heat better than when wearing the PVC suit. As one would expect, the Tyvek ${ }^{\circledR}$ suit provided the greatest overall core temperature dissipation but in several of the tests the MTR suit had comparable results. These results are based on over 2000 core temperature readings for each task with each suit. This is a large database. 
The regression equations are particularly illustrative. They demonstrate that the slope for the temperature increase over time is consistently better for the MTR suit than the PVC. As the graphs indicate, the regression equations predict that the test subjects would have been able to wear the MTR suit and continue the tasks for two hours without reaching the ACGIH heat stroke temperature of 40 degrees Celsius, while they would have been in trouble wearing the PVC suit within an hour in most cases.

The coefficient of determination $\left(\mathrm{R}^{2}\right)$ for several of the regressions analyses is small. This is an indication of the prediction power of the equation. For instance, $\mathrm{R}^{2}$ for subject number 6 wearing the MTR suit while performing the wheelbarrow task is only 0.1837 . This indicates that the amount of error is only 18 percent smaller using this predictive equation than just taking a mean of all the data points.

To ensure that there were significant differences among the means of the data for the three suits, Analysis of Variance (ANOVA) calculations were made. The analysis of variance was reasonable in this situation because these data met the standard assumptions:

1. The population distributions are normal;

2. The standard deviations of the population distributions are fairly equal; and

3. Independent random samples were selected from the populations.

The results indicated that there was significant difference among the core temperature readings for the three suits when 6000 data points for all tasks were combined. The F-statistic for TableD-MPT is greater than 24 with a p-value of less than $3.6 \times 10^{-11}$, an indication of strong significance. Additional ANOVA tests showed that there were significant differences in core temperatures among the three tasks for each suit.

\subsection{Qualitative}

Descriptive statistics, such as the number of answers (n) and the average (Avg.) were calculated for each questionnaire. The results of the questionnaires appear in Appendix $A$ and $B$ in both graphic and tabular form. Table B follows and contains a summary of the averages from the questionnaires. A brief discussion of results follows.

\section{Table B: Questionnaire Answer Averages}

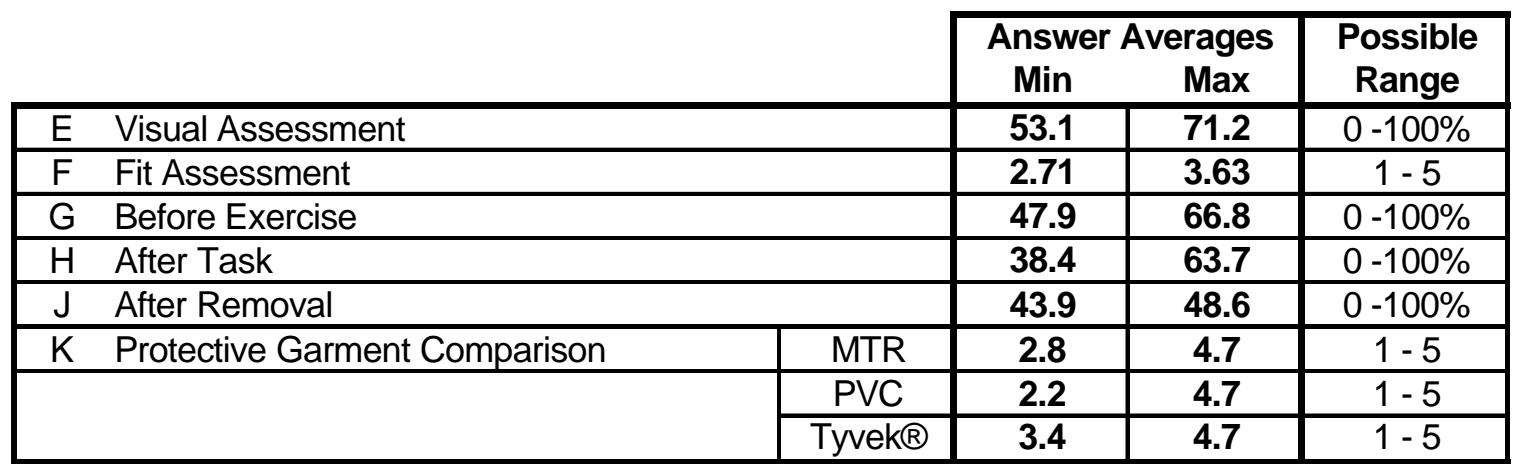

The "visual assessment" questionnaire contained questions about the appearance of the MTR suit. This questionnaire was completed before the ensemble was donned. The questionnaire 
contained ten questions and used the visual analog scale (VAS) for response recording. The responses were reported as percentages of the question. The questions were worded so that the desirable qualities such as comfort and protectiveness result in a high percentage. The higher the percentage a question received the better the MTR suit was rated. The rating percentages ranged from 53 to 72 percent. The ratings were all above 50 percent, which show the MTR suit to be moderately liked by appearance by the questionnaire subjects.

The "fit assessment" questionnaire evaluated the physical size of the suit. The questionnaire used boxes with descriptors of the fit, rather than numerical values. The assigned values ranged from 1 to 5 in 0.5 increments. The questions were worded so that the ideal fit occurred at a value of 3. The mean scores ranged from 2.7 to 3.6, which indicated that, the subjects ranked the MTR suit from slightly short to slightly long.

The "before exercise" questionnaire used the visual analog scale previously explained. Test subjects completed the questionnaire before they began any physical activity. The questionnaire asked questions that referred to how the suit felt. The rating percentages ranged from 47 to 67 percent. The ratings show the MTR suit to feel moderately okay by the test subjects before any physical activity.

The "after task performance" questionnaire again used the visual analog scale. The test subjects completed the questionnaire after they completed the physical activity required by the task. The rating percentages ranged from 38 to 64 percent. The ratings show the MTR suit to feel less than okay on average by the test subjects after they completed the physical activity required by the task.

The "after removing coverall" questionnaire again used the visual analog scale. Test subjects completed the questionnaire after they completed the task and removed their suit/coverall. The questionnaire asked questions that referred to how they felt after having removed the suit/coverall. The rating percentages ranged from 43 to 49 percent. The ratings show the test subjects felt less than ok after having completed the physical activity required by the task and removing the MTR suit.

The "user satisfaction" questionnaire used an answer scale from 1 to 5 to rate each of the three suits for each question on the questionnaire. The questions were worded so that the higher the answer the better the suit in question was rated. Each test subject completed the questionnaire after having worn each of the three suits. The mean scores for the MTR suit ranged from 2.8 to 4.7. The mean scores for the PVC suit ranged from 2.2 to 4.7. The mean scores for the Tyvek ${ }^{\circledR}$ suit ranged from 3.4 to 4.7 . The results showed the test subjects rated the Tyvek ${ }^{\circledR}$ suit higher on every question, except question seven. Question seven rated the suit from "1-Very Cold to 5Not Cold" and 4.7 was the average for all three suits. Question seven was the only question that the PVC suit was rated similar to the Tyvek ${ }^{\circledR}$ and MTR suits. On all other questions the PVC suit was rated lower than the other two suits. The MTR suit was rated numerically halfway between the Tyvek ${ }^{\circledR}$ and PVC suits except question seven.

Results of all the MTR questionnaires, on the average, show the subjects rated the MTR suit to be generally in the range of less than adequate to adequate. The results, however, represent a small test sample. The results of the "user satisfaction" questionnaire rated the MTR suit lower than the Tyvek ${ }^{\circledR}$ suit and higher than the PVC suit but adequate in most categories. 
Comments taken from the questionnaires were also quite insightful and follow in Table C.

\section{Table C: Questionnaire Comments}

\begin{tabular}{|c|c|c|c|}
\hline Suit & Task & Comment & Subject \\
\hline MTR & Confined Space & "Hood was a little tight on me." & $\mathrm{S5}$ \\
\hline MTR & Confined Space & "Too hot. & $\mathrm{S} 15$ \\
\hline MTR & Confined Space & "The prior suits can do as good." & S26 \\
\hline MTR & Pit & $\begin{array}{l}\text { "Yellow MTR suit does satisfactory job overall. Blue } \\
\text { suit does absorb good. Both have excellent zipper } \\
\text { closures." }\end{array}$ & S25 \\
\hline MTR & Pit & "Yellow suit should be smaller in waist and chest." & $\overline{S 13}$ \\
\hline MTR & Pit & $\begin{array}{l}\text { Not a strenuous task. Blue suit did not soak up } \\
\text { sweat." }\end{array}$ & S26 \\
\hline MTR & Pit & $\begin{array}{l}\text { "Seemed to sweat more with ensemble on during pit } \\
\text { task." }\end{array}$ & S20 \\
\hline MTR & Wheelbarrow & "Not a bad suit." & $\mathrm{S} 1$ \\
\hline PVC & Confined Space & "Was able to work with little difficulty." & $\mathrm{S} 18$ \\
\hline PVC & Confined Space & $\begin{array}{l}\text { "Blue inner suit wicked away sweat very well. Outer } \\
\text { green suit very hot" }\end{array}$ & S25 \\
\hline PVC & Confined Space & "Hot SOB with suit on." & $\mathrm{S} 20$ \\
\hline PVC & Pit & $\begin{array}{l}\text { "With harness on, when I bent over to unhook hook, } \\
\text { felt seat rip out of blue suit." }\end{array}$ & S20 \\
\hline PVC & Wheelbarrow & $\begin{array}{l}\text { "There is a noticeable difference in temperature } \\
\text { wearing the green suit." }\end{array}$ & S24 \\
\hline PVC & Wheelbarrow & "Need material to keep from rubbing the neck." & $\mathrm{S} 2$ \\
\hline PVC & Wheelbarrow & "Very comfortable." & S26 \\
\hline PVC & Wheelbarrow & $\begin{array}{l}\text { "Suit soaks up sweat, semi-loose fitting. Need } 2 \mathrm{XL} \\
\text { blue suits. Once suit is wet, seems to rip easily." }\end{array}$ & S20 \\
\hline Tyvek $^{\circledR}$ & Confined Space & $\begin{array}{l}\text { "The inner suit from KC was easily torn when wet. I } \\
\text { could not see a difference in the KC suits, from any } \\
\text { other suit l've tried." }\end{array}$ & $\overline{S 12}$ \\
\hline Tyvek $^{\circledR}$ & Confined Space & $\begin{array}{l}\text { "Suit was comfortable to wear - didn't irritate, but } \\
\text { ripped easily once wet or restricted positions." }\end{array}$ & S20 \\
\hline Tyvek $^{\circledR}$ & Pit & "Was able to move freely without much restrictions." & $\overline{S 18}$ \\
\hline Tyvek $^{\circledR}$ & Pit & "Very comfortable, I like it a lot." & $\overline{S 26}$ \\
\hline Tyvek $^{\circledR}$ & Pit & "Seemed cooler using Tyvek ${ }^{\circledR} . "$ & S20 \\
\hline Tyvek $^{\circledR}$ & Wheelbarrow & "Easy to work in." & $\overline{S 2}$ \\
\hline Tyvek $^{\circledR}$ & Wheelbarrow & $\begin{array}{l}\text { "Overall performance ok. Heat stress in this suit could } \\
\text { be a problem if working in high temperatures." }\end{array}$ & S25 \\
\hline
\end{tabular}




\subsection{CONCLUSIONS}

\subsection{Quantitative}

Regression analysis of the data indicated that the MTR suit, for most subjects and tasks, allowed core body heat to dissipate more thoroughly than the impermeable PVC suit. If the MTR suit provides protection against chemicals comparable to impermeable protective garments, it represents a significant improvement because of its advantage in the prevention of heat-related illnesses.

\subsection{Qualitative}

The qualitative results show that the operators perceived the MTR suit to be an acceptable protective garment. The operators considered several aspects, such as style of the coverall, fit and feel of the garment. The Visual Analog Scale (VAS) scale used in this study did not conform to the $10 \mathrm{~cm}$ length commonly accepted in the field of psychophysics. The VAS scales had different lengths that had to be evaluated as a percentage. This could have affected the true ratings received from the operators. Also, it seems that the ratings were clustered at the lower end of the scale and the midpoint of the scale. This indicates a bi-modal distribution of ratings. Other researchers that have used VAS reported that a tri-modal distribution is more likely, with clusters at the midpoint and at the two extremes of the scales. The subjects in this study did not follow this trend. The bi-modal distribution seen in this study could be attributed to the fact that subjects have not been selected randomly from the general population. Furthermore, the intensity of the work may have been too low and the duration of the exposure may have been too short for the operating engineers to formulate accurate ratings that resulted in the lower ratings obtained in this study. In the future, it might be justifiable to test the application of a VAS with more than two verbal anchors for the operating engineers.

\subsection{RECOMMENDATIONS FOR FUTURE STUDIES}

Based on the results of this study, several recommendations are made to improve future study designs:

1. Test the plausibility of using a VAS with more verbal anchors. These verbal anchors may assist the operating engineers in accurately reporting their perception.

2. Use VAS that is of standard length $(10 \mathrm{~cm})$ to obtain all ratings.

3. Increase the duration and intensity of exposure to be evaluated. It is possible that the short exposure duration or intensity examined was not sufficient to realize ratings at the higher end of the scale.

4. Gather data on personal characteristics of the operating engineers (such as weight, height, personal fitness, acclimation to heat) that may influence the study.

5. Collect more data to specifically evaluate tasks separately. This would increase the sample size and statistical power in future study.

6. Focus on different tasks performed by the same operating engineer. This will enable us to understand whether there are notable differences between different tasks performed by 
the same operating engineer. Also we can examine any intra-variability of the operating engineer within the different trials.

7. Focus on same task and two or more operating engineers. This will enable us to understand whether there are notable differences between the operating engineers while the task is kept constant.

\subsection{RELATED MATERIALS}

American Conference of Governmental Industrial Hygienists (ACGIH). 1990. Documentation of the Threshold Limit Values and Biological Exposure Indices. 6th ed. Cincinnati: American Conference of Governmental Industrial Hygienists.

American Conference of Governmental Industrial Hygienists (ACGIH). 1996-1997 Threshold Limit Values for Chemical Substances and Physical Agents and Biological Exposure Indices. Cincinnati: American Conference of Governmental Industrial Hygienists.

American Industrial Hygiene Association (AIHA). 1975. Heating and Cooling for Man in Industry. 2nd ed.Akron, $\mathrm{OH}$ : American Industrial Hygiene Association.

Eastman Kodak Company. 1983. Ergonomic Design for People at Work. Vol. II. Belmont, CA: Lifetime Learning Publications.

Electric Power Research Institute (EPRI). 1987. Heat-Stress Management Program for Nuclear Power Plants. Palo Alto, CA: Electric Power Research Institute.

Ely, W.D. 1987. An Evaluation of Heat Strain Monitoring Methods for Workers in Encapsulating, Impermeable Protective Clothing. U.S. Department of Transportation, Office of Research and Development. Report No. CG-D-12-87.

Minard, D. 1961. Prevention of Heat Casualties in Marine Corps Recruits. Military Medicine, Vol. 126, No. 4, pages 261-272.

National Institute for Occupational Safety and Health. Criteria for a Recommended Standard--Occupational Exposure to Hot Environments. DHHS (NIOSH) Publication No. 86-113, April 1986.

National Institute for Occupational Safety and Health. Occupational Safety and Health Guidance Manual for Hazardous Waste Site Activities. DHHS (NIOSH) Publication No. 85-115, 1985.

National Institute for Occupational Safety and Health. Standards for Occupational Exposures to Hot Environments: Proceedings of a Symposium. DHHS (NIOSH) Publication No. 76-100, January 1976.

National Institute for Occupational Safety and Health. Working in Hot Environments. DHHS (NIOSH) Publication No. 86-112. Revised 1986.

National Safety Council. 1996. Pocket Guide to Heat Stress. Chicago, L: National Safety Council. 
Ramsey, J. D., Buford, C. L., Beshir, M.Y., and Jensen, R .C. Effects of work place thermal conditions on safe work behavior. Journal of Safety Research 14:105-114, 1983.

Zenz, C. 1988. Occupational Medicine: Principles and Practical Applications. 2nd ed. St. Louis, MO: Mosby Year Book, Inc.

\subsection{LIST OF ACRONYMS}

$\begin{array}{ll}\text { ACGIH } & \text { American Conference of Governmental Industrial Hygienists } \\ \text { ANOVA } & \text { Analysis of variance } \\ \text { ANSI } & \text { American National Standards Institute } \\ \text { CV } & \text { Coefficient of variation } \\ \text { D\&D } & \text { Deactivation and decommissioning } \\ \text { DOE } & \text { Department of Energy } \\ \text { EPA } & \text { Environmental Protection Agency } \\ \text { HAZWOPER } & \text { Hazardous Waste Operations and Emergency Response } \\ \text { IUOE } & \text { International Union of Operating Engineers } \\ \text { MTR } & \text { Membrane Technology \& Research, Inc } \\ \text { NETL } & \text { National Energy Technology Laboratory } \\ \text { NIOSH } & \text { National Institute of Occupational Safety and Health } \\ \text { OENHP } & \text { Operating Engineers National Hazmat Program } \\ \text { OSHA } & \text { Occupational Safety and Health Administration } \\ \text { PPE } & \text { Personal protective equipment } \\ \text { PVC } & \text { Polyvinyl chloride } \\ \text { SCBA } & \text { Self-contained breathing apparatus } \\ \text { SD } & \text { Standard deviation } \\ \text { USCG } & \text { United States Coast Guard } \\ \text { VAS } & \text { Visual analog scale } \\ \text { WBGT } & \text { Wet-bulb globe temperature }\end{array}$

\subsection{APPENDICES}




$$
9.1 .
$$

Appendix A:

$$
\text { Charts }
$$




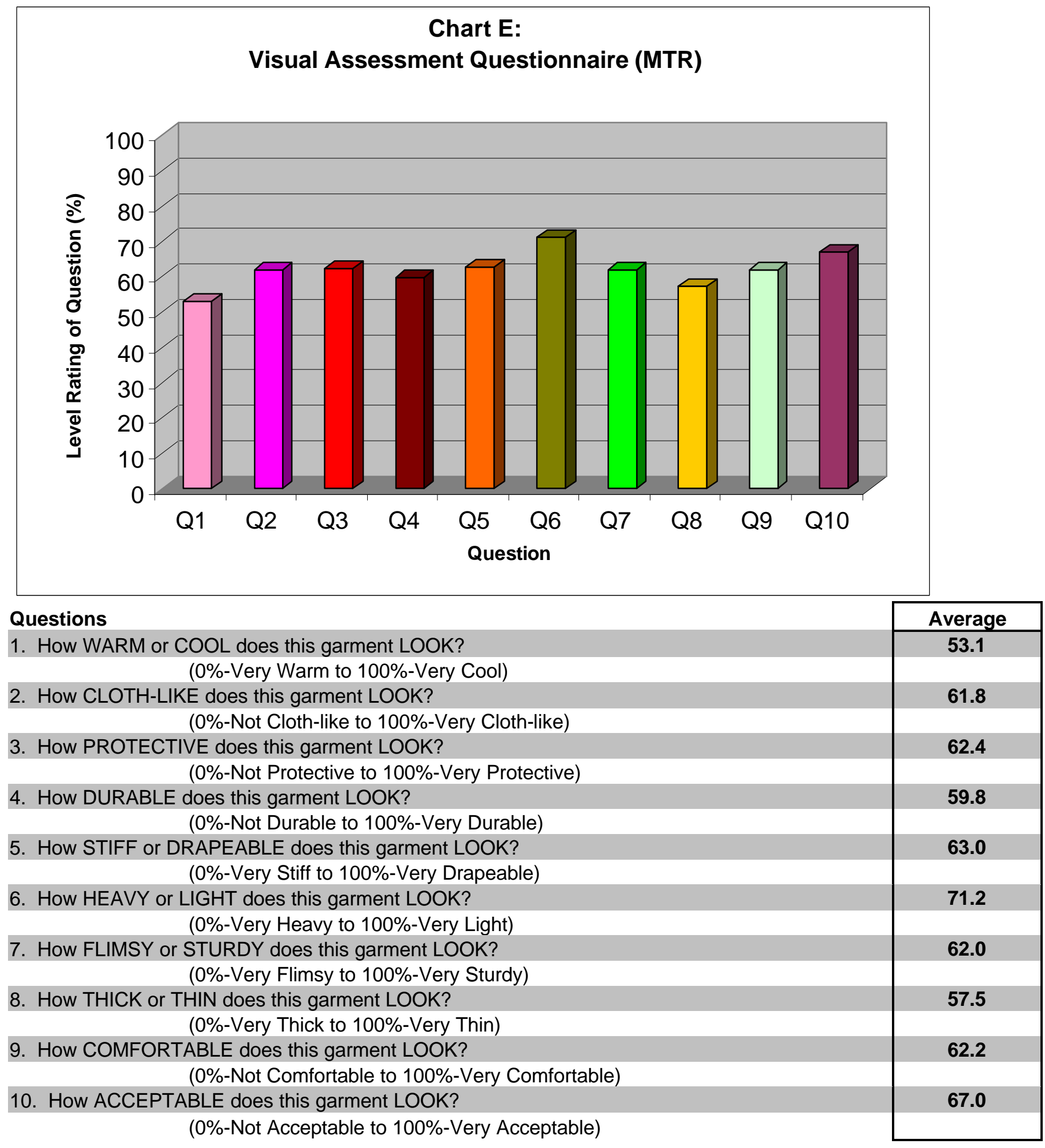




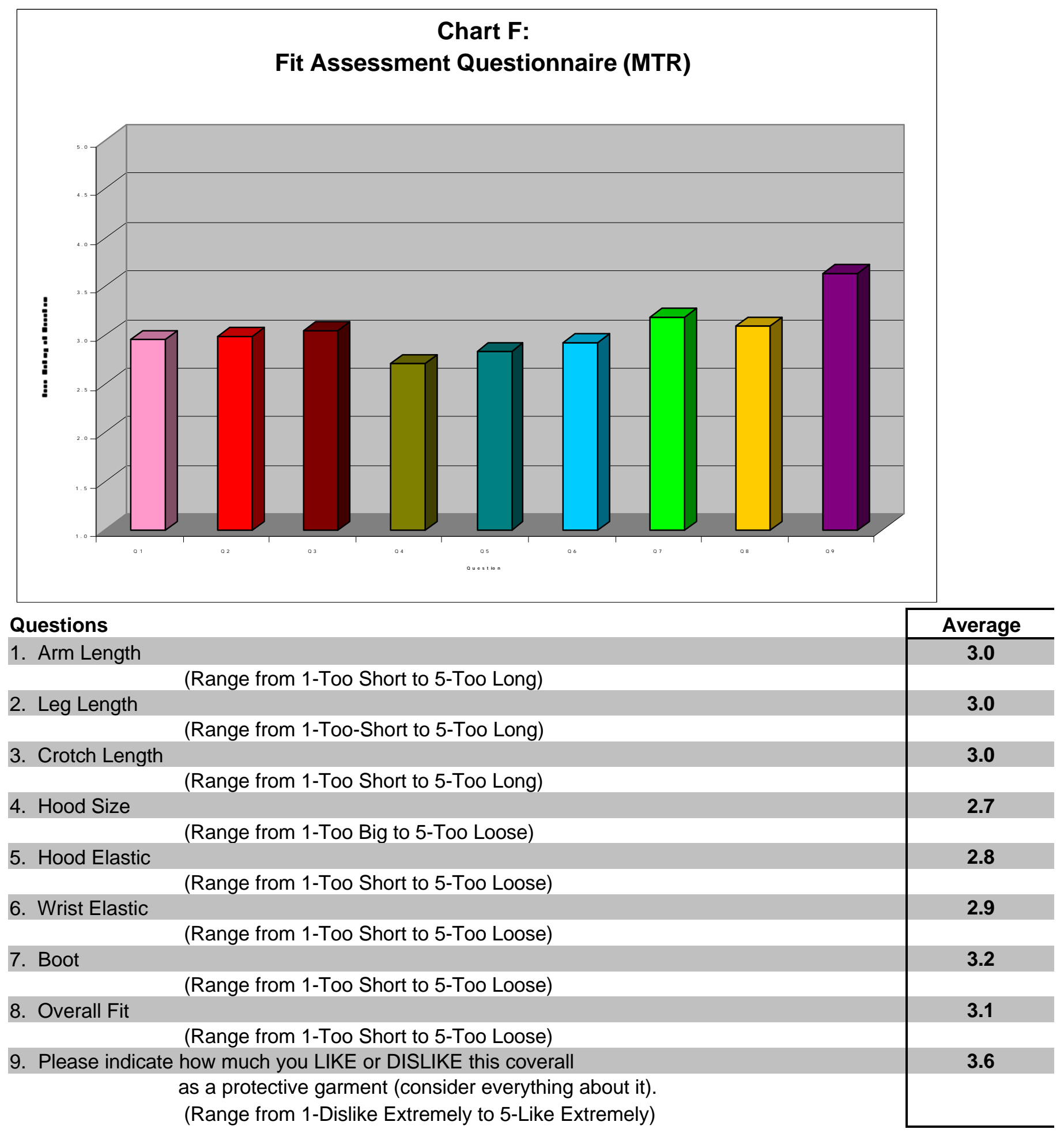




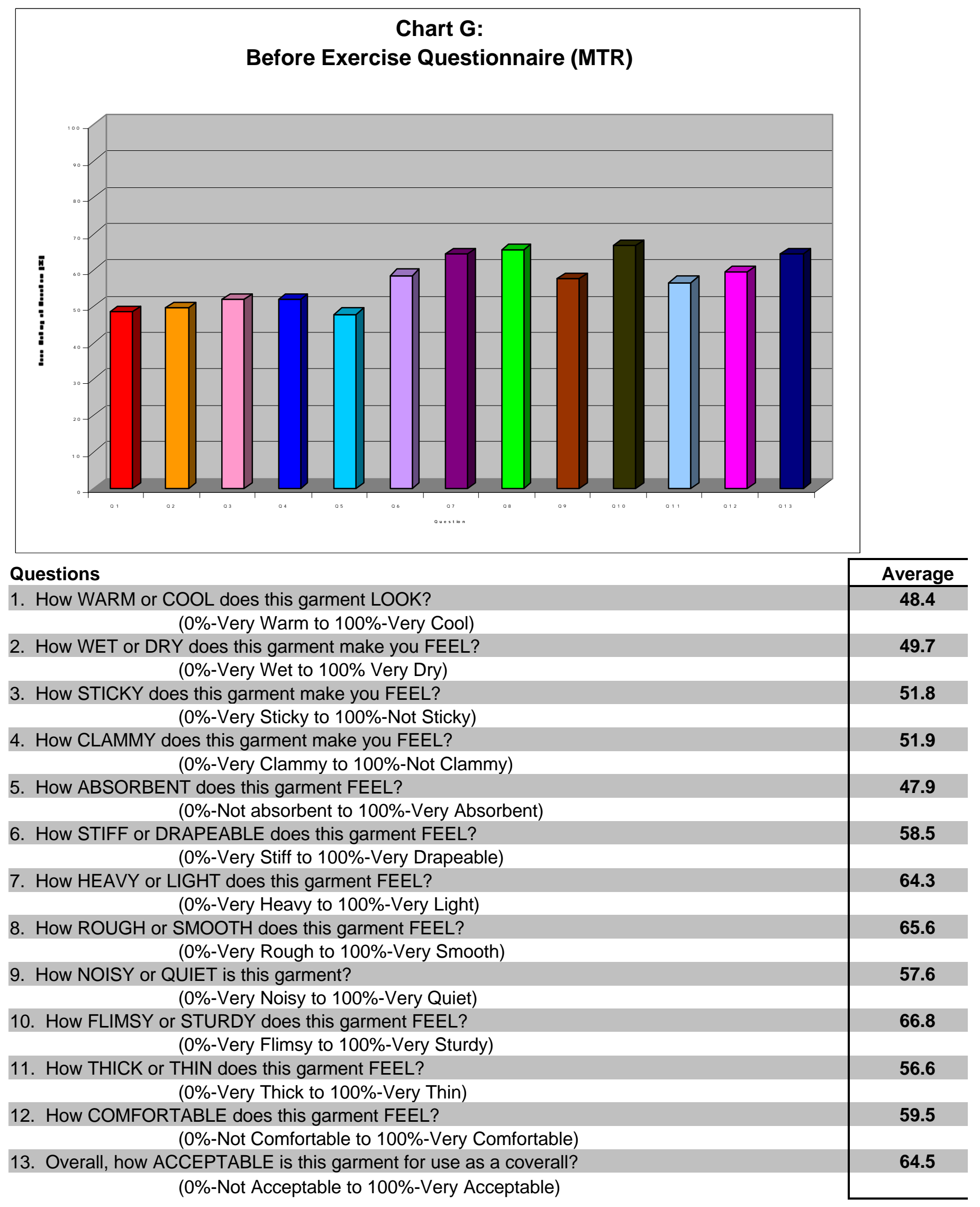




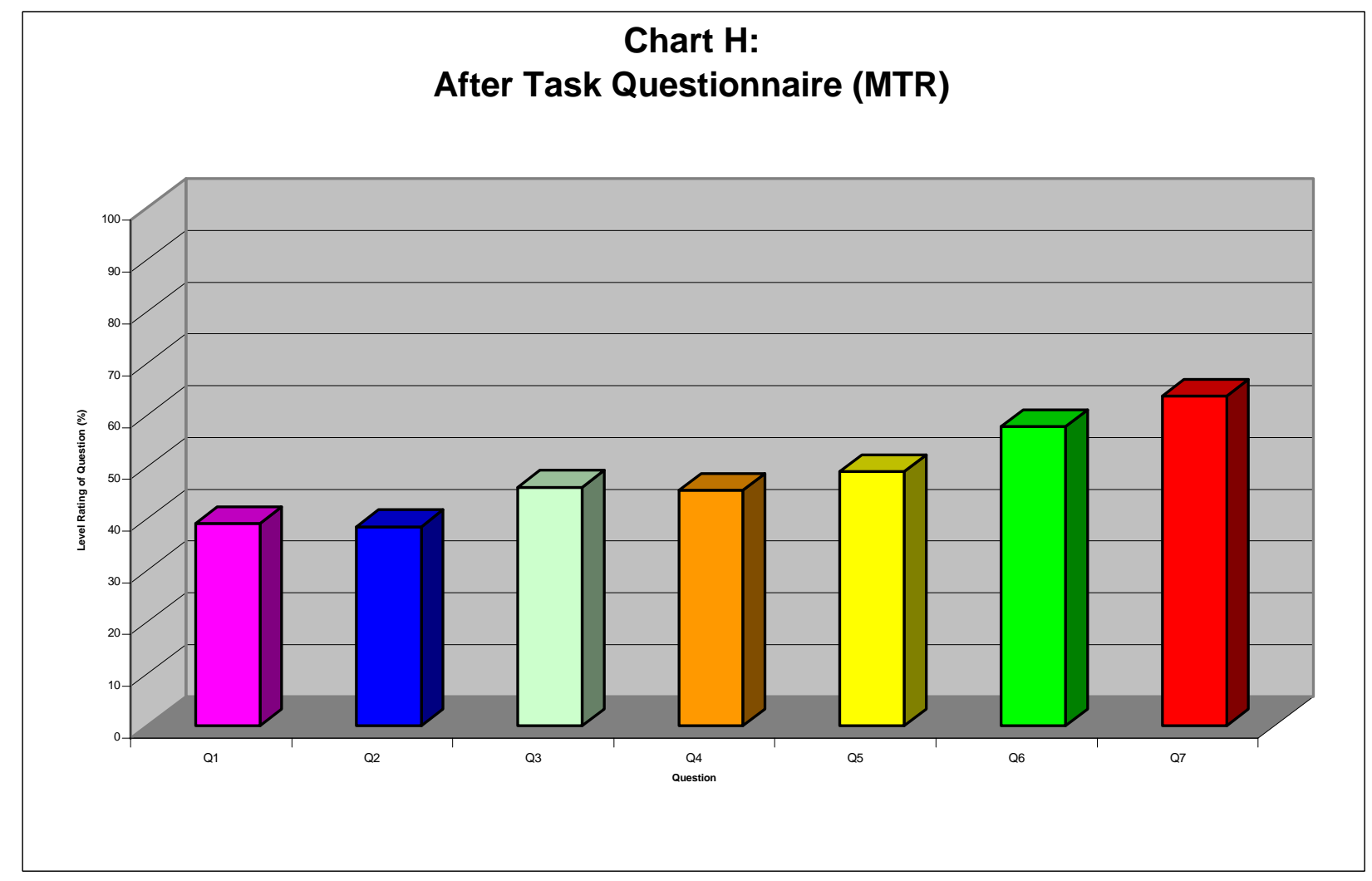

Questions

1. How WARM or COOL does this garment make you FEEL?

Average

(0\%-Very Warm to $100 \%$-Very Cool)

2. How WET or DRY does this garment make you FEEL?

(0\%-Very Wet to $100 \%$ Very Dry)

3. How STICKY does this garment make you FEEL?

(0\%-Very Sticky to $100 \%-$ Not Sticky)

4. How CLAMMY does this garment make you FEEL?

(0\%-Very Clammy to $100 \%-N o t$ Clammy)

5. How ABSORBENT does this garment FEEL?

(0\%-Not absorbent to $100 \%$-Very Absorbent)

6. How COMFORTABLE do you FEEL in this garment?

(0\%-Not Comfortable to $100 \%$-Very Comfortable)

7. Overall, how ACCEPTABLE is this garment for use as a coverall?

(0\%-Not Acceptable to 100\%-Very Acceptable) 


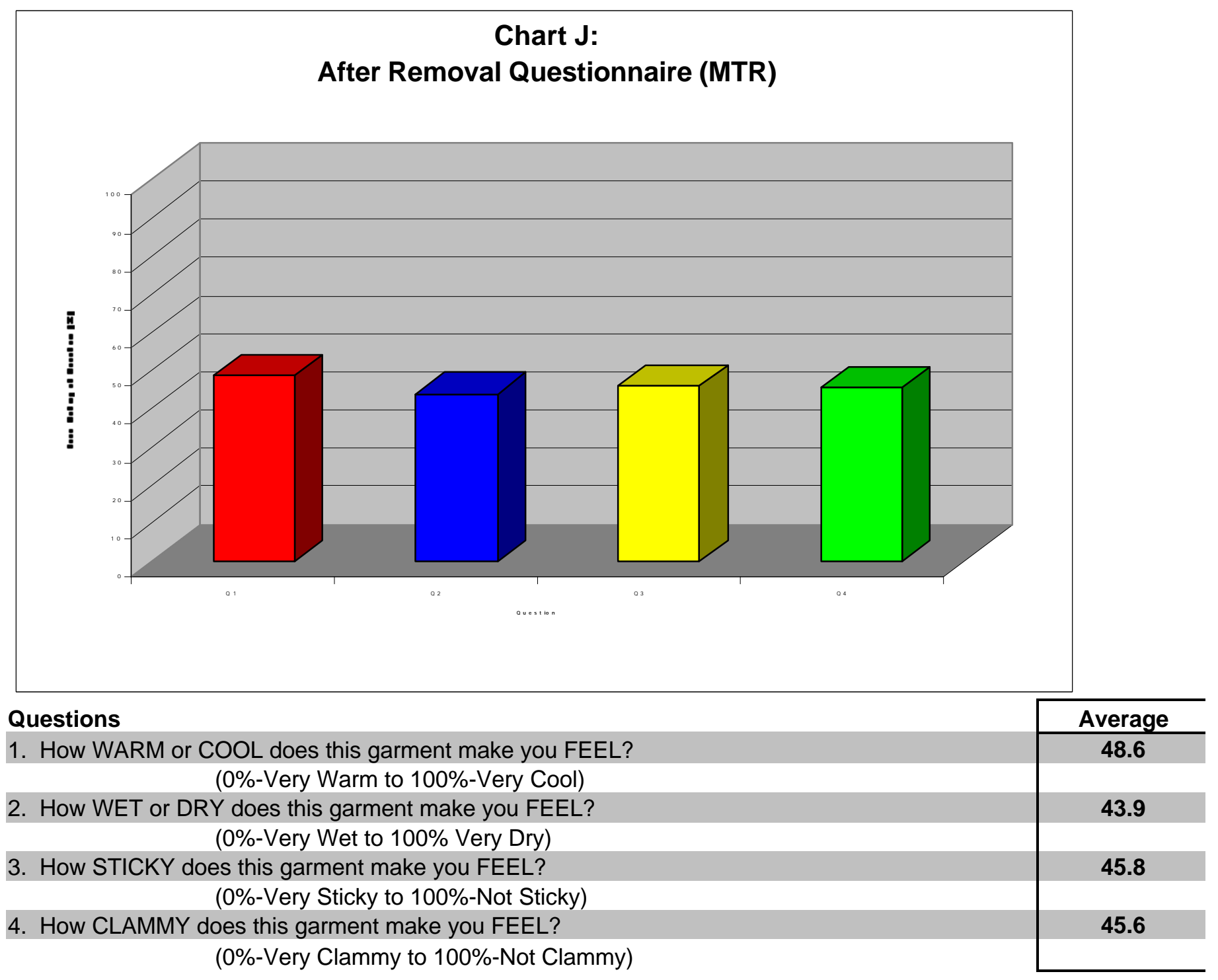




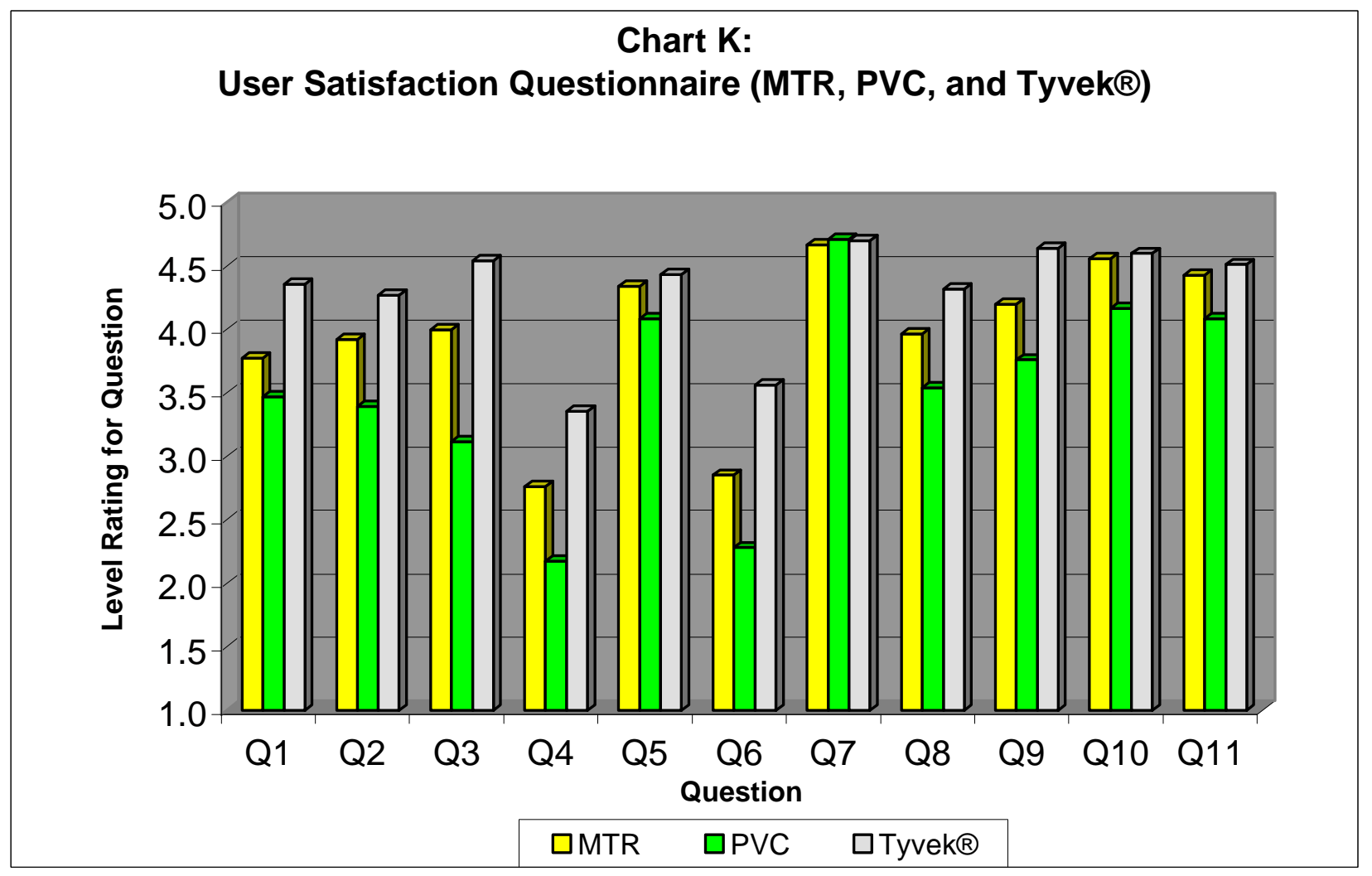

Questions (with extremes)

1. Comfort

(1-Uncomfortable to 5-Very Comfortable)

2. Flexibility

(1-Inflexible to 5-Very Flexible)

3. Weight

(1-Heavy to 5-Light)

4. Sweating

(1-Heavy Sweating to 5-No sweating)

5. Interference with Communication

(1-Severly Interfering to 5-No Interference)

6. Hot

(1-Very Hot to 5-Not Hot)

7. Cold

(1-Very Cold to 5-Not Cold)

8. Freedom of Movement

(1-Completely Restricted to 5-Not Restricted)

9. Irritating

(1-Very Irritating to 5-Not Irritating)

10. Interference with Visibility

(1-Serious Interference to 5-No Interference)

11. Interference with Peripheral Vision

(1-Serious Interference to 5-No Interference)

\begin{tabular}{|c|c|c|}
\hline $\begin{array}{c}\text { MTR } \\
\text { Average }\end{array}$ & $\begin{array}{c}\text { PVC } \\
\text { Average }\end{array}$ & $\begin{array}{c}\text { Tyvek }{ }^{\circledR} \\
\text { Average }\end{array}$ \\
\hline 3.8 & 3.5 & 4.4 \\
3.9 & 3.4 & 4.3 \\
4.0 & 3.1 & 4.5 \\
2.8 & 2.2 & 3.4 \\
4.3 & 4.1 & 4.4 \\
2.9 & 2.3 & 3.6 \\
4.7 & 4.7 & 4.7 \\
4.0 & 3.5 & 4.3 \\
4.2 & 3.8 & 4.6 \\
4.6 & 4.2 & 4.6 \\
4.4 & 4.1 & 4.5 \\
\hline
\end{tabular}


Chart S-2-CS:

Subject No. 2 Wearing MTR, PVC, and Tyvek® Suits

While Performing the Confined Space Task

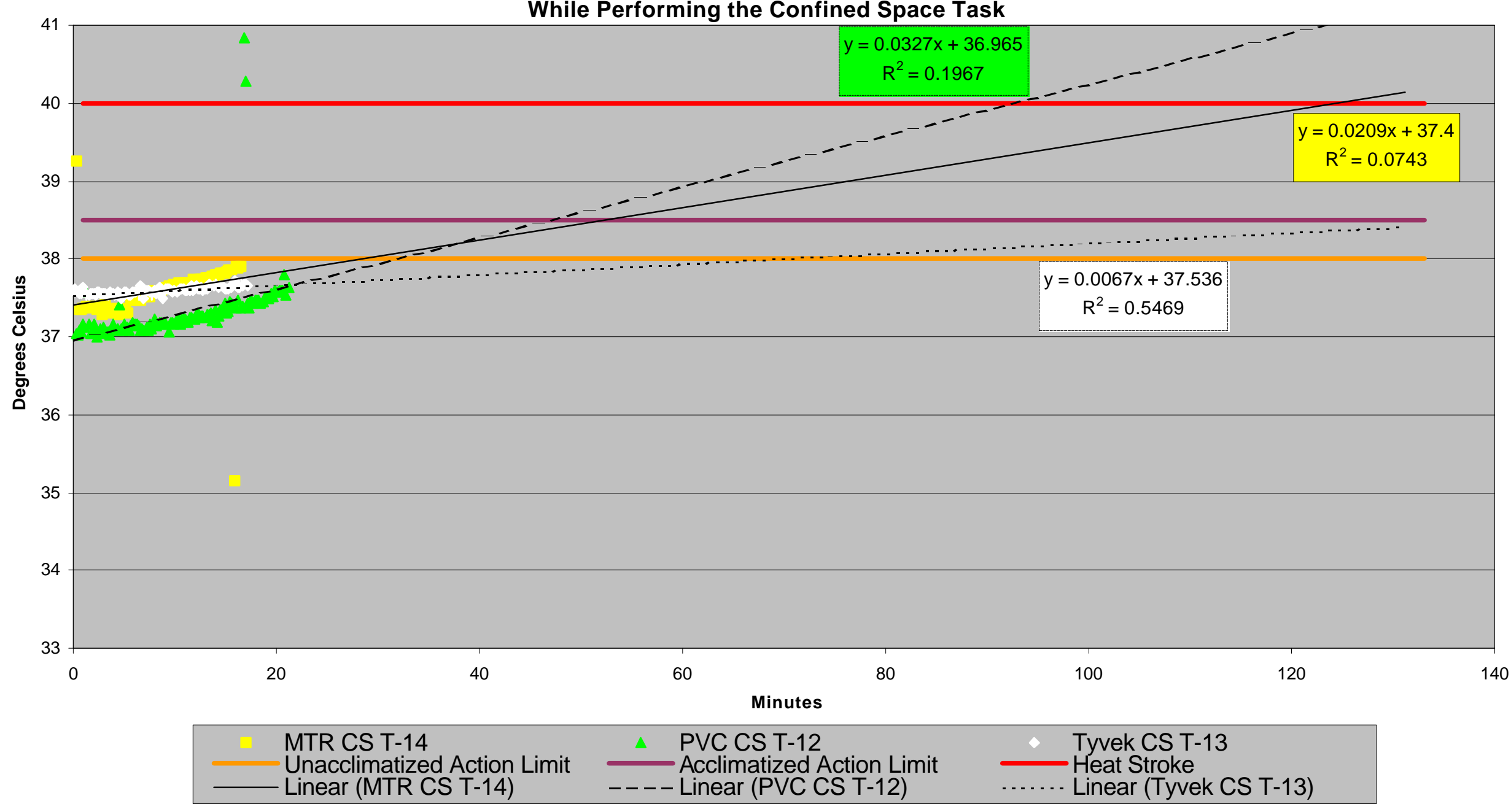


Chart S-2-PIT:

Subject No. 2 Wearing MTR, PVC, and Tyvek ${ }^{\circledR}$ Suits While Performing the PIT Task

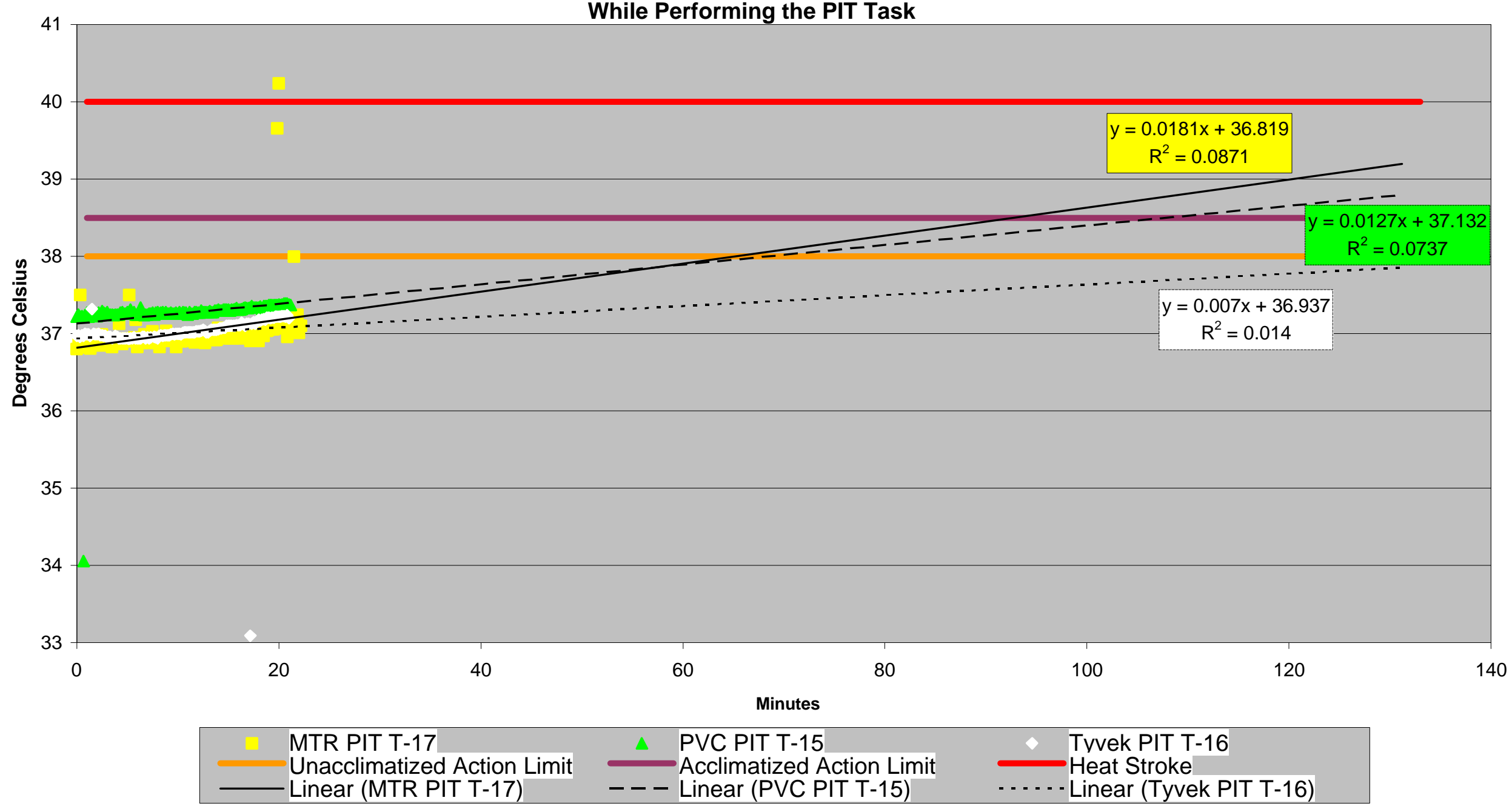




\section{Chart S-2-WB:}

Subject No. 2 Wearing MTR, PVC, and Tyvek® Suits

While Performing the Wheelbarrow Task

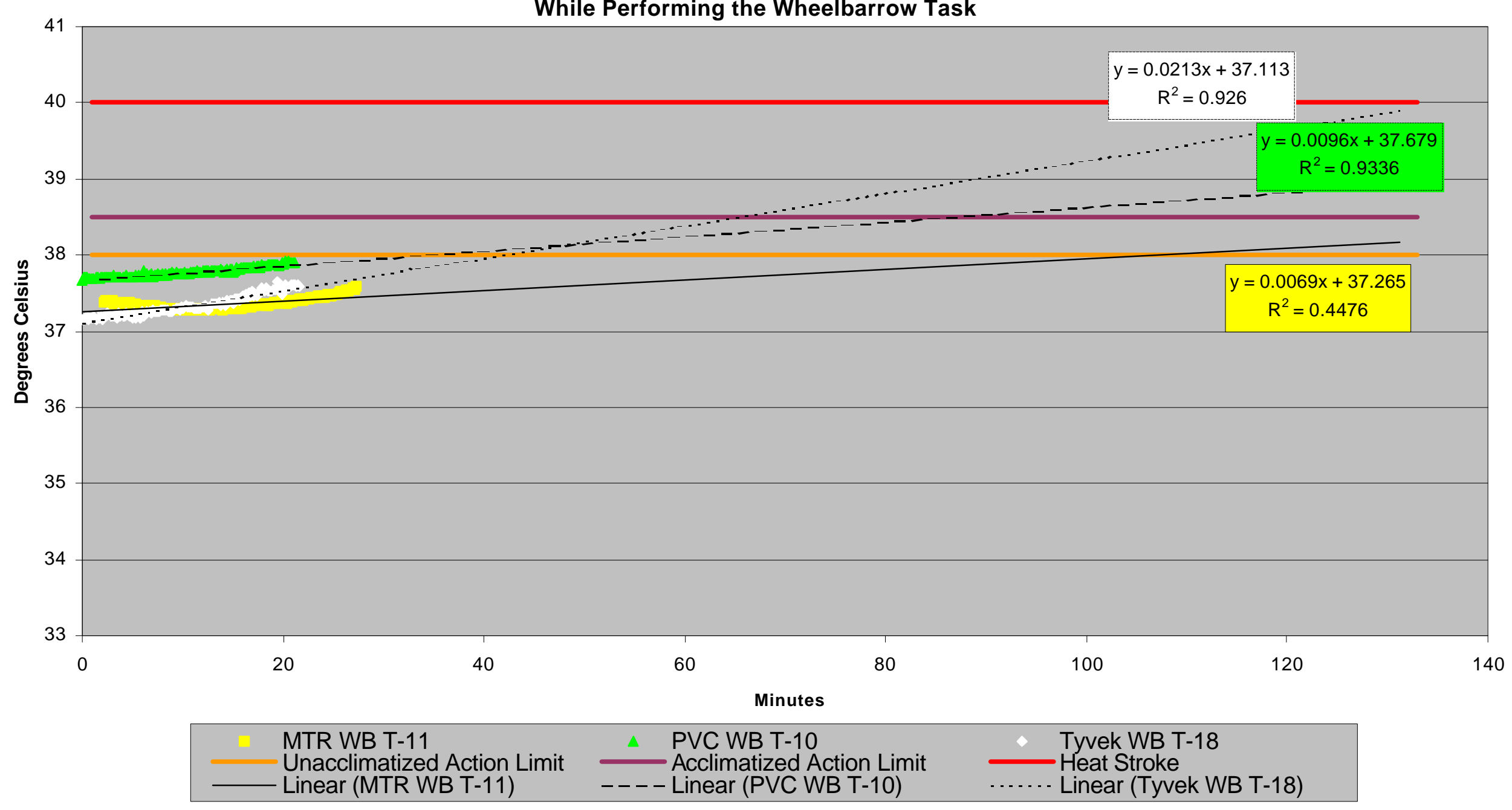


Chart S-2-TSA:

Subject No. 2 Task Set Averages With Standard Deviations

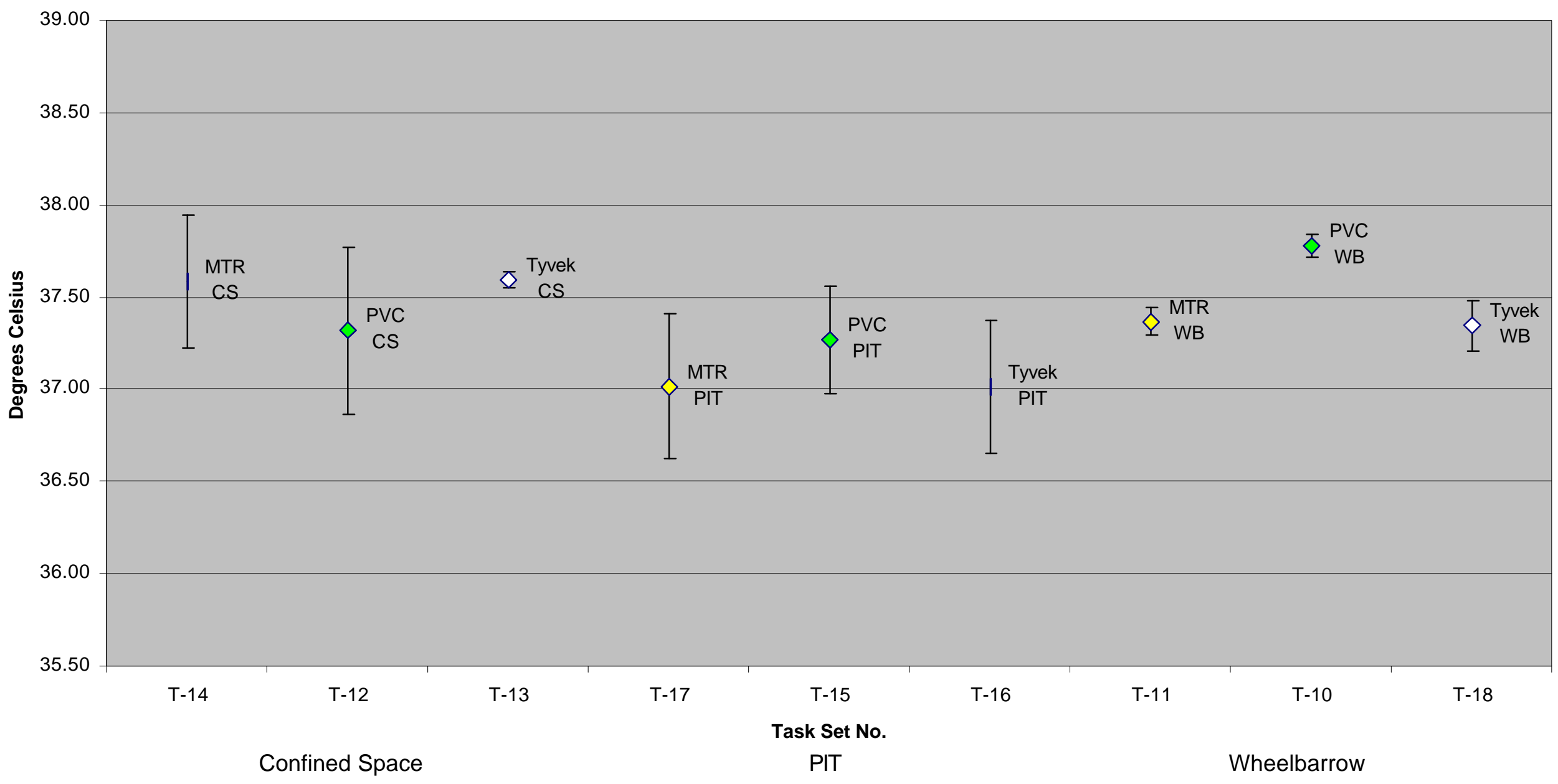




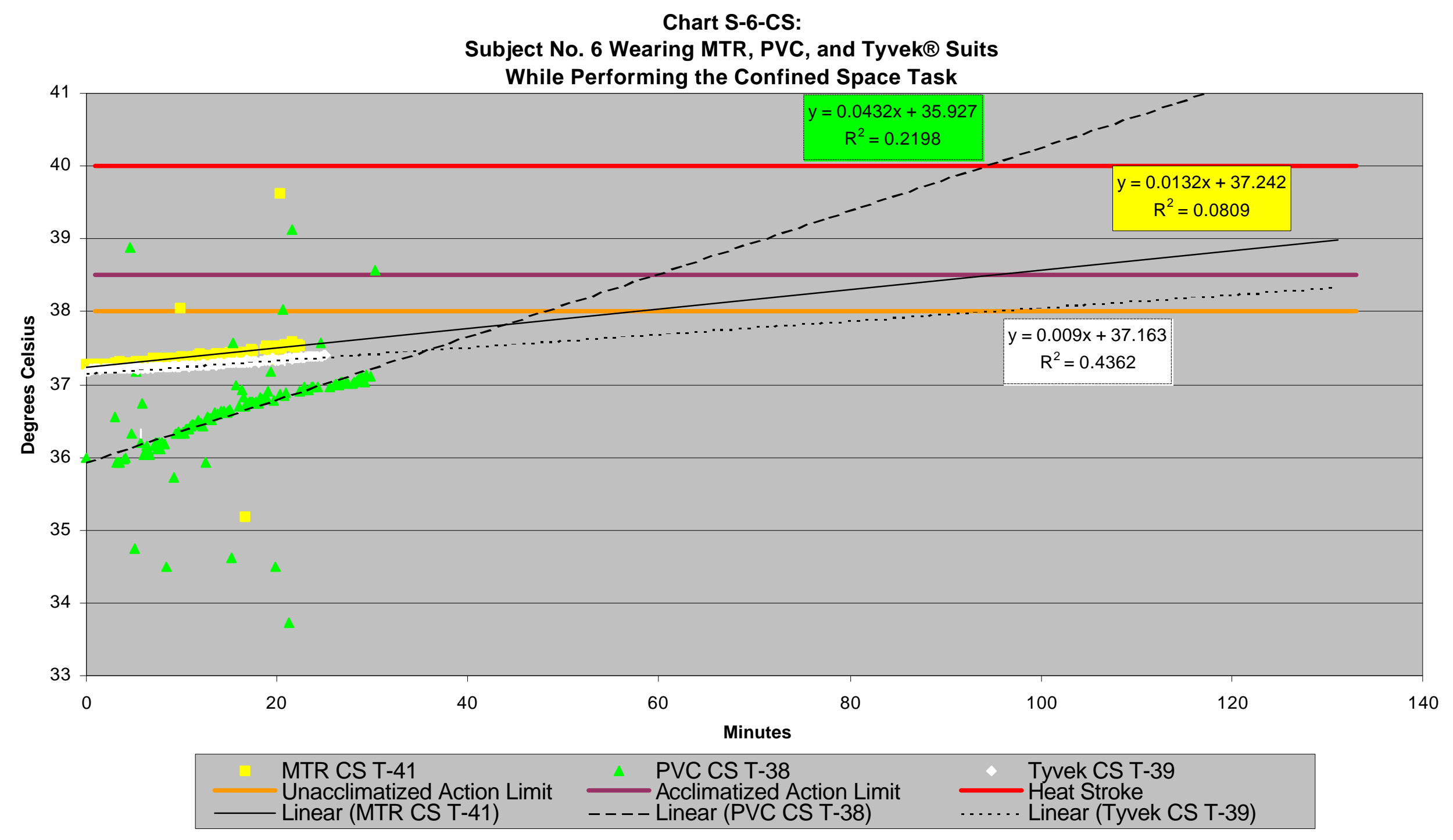




\section{Chart S-6-PIT:}

Subject No. 6 Wearing MTR, PVC, and Tyvek® Suits

While Performing the PIT Task

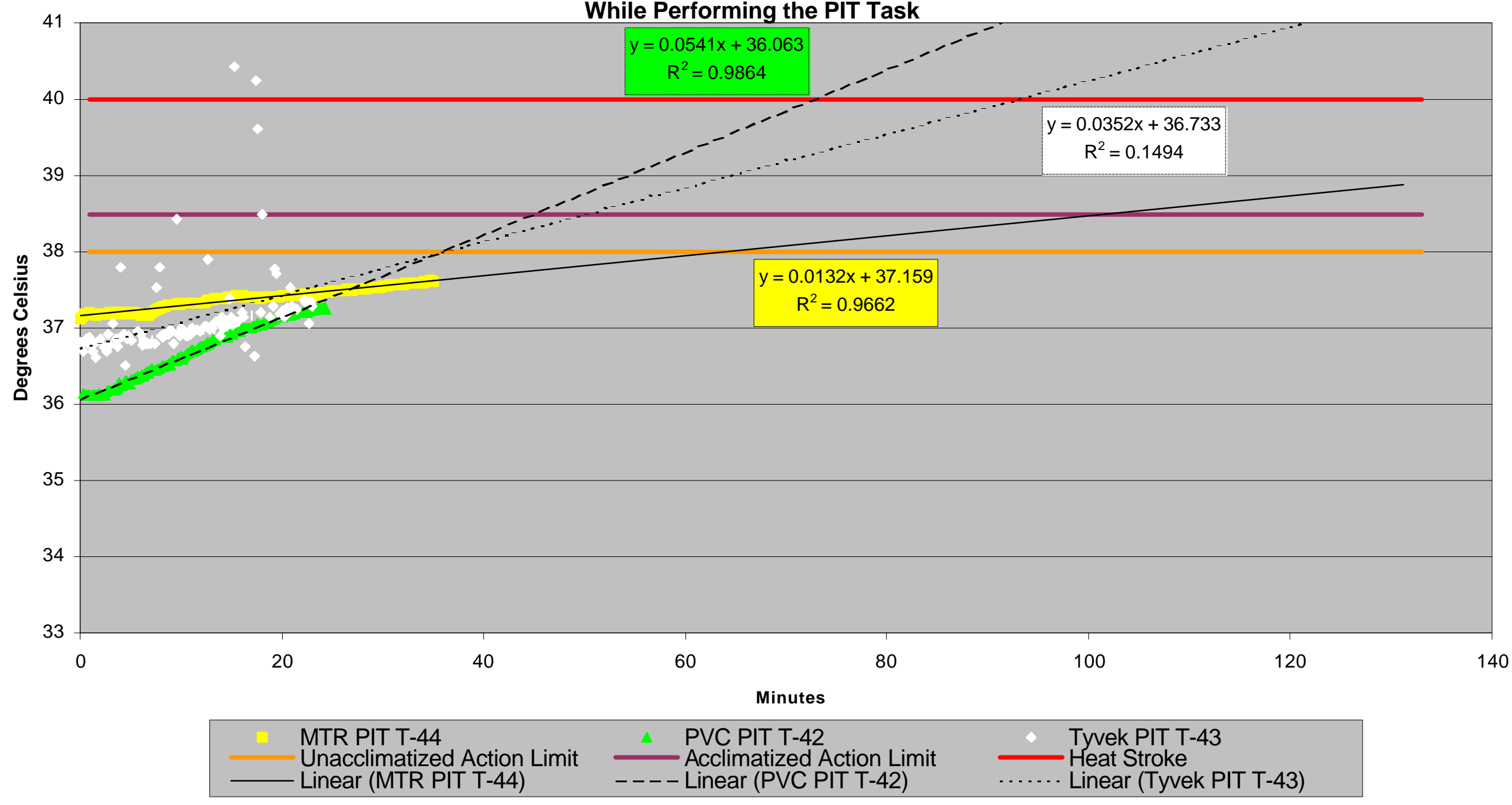


Chart S-6-WB:

Subject No. 6 Wearing MTR, PVC, and Tyvek® Suits

While Performing the Wheelbarrow Task

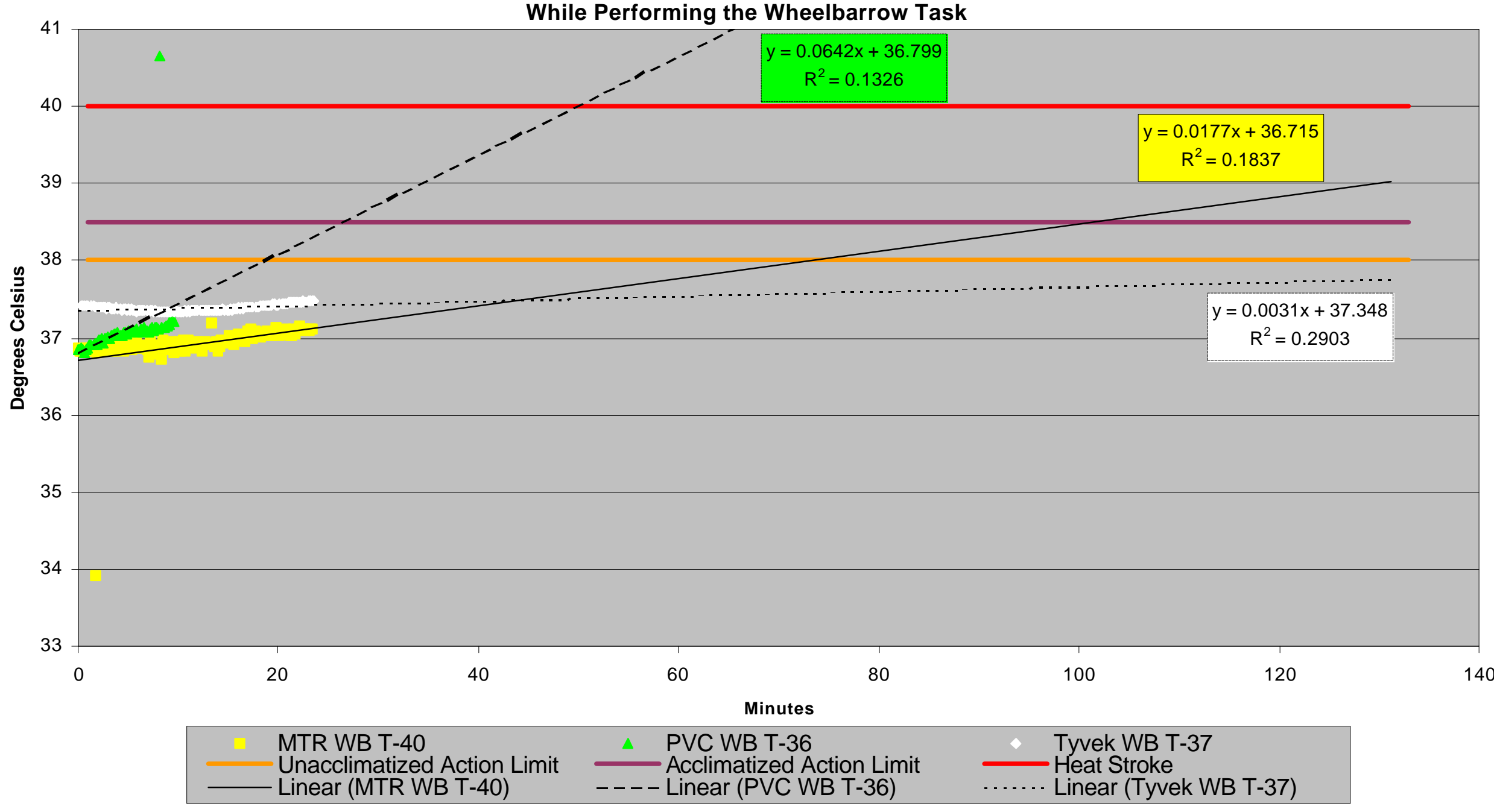




\section{Chart S-6-TSA:}

Subject No. 6 Task Set Averages With Standard Deviations

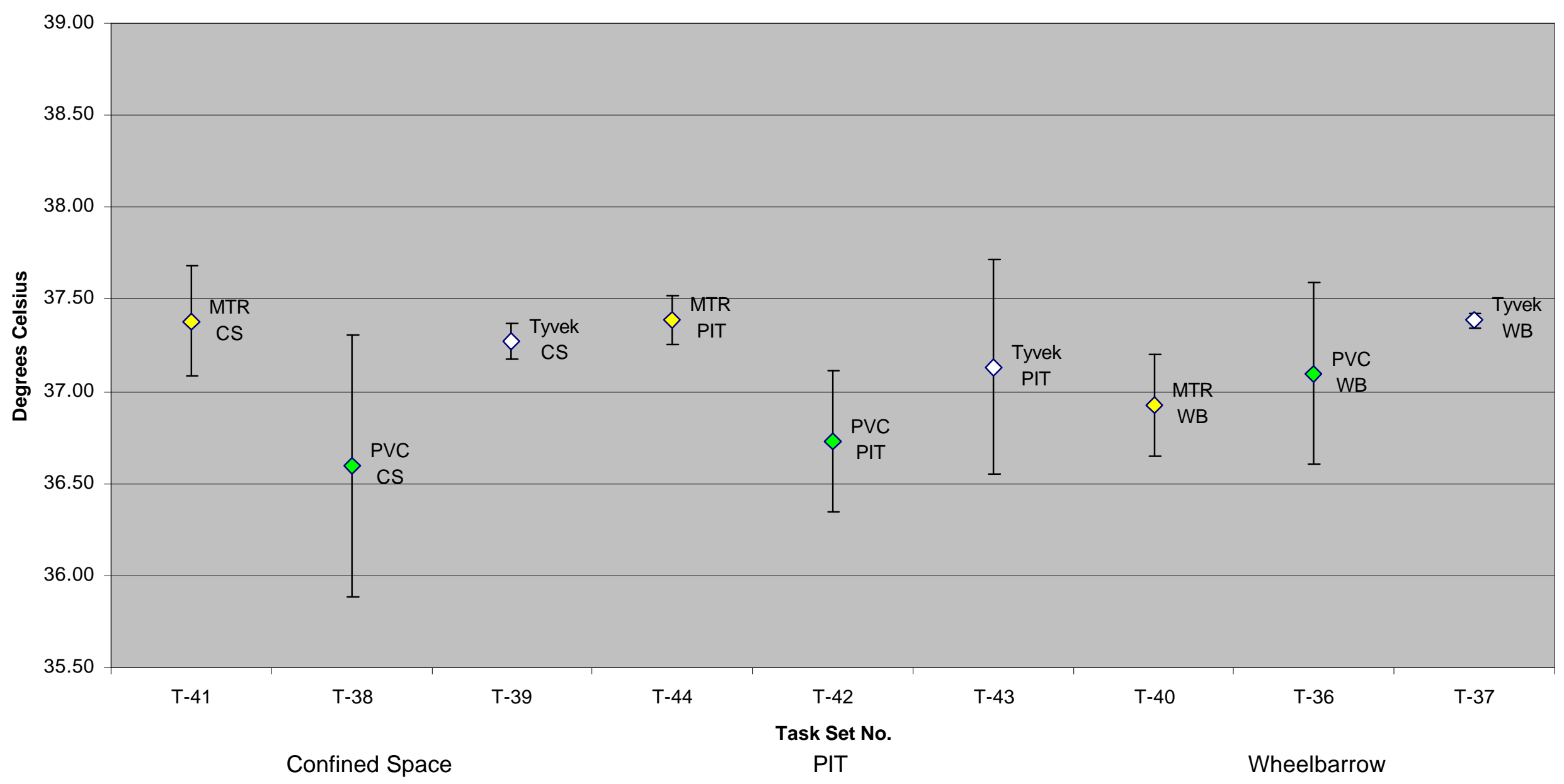


Chart S-8-CS:

Subject No. 8 Wearing MTR, PVC, and Tyvek ${ }^{\circledR}$ Suits

While Performing the Confined Space Task

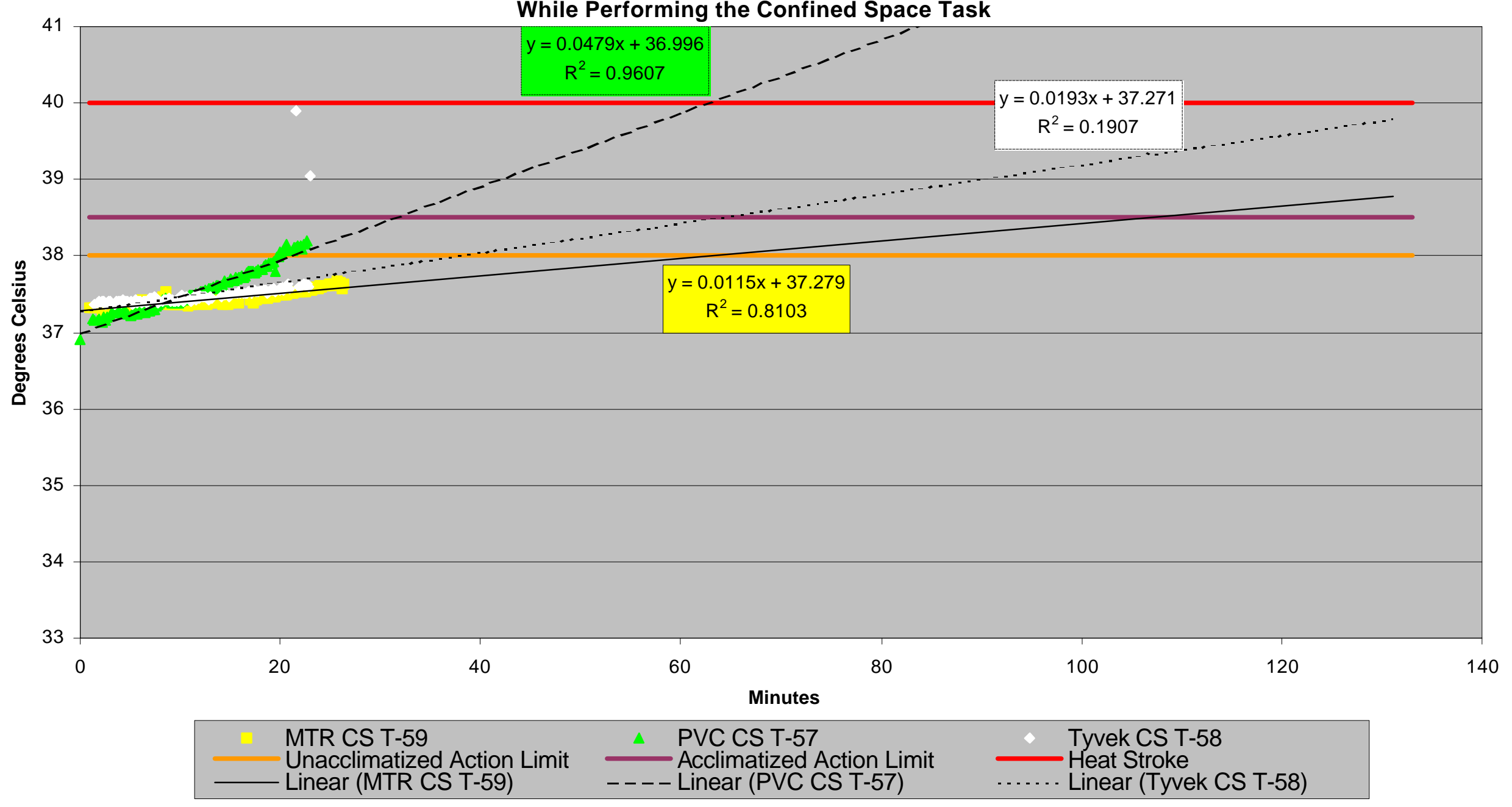




\section{Chart S-8-PIT:}

Subject No. 8 Wearing MTR, PVC, and Tyvek $\circledast$ Suits

While Performing the PIT Task

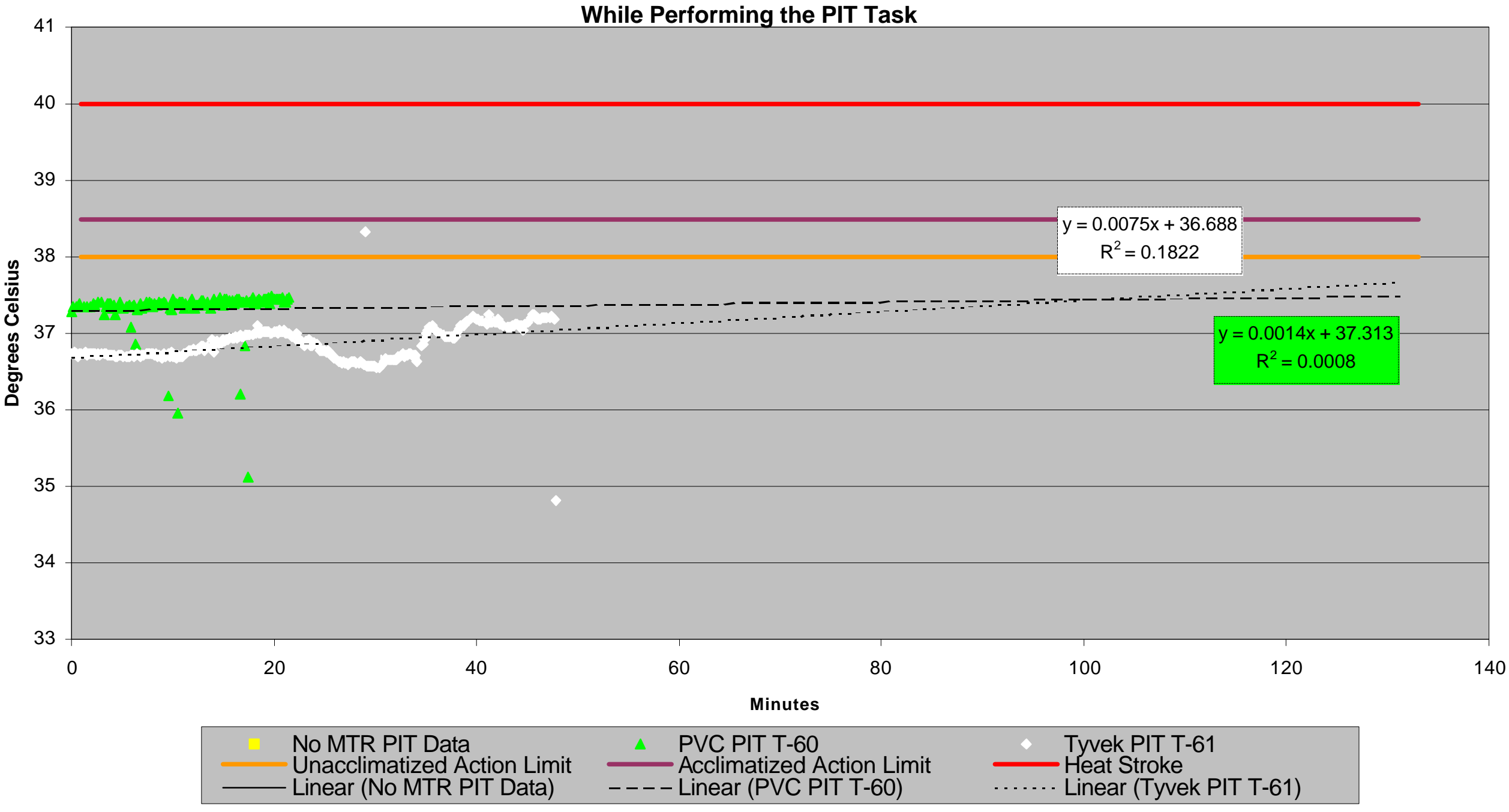


Chart S-8-WB:

Subject No. 8 Wearing MTR, PVC, and Tyvek® Suits

While Performing the Wheelbarrow Task

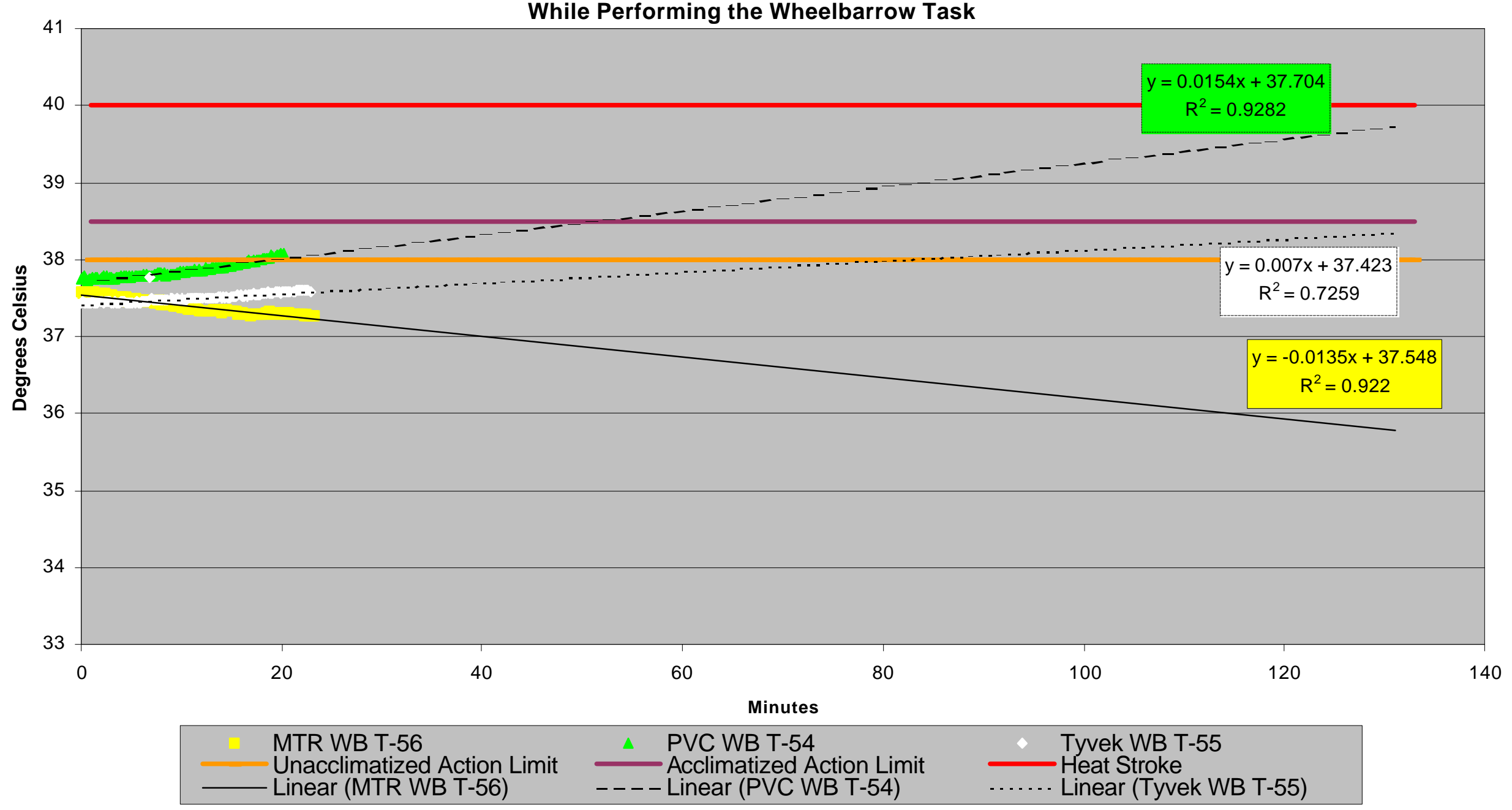




\section{Chart S-8-TSA:}

Subject No. 8 Task Set Averages With Standard Deviations

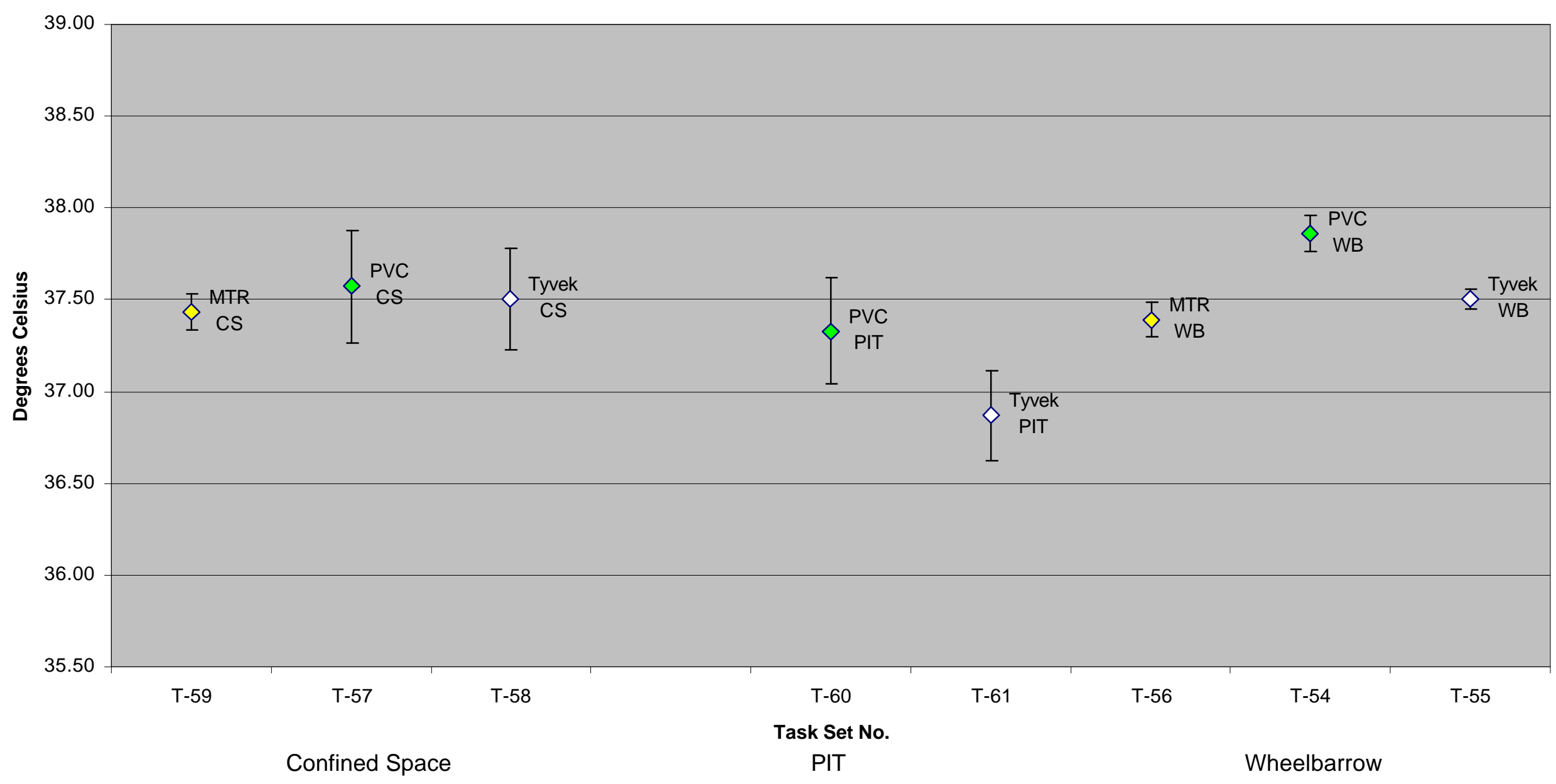


Chart S-13-CS:

Subject No. 13 Wearing MTR, PVC, and Tyvek ${ }^{\circledR}$ Suits

While Performing the Confined Space Task

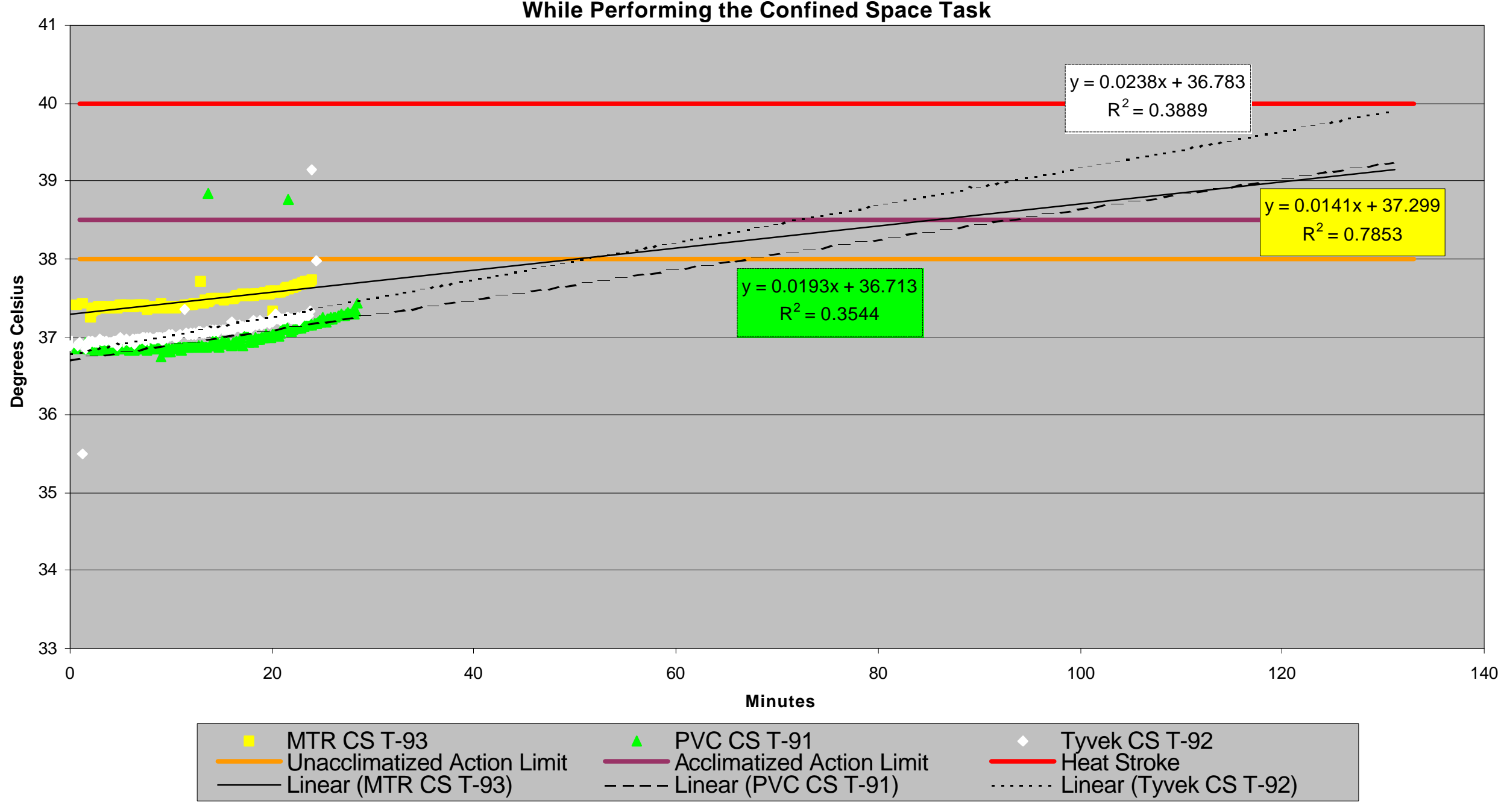


Chart S-13-PIT:

Subject No. 13 Wearing MTR, PVC, and Tyvek® Suits

While Performing the PIT Task

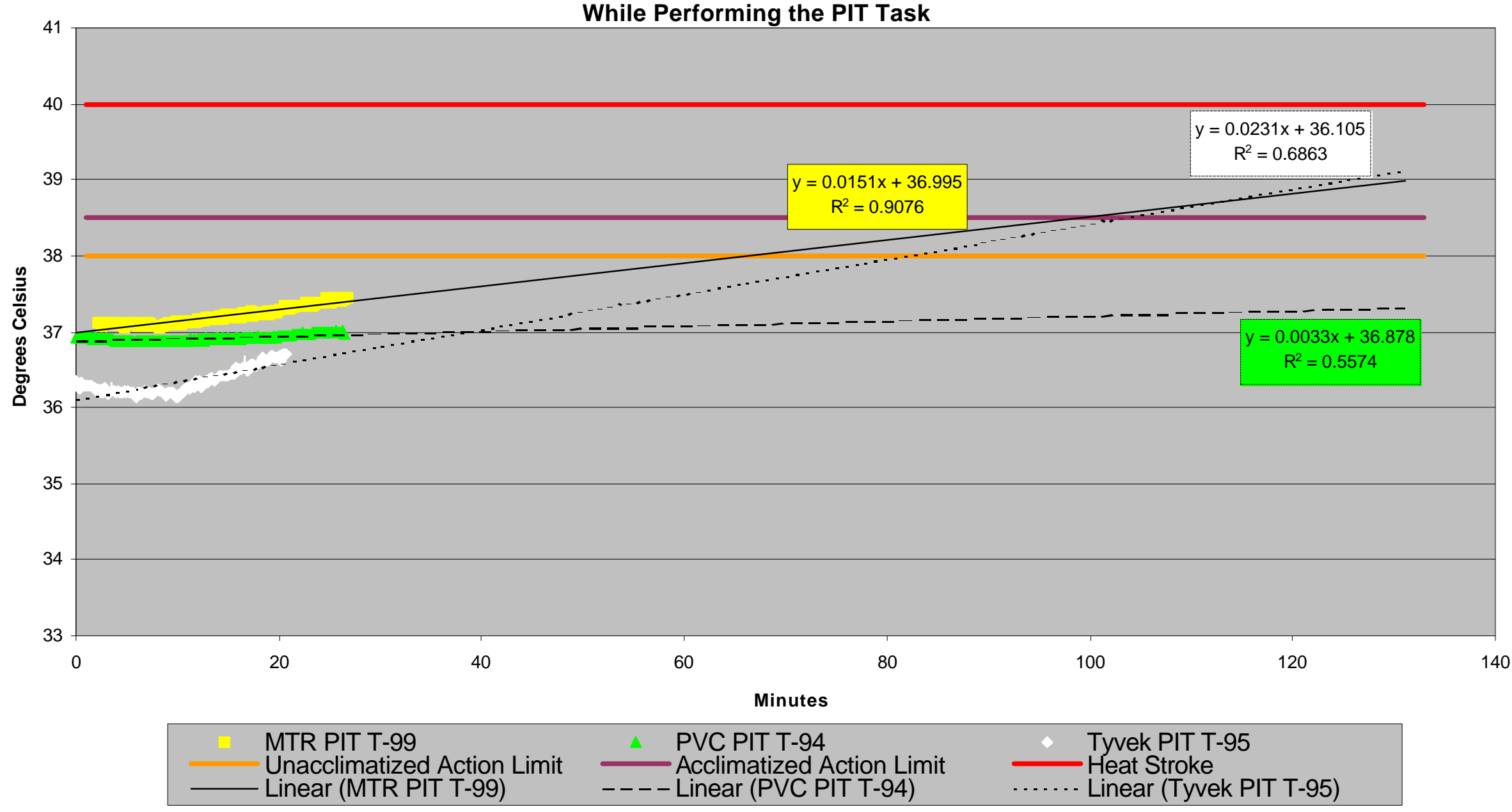




\section{Chart S-13-WB:}

Subject No. 13 Wearing MTR, PVC, and Tyvek® Suits

While Performing the Wheelbarrow Task

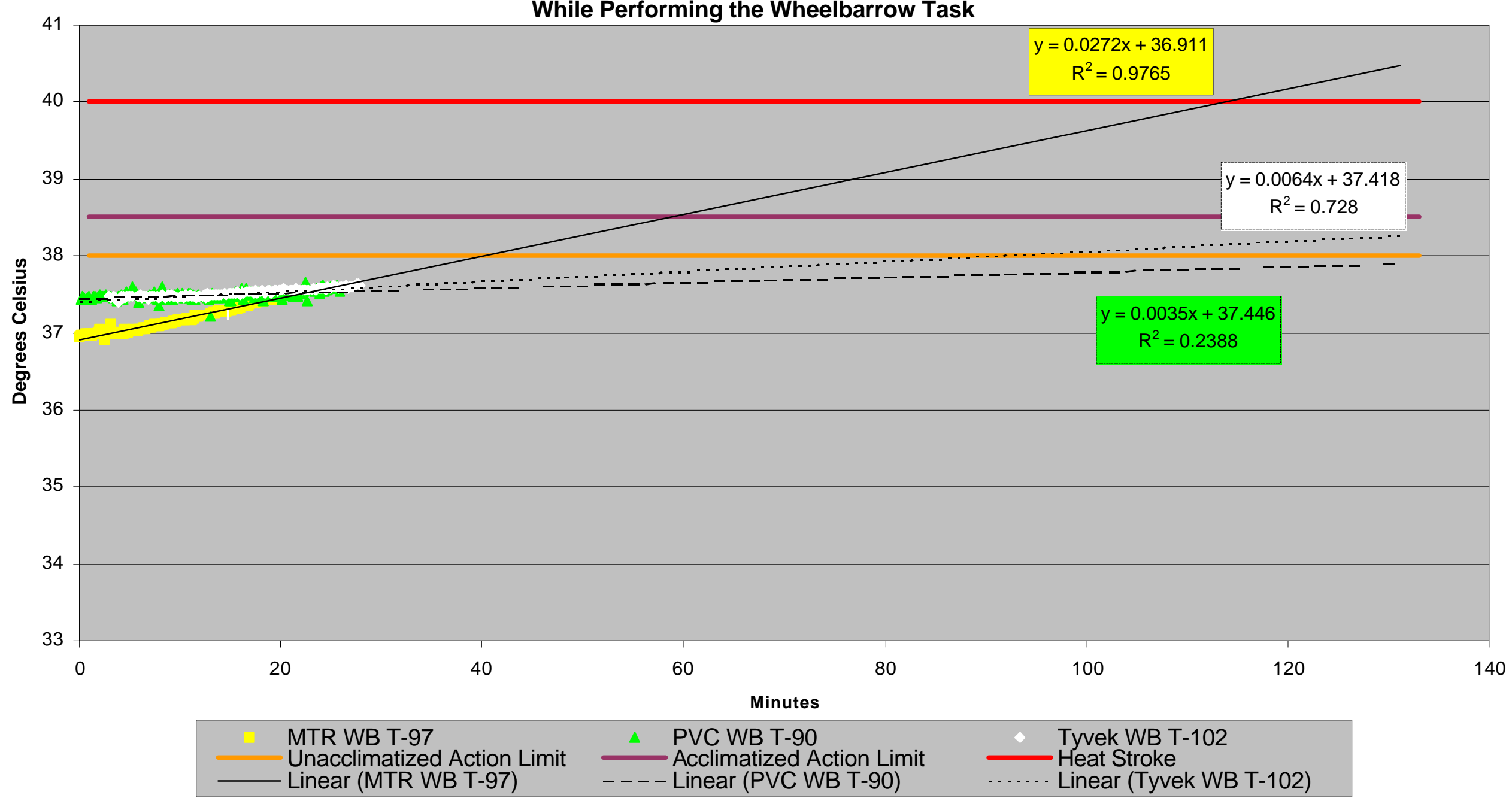




\section{Chart S-13-TSA:}

Subject No. 13 Task Set Averages With Standard Deviations

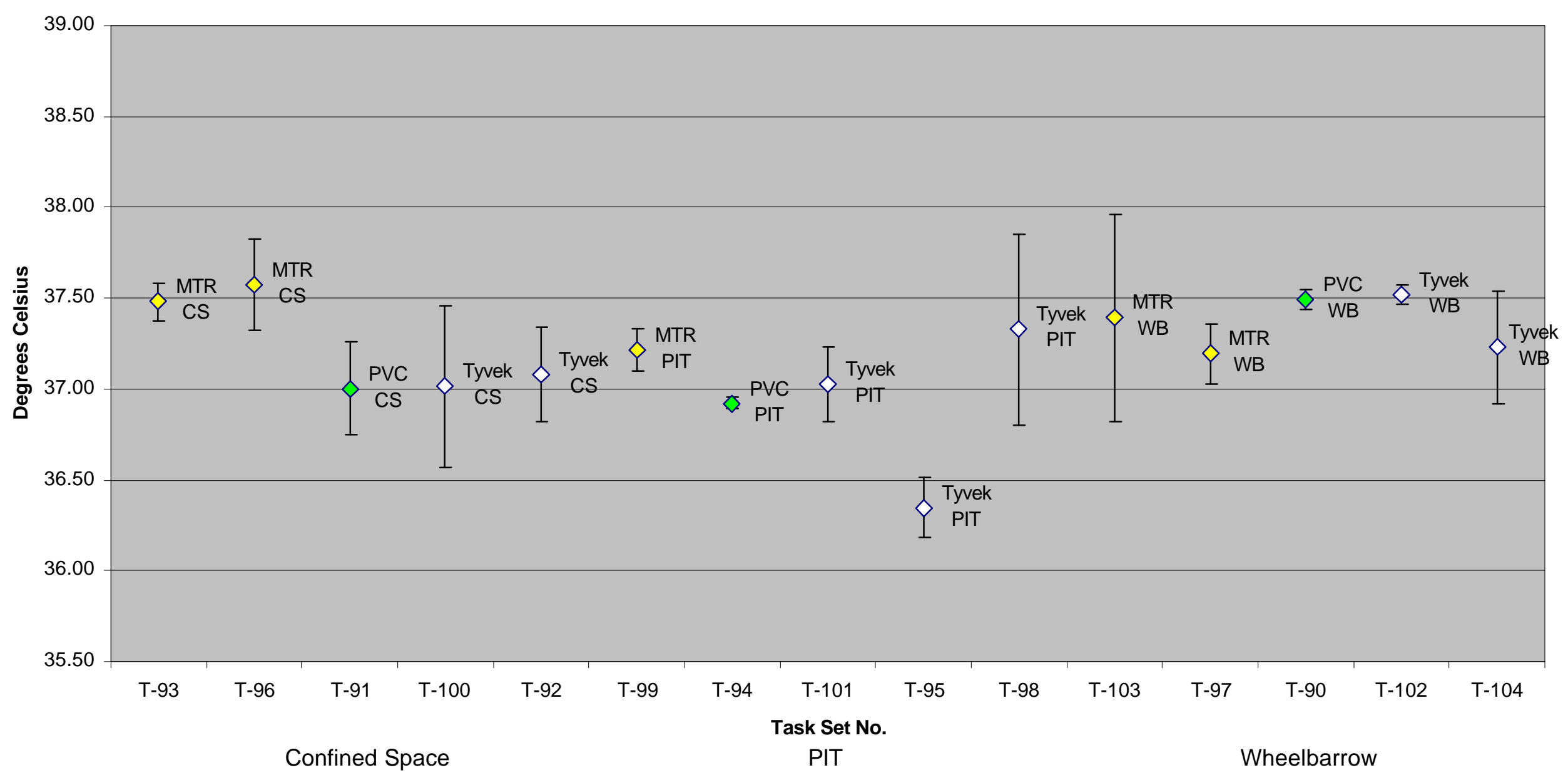


Chart S-17-CS:

Subject No. 17 Wearing MTR, PVC, and Tyvek® Suits

While Performing the Confined Space Task

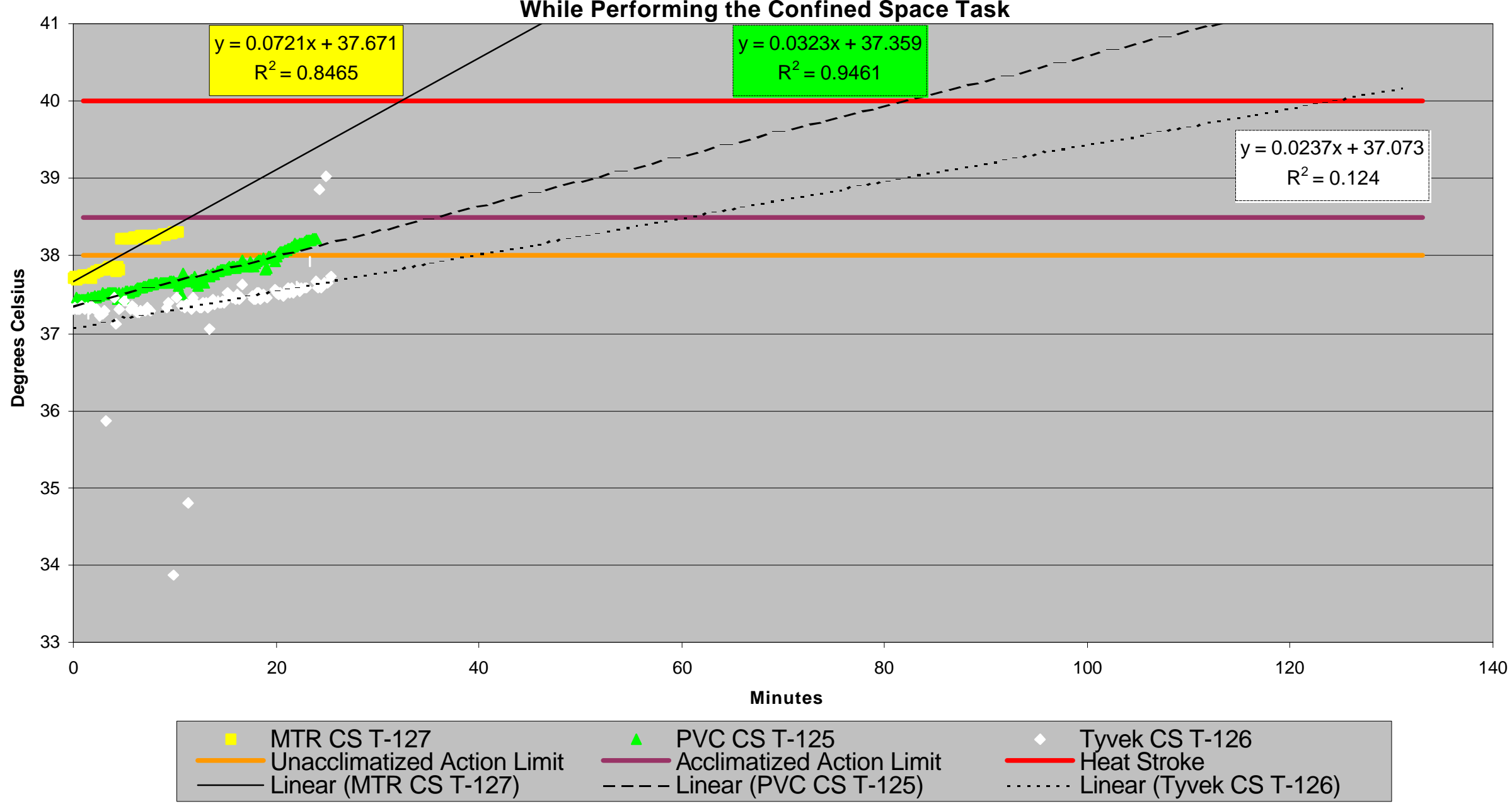


Chart S-17-PIT:

Subject No. 17 Wearing MTR, PVC, and Tyvek $\circledast$ Suits

While Performing the PIT Task

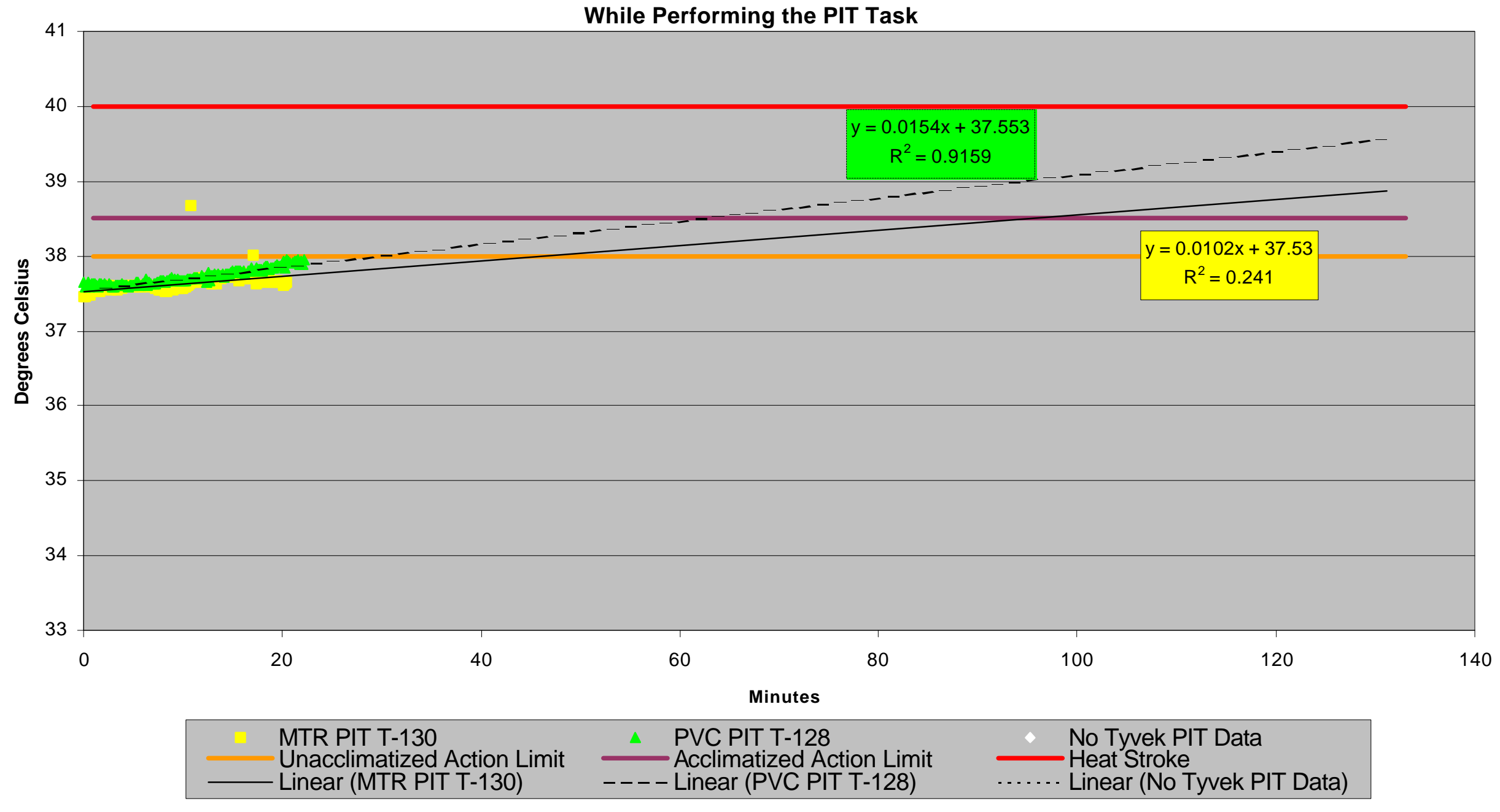




\section{Chart S-17-WB:}

Subject No. 17 Wearing MTR, PVC, and Tyvek ${ }^{\circledR}$ Suits

While Performing the Wheelbarrow Task

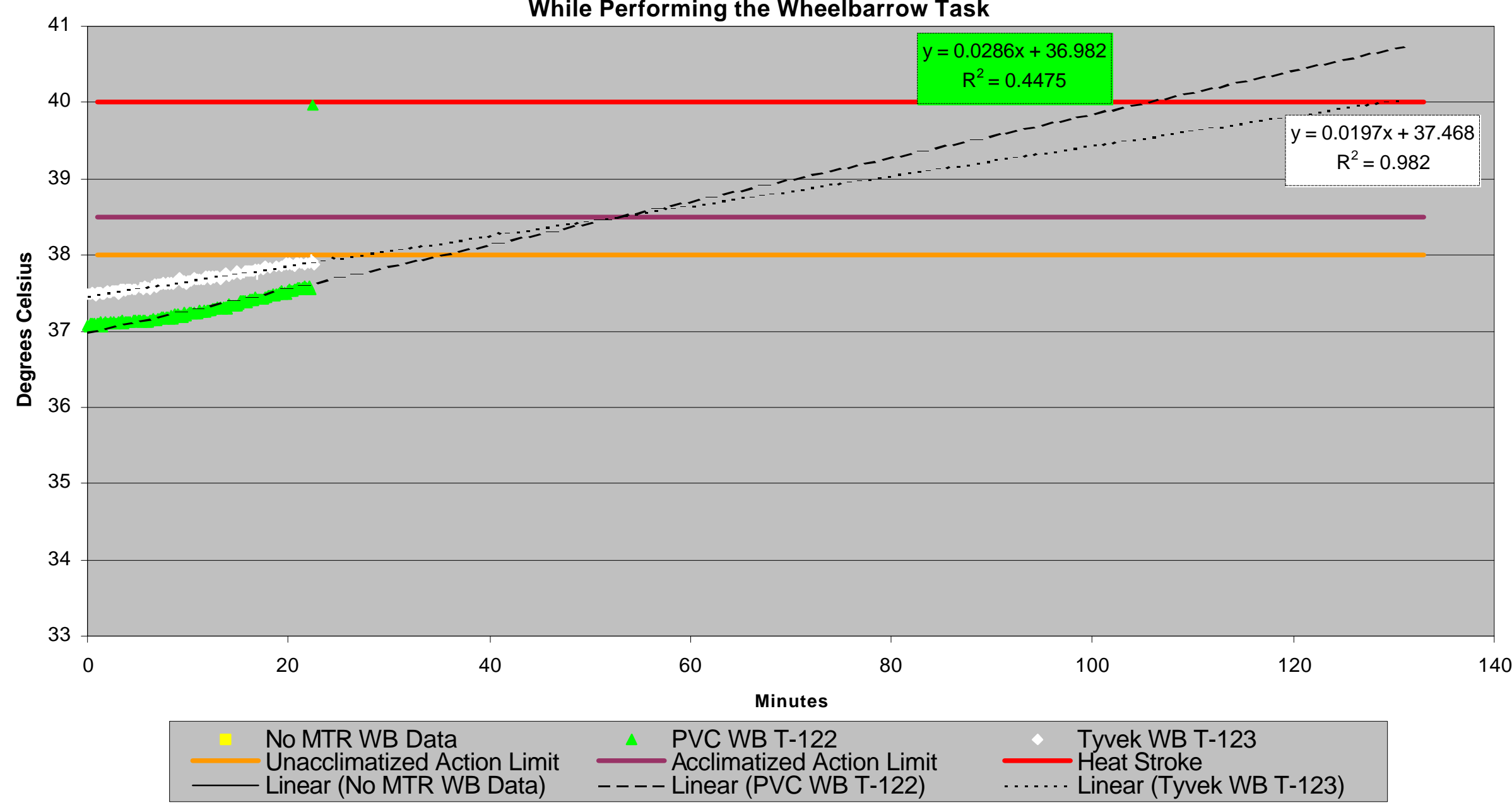




\section{Chart S-17-TSA:}

Subject No. 17 Task Set Averages With Standard Deviations

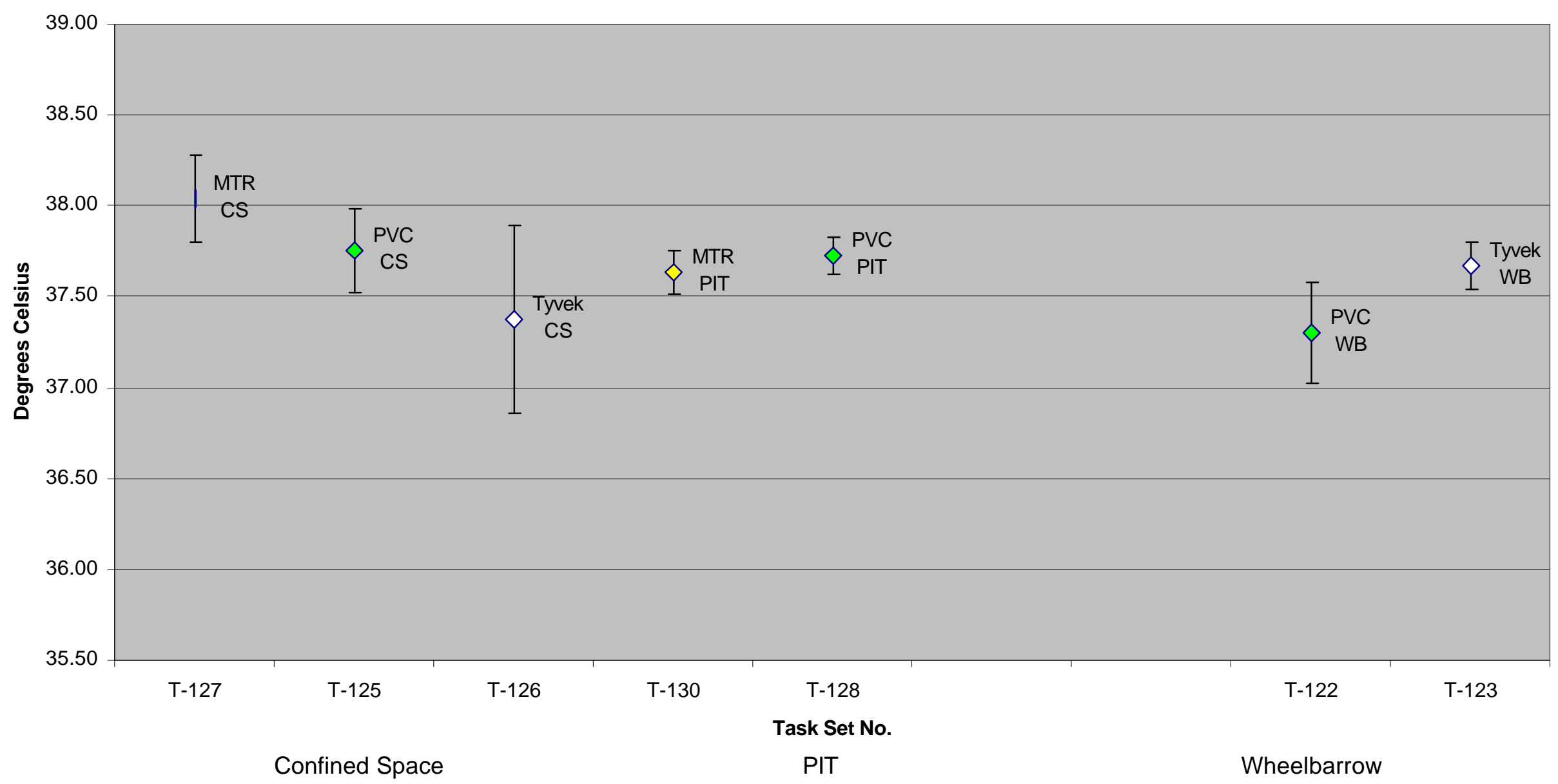




\section{Chart S-24-CS:}

Subject No. 24 Wearing MTR, PVC, and Tyvek® Suits

While Performing the Confined Space Task

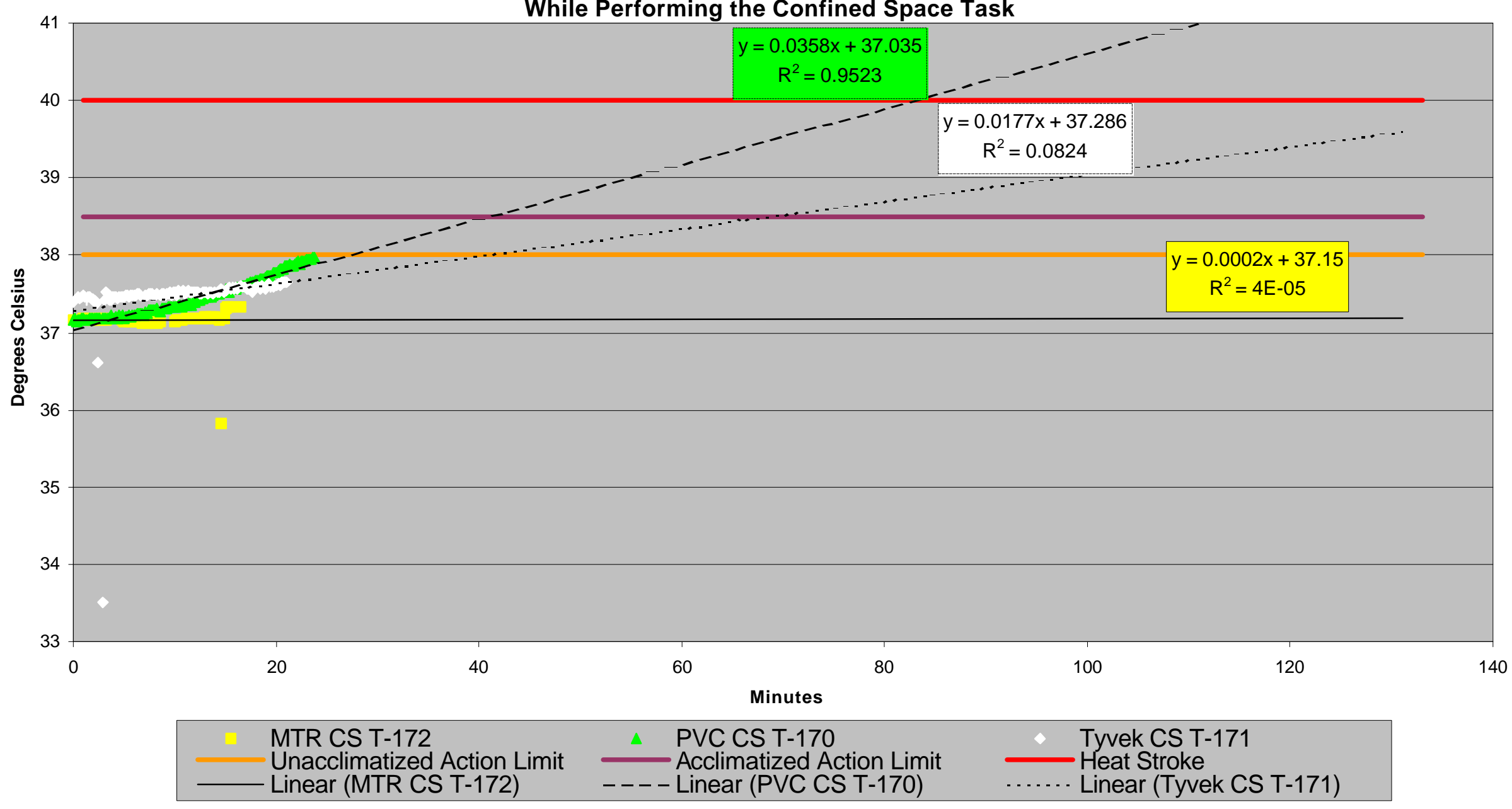




\section{Chart S-24-PIT:}

Subject No. 24 Wearing MTR, PVC, and Tyvek® Suits

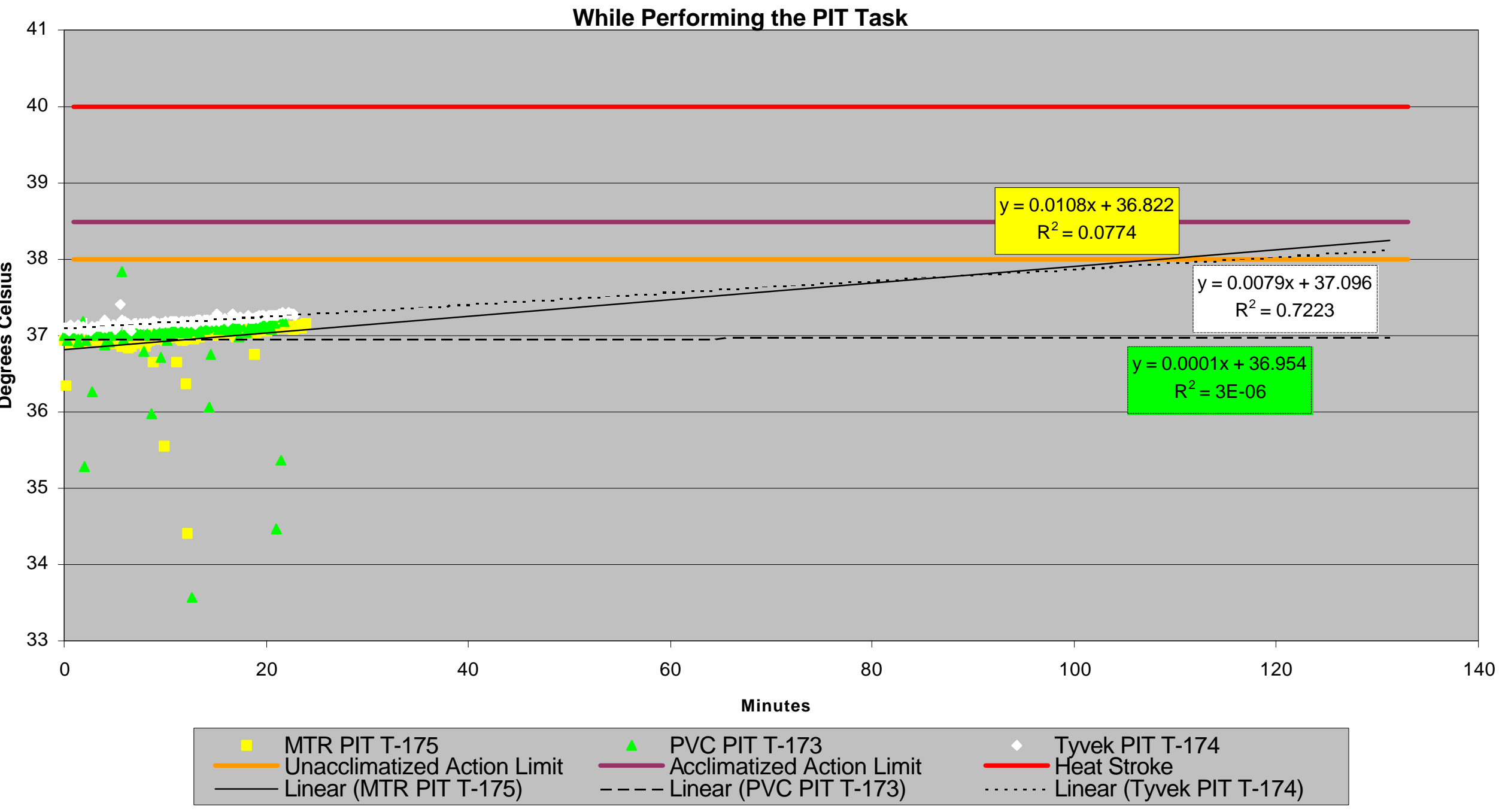


Chart S-24-WB:

Subject No. 24 Wearing MTR, PVC, and Tyvek ${ }^{\circledR}$ Suits

While Performing the Wheelbarrow Task

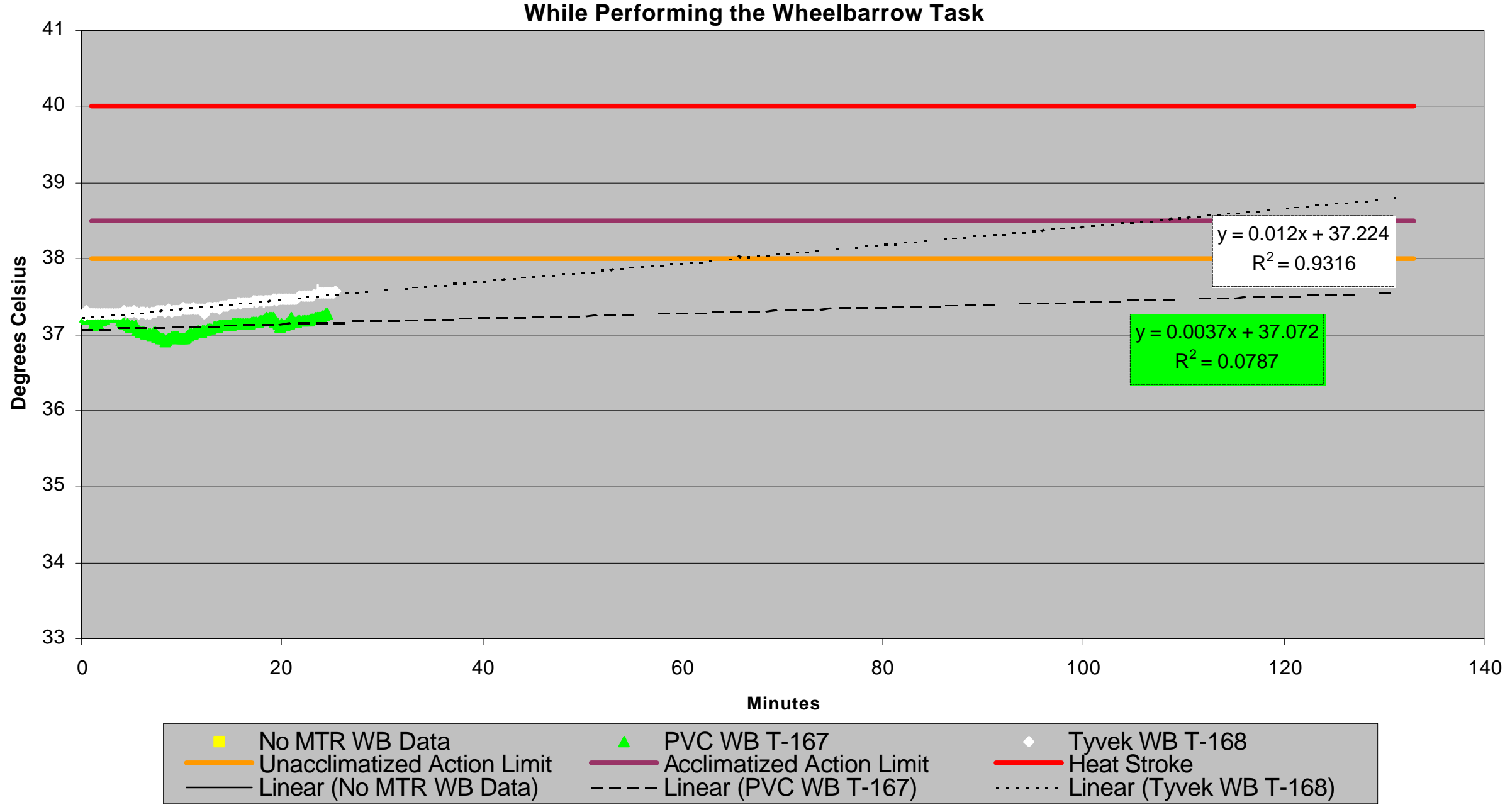




\section{Chart S-24-TSA:}

Subject No. 24 Task Set Averages With Standard Deviations

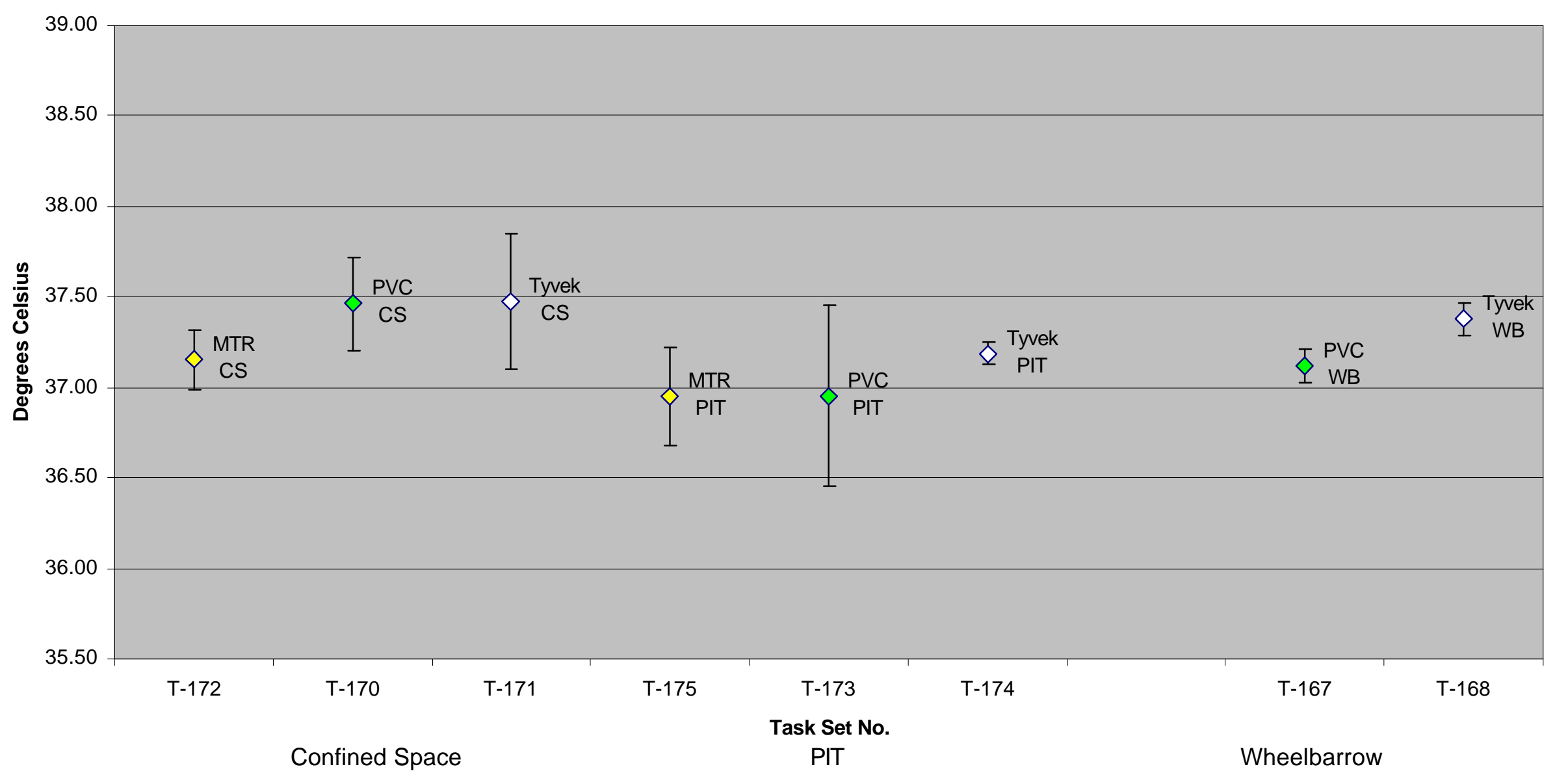




\section{Chart S-26-CS:}

Subject No. 26 Wearing MTR, PVC, and Tyvek ${ }^{\circledR}$ Suits

While Performing the Confined Space Task

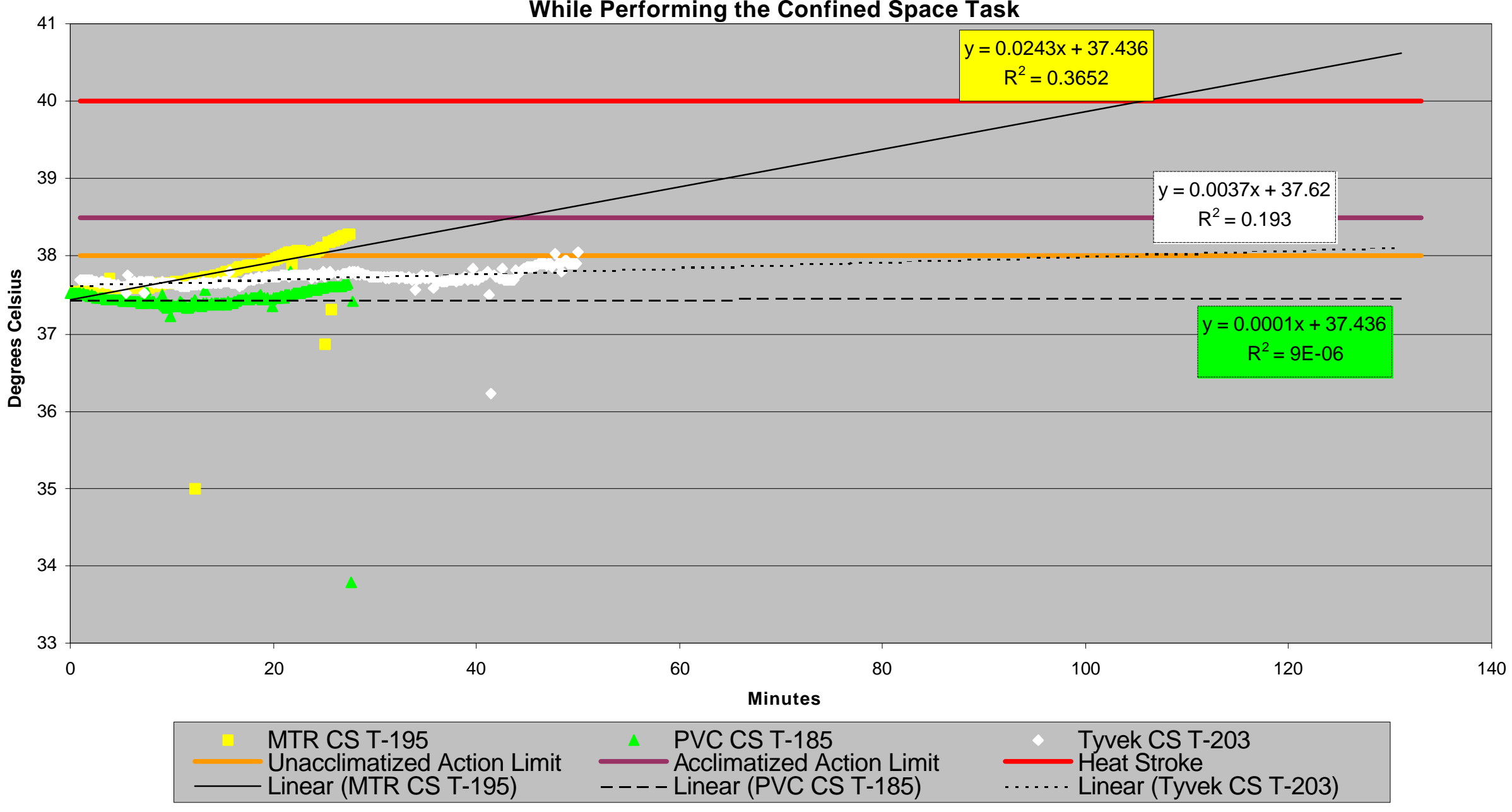




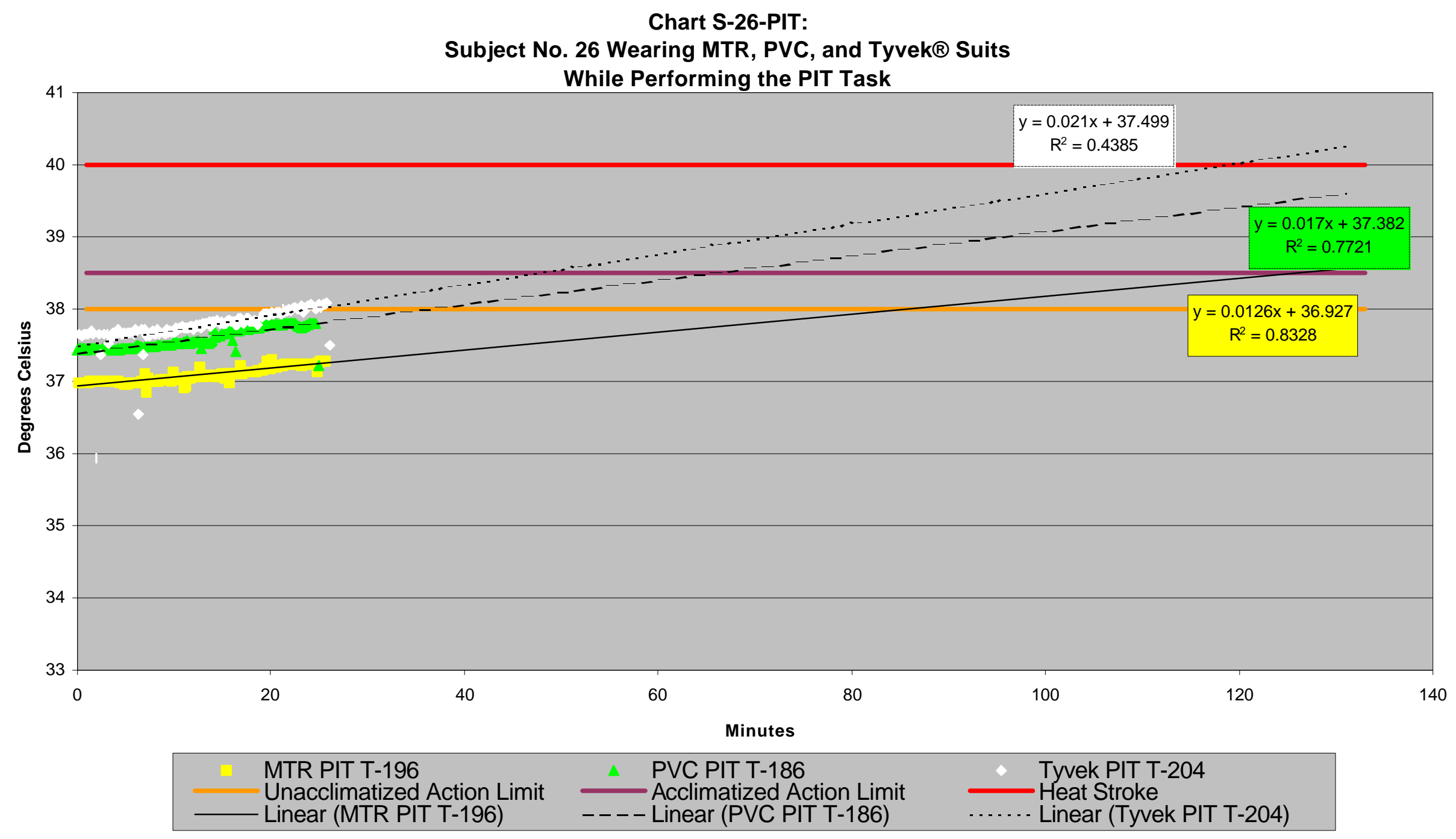


Chart S-26-WB:

Subject No. 26 Wearing MTR, PVC, and Tyvek® Suits

While Performing the Wheelbarrow Task

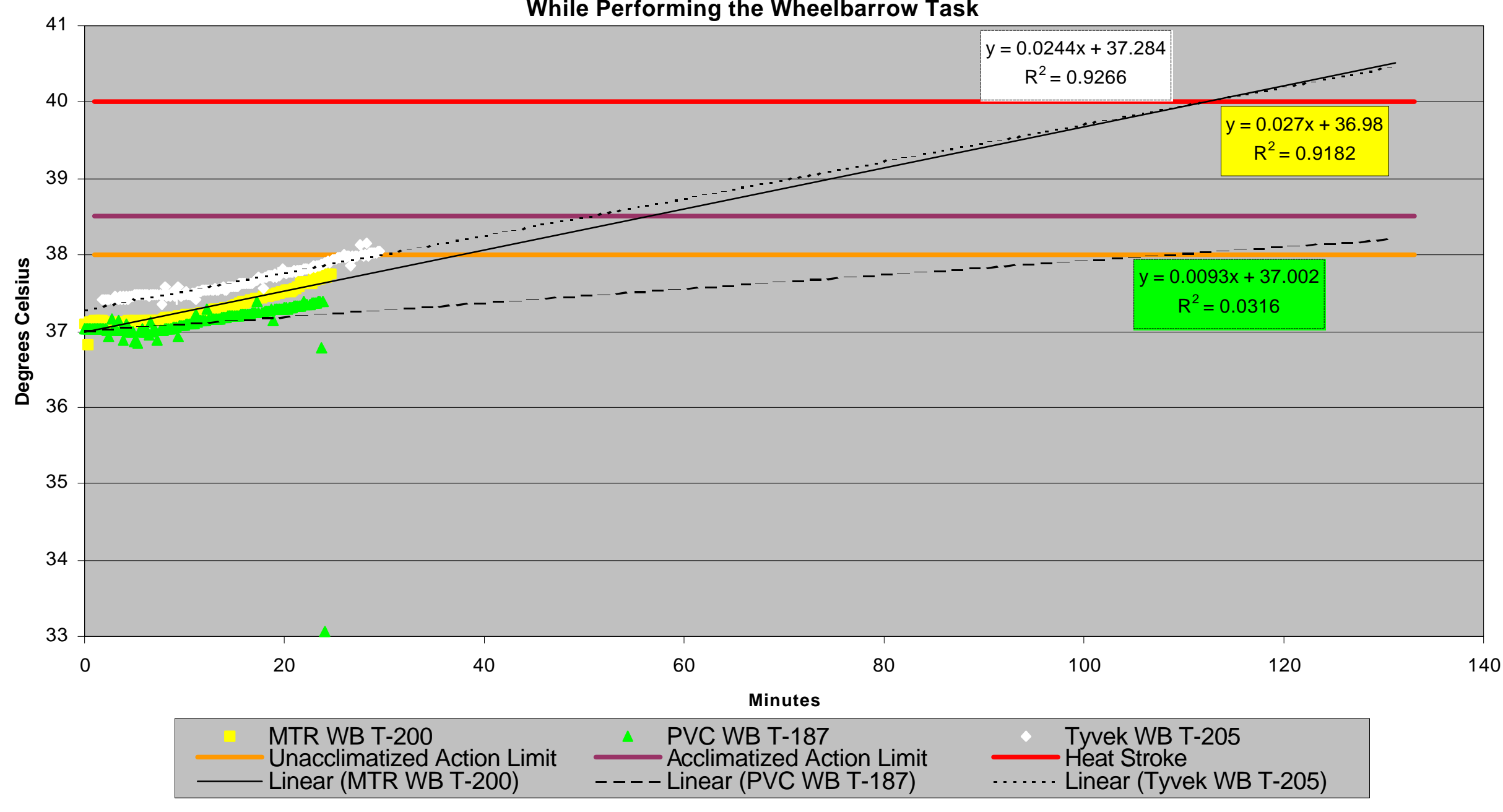




\section{Chart S-26-TSA:}

\section{Subject No. 26 Task Set Averages With Standard Deviations}

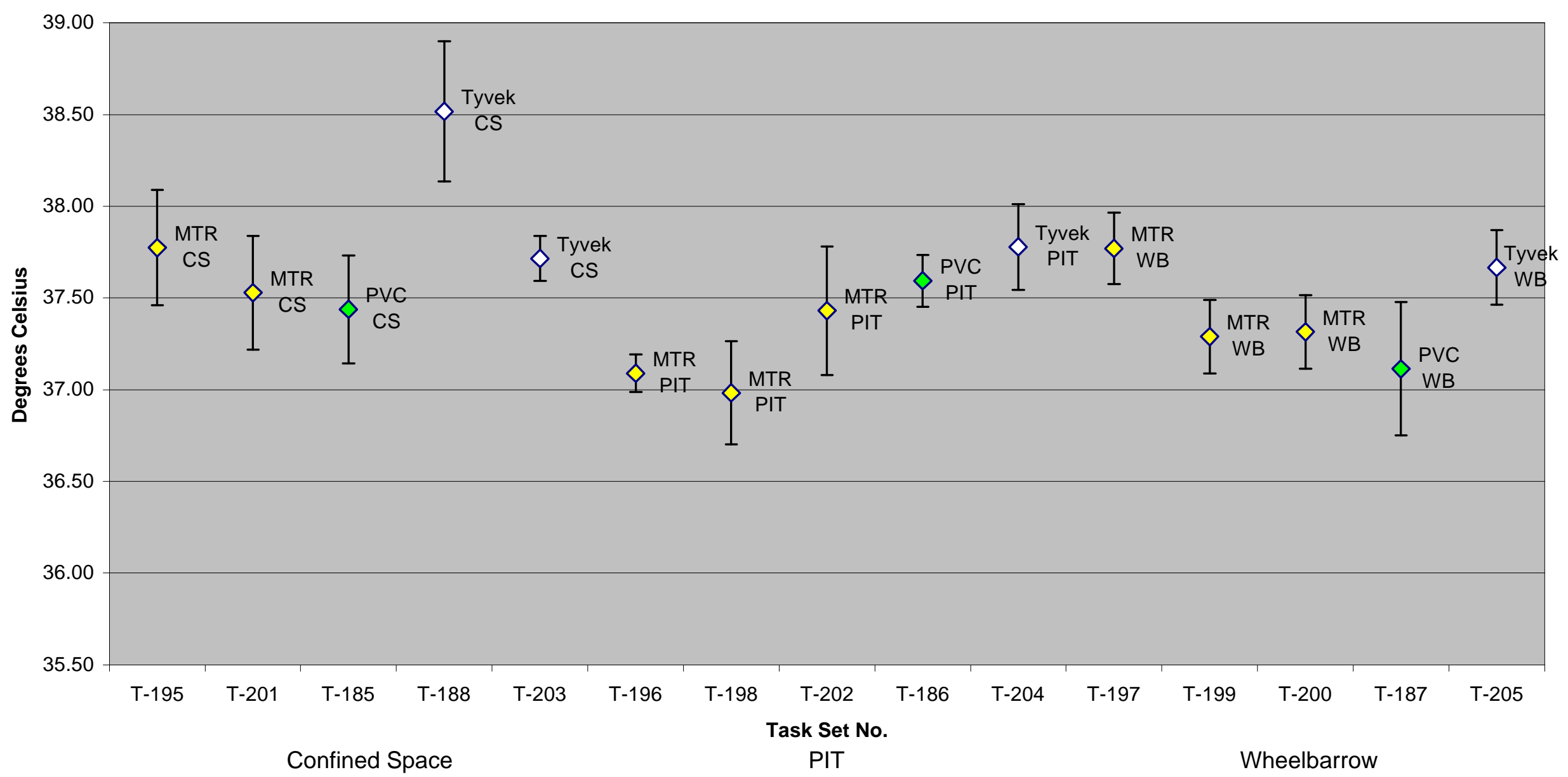


9.2.

\title{
Appendix B:
}

\author{
Tables
}


Table A: Subjects' core body temperature while wearing suit as indicated.

\begin{tabular}{|c|c|c|c|c|c|c|c|c|c|c|c|c|c|c|c|c|c|}
\hline \multicolumn{2}{|c|}{ Suit } & \multicolumn{4}{|c|}{$\begin{array}{c}\text { Table S-MTR } \\
\text { MTR }\end{array}$} & \multicolumn{4}{|c|}{$\begin{array}{c}\text { Table S-PVC } \\
\text { PVC }\end{array}$} & \multicolumn{4}{|c|}{$\begin{array}{c}\text { Table S-Tyvek } \\
\text { Tyvek® }\end{array}$} & \multicolumn{4}{|c|}{$\begin{array}{c}\text { Table S-(MTR,PVC, and Tyvek®) } \\
\text { All } 3\end{array}$} \\
\hline & & $\mathbf{n}$ & Avg. & Stdev & CV\% & $n$ & Avg. & Stdev & CV\% & $\mathbf{n}$ & Avg. & Stdev & CV\% & $\mathbf{n}$ & Avg. & Stdev & CV\% \\
\hline \multirow{4}{*}{ 产 } & CS & 16 & 37.37 & 0.46 & 1.22 & 16 & 37.36 & 0.54 & 1.46 & 16 & 37.40 & 0.48 & 1.30 & 48 & 37.38 & 0.50 & 1.33 \\
\hline & PIT & 16 & 37.31 & 0.26 & 0.69 & 15 & 37.19 & 0.43 & 1.15 & 18 & 37.01 & 0.46 & 1.24 & 49 & 37.16 & 0.41 & 1.11 \\
\hline & WB & 17 & 37.27 & 0.36 & 0.97 & 17 & 37.22 & 0.47 & 1.27 & 16 & 37.34 & 0.28 & 0.75 & 50 & 37.28 & 0.38 & 1.03 \\
\hline & All 3 & 49 & 37.31 & 0.37 & 0.99 & 48 & 37.26 & 0.49 & 1.32 & 50 & 37.24 & 0.45 & 1.22 & 147 & 37.27 & 0.44 & 1.19 \\
\hline
\end{tabular}


Table B: Questionnaire Answer Averages

\begin{tabular}{|c|c|c|c|c|c|}
\hline & & & \multicolumn{2}{|c|}{ Answer Averages } & \multirow{2}{*}{$\begin{array}{c}\text { Possible } \\
\text { Range }\end{array}$} \\
\hline & & & Min & Max & \\
\hline$E$ & \multicolumn{2}{|l|}{ Visual Assessment } & 53.1 & 71.2 & $0-100 \%$ \\
\hline $\mathrm{F}$ & \multicolumn{2}{|l|}{ Fit Assessment } & 2.71 & 3.63 & $1-5$ \\
\hline G & \multicolumn{2}{|l|}{ Before Exercise } & 47.9 & 66.8 & $0-100 \%$ \\
\hline $\mathrm{H}$ & \multicolumn{2}{|l|}{ After Task } & 38.4 & 63.7 & $0-100 \%$ \\
\hline$J$ & \multicolumn{2}{|l|}{ After Removal } & 43.9 & 48.6 & $0-100 \%$ \\
\hline \multirow[t]{3}{*}{$\mathrm{K}$} & Protective Garment Comparison & MTR & 2.8 & 4.7 & $1-5$ \\
\hline & & PVC & 2.2 & 4.7 & $1-5$ \\
\hline & & Tyvek® & 3.4 & 4.7 & $1-5$ \\
\hline
\end{tabular}


Table C: Questionnaire Comments

\begin{tabular}{|c|c|c|c|}
\hline Suit & Task & Comment & Subject \\
\hline MTR & Confined Space & "Hood was a little tight on me." & S5 \\
\hline MTR & Confined Space & "Too hot. & $\mathrm{S} 15$ \\
\hline MTR & Confined Space & "The prior suits can do as good." & S26 \\
\hline MTR & Pit & $\begin{array}{l}\text { "Yellow MTR suit does satisfactory job overall. } \\
\text { Blue suit does absorb good. Both have } \\
\text { excellent zipper closures." }\end{array}$ & S25 \\
\hline MTR & Pit & $\begin{array}{l}\text { "Yellow suit should be smaller in waist and } \\
\text { chest." }\end{array}$ & S13 \\
\hline MTR & Pit & $\begin{array}{l}\text { Not a strenuous task. Blue suit did not soak } \\
\text { up sweat." }\end{array}$ & S26 \\
\hline MTR & Pit & $\begin{array}{l}\text { "Seemed to sweat more with ensemble on } \\
\text { during pit task." }\end{array}$ & $\mathrm{S} 20$ \\
\hline MTR & Wheelbarrow & "Not a bad suit." & S1 \\
\hline PVC & Confined Space & "Was able to work with little difficulty." & S18 \\
\hline PVC & Confined Space & $\begin{array}{l}\text { "Blue inner suit wicked away sweat very well. } \\
\text { Outer green suit very hot" }\end{array}$ & $\mathrm{S} 25$ \\
\hline PVC & Confined Space & "Hot SOB with suit on." & $\mathrm{S} 20$ \\
\hline PVC & Pit & $\begin{array}{l}\text { "With harness on, when I bent over to unhook } \\
\text { hook, felt seat rip out of blue suit." }\end{array}$ & S20 \\
\hline PVC & Wheelbarrow & $\begin{array}{l}\text { "There is a noticeable difference in } \\
\text { temperature wearing the green suit." }\end{array}$ & S24 \\
\hline PVC & Wheelbarrow & "Need material to keep from rubbing the neck." & S2 \\
\hline PVC & Wheelbarrow & "Very comfortable." & S26 \\
\hline PVC & Wheelbarrow & $\begin{array}{l}\text { "Suit soaks up sweat, semi-loose fitting. Need } \\
2 \text { XL blue suits. Once suit is wet, seems to rip } \\
\text { easily." }\end{array}$ & S20 \\
\hline Tyvek® & Confined Space & $\begin{array}{l}\text { "The inner suit from KC was easily torn when } \\
\text { wet. I could not see a difference in the KC } \\
\text { suits, from any other suit l've tried." }\end{array}$ & S12 \\
\hline Tyvek® & Confined Space & $\begin{array}{l}\text { "Suit was comfortable to wear - didn't irritate, } \\
\text { but ripped easily once wet or restricted } \\
\text { positions." }\end{array}$ & S20 \\
\hline Tyvek® & Pit & $\begin{array}{l}\text { "Was able to move freely without much } \\
\text { restrictions." }\end{array}$ & S18 \\
\hline Tyvek® & Pit & "Very comfortable, I like it a lot." & S26 \\
\hline
\end{tabular}




\begin{tabular}{|lclc|} 
Tyvek ${ }^{\circledR}$ & Pit & "Seemed cooler using Tyvek®." & S20 \\
\hline Tyvek ${ }^{\circledR}$ & Wheelbarrow & "Easy to work in." & S2 \\
\hline Tyvek ${ }^{\circledR}$ & Wheelbarrow & $\begin{array}{l}\text { "Overall performance ok. Heat stress in this } \\
\text { suit could be a problem if working in high } \\
\text { temperatures." }\end{array}$ & S25 \\
\hline
\end{tabular}


Table D-MPT: ANOVA of MTR, PVC, and Tyvek® suits.

\begin{tabular}{|cccccc} 
SUMMARY & & & & & \\
\hline Groups & & Count & Sum & Average & Variance \\
\hline & MTR & 6000 & 223927 & 37.32117 & 0.18546 \\
& PVC & 6000 & 223592.6 & 37.26543 & 0.240629 \\
& Tyvek® & 6000 & 223638.5 & 37.27308 & 0.256626 \\
\hline
\end{tabular}

ANOVA

\begin{tabular}{|c|c|c|c|c|c|c|c|}
\hline Source of Variation & & ss & $d f$ & MS & $F$ & $P$-value & F crit \\
\hline & Between Groups & 10.95708 & 2 & 5.478541 & 24.07389 & $3.62079 \mathrm{E}-11$ & 2.996231 \\
\hline & Within Groups & 4095.611 & 17997 & 0.227572 & & & \\
\hline & Total & 4106.569 & 17999 & & & & \\
\hline
\end{tabular}




\section{Table D-MTR: ANOVA of tasks with MTR suit.}

\begin{tabular}{|cccccc} 
SUMMARY \\
\hline Groups & & Count & Sum & Average & Variance \\
\hline & MTR CS & 2000 & 74731.48 & 37.36574 & 0.259656 \\
& MTR PIT & 2000 & 74587.92 & 37.29396 & 0.138883 \\
& MTR WB & 2000 & 74607.63 & 37.30382 & 0.154998 \\
\hline
\end{tabular}

ANOVA

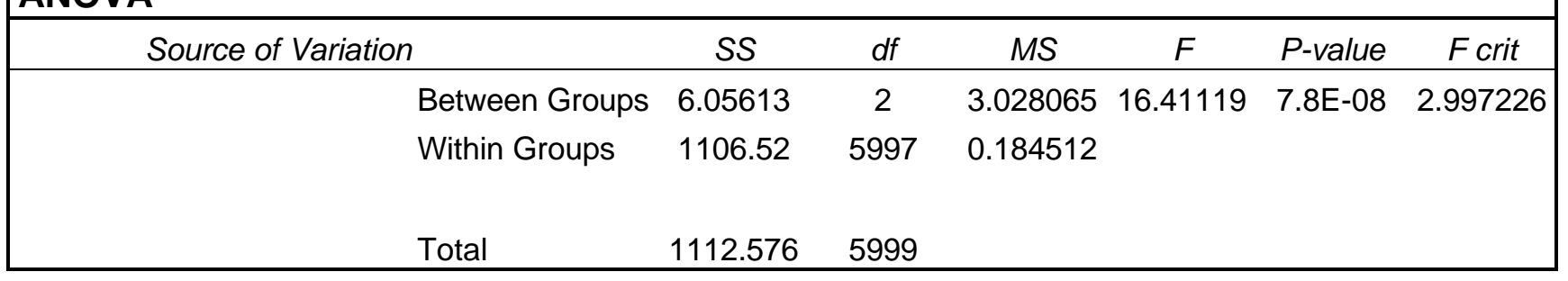


Table D-PVC: ANOVA of tasks with PVC suit.

\begin{tabular}{|cccccc} 
SUMMARY \\
\hline Groups & & Count & Sum & Average & Variance \\
\hline & PVC CS & 2000 & 74593.25 & 37.29662 & 0.333312 \\
& PVC PIT & 2000 & 74431.49 & 37.21575 & 0.188053 \\
& PVC WB & 2000 & 74567.83 & 37.28392 & 0.196979 \\
\hline
\end{tabular}

ANOVA

\begin{tabular}{|c|c|c|c|c|c|c|c|}
\hline Source of Variation & & SS & $d f$ & $M S$ & $F$ & $P$-value & F crit \\
\hline & Between Groups & 7.566845 & 2 & 3.783422 & 15.80061 & $1.43 E-07$ & 2.997226 \\
\hline & Within Groups & 1435.968 & 5997 & 0.239448 & & & \\
\hline & Total & 1443.535 & 5999 & & & & \\
\hline
\end{tabular}


Table D-Tyvek $\AA$ : ANOVA of tasks with Tyvek $\AA$ suit.

\begin{tabular}{|cccccc} 
SUMMARY & & & & & \\
\hline Groups & & Count & Sum & Average & Variance \\
\hline & Tyvek $\circledast$ CS & 2000 & 74835.62 & 37.41781 & 0.372566 \\
& Tyvek® PIT & 2000 & 74082.59 & 37.0413 & 0.208744 \\
& Tyvek® WB & 2000 & 74720.28 & 37.36014 & 0.106534 \\
\hline
\end{tabular}

ANOVA

\begin{tabular}{|c|c|c|c|c|c|c|c|}
\hline Source of Variatio & & sS & $d f$ & MS & $F$ & $P$-value & F crit \\
\hline & Between Groups & 164.501 & 2 & 82.2505 & 358.732 & $6.9 \mathrm{E}-148$ & 2.997226 \\
\hline & Within Groups & 1374.999 & 5997 & 0.229281 & & & \\
\hline & Total & 1539.5 & 5999 & & & & \\
\hline
\end{tabular}


Table D-TF: Two-factor ANOVA of tasks and suits (with replication).

\begin{tabular}{|c|c|c|c|c|c|c|}
\hline \multicolumn{6}{|c|}{ CS } & \\
\hline Count & & 2000 & 2000 & 2000 & 6000 & \\
\hline Sum & & 74731.48 & 74593.25 & 74835.62 & 224160.4 & \\
\hline Average & & 37.36574 & 37.29662 & 37.41781 & 37.36006 & \\
\hline Variance & & 0.259656 & 0.333312 & 0.372566 & 0.324202 & \\
\hline \multicolumn{7}{|c|}{$\mathrm{PIT}$} \\
\hline Count & & 2000 & 2000 & 2000 & 6000 & \\
\hline Sum & & 74587.92 & 74431.49 & 74082.59 & 223102 & \\
\hline Average & & 37.29396 & 37.21575 & 37.0413 & 37.18367 & \\
\hline Variance & & 0.138883 & 0.188053 & 0.208744 & 0.189657 & \\
\hline \multicolumn{7}{|c|}{ WB } \\
\hline Count & & 2000 & 2000 & 2000 & 6000 & \\
\hline Sum & & 74607.63 & 74567.83 & 74720.28 & 223895.7 & \\
\hline Average & & 37.30382 & 37.28392 & 37.36014 & 37.31596 & \\
\hline Variance & & 0.154998 & 0.196979 & 0.106534 & 0.153828 & \\
\hline \multicolumn{7}{|c|}{ Total } \\
\hline Count & & 6000 & 6000 & 6000 & & \\
\hline Sum & & 223927 & 223592.6 & 223638.5 & & \\
\hline Average & & 37.32117 & 37.26543 & 37.27308 & & \\
\hline Variance & & 0.18546 & 0.240629 & 0.256626 & & \\
\hline \multicolumn{7}{|l|}{ ANOVA } \\
\hline Source of Variation & & $S S$ & $d f$ & $M S$ & $F$ & $P$-value \\
\hline & Sample & 101.1192 & 2 & 50.55962 & 232.1943 & $2.7 \mathrm{E}-1002.996231$ \\
\hline & Columns & 10.95708 & 2 & 5.478541 & 25.16011 & $1.23 \mathrm{E}-112.996231$ \\
\hline & Interaction & 77.00474 & 4 & 19.25118 & 88.41076 & $1.56 \mathrm{E}-742.372424$ \\
\hline & Within & 3917.488 & 17991 & 0.217747 & & \\
\hline & Total & 4106.569 & 17999 & & & \\
\hline
\end{tabular}


Table E: Visual Assessment Questionnaire Answers (MTR)

\begin{tabular}{|c|c|c|c|c|c|c|c|c|c|c|}
\hline Task & $\begin{array}{l}\text { Q1 } \\
\text { (\%) }\end{array}$ & $\begin{array}{l}\text { Q2 } \\
(\%)\end{array}$ & $\begin{array}{l}\text { Q3 } \\
(\%)\end{array}$ & $\begin{array}{l}\text { Q4 } \\
(\%)\end{array}$ & $\begin{array}{l}\text { Q5 } \\
\text { (\%) }\end{array}$ & $\begin{array}{l}\text { Q6 } \\
(\%)\end{array}$ & $\begin{array}{l}\text { Q7 } \\
\text { (\%) }\end{array}$ & $\begin{array}{l}88 \\
(\%)\end{array}$ & $\begin{array}{l}99 \\
(\%)\end{array}$ & $\begin{array}{l}\text { Q10 } \\
(\%)\end{array}$ \\
\hline Confined Space & 16.4 & 35.8 & 96.6 & 97.4 & 50.0 & 21.3 & 70.9 & 25.8 & 25.4 & 99.6 \\
\hline Confined Space & 49.3 & 71.6 & 50.0 & 70.9 & 91.8 & 50.0 & 80.2 & 39.4 & 36.0 & 49.2 \\
\hline Confined Space & 47.0 & 56.0 & 43.3 & 56.7 & 43.3 & 56.0 & 44.0 & 45.8 & 53.4 & 43.9 \\
\hline Confined Space & 43.3 & 15.7 & 45.9 & 44.0 & 71.3 & 60.1 & 47.0 & 54.5 & 55.3 & 53.0 \\
\hline Confined Space & 12.7 & 46.6 & 91.4 & 15.7 & 39.2 & 78.0 & 80.6 & 40.2 & 58.0 & 61.0 \\
\hline Confined Space & 67.2 & 68.3 & 79.9 & 73.1 & 85.8 & 89.6 & 63.1 & 51.5 & 79.5 & 81.4 \\
\hline Confined Space & 57.8 & 76.5 & 61.9 & 71.6 & 49.3 & 72.4 & 59.0 & 712 & 70.1 & 74.2 \\
\hline Confined Space & 79.1 & 79.5 & 82.1 & 89.6 & 88.8 & 94.0 & 95.5 & 91.7 & 83.3 & 85.2 \\
\hline Confined Space & 54.9 & 70.9 & 56.0 & 53.7 & 52.2 & 50.0 & 50.0 & 48.5 & 50.0 & 50.0 \\
\hline Confined Space & 68.3 & 93.3 & 79.1 & 50.0 & 72.8 & 97.0 & 71.3 & 84.8 & 95.8 & 89.0 \\
\hline Confined Space & 60.1 & 76,5 & 10.1 & 10.4 & 43.3 & 100.0 & 28.4 & 87.1 & 78.0 & 90.9 \\
\hline Confined Space & 50.4 & 49.3 & NA & 23.5 & 50.0 & 79.1 & 50.0 & 50.0 & 50.0 & 50.0 \\
\hline Confined Space & 50.0 & 100.0 & 70.1 & 71.6 & 84.7 & 85.8 & 91.0 & 50.0 & 78.4 & 73.5 \\
\hline Confined Space & 66.4 & 66.0 & 36.9 & 50.0 & 78.4 & 66.4 & 41.4 & 40.9 & 72.0 & 91.3 \\
\hline Confined Space & 59.7 & 44.8 & 63.4 & 70.9 & 42.9 & 60.4 & 67.2 & 40.2 & 37.9 & 76.9 \\
\hline Pit & 38.4 & 40.3 & 66.0 & 65.3 & 54.9 & 58.6 & 63.4 & 40.9 & 70.5 & 72.7 \\
\hline Pit & 73.5 & 73.9 & 75.4 & 73.1 & 100.0 & 82.1 & 82.1 & 74.6 & 73.5 & 70.8 \\
\hline Pit & 48.5 & 33.6 & 69.4 & 68.7 & 48.5 & 62.7 & 59.7 & 49.6 & 48.9 & 46.2 \\
\hline Pit & 21.3 & 79.5 & 87.3 & 85.1 & 58.2 & 86.6 & 78.4 & 71.2 & 72.3 & 79.5 \\
\hline Pit & 50.0 & 50.0 & 48.5 & 48.9 & 50.0 & 50.0 & 50.0 & 49.6 & 49.6 & 48.5 \\
\hline Pit & 50.0 & 21.3 & 64.2 & 50.0 & 50.0 & 79.5 & 49.6 & 49.6 & 49.6 & 49.6 \\
\hline Pit & 24.6 & 25.0 & 100.0 & 100.0 & 50.0 & 25.4 & 100.0 & 49.6 & 49.6 & 100.0 \\
\hline Pit & 43.3 & 92.5 & 51.5 & 54.1 & 51.5 & 93.7 & 54.1 & 53.0 & 56.1 & 52.3 \\
\hline Pit & 73.1 & 68.7 & 64.6 & 64.2 & 82.1 & 81.0 & 76.5 & 69.3 & 77.3 & 76.9 \\
\hline Pit & 50.4 & 21.3 & 50.4 & 50.4 & 80.2 & 100.0 & 50.4 & 50.0 & 50.0 & 50.0 \\
\hline Pit & 50.0 & 64.2 & 50.0 & 31.7 & 55.6 & 50.0 & 50.0 & 64.4 & 23.5 & 50.0 \\
\hline Pit & 32.1 & 74.6 & 94.0 & 71.6 & 38.4 & 50.0 & 53.7 & 44.7 & 50.0 & 50.0 \\
\hline Pit & 82.8 & 83.2 & 90.3 & 90.3 & 89.9 & 89.9 & 90.7 & 86.0 & 87.5 & 88.3 \\
\hline Pit & 38.1 & 36.9 & 53.7 & 44.8 & 57.5 & 56.7 & 44.0 & 67.0 & 65.9 & 69.7 \\
\hline Pit & 52.2 & 78.7 & 56.0 & 66.0 & 66.4 & 69.0 & 68.7 & 69.7 & 72.0 & 75.4 \\
\hline Pit & 49.3 & 57.8 & 2.2 & 14.9 & 77.6 & 100.0 & 21.6 & 92.4 & 100.0 & 70.5 \\
\hline Whe & 500 & 100.0 & 100.0 & 100.0 & 50.0 & 72.8 & 74.6 & 50.0 & 50.0 & 50.0 \\
\hline Wh & 26.9 & 47.0 & 81.3 & 83.6 & 79.1 & 88.4 & 76.9 & 57.6 & 59.1 & 75.0 \\
\hline Whe & 41.0 & 37.3 & 39.6 & 51.9 & 52.2 & 53.4 & 52.6 & 47.0 & 53.0 & 52.7 \\
\hline Whe & 70.9 & 93.7 & 89.6 & 86.9 & 77.6 & 90.3 & 82.5 & 72.0 & 86.4 & 82.2 \\
\hline Wh & 50.0 & 53.0 & 52.2 & 51.5 & 45.5 & 50.0 & 50.0 & 52.7 & 50.0 & 50.0 \\
\hline Whe & 49.3 & 70.9 & 60.1 & 62.7 & 50.4 & 57.1 & 62.7 & 50.0 & 50.0 & 65.5 \\
\hline Wheelbarrow & 84.3 & 98.5 & 51.1 & 50.4 & 51.1 & 98.9 & 50.0 & 70.5 & 50.8 & 50.0 \\
\hline Wheelbarrow & 63.4 & 69.4 & 72.8 & 53.0 & 57.5 & 82.8 & 70.9 & 74.2 & 71.2 & 72.3 \\
\hline Wheelbarrow & 67.9 & 73.1 & 53.0 & 52.6 & 60.8 & 50.0 & 52.2 & 78.8 & 77.3 & 65.9 \\
\hline Wheelbarrow & 88.4 & 77.2 & 0.0 & 50.0 & 90.7 & 90.3 & 73.9 & 75.8 & 71.6 & 63.6 \\
\hline Wheelbarrow & 38.4 & 61.2 & 50.0 & 38.1 & 50.4 & 50.4 & 50.0 & 49.6 & 49.6 & 49.6 \\
\hline Wheelbarrow & 73.9 & 28.4 & 81.0 & 38.8 & 61.2 & 88.1 & 35.8 & 57.6 & NA & 50.0 \\
\hline Wheelbarrow & 50.0 & 50.4 & 48.9 & 49.3 & 50.0 & 50.0 & 50.4 & 50.0 & 50.0 & 49.6 \\
\hline Wheelbarrow & 86.6 & 89.9 & 90.7 & 93.3 & 94.4 & 94.8 & 95.5 & 12.1 & 93.9 & 91.3 \\
\hline Wheelbarrow & 40.3 & 41.8 & 46.3 & 60.4 & 71.3 & 64.2 & 41.8 & 41.7 & 65.9 & 94.3 \\
\hline $\bar{n}$ & 46 & $\overline{46}$ & $\overline{46}$ & $\overline{46}$ & 46 & 46 & $\overline{46}$ & $\overline{46}$ & 46 & 46 \\
\hline Average & 53.1 & 61.8 & 62.4 & 59.8 & 63.0 & 71.2 & 62.0 & 57.5 & 62.2 & 67.0 \\
\hline
\end{tabular}


Table F: Fit Assessment Questionnaire Answers (MTR)

\begin{tabular}{|c|c|c|c|c|c|c|c|c|c|}
\hline Task & Q1 & Q2 & Q3 & Q4 & Q5 & Q6 & Q7 & Q8 & Q9 \\
\hline Confined Space & 3.0 & 3.0 & 3.0 & 3.0 & 3.0 & 3.0 & 3.0 & 3.0 & 2.5 \\
\hline Confined Space & 3.0 & 2.0 & 3.0 & 2.0 & 2.0 & 3.0 & 4.0 & 2.0 & 3.0 \\
\hline Confined Space & 4.0 & 4.0 & 3.5 & 3.5 & 4.0 & 3.5 & 4.0 & 3.5 & 3.0 \\
\hline Confined Space & 3.0 & 3.0 & 3.0 & 3.0 & 3.0 & 3.0 & 3.0 & 3.5 & 3.5 \\
\hline Confined Space & 4.0 & 4.0 & 4.0 & 3.0 & 2.0 & 2.5 & 3.0 & 4.0 & 4.5 \\
\hline Confined Space & 3.0 & 3.0 & 3.0 & 2.5 & 3.0 & 3.0 & NA & 3.5 & 4.0 \\
\hline Confined Space & 2.5 & 2.5 & 2.0 & 2.0 & 2.0 & 2.5 & 3.0 & 2.5 & 4.0 \\
\hline Confined Space & 3.0 & 3.0 & 3.0 & 2.0 & 3.0 & 3.0 & 3.0 & 3.0 & 4.5 \\
\hline Confined Space & 3.0 & 3.5 & 4.0 & 3.5 & 3.0 & 3.0 & 3.0 & 3.5 & 4.0 \\
\hline Confined Space & 3.0 & 3.0 & 3.0 & 4.5 & 3.0 & 3.0 & NA & 3.0 & 4.0 \\
\hline Confined Space & 3.0 & 3.0 & 4.0 & 2.0 & 3.0 & 2.0 & 3.0 & 3.0 & 3.0 \\
\hline Confined Space & 2.0 & 2.0 & 2.0 & 2.0 & 1.5 & 2.0 & NA & 2.0 & 3.0 \\
\hline Confined Space & 2.0 & 2.0 & 3.0 & 2.0 & 3.0 & 3.0 & 3.0 & 2.0 & 3.5 \\
\hline Confined Space & 4.0 & 4.0 & 3.5 & 2.0 & 3.0 & 3.5 & 3.5 & 4.0 & 4.0 \\
\hline Confined Space & 3.0 & 3.0 & 3.0 & 3.0 & 3.0 & 3.0 & 3.0 & 3.0 & 4.5 \\
\hline Pit & 4.0 & 4.0 & 3.5 & 4.0 & 4.0 & 4.0 & 4.0 & 4.0 & 4.0 \\
\hline Pit & 2.0 & 2.0 & 2.0 & 2.0 & 2.0 & 3.0 & 3.0 & 2.0 & 4.0 \\
\hline Pit & 3.0 & 3.0 & 4.0 & 3.0 & 3.0 & 3.0 & NA & 4.0 & 4.0 \\
\hline Pit & 3.5 & 3.5 & 3.5 & 3.0 & 2.5 & 2.5 & 2.5 & 3.5 & 4.0 \\
\hline Pit & 3.0 & 2.0 & 2.0 & 2.0 & 2.0 & 3.0 & 4.0 & 2.5 & 3.0 \\
\hline Pit & 1.5 & 1.5 & 1.5 & 2.0 & 2.5 & 2.0 & NA & 2.0 & 3.0 \\
\hline Pit & 3.0 & 3.0 & 3.0 & 3.0 & 3.0 & 3.0 & 3.0 & 3.0 & 4.5 \\
\hline Pit & 4.0 & 4.0 & 4.0 & 4.0 & 3.5 & 3.0 & 2.5 & 4.0 & 3.0 \\
\hline Pit & 3.0 & 3.0 & 2.0 & 3.0 & 3.0 & 3.0 & 3.0 & 3.0 & 4.0 \\
\hline Pit & 3.0 & 4.0 & 3.0 & 3.0 & 3.0 & 4.0 & NA & 4.0 & 3.0 \\
\hline Pit & 3.0 & 4.0 & 4.0 & 3.0 & 3.0 & 3.0 & 3.0 & 3.5 & 3.0 \\
\hline Pit & 3.0 & 2.0 & 1.5 & 2.0 & 2.5 & 2.5 & 2.5 & 2.5 & 3.0 \\
\hline Pit & 3.0 & 3.0 & 3.0 & 3.0 & 3.0 & 3.0 & 3.0 & 3.0 & 4.5 \\
\hline Pit & 3.0 & 4.0 & 4.0 & 4.0 & 3.0 & NA & 4.0 & 3.0 & 3.0 \\
\hline Pit & 3.0 & 3.0 & 3.0 & 2.5 & 3.0 & 3.0 & NA & 3.5 & 4.0 \\
\hline Pit & 2.0 & 2.0 & 4.0 & 3.0 & 3.0 & 3.0 & 3.0 & 3.0 & 3.0 \\
\hline arrow & 2.0 & 2.0 & 3.0 & 2.0 & 3.0 & 3.0 & 3.0 & 2.0 & 4.0 \\
\hline arrow & 3.0 & 3.5 & 3.5 & 3.0 & 2.5 & 2.5 & 3.0 & 3.0 & 4.0 \\
\hline arrow & 3.5 & 3.5 & 4.0 & 2.0 & 2.5 & 2.5 & 4.0 & 3.5 & 3.5 \\
\hline barrow & 3.0 & 3.0 & 3.0 & 3.0 & 4.0 & 3.0 & 3.5 & 3.0 & 4.5 \\
\hline Ibarrow & 3.5 & 4.0 & 4.0 & 3.0 & 3.0 & 3.0 & 3.0 & 3.5 & 4.0 \\
\hline Wheelbarrow & 2.5 & 3.0 & 2.5 & 2.0 & 2.5 & 2.0 & 3.0 & 2.5 & 4.0 \\
\hline barrow & 3.0 & 3.0 & 4.0 & 3.0 & 3.0 & 3.0 & 3.0 & 4.0 & 3.0 \\
\hline Wheelbarrow & 3.5 & 3.5 & 3.0 & 2.5 & 3.0 & 3.0 & NA & 3.5 & 4.0 \\
\hline Wheelbarrow & 3.0 & 3.5 & 3.0 & 3.5 & 3.0 & 3.5 & 3.0 & 3.5 & 3.0 \\
\hline barrow & 2.0 & 2.0 & 2.0 & 2.0 & 3.0 & 3.0 & 3.0 & 3.0 & $\mathrm{NA}$ \\
\hline Wheelbarrow & 1.5 & 1.5 & 1.5 & 2.0 & 2.0 & 2.5 & NA & 2.5 & 3.0 \\
\hline Wheelbarrow & 3.0 & 3.0 & 3.0 & 3.0 & 3.0 & 3.0 & 3.0 & 3.0 & 3.0 \\
\hline Wheelbarrow & 3.0 & 2.0 & 2.0 & 2.0 & 2.0 & 3.0 & 4.0 & 2.5 & 3.0 \\
\hline Wheelbarrow & 3.0 & 3.0 & 3.0 & 3.0 & 3.0 & 3.0 & 3.0 & 3.0 & 4.5 \\
\hline Wheelbarrow & 4.0 & 4.0 & 3.5 & 2.0 & 3.0 & 3.5 & 3.5 & 4.0 & 4.0 \\
\hline$n$ & 46 & 46 & 46 & 46 & 46 & 46 & 46 & 46 & 46 \\
\hline Average & 3.0 & 3.0 & 3.0 & 2.7 & 2.8 & 2.9 & 3.2 & 3.1 & 3.6 \\
\hline
\end{tabular}


Table G: Before Exercise Questionnaire Answers (MTR)

\begin{tabular}{|c|c|c|c|c|c|c|c|c|c|c|c|c|c|}
\hline Task & $\begin{array}{l}\text { Q1 } \\
(\%)\end{array}$ & $\begin{array}{l}\text { Q2 } \\
(\%)\end{array}$ & $\begin{array}{l}\text { Q3 } \\
(\%)\end{array}$ & $\begin{array}{l}\text { Q4 } \\
(\%)\end{array}$ & $\begin{array}{l}\text { Q5 } \\
(\%)\end{array}$ & $\begin{array}{c}Q 6 \\
(\%)\end{array}$ & $\begin{array}{l}\text { Q7 } \\
(\%)\end{array}$ & $\begin{array}{l}Q 8 \\
(\%)\end{array}$ & $\begin{array}{l}09 \\
(\%)\end{array}$ & $\begin{array}{l}\text { Q10 } \\
(\%)\end{array}$ & $\begin{array}{l}\text { Q11 } \\
(\%)\end{array}$ & $\begin{array}{l}\text { Q12 } \\
(\%)\end{array}$ & $\begin{array}{l}\text { Q13 } \\
(\%)\end{array}$ \\
\hline Confined Space & 13.0 & 48.9 & 50.0 & 50.0 & 65.5 & 50.0 & 38.0 & 48.9 & 48.6 & 83.5 & 33.8 & 24.6 & 48.8 \\
\hline Confined Space & 71.8 & 30.6 & 31.3 & 25.4 & 20.4 & 21.8 & 47.9 & 33.5 & 48.9 & 74.6 & 38.4 & 24.9 & 43.1 \\
\hline Confined Space & 47.2 & 45.8 & 46.5 & 52.8 & 44.0 & 52.1 & 62.0 & NA & 33.5 & 68.7 & 41,3 & 55.5 & 39.1 \\
\hline Confined Space & 33.8 & 37.3 & 55.3 & 52.8 & 47.9 & 52.8 & 47.9 & 51.8 & 54.2 & 54.6 & 56.2 & 42.7 & 54.8 \\
\hline Confined Space & 33.8 & 51.4 & 52.5 & 52.5 & 26.8 & 44.4 & 68.0 & 68.7 & 57.4 & 71.5 & 42.0 & 75.4 & 82.9 \\
\hline Confined Space & 32.0 & 42.3 & 32.4 & 33.8 & 68.7 & 602 & 79.9 & 79.2 & 500 & 79.6 & 73.3 & 77.9 & 82.6 \\
\hline Confined Space & 50.0 & 36.3 & 78.9 & 50.4 & 31.7 & 63.0 & 63.0 & 62.0 & 68.3 & 50.0 & 49.5 & 612 & 60.5 \\
\hline Confined Space & 77.1 & 81.0 & 66.2 & 79.6 & 80.3 & 80.6 & 71.1 & 81.0 & 69.7 & 76.1 & 69.4 & 68.0 & 70.5 \\
\hline Confined Space & 50.0 & 50.0 & 50.0 & 50.0 & 50.0 & 50.0 & 50.7 & 52.5 & 50.7 & 50.0 & 47.0 & 53.4 & 61.2 \\
\hline Space & 75.0 & 94.7 & 84.5 & 83.1 & 81.7 & 85.2 & 94.4 & 92.3 & 90.8 & 88.0 & 86.8 & 83.6 & 81.9 \\
\hline Confined Space & NA & 31.3 & 26.1 & 22.5 & 75.0 & 77.5 & 95.8 & 95.4 & 97.2 & 20.4 & 76.5 & 75.4 & 74.0 \\
\hline Confined Space & 14.4 & 12.3 & 10.6 & 9.5 & NA & 73.2 & 50.0 & 65.1 & 50.0 & 49.3 & 49.1 & 23.8 & 49.1 \\
\hline Confined Space & 28.5 & 28.5 & 50.0 & 50.0 & 50.0 & 72.9 & 73.6 & 91.5 & 91.5 & 91.9 & 502 & 76.2 & 71.9 \\
\hline Confined Space & 58.5 & 54.9 & 56.3 & 56.3 & 59.9 & 51.1 & 51.1 & 66.2 & 35.2 & 62.7 & 37.4 & 52.3 & 50.2 \\
\hline Confined Space & 73.2 & 73.9 & 93.0 & 93.0 & 26.1 & 78.5 & 79.6 & 68.3 & 37.7 & 70.1 & 65.1 & 67.3 & 84.3 \\
\hline Pit & 56.3 & 35.9 & 37.0 & 38.0 & 57.0 & 58.5 & 57.4 & 60.2 & 43.0 & 73.9 & 42.7 & 67.3 & 65.1 \\
\hline Pit & 28.2 & 26.8 & 25.4 & 28.5 & 22.5 & 100.0 & 76.8 & 75.0 & 73.6 & 76.1 & 75.4 & 76.2 & 79.4 \\
\hline Pit & 48.2 & 36.6 & 34.9 & 36.3 & 42.3 & 48.6 & 48.6 & 63.4 & 34.2 & 48.2 & 42.0 & 48.0 & 55.5 \\
\hline$\overline{P i t}$ & 19.7 & 19.4 & 34.2 & 54.2 & 5.3 & 45.4 & 80.6 & 68.0 & 44.4 & 81.0 & 57.7 & 72.6 & 87.2 \\
\hline Pit & 43.0 & 43.0 & 41.5 & 28.5 & 25.4 & 31.0 & 48.2 & 38.7 & 38.7 & 76.8 & 48.4 & 43.4 & 49.1 \\
\hline Pit & 50.0 & 50.0 & 73.9 & 73.6 & 50.0 & 50.0 & 69.0 & 33.1 & 50.0 & 50.0 & 48.8 & 48.0 & 48.8 \\
\hline Pit & 39.1 & 39.4 & 41.5 & 41.9 & 20.8 & 48.9 & 48.9 & 50.0 & 50.0 & 77.1 & 28.1 & 29.2 & 48.8 \\
\hline Pit & 14.1 & 27.8 & 20.1 & 16.9 & 44.4 & 72.5 & 98.2 & 56.3 & 51.4 & 57.0 & 52.7 & 53.4 & 46.6 \\
\hline Pit & 71.5 & 70.4 & 68.3 & 58.5 & 66.2 & 66.9 & 59.2 & 66.2 & 73.2 & 81.7 & 74.0 & 74.4 & 80.4 \\
\hline Pit & 50.0 & 50.0 & 46.1 & 50.0 & 50.0 & 28.2 & 50.0 & 31.3 & 50.0 & 50.0 & 49.5 & 49.5 & 64.4 \\
\hline Pit & 62.0 & 50.0 & 50.0 & 50.0 & 22.2 & 43.0 & 52.1 & 50.0 & 45.8 & 51.4 & 49.5 & 55.5 & 55.5 \\
\hline Pit & 21.1 & 19.7 & 50,0 & 21.5 & 50.0 & 50.0 & 50.0 & 58.5 & 50.0 & 59.9 & 50.2 & 50.2 & 50.2 \\
\hline Pit & 79.9 & 84.5 & 83.1 & 85.2 & 82.0 & 83.5 & 87.0 & 87.0 & 88.0 & 89.4 & 86.8 & 87.9 & 88.3 \\
\hline Pit & 21.8 & 36.6 & 36.3 & 35.2 & 33.8 & 36.6 & 39.8 & 43.7 & 67.6 & 38.4 & 63.7 & 32.0 & 61.6 \\
\hline Pit & 63.4 & 71.1 & 78.2 & 96.5 & 76.1 & 71.1 & 96.5 & 98.6 & 98.2 & 81.0 & 97.5 & 96.1 & 72.6 \\
\hline Whe & 50.0 & 50.0 & 50.0 & 50.0 & 24.6 & 75.0 & 11.6 & 72.2 & 26.8 & 74.3 & 49.1 & 73.0 & 712 \\
\hline Whe & 33.1 & 35.2 & 55.3 & 55.6 & 21.1 & 29.6 & 66.9 & 69.0 & 67.6 & 82.0 & 65.5 & 69.8 & 80.4 \\
\hline Wheelbarrow & 33.8 & 29.6 & 31.3 & 34.2 & 35.2 & 39.1 & 58.5 & 59.2 & 49.6 & 44.7 & 52.3 & 41.3 & 41.3 \\
\hline Wheelbarrow & 84.5 & 73.2 & 80.3 & 75.0 & 75.0 & 80.3 & 90.1 & 91.9 & 92.3 & 90.1 & 79.7 & 77.6 & 88.3 \\
\hline Wheelbarrow & 40.8 & 42.3 & 44.4 & 44.7 & 50.7 & 51.4 & 63.4 & 53.9 & 50.0 & 52.1 & 45.2 & 51.6 & 55.9 \\
\hline Wh & 15.8 & 50.0 & 48,9 & 50.0 & 59.2 & 50.4 & 59.2 & 63.4 & 55.3 & 60.6 & 49.5 & 63.3 & 64.1 \\
\hline Wheelbarrow & 51.1 & 50.0 & 50,0 & 50.0 & 69.0 & 95.8 & 89.8 & 92.6 & 91.2 & 50.4 & 52.3 & 50.2 & 50.5 \\
\hline Wheelbarrow & 63.4 & 64.1 & 62.0 & 63.4 & 65.5 & 65.5 & 66.9 & 62.3 & 50,0 & 74.6 & 74.0 & 86.8 & 89.7 \\
\hline Wheelbarrow & 60.6 & 78.5 & 59.9 & 78.2 & 58.5 & 81.3 & 72.2 & 56.3 & 62.0 & 76.8 & 56.9 & 40.9 & 49.1 \\
\hline Wheelbarrow & 49.6 & 50.0 & 50.0 & 50.0 & 59.5 & 53.9 & 49.6 & 85.2 & 49.6 & 55.3 & 49.1 & 66.2 & 54.4 \\
\hline Wheelbarrow & 54.9 & 69.0 & 34.5 & 35.9 & 59.2 & 32.7 & 58.5 & 83.8 & 27.1 & NA & 50.2 & 61.2 & 60.5 \\
\hline Wheelbarrow & 50.0 & 48.2 & 27.1 & 40.1 & 29.9 & 17.6 & 50.7 & 40.1 & 38.0 & 76.1 & 38.4 & 40.9 & 50.2 \\
\hline Wheelbarrow & 92.6 & 90.5 & 90.1 & 90.8 & 50.7 & 83.1 & 83.5 & 91.2 & 91.5 & 912 & 86.8 & 92.5 & 91.1 \\
\hline Wheelbarrow & 75.7 & 74.6 & 90.8 & 89.1 & 26.1 & 72.2 & 73.9 & 61,3 & 40.8 & 62.3 & 59.1 & 55.9 & 83.6 \\
\hline $\bar{n}$ & $\overline{44}$ & 44 & 44 & 44 & $\overline{44}$ & 44 & 44 & $\overline{44}$ & 44 & $\overline{44}$ & 44 & $\overline{44}$ & 44 \\
\hline Average & 48.4 & 49.7 & 51.8 & 51.9 & 47.9 & 58.5 & 64.3 & 65.6 & 57.6 & 66.8 & 56.6 & 59.5 & 64.5 \\
\hline
\end{tabular}


Table H: After Task Performance Questionnaire Answers (MTR)

\begin{tabular}{|c|c|c|c|c|c|c|c|}
\hline & $\begin{array}{l}\text { Q1 } \\
(\%)\end{array}$ & $\begin{array}{l}\text { Q2 } \\
\text { (\%) }\end{array}$ & $\begin{array}{l}\text { Q3 } \\
(\%)\end{array}$ & $\begin{array}{l}\text { Q4 } \\
(\%)\end{array}$ & $\begin{array}{l}\text { Q5 } \\
(\%)\end{array}$ & $\begin{array}{l}\text { Q6 } \\
\text { (\%) }\end{array}$ & $\begin{array}{l}\text { Q7 } \\
(\%)\end{array}$ \\
\hline Confined Space & 8.5 & 33.5 & 33.8 & 33.8 & 86.6 & 28.2 & 48.9 \\
\hline Confined Space & 43.3 & 28.9 & 38.7 & 31.7 & 38.0 & 32.0 & 38.7 \\
\hline Confined Space & 52.5 & 45.1 & 43.3 & 39.4 & 39.1 & 39.1 & 41.2 \\
\hline Confined Space & 47.2 & 51.8 & 48.9 & 50.4 & 43.0 & 48.9 & 53.5 \\
\hline Confined Space & 10.6 & 10.2 & 16.2 & 22.2 & 23.9 & 45.8 & 80.3 \\
\hline Confined Space & 15.5 & 23.2 & 18.0 & 19.4 & 60.6 & 71.5 & 75.7 \\
\hline Confined Space & 41.5 & 29.9 & 50.0 & 33.5 & 58.5 & 57.7 & 54.9 \\
\hline Confined Space & 86.3 & 66.9 & 66.2 & 64.8 & 78.9 & 80.6 & 66.5 \\
\hline Confined Space & 35.2 & 37.3 & 44.4 & 45.1 & 21.1 & 61.3 & 69.0 \\
\hline Confined Space & 88.0 & 89.8 & 90.1 & 91.5 & 88.4 & 85.9 & 90.5 \\
\hline Confined Space & 7.7 & 6.3 & 23.2 & 25.4 & 80.6 & 50.0 & 50.0 \\
\hline Confined Space & 20.8 & 23.2 & 23.9 & 24.3 & 24.6 & 49.6 & 49.6 \\
\hline Confined Space & 31.7 & 40.5 & 54.2 & 59.9 & 71.1 & 59.9 & 58.5 \\
\hline Confined Space & 41.5 & 26.4 & 65.8 & 63.4 & 35.2 & 74.6 & 88.4 \\
\hline Pit & 36.6 & 26.8 & 25.0 & 47.2 & 56.0 & 59.2 & 69.7 \\
\hline Pit & 28.9 & 28.2 & 28.2 & 26.4 & 23.9 & 25.0 & 75.4 \\
\hline Pit & 47.9 & 47.9 & 57.0 & 47.9 & 48.2 & 56.3 & 50.0 \\
\hline Pit & 4.2 & 4.2 & 33.8 & 35.2 & 3.9 & 70.1 & 80.3 \\
\hline Pit & 38.7 & 35.9 & 35.2 & 23.6 & 33.5 & 37.7 & 47.9 \\
\hline Pit & 7.4 & 9.9 & 10.6 & NA & 23.2 & $\mathrm{NA}$ & NA \\
\hline Pit & 7.7 & 48.9 & 48.9 & 48.9 & 76.8 & 48.9 & 48.9 \\
\hline Pit & 56.0 & 52.1 & 51.4 & 45.8 & 45.4 & 47.2 & 55.6 \\
\hline Pit & 30.3 & 47.9 & 47.9 & 48.9 & 59.9 & 59.9 & 58.1 \\
\hline Pit & 50.0 & 38.4 & 77.8 & 50.0 & 20.4 & 50.0 & 50.0 \\
\hline Pit & 15.1 & 31.0 & 50.0 & 45.8 & 51.1 & 52.1 & 56.0 \\
\hline Pit & 23.9 & 22.5 & 50.0 & 23.2 & 51.4 & 50.0 & 50.0 \\
\hline Pit & 85.6 & 85.9 & 83.8 & 85.9 & 83.1 & 83.1 & 83.8 \\
\hline Pit & 31.0 & 21.8 & 21.1 & 28.2 & 33.1 & 47.9 & 51.4 \\
\hline Pit & 70.4 & 47.9 & 81.7 & 70.4 & 91.9 & 88.7 & 92.3 \\
\hline Wheelbarrow & 22.5 & 0.0 & 0.0 & 0.0 & 0.0 & 40.1 & 73.6 \\
\hline Wheelbarrow & 8.8 & 10.6 & 44.4 & 43.7 & 17.6 & 72.5 & 82.0 \\
\hline Wheelbarrow & 44.0 & 42.3 & 39.1 & 39.8 & 41.2 & 40.5 & 43.7 \\
\hline Wheelbarrow & 93.3 & 94.4 & 93.7 & 91.5 & 90.5 & 88.7 & 88.0 \\
\hline Wheelbarrow & 45.8 & 45.1 & 42.3 & 41.5 & 46.5 & 56.3 & 58.5 \\
\hline Wheelbarrow & 6.3 & 5.6 & 27.1 & 28.9 & 65.5 & 55.3 & 54.6 \\
\hline Wheelbarrow & 50.0 & 52.5 & 50.0 & 50.0 & 50.0 & 70.4 & 60.6 \\
\hline Wheelbarrow & 17.6 & 28.9 & 28.2 & 18.0 & 39.4 & 63.7 & 73.2 \\
\hline Wheelbarrow & 63.7 & 61.6 & 35.2 & 58.8 & 36.3 & 62.7 & 58.5 \\
\hline Wheelbarrow & 35.9 & 35.9 & 48.6 & 48.9 & 62.3 & 61.3 & 54.9 \\
\hline Wheelbarrow & 49.6 & 57.7 & 62.7 & 73.2 & 37.0 & 49.6 & 67.6 \\
\hline Wheelbarrow & 47.9 & 40.5 & 41.2 & 35.2 & 44.0 & 44.0 & 49.6 \\
\hline Wheelbarrow & 91.2 & 88.4 & 91.5 & 92.3 & 91.5 & 91.5 & 91.9 \\
\hline Wheelbarrow & 37.3 & 27.1 & 57.7 & 54.9 & 35.6 & 69.0 & 82.4 \\
\hline $\bar{n}$ & 43 & 43 & 43 & 43 & 43 & 43 & 43 \\
\hline Average & 39.0 & 38.4 & 46.1 & 45.4 & 49.0 & 57.8 & 63.7 \\
\hline
\end{tabular}


Table J: After Removing Coverall Questionnaire Answers (MTR)

\begin{tabular}{|l|c|c|c|c|}
\cline { 2 - 5 } \multicolumn{1}{c|}{} & $\begin{array}{c}\text { Q1 } \\
\text { Task }\end{array}$ & $\begin{array}{c}\text { Q2 } \\
(\%)\end{array}$ & $\begin{array}{c}\text { Q3 } \\
(\%)\end{array}$ & $\begin{array}{c}\text { Q4 } \\
(\%)\end{array}$ \\
\hline Confined Space & 13.2 & 34.2 & 34.5 & 35.2 \\
\hline Confined Space & 30.6 & 32.7 & 35.6 & 35.6 \\
\hline Confined Space & 46.6 & 45.9 & 46.6 & 45.6 \\
\hline Confined Space & 50.9 & 48.0 & 46.6 & 44.5 \\
\hline Confined Space & 12.8 & 17.4 & 30.6 & 32.0 \\
\hline Confined Space & 49.5 & 35.6 & 35.2 & 33.1 \\
\hline Confined Space & 56.6 & 36.3 & 40.2 & 38.4 \\
\hline Confined Space & 19.9 & 15.7 & 21.4 & 27.0 \\
\hline Confined Space & 100.0 & 0.0 & 23.5 & 21.4 \\
\hline Confined Space & 60.5 & 79.7 & 80.4 & 83.6 \\
\hline Confined Space & 47.7 & 47.7 & 47.3 & 47.0 \\
\hline Pit & 59.4 & 40.6 & 59.8 & 60.5 \\
\hline Pit & 100.0 & 74.7 & 24.2 & 21.4 \\
\hline Pit & 42.7 & 43.1 & 50.9 & 49.5 \\
\hline Pit & 6.0 & 6.4 & 28.5 & 32.4 \\
\hline Pit & 43.1 & 40.6 & 33.8 & 30.6 \\
\hline Pit & 0.0 & 0.0 & 18.9 & 24.2 \\
\hline Pit & 15.3 & 49.5 & 49.5 & 49.5 \\
\hline Pit & 46.3 & NA & 29.2 & NA \\
\hline Pit & 66.2 & 61.6 & 53.4 & 51.6 \\
\hline Pit & 66.5 & 65.1 & 49.1 & 49.1 \\
\hline Pit & 37.0 & 41.6 & 49.5 & 49.5 \\
\hline Pit & 23.1 & 21.0 & 49.1 & 20.6 \\
\hline Pit & 88.3 & 79.7 & 74.7 & 76.2 \\
\hline Wheelbarrow & 100.0 & 100.0 & 76.5 & 76.2 \\
\hline Wheelbarrow & 12.1 & 14.2 & 44.8 & 44.1 \\
\hline Wheelbarrow & 42.7 & 41.6 & 41.3 & 42.0 \\
\hline Wheelbarrow & 74.7 & 76.2 & 78.3 & 77.9 \\
\hline Wheelbarrow & 37.7 & 35.2 & 34.9 & 33.1 \\
\hline Wheelbarrow & 65.8 & 20.3 & 22.1 & 22.4 \\
\hline Wheelbarrow & 61.6 & 55.5 & 39.1 & 59.1 \\
\hline Wheelbarrow & 39.9 & 40.9 & 58.0 & 48.4 \\
\hline Wheelbarrow & 62.6 & 49.5 & 60.5 & 58.4 \\
\hline Wheelbarrow & 41.3 & 41.6 & 32.7 & 32.7 \\
\hline Wheelbarrow & 68.7 & 72.2 & 74.4 & 72.6 \\
\hline Wheelbarrow & 58.7 & 71.2 & 72.6 & 71.9 \\
\hline \multicolumn{1}{|c|}{$\mathbf{n}$} & 36 & 36 & 36 & 36 \\
\hline \multicolumn{1}{|c|}{ Average } & 48.6 & 43.9 & 45.8 & 45.6 \\
\hline
\end{tabular}


Table K-1: User Satisfaction Questionnaire Answers (MTR)

\begin{tabular}{|c|c|c|c|c|c|c|c|c|c|c|c|}
\hline Task & Q1 & Q2 & Q3 & $\overline{Q 4}$ & Q5 & $\overline{Q 6}$ & Q7 & Q8 & Q9 & Q10 & Q11 \\
\hline Confined Space & 3.0 & 3.0 & 3.0 & 3.0 & 3.0 & 3.0 & 4.0 & 2.0 & 3.0 & 3.0 & 3.0 \\
\hline Confined Space & 3.0 & 3.0 & 3.0 & 3.0 & 3.0 & 2.0 & 5.0 & 3.0 & 3.0 & 3.0 & 3.0 \\
\hline Confined Space & 4.0 & 3.0 & 3.0 & 1.0 & 4.0 & 2.0 & NA & 4.0 & 4.0 & $\mathrm{NA}$ & NA \\
\hline Confined Space & 3.0 & 3.0 & 5.0 & 2.0 & 5.0 & 1.0 & 5.0 & 5.0 & 5.0 & 5.0 & 5.0 \\
\hline Confined Space & 3.0 & 3.0 & 3.0 & 3.0 & 4.0 & 3.0 & 5.0 & 3.0 & 3.0 & 5.0 & 4.0 \\
\hline Confined Space & 4.0 & 4.0 & 3.0 & 2.0 & 5.0 & 2.0 & 5.0 & 5.0 & 5.0 & 5.0 & 5.0 \\
\hline Confined Space & 4.0 & 4.0 & 5.0 & 4.0 & 4.0 & 4.0 & 3.0 & 4.0 & 5.0 & 5.0 & 5.0 \\
\hline Confined Space & 3.0 & 4.0 & 4.0 & 2.0 & 4.0 & 3.0 & 5.0 & 3.0 & NA & 5.0 & 5.0 \\
\hline Confined Space & 3.0 & 3.0 & 3.0 & 3.0 & 5.0 & 3.0 & 5.0 & 4.0 & 5.0 & 5.0 & 5.0 \\
\hline Confined Space & 4.0 & 5.0 & 5.0 & 2.0 & 4.0 & 2.0 & 5.0 & 4.0 & 5.0 & 5.0 & 5.0 \\
\hline Confined Space & 5.0 & 5.0 & 5.0 & 3.0 & 5.0 & 3.0 & 5.0 & 5.0 & 5.0 & 5.0 & 5.0 \\
\hline Confined Space & 3.0 & 3.0 & 4.0 & 3.0 & 4.0 & 3.0 & 5.0 & 3.0 & 4.0 & 4.0 & 3.0 \\
\hline Confined Space & 4.0 & 4.0 & 3.0 & 2.0 & 4.0 & 2.0 & 5.0 & 4.0 & 4.0 & 5.0 & 4.0 \\
\hline Confined Space & 4.5 & 4.0 & 4.0 & 3.5 & 5.0 & 3.5 & 5.0 & 4.5 & 4.5 & 5.0 & 5.0 \\
\hline Confined Space & 4.0 & 4.0 & 5.0 & 2.0 & 4.0 & 2.0 & 5.0 & 4.0 & 4.0 & 4.0 & 4.0 \\
\hline Pit & 3.0 & 3.0 & 3.0 & 3.0 & 5.0 & 2.0 & 5.0 & 3.0 & 2.0 & 5.0 & 5.0 \\
\hline$\overline{\text { Pit }}$ & 2.0 & 3.0 & 3.0 & 2.0 & 4.0 & 3.0 & NA & $\mathrm{NA}$ & 4.0 & 4.0 & 4.0 \\
\hline Pit & 4.0 & 4.0 & 5.0 & 4.0 & 4.0 & 4.0 & 5.0 & 5.0 & 5.0 & 5.0 & 5.0 \\
\hline Pit & 5.0 & 5.0 & 5.0 & 3.0 & 5.0 & 4.0 & 5.0 & 4.0 & 5.0 & 5.0 & 5.0 \\
\hline Pit & 4.0 & 5.0 & 5.0 & 2.0 & 5.0 & 3.0 & 5.0 & 5.0 & 5.0 & 5.0 & 5.0 \\
\hline Pit & 5.0 & 5.0 & 5.0 & 5.0 & 5.0 & 5.0 & 5.0 & 5.0 & 5.0 & 5.0 & 5.0 \\
\hline Pit & 4.0 & 4.0 & 3.0 & 2.0 & 4.0 & 2.0 & 5.0 & 4.0 & 4.0 & 5.0 & 5.0 \\
\hline Pit & 4.0 & 4.0 & 3.0 & 4.0 & 5.0 & 4.0 & 5.0 & 4.0 & 4.0 & 5.0 & 5.0 \\
\hline Pit & 4.0 & 4.0 & 5.0 & 3.0 & 5.0 & 4.0 & 2.0 & 4.0 & 5.0 & 5.0 & 5.0 \\
\hline Pit & 4.0 & 5.0 & 5.0 & 3.0 & 5.0 & 3.0 & 5.0 & 5.0 & 5.0 & 5.0 & 5.0 \\
\hline Pit & 3.0 & 3.0 & 3.0 & 3.0 & 3.0 & 3.0 & 3.0 & 3.0 & 3.0 & 3.0 & 3.0 \\
\hline Pit & 3.0 & 4.0 & 4.0 & 2.0 & 5.0 & 3.0 & 5.0 & 3.0 & 4.0 & 4.0 & 4.0 \\
\hline Pit & 4.0 & 4.0 & 3.0 & 3.0 & 5.0 & 2.0 & 5.0 & 4.0 & 5.0 & 5.0 & 5.0 \\
\hline Pit & 5.0 & 5.0 & 5.0 & 4.0 & 4.0 & 3.0 & 5.0 & 5.0 & 4.0 & 4.0 & 4.0 \\
\hline Wheelbarrow & 3.0 & 3.0 & 4.0 & 3.0 & 3.0 & 4.0 & 3.0 & 4.0 & 3.0 & 3.0 & 3.0 \\
\hline Wheelbarrow & 3.0 & 3.0 & 3.0 & 2.0 & 4.0 & 2.0 & 4.0 & 2.0 & 4.0 & 4.0 & 4.0 \\
\hline Wheelbarrow & 4.0 & 4.0 & 5.0 & 1.0 & 5.0 & 1.0 & 5.0 & 5.0 & 4.0 & 5.0 & NA \\
\hline Wheelbarrow & 3.0 & 3.0 & 3.0 & 3.0 & 5.0 & 3.0 & 5.0 & 3.0 & 3.0 & 5.0 & 5.0 \\
\hline Wheelbarrow & 4.0 & 5.0 & 5.0 & 1.0 & 5.0 & 2.0 & 4.0 & 5.0 & 5.0 & 5.0 & 5.0 \\
\hline Wheelbarrow & 4.0 & 4.0 & 4.0 & 4.0 & 4.0 & 4.0 & 4.0 & 4.0 & 4.0 & 4.0 & 4.0 \\
\hline Wheelbarrow & 3.0 & 4.0 & 4.0 & 3.0 & 4.0 & 3.0 & 5.0 & 3.0 & 3.0 & 5.0 & 5.0 \\
\hline Wheelbarrow & 4.0 & 3.0 & 4.0 & 3.0 & 4.0 & 2.0 & 5.0 & 3.0 & 4.0 & 5.0 & 5.0 \\
\hline Wheelbarrow & 4.0 & 4.0 & 4.0 & 3.0 & 4.0 & 2.0 & 5.0 & 4.0 & 4.0 & 5.0 & 5.0 \\
\hline Wheelbarrow & 5.0 & 5.0 & 5.0 & 3.0 & 5.0 & 5.0 & 5.0 & 5.0 & 5.0 & 5.0 & 5.0 \\
\hline Wheelbarrow & 5.0 & 5.0 & 5.0 & 3.0 & 5.0 & 4.0 & 5.0 & 5.0 & 5.0 & 5.0 & 5.0 \\
\hline Wheelbarrow & 3.0 & 3.0 & 3.0 & 3.0 & 3.0 & 3.0 & 4.0 & 4.0 & 4.0 & 4.0 & 3.0 \\
\hline Wheelbarrow & 4.0 & 4.0 & 3.0 & 1.0 & 4.0 & 1.0 & 5.0 & 3.0 & 4.0 & 4.0 & 3.0 \\
\hline Wheelbarrow & 4.5 & 4.5 & 4.0 & 4.0 & 5.0 & 4.0 & 5.0 & 5.0 & 5.0 & 5.0 & 5.0 \\
\hline Wheelbarrow & 4.0 & 5.0 & 5.0 & 3.0 & 4.0 & 2.0 & 5.0 & 4.0 & 4.0 & 3.0 & 3.0 \\
\hline $\mathrm{n}$ & 44 & 44 & 44 & 44 & 44 & 44 & 44 & 44 & 44 & 44 & 44 \\
\hline Average & 3.8 & 3.9 & 4.0 & 2.8 & 4.3 & 2.9 & 4.7 & 4.0 & 4.2 & 4.6 & 4.4 \\
\hline
\end{tabular}


Table K-2: User Satisfaction Questionnaire Answers (PVC)

\begin{tabular}{|c|c|c|c|c|c|c|c|c|c|c|c|}
\hline Task & $\overline{\text { Q1 }}$ & Q2 & $\overline{Q 3}$ & $\overline{Q 4}$ & Q5 & $\overline{Q 6}$ & Q7 & $Q 88$ & Q9 & Q10 & $\overline{\text { Q11 }}$ \\
\hline Confined Space & 4.0 & 4.0 & 4.0 & 3.0 & 3.0 & 3.0 & 4.0 & 3.0 & 3.0 & 3.0 & 3.0 \\
\hline Confined Space & 4.0 & 4.0 & 4.0 & 2.0 & 4.0 & 2.0 & NA & 4.0 & 4.0 & 5.0 & 5.0 \\
\hline Confined Space & 5.0 & 5.0 & 5.0 & 1.0 & 5.0 & 1.0 & 5.0 & 2.0 & 3.0 & 5.0 & 5.0 \\
\hline Confined Space & 3.0 & 3.0 & 2.0 & 3.0 & 3.0 & 3.0 & 3.0 & 3.0 & 3.0 & 3.0 & 3.0 \\
\hline Confined Space & 1.0 & 2.0 & 5.0 & 1.0 & 5.0 & 3.0 & 5.0 & 2.0 & 5.0 & 5.0 & 5.0 \\
\hline Confined Space & 4.0 & 4.0 & 4.0 & 3.0 & 4.0 & 4.0 & 4.0 & 3.0 & 4.0 & 5.0 & 4.0 \\
\hline Confined Space & 3.0 & 3.0 & 2.0 & 1.0 & 5.0 & 2.0 & 5.0 & 3.0 & 3.0 & 4.0 & 4.0 \\
\hline Confined Space & 5.0 & 2.0 & 2.0 & 1.0 & 4.0 & 1.0 & 5.0 & 2.0 & 2.0 & 3.0 & 3.0 \\
\hline Confined Space & 3.0 & 4.0 & 2.0 & 1.0 & 5.0 & 2.0 & 3.0 & 4.0 & 4.0 & 4.0 & 4.0 \\
\hline Confined Space & 2.0 & 2.0 & 2.0 & 2.0 & 3.0 & 2.0 & 5.0 & 3.0 & 3.0 & 3.0 & 4.0 \\
\hline Confined Space & 3.0 & 3.0 & 3.0 & 1.0 & 4.0 & 1.0 & 5.0 & 3.0 & 3.0 & 4.0 & 4.0 \\
\hline Confined Space & 3.0 & 3.0 & 2.0 & 2.0 & 5.0 & 2.0 & 5.0 & 3.0 & 3.0 & 5.0 & 5.0 \\
\hline Confined Space & 5.0 & 5.0 & 3.0 & 2.0 & 4.0 & 3.0 & 5.0 & 5.0 & 5.0 & 5.0 & 5.0 \\
\hline Confined Space & 4.0 & 5.0 & 4.0 & 3.0 & 4.0 & 2.0 & 5.0 & 4.0 & 4.0 & 4.0 & 4.0 \\
\hline Confined Space & 2.0 & 3.0 & 2.0 & 2.0 & 3.0 & 2.0 & 5.0 & 3.0 & 3.0 & 3.0 & 2.0 \\
\hline Confined Space & 4.0 & 4.0 & 3.0 & 2.0 & 4.0 & 2.0 & 5.0 & 4.0 & 5.0 & 5.0 & 4.0 \\
\hline Confined Space & 3.0 & 3.0 & 4.0 & 3.0 & 3.0 & 3.0 & 5.0 & 3.0 & 4.0 & 4.0 & 4.0 \\
\hline Confined Space & 4.5 & 4.0 & 4.0 & 1.0 & 5.0 & 2.5 & 5.0 & 5.0 & 4.5 & 5.0 & 5.0 \\
\hline Pit & 4.0 & 3.0 & 3.0 & 3.0 & 3.0 & 3.0 & 4.0 & 3.0 & 4.0 & 3.0 & 3.0 \\
\hline Pit & 4.0 & 4.0 & 4.0 & 3.0 & 5.0 & 3.0 & NA & 5.0 & 5.0 & 5.0 & 5.0 \\
\hline Pit & 5.0 & 4.5 & 5.0 & 2.5 & 5.0 & 2.0 & 5.0 & 5.0 & 5.0 & 5.0 & 5.0 \\
\hline Pit & 3.0 & 3.0 & 3.0 & 3.0 & 3.0 & 3.0 & 4.0 & 3.0 & 3.0 & 3.0 & 3.0 \\
\hline Pit & 3.0 & 3.0 & 2.0 & 1.0 & 4.0 & 2.0 & 5.0 & 3.0 & 3.0 & 4.0 & 5.0 \\
\hline Pit & 4.0 & 4.0 & 2.0 & 1.0 & 5.0 & 2.0 & 4.0 & 5.0 & 5.0 & 5.0 & 5.0 \\
\hline Pit & 3.0 & 3.0 & 3.0 & 3.0 & 4.0 & 1.0 & 5.0 & 3.0 & 3.0 & 4.0 & 3.0 \\
\hline Pit & 2.0 & 3.0 & 3.0 & 1.0 & 4.0 & 1.0 & 5.0 & 3.0 & 3.0 & 5.0 & 5.0 \\
\hline Pit & 3.0 & 2.0 & 2.0 & 2.0 & 5.0 & 2.0 & 5.0 & 3.0 & 5.0 & 5.0 & 5.0 \\
\hline Pit & 4.0 & 4.0 & 4.0 & 3.0 & 4.0 & 3.0 & 5.0 & 4.0 & 4.0 & 4.0 & 4.0 \\
\hline Pit & 2.0 & 2.0 & 2.0 & 2.0 & 3.0 & 2.0 & 5.0 & 3.0 & 3.0 & 3.0 & 3.0 \\
\hline Pit & 4.0 & 3.0 & 2.0 & 2.0 & 4.0 & 2.0 & 5.0 & 3.0 & 4.0 & 4.0 & 3.0 \\
\hline Pit & 5.0 & 5.0 & 5.0 & 4.0 & 5.0 & 40 & 5.0 & 5.0 & 5.0 & 5.0 & 5.0 \\
\hline Pit & 4.5 & 4.5 & 4.0 & 3.0 & 5.0 & 3.5 & 5.0 & 4.5 & 5.0 & 5.0 & 5.0 \\
\hline Wheelbarrow & 4.0 & 3.0 & 3.0 & 4.0 & 3.0 & 2.0 & 3.0 & 3.0 & 2.0 & 3.0 & 3.0 \\
\hline Wheelbarrow & 4.0 & 4.0 & 4.0 & 2.0 & 5.0 & 2.0 & NA & 4.0 & 4.0 & 5.0 & 5.0 \\
\hline Wheelbarrow & 5.0 & 4.5 & 5.0 & 2.5 & 5.0 & 2.5 & 5.0 & 3.0 & 5.0 & 3.0 & 3.0 \\
\hline Wheelbarrow & 3.0 & 3.0 & 3.0 & 3.0 & 2.0 & 3.0 & 3.0 & 3.0 & 3.0 & 3.0 & 3.0 \\
\hline Wheelbarrow & 3.0 & 3.0 & 2.0 & 2.0 & 4.0 & 2.0 & 5.0 & 3.0 & 3.0 & 4.0 & 4.0 \\
\hline Whe & 5.0 & 2.0 & 3.0 & 1.0 & 5.0 & 1.0 & 5.0 & 4.0 & 4.0 & 5.0 & 5.0 \\
\hline Whee & 2.0 & 2.0 & 2.0 & 2.0 & 3.0 & 1.0 & 5.0 & 3.0 & 4.0 & 3.0 & 3.0 \\
\hline Whec & 2.0 & 3.0 & 2.0 & 1.0 & 4.0 & 1.0 & 5.0 & 3.0 & 3.0 & 4.0 & 4.0 \\
\hline Whee & 3.0 & 3.0 & 2.0 & 2.0 & 4.0 & 2.0 & 5.0 & 3.0 & 3.0 & 5.0 & 5.0 \\
\hline Wheelbarrow & 3.0 & 3.0 & 3.0 & 2.0 & 4.0 & 2.0 & 5.0 & 4.0 & 4.0 & 4.0 & 4.0 \\
\hline Wheelbarrow & 3.0 & 5.0 & 4.0 & 3.0 & 5.0 & 4.0 & 5.0 & 5.0 & 5.0 & 5.0 & 5.0 \\
\hline Wheelbarrow & 2.0 & 2.0 & 1.0 & 2.0 & 2.0 & 2.0 & 5.0 & 3.0 & 3.0 & 3.0 & 20 \\
\hline Wheelbarrow & 3.0 & 3.0 & 2.0 & 2.0 & 4.0 & 2.0 & 5.0 & 4.0 & 4.0 & 4.0 & 4.0 \\
\hline Wheelbarrow & 3.0 & 3.0 & 4.0 & 20 & 4.0 & 2.0 & 5.0 & 4.0 & 1.0 & 4.0 & 4.0 \\
\hline Wheelbarrow & 4.0 & 4.0 & 5.0 & 3.0 & 5.0 & 4.0 & 5.0 & 5.0 & 5.0 & 5.0 & 5.0 \\
\hline Wheelbarrow & 4.5 & 4.5 & 3.5 & 3.5 & 5.0 & 3.0 & 5.0 & 4.5 & 5.0 & 5.0 & 5.0 \\
\hline n & 48 & 48 & 48 & 48 & 48 & 48 & 48 & 48 & 48 & 48 & 48 \\
\hline Average & 3.5 & 3.4 & 3.1 & 2.2 & 4.1 & 2.3 & 4.7 & 3.5 & 3.8 & 4.2 & 4.1 \\
\hline
\end{tabular}


Table K-3: User Satisfaction Questionnaire Answers (Tyvek®)

\begin{tabular}{|c|c|c|c|c|c|c|c|c|c|c|c|}
\hline Task & Q1 & Q2 & Q3 & Q4 & Q5 & Q6 & Q7 & Q8 & Q9 & Q10 & Q11 \\
\hline Confined Space & 3.0 & 3.0 & 3.0 & 2.0 & 2.0 & 2.0 & 3.0 & 3.0 & 3.0 & 3.0 & 3.0 \\
\hline Confined Space & 4.0 & 4.0 & 4.0 & 2.0 & 4.0 & 3.0 & NA & 4.0 & 5.0 & 5.0 & 5.0 \\
\hline Confined Space & 5.0 & 4.0 & 5.0 & 3.0 & 5.0 & 4.0 & 5.0 & 4.0 & 5.0 & 5.0 & 5.0 \\
\hline Confined Space & 4.0 & 3.0 & 4.0 & 4.0 & 5.0 & 4.0 & 5.0 & 3.0 & 4.0 & 5.0 & 5.0 \\
\hline Confined Space & 5.0 & 5.0 & 5.0 & 3.0 & 5.0 & 5.0 & 2.0 & 5.0 & 5.0 & 5.0 & 5.0 \\
\hline Confined Space & 5.0 & 5.0 & 5.0 & 5.0 & 5.0 & 3.0 & 5.0 & 5.0 & 4.0 & 5.0 & 5.0 \\
\hline Confined Space & 4.0 & 4.0 & 5.0 & 3.0 & 5.0 & 3.0 & 5.0 & 4.0 & 4.0 & 5.0 & 5.0 \\
\hline Confined Space & 5.0 & 5.0 & 5.0 & 4.0 & 5.0 & 5.0 & 5.0 & 5.0 & 5.0 & 5.0 & 5.0 \\
\hline Confined Space & 5.0 & 4.0 & 5.0 & 3.0 & 5.0 & 3.0 & 5.0 & 5.0 & 5.0 & 5.0 & 5.0 \\
\hline Confined Space & 5.0 & 5.0 & 5.0 & 3.0 & 5.0 & 3.0 & 5.0 & 5.0 & 5.0 & 5.0 & 5.0 \\
\hline Confined Space & 3.0 & 3.0 & 3.0 & 3.0 & 3.0 & 3.0 & 4.0 & 3.0 & 4.0 & 3.0 & 3.0 \\
\hline Confined Space & 4.0 & 4.0 & 5.0 & 3.0 & 5.0 & 3.0 & 5.0 & 5.0 & 5.0 & 5.0 & 5.0 \\
\hline Confined Space & 4.0 & 4.0 & 5.0 & 3.0 & 3.0 & 2.0 & 5.0 & 4.0 & 4.0 & 4.0 & 4.0 \\
\hline Confined Space & 5.0 & 4.0 & 5.0 & 4.0 & 5.0 & 3.0 & 5.0 & 4.5 & 5.0 & 5.0 & 5.0 \\
\hline Pit & 3.0 & 3.0 & 4.0 & 4.0 & 3.0 & 3.0 & 3.0 & 3.0 & 3.0 & 3.0 & 3.0 \\
\hline Pit & 4.0 & 4.0 & 4.0 & 3.0 & 4.0 & 3.0 & NA & 4.0 & 5.0 & NA & $\mathrm{NA}$ \\
\hline Pit & 5.0 & 5.0 & 5.0 & 3.0 & 5.0 & 4.0 & 5.0 & 5.0 & 5.0 & 5.0 & 5.0 \\
\hline Pit & 5.0 & 5.0 & 3.0 & 3.0 & 5.0 & 3.0 & 5.0 & 5.0 & 5.0 & 5.0 & 5.0 \\
\hline Pit & 5.0 & 4.0 & 5.0 & 3.0 & 5.0 & 4.0 & 5.0 & 4.0 & 5.0 & 5.0 & 4.0 \\
\hline Pit & 4.0 & 4.0 & 4.0 & 4.0 & 4.0 & 3.0 & 5.0 & 3.0 & 5.0 & 5.0 & 5.0 \\
\hline Pit & 4.0 & 3.0 & 5.0 & 3.0 & 5.0 & 4.0 & 5.0 & 3.0 & 5.0 & 5.0 & 4.0 \\
\hline Pit & 5.0 & 5.0 & 5.0 & 3.0 & 5.0 & 4.0 & 4.0 & 5.0 & 5.0 & 5.0 & 5.0 \\
\hline Pit & 4.0 & 4.0 & 2.0 & 5.0 & 4.0 & 5.0 & 5.0 & 5.0 & 5.0 & 5.0 & 4.0 \\
\hline Pit & 4.0 & 4.0 & 5.0 & 4.0 & 4.0 & 4.0 & 5.0 & 5.0 & 5.0 & 5.0 & 5.0 \\
\hline Pit & 4.0 & 3.0 & 3.0 & 4.0 & 3.0 & 5.0 & 5.0 & 3.0 & 5.0 & 5.0 & 5.0 \\
\hline Pit & 4.0 & 5.0 & 5.0 & 4.0 & 5.0 & 4.0 & 5.0 & 4.0 & 4.0 & 5.0 & 5.0 \\
\hline Pit & 5.0 & 5.0 & 5.0 & 3.0 & 5.0 & 4.0 & 5.0 & 5.0 & 5.0 & 5.0 & 5.0 \\
\hline Pit & 4.0 & 3.0 & 3.0 & 3.0 & NA & NA & NA & NA & NA & NA & NA \\
\hline Pit & 5.0 & 4.0 & 5.0 & 4.0 & 4.0 & 4.0 & 5.0 & 5.0 & 5.0 & 5.0 & 4.0 \\
\hline$\overline{\text { Pit }}$ & 4.0 & 4.0 & 5.0 & 4.0 & 4.0 & 3.0 & 5.0 & 4.0 & 5.0 & 3.0 & 3.0 \\
\hline Pit & 5.0 & 5.0 & 5.0 & 4.0 & 5.0 & 5.0 & 5.0 & 5.0 & 5.0 & 5.0 & 5.0 \\
\hline Pit & 5.0 & 5.0 & 5.0 & 4.0 & 5.0 & 4.5 & 5.0 & 5.0 & 5.0 & 5.0 & 5.0 \\
\hline Wheelbarrow & 2.0 & 4.0 & 4.0 & 2.0 & 3.0 & 2.0 & 4.0 & 3.0 & 3.0 & 2.0 & 3.0 \\
\hline Wheelbarrow & 4.0 & 4.0 & 4.0 & 3.0 & 5.0 & 3.0 & NA & 5.0 & 4.0 & 5.0 & 5.0 \\
\hline Wheelbarrow & 2.0 & 5.0 & 5.0 & 3.0 & $\mathrm{NA}$ & 4.0 & NA & 5.0 & 5.0 & 4.0 & 4.0 \\
\hline Wheelbarrow & 5.0 & 5.0 & 5.0 & 3.0 & 5.0 & 3.0 & 5.0 & 4.5 & 5.0 & 5.0 & 5.0 \\
\hline Wheelbarrow & 4.0 & 4.0 & 4.0 & 3.0 & 5.0 & 3.0 & 5.0 & 3.0 & 4.0 & 5.0 & 5.0 \\
\hline Wheelbarrow & 5.0 & 5.0 & 5.0 & 3.0 & 5.0 & 5.0 & 2.0 & 5.0 & 5.0 & 5.0 & 5.0 \\
\hline Wheelbarrow & 5.0 & 5.0 & 5.0 & 5.0 & 4.0 & 3.0 & 5.0 & 5.0 & 5.0 & 5.0 & 5.0 \\
\hline Wheelbarrow & 4.0 & 4.0 & 5.0 & 3.0 & 5.0 & 3.0 & 5.0 & 4.0 & 4.0 & 5.0 & 5.0 \\
\hline Wheelbarrow & 5.0 & 5.0 & 5.0 & 4.0 & 5.0 & 5.0 & 5.0 & 5.0 & 5.0 & 5.0 & 5.0 \\
\hline Wheelbarrow & 5.0 & 5.0 & 5.0 & 3.0 & 5.0 & 4.0 & 5.0 & 5.0 & 5.0 & NA & NA \\
\hline Wheelbarrow & 5.0 & 5.0 & 5.0 & 3.0 & 5.0 & 4.0 & 5.0 & 5.0 & 5.0 & 5.0 & 5.0 \\
\hline Wheelbarrow & 4.0 & 3.0 & 4.0 & 3.0 & 3.0 & 3.0 & 5.0 & 3.0 & 3.0 & 3.0 & 3.0 \\
\hline Wheelbarrow & 4.0 & 4.0 & 5.0 & 3.0 & 3.0 & 3.0 & 5.0 & 4.0 & 5.0 & 2.0 & 2.0 \\
\hline Wheelbarrow & 5.0 & 5.0 & 5.0 & 3.0 & 4.0 & 3.0 & 5.0 & 4.0 & 5.0 & 5.0 & 4.0 \\
\hline Wheelbarrow & 5.0 & 5.0 & 5.0 & 4.0 & 5.0 & 4.0 & 5.0 & 5.0 & 5.0 & 5.0 & 5.0 \\
\hline Wheelbarrow & 5.0 & 5.0 & 5.0 & 3.0 & 5.0 & 3.0 & 5.0 & 5.0 & 5.0 & 5.0 & 5.0 \\
\hline $\bar{n}$ & 48 & 48 & 48 & 48 & 48 & 48 & 48 & 48 & 48 & 48 & 48 \\
\hline Average & 4.4 & 4.3 & 4.5 & 3.4 & 4.4 & 3.6 & 4.7 & 4.3 & 4.6 & 4.6 & 4.5 \\
\hline
\end{tabular}


Table S-MTR: Subjects' core body temperature while wearing MTR suit.

\begin{tabular}{|c|c|c|c|c|c|c|c|c|c|c|c|c|c|c|c|c|c|c|}
\hline \multirow{2}{*}{$\begin{array}{l}\text { Task } \\
\text { Set No. }\end{array}$} & \multirow{2}{*}{\begin{tabular}{|c|} 
Subject \\
No.
\end{tabular}} & \multirow{2}{*}{$\begin{array}{l}\text { Task } \\
\text { Date }\end{array}$} & \multicolumn{3}{|c|}{ Outer Suit } & \multirow{2}{*}{$\begin{array}{l}\text { Task } \\
\text { Pert. }\end{array}$} & \multicolumn{4}{|c|}{ Task Set Data (TSD) } & \multicolumn{4}{|c|}{ TSO: Sult and Task } & \multicolumn{4}{|c|}{ TSD: Suit } \\
\hline & & & Mifr. & Color & Material & & $n$ & AVg. & SD & $\mathrm{CV}$ & $n$ & Avg & SD & CV\% & $\mathrm{n}$ & Avg. & SD & CV/\% \\
\hline$T-14$ & 2 & $8 / 4 \sqrt{20}$ & $\mathrm{KC}$ & Yellow & MTR & Cs & 91 & 37.58 & $\overline{036}$ & 0.95 & \multirow{16}{*}{16} & \multirow{16}{*}{ 37.37 } & \multirow{16}{*}{0.46} & \multirow{16}{*}{1.22} & & \multirow{49}{*}{37.31} & \multirow{49}{*}{0.37} & \\
\hline$T-30$ & 5 & $8 / 4 / 90$ & KC & Yellow & MTR & CS & 142 & 35.82 & 0.25 & 0.71 & & & & & & & & \\
\hline$T-4 t$ & 6 & 8/4/99 & KC & Yellow & MTR & CS & 122 & 37.28 & 0.30 & 0.80 & & & & & & & & \\
\hline$T-49$ & 7 & $8 / 4 / 99$ & KC & Yellow & MTR & CS & 123 & 37.49 & 0.26 & 069 & & & & & & & & \\
\hline$T .59$ & 8 & 89v00 & KC & Yellow & MTR & cs & 142 & 37.43 & 0.10 & 0.26 & & & & & & & & \\
\hline$T-79$ & 12 & $7 / 19 / 99$ & KC & Yellow & MTR & CS & 120 & 27.35 & 0.37 & 0.98 & & & & & & & & \\
\hline$T-93$ & 13 & $8 / 4 / 99$ & KC & Yellow & MTR & CS & 132 & 37.48 & 0.10 & 028 & & & & & & & & \\
\hline$T-96$ & 13 & $6 / 24 / 99$ & KC & Yellow & MTR & CS & 205 & 37.57 & 0.25 & 0.51 & & & & & & & & \\
\hline$T-110$ & 14 & $7 / 28 / 99$ & KC & Yellow & MTR & CS & 148 & 37,10 & 0.22 & 0.60 & & & & & & & & \\
\hline T-114 & 15 & $7 / 19 / 99$ & KC & Yellow & MTR & CS & 154 & 37.40 & 0.38 & 0.96 & & & & & & & & \\
\hline$T-127$ & 17 & $8 / 9,99$ & KC & Yellow & MTR & CS & 62 & 3804 & 0.24 & 0.63 & & & & & & & & \\
\hline$T=145$ & 20 & $7 / 19 / 99$ & KC & Yellaw & MTR & cs & 128 & 37.54 & 0.16 & 0.43 & & & & & & & & \\
\hline$T-172$ & 24 & $7 / 29190$ & KC & Yellaw & MTR & CS & 71 & 37,15 & 0.17 & 0.45 & & & & & & & & \\
\hline$T-180$ & 25 & $8 / 4 / 99$ & $\mathrm{KC}$ & Yellow & MTR & Cs & 113 & 3730 & 0.25 & 0.68 & & & & & & & & \\
\hline$T-185$ & 26 & $7119 / 99$ & KC & Yellow & MTR & cs & 162 & $37 \pi$ & 0.31 & 0.39 & & & & & & & & \\
\hline$T-201$ & 26 & $6 / 24 / 99$ & KC & Yellow & MTR & CS & 147 & 37.53 & 0.31 & 0.83 & & & & & & & & \\
\hline$T-9$ & 7 & $7 / 299$ & $\overline{\mathrm{KC}}$ & Yeliow & MIR & Pit & Iद1 & 3780 & 0.23 & 0.61 & & & & & & & & \\
\hline$T-17$ & 2 & $7 / 29 / 99$ & KC & Yellow & MTR & Pit & 131 & 3702 & 039 & 100 & & & & & & & & \\
\hline$T-41$ & 6 & $8 / 4 / 99$ & KC & Yellow & MTR & Pit & 211 & $37: 39$ & 0.14 & 0.36 & & & & & & & & \\
\hline$T-30$ & 12 & $7 / 19 / 99$ & KC & Yellow & MTR & Pt & 152 & 37.54 & 0.05 & 0.14 & & & & & & & & \\
\hline$T .31$ & 12 & $7 / 12 / 99$ & KC & Yellow & MTR & Pt & 140 & 37,34 & 0.41 & 1.10 & & & & & & & & \\
\hline$T+\infty$ & 13 & $6 / 24 / 99$ & KC & Yellow & MTR & Pit & 149 & 37.21 & 0.11 & 0.31 & & & & & & & & \\
\hline$T-113$ & 14 & $8 / 999$ & KC & Yellow & MTR & Pit & 111 & 37.35 & 0.22 & 0.00 & & & & & & & & \\
\hline$T-115$ & 15 & $7 / 19 / 99$ & KC & Yellow & MTR & Pit & 151 & 37.18 & 0.39 & $1 \infty$ & 16 & 37.31 & 0.26 & 0.69 & & & & \\
\hline$T \cdot 130$ & 17 & $7 / 2 \% 109$ & $\mathrm{KC}$ & Yellow & MTR & Pit & 123 & 37.63 & 0.12 & 0.33 & & & & & 49 & & & 0.99 \\
\hline$T-147$ & 20 & $7 / 1 \% 8$ & KC & Yellow & MTR & Pit & 136 & 37.22 & 0.18 & 0.50 & & & & & & & & \\
\hline$T-160$ & 21 & 8/4/99 & KC & Yellow & MTR & Pit & 120 & 37.69 & 0.22 & 0.59 & & & & & & & & \\
\hline T-163 & 21 & $7 / 29 / 99$ & KC & Yellow & MTR & Pit & 138 & 37.06 & 0.44 & 1.18 & & & & & & & & \\
\hline$T-175$ & 24 & 89/99 & KC & Yellow & MTR & PIt & 139 & 3695 & 0.27 & 0.74 & & & & & & & & \\
\hline$T-196$ & 26 & $7 / 19 / 99$ & KC & Yellow & MTR & Pit & 154 & 37.09 & 0.10 & 0.28 & & & & & & & & \\
\hline$t-190$ & 26 & 7/19/99 & KC & Yellew & MTR & Pit & 159 & 36.98 & 0.28 & 0.78 & & & & & & & & \\
\hline$T-202$ & 26 & $6 / 24 / 99$ & KC & Yellow & MTR & Pit & 131 & 37.43 & 0.35 & 0.93 & & & & & & & & \\
\hline$T=11$ & 2 & $7 / 2999$ & KC & Yellow & MTR & $\overline{W B}$ & 152 & 3737 & 0.08 & 0.20 & & & & & & & & \\
\hline$T-27$ & 5 & $7 / 29,99$ & KC & Yellow & MTR & WB & 37 & 36.05 & 0.27 & 0.75 & & & & & & & & \\
\hline$T-40$ & 6 & $7 / 2999$ & KC & Yellow & MTR & WB & 135 & 36.93 & 0.28 & 0.76 & & & & & & & & \\
\hline$T-46$ & 7 & $7 / 29199$ & KC & Yellow & MTR & WB & 149 & 37.27 & 0.26 & 0.69 & & & & & & & & \\
\hline$T-56$ & 8 & 8/9/99 & KC & Yellow & MTR & WE & 140 & 37.30 & 0.00 & 0.25 & & & & & & & & \\
\hline$T-82$ & 12 & 714999 & KC & Yellow & MTR & WB & 129 & 37,04 & 0.29 & 0.70 & & & & & & & & \\
\hline$T-85$ & 12 & $776 / 99$ & $K C$ & Yellow & MTR & WB & 128 & 37.44 & 0.25 & 0.66 & & & & & & & & \\
\hline T-103: & 13 & $6 / 24 / 99$ & KC & Yellow & NTR & WB & 155 & 37.39 & 0.57 & 1.52 & & & & & & & & \\
\hline$T-97$ & 13 & $7 / 2999$ & $K C$ & Yellow & MTR & WB & 126 & 37.19 & 0.17 & 0.45 & 17 & 37.27 & 0.35 & 0.97 & & & & \\
\hline T-107 & 14 & $8 / 9 / 99$ & $K C$ & Yeliow & MTR & WB & 44 & 37.83 & 0.65 & 1.72 & & & & & & & & \\
\hline$T-138$ & 20 & $7 / 19 / 99$ & KC & Yellow & MTR & WB & 128 & 37.47 & 0.45 & 1.20 & & & & & & & & \\
\hline$T=148$ & 20 & $7 / 19199$ & $K C$ & Yellow & MTR & WB & 132 & 37.33 & 0.56 & 1.51 & & & & & & & & \\
\hline$T-157$ & 21 & $7 / 29199$ & $K C$ & Yellow & MTR & WB & 91 & 37.33 & 0.58 & 1.54 & & & & & & & & \\
\hline$T-177$ & 25 & $7 / 29190$ & KC & Yollow & MTR & WB & 141 & 37.33 & 0.11 & 0.29 & & & & & & & & \\
\hline$T-197$ & 26 & $7 / 19 / 99$ & KC & Yellow & MTR & WB & 123 & 37.77 & 0.19 & 0.52 & & & & & & & & \\
\hline$T-199$ & 26 & $7 / 19 / 99$ & KC & Yellow & MTR & WB & 130 & 37.29 & 0.20 & 054 & & & & & & & & \\
\hline$T+200$ & 26 & $6 / 24199$ & $K C$ & Yellow & MTR & WB & 148 & 37.31 & 0.20 & 0.54 & & & & & & & & \\
\hline
\end{tabular}


Table S-PVC: Subjects' core body temperature while wearing PVC suit.

\begin{tabular}{|c|c|c|c|c|c|c|c|c|c|c|c|c|c|c|c|c|c|c|}
\hline \multirow{2}{*}{$\begin{array}{l}\text { Task } \\
\text { Set No }\end{array}$} & \multirow{2}{*}{$\begin{array}{c}\text { Subject } \\
\text { No. }\end{array}$} & \multirow{2}{*}{$\begin{array}{l}\text { Taski } \\
\text { Dato } \\
\end{array}$} & \multicolumn{3}{|c|}{ Outer Suit } & \multirow{2}{*}{$\begin{array}{l}\text { Task } \\
\text { Perf. } \\
\end{array}$} & \multicolumn{4}{|c|}{ Task Ser Data (TSO) } & \multicolumn{4}{|c|}{ TSD: Suit and Task } & \multicolumn{4}{|c|}{ TSD: Suit } \\
\hline & & & Mifr. & Color & Material & & $\mathrm{n}$ & Avg: & 50 & cves & $n$ & Avg. & SO & CVW & $n$ & Ang. & So & CVX \\
\hline$T-4$ & 1 & $8 / 0199$ & Bata & Gleen & PVC & CS & 165 & 37.48 & 0.13 & 0.35 & \multirow{16}{*}{16} & \multirow{16}{*}{37.36} & \multirow{16}{*}{0.54} & \multirow{16}{*}{1.46} & \multirow{48}{*}{48} & \multirow{48}{*}{37.26} & \multirow{48}{*}{0.49} & \\
\hline$T-12$ & 2 & $7 / 29 / 99$ & Bate & Green & PVC & CS & 123 & 37.32 & 0.45 & 1.21 & & & & & & & & \\
\hline$T-28$ & 5 & $7729 / 99$ & Beta & Green & PUC & CS & 170 & 35.89 & 0.15 & 0.43 & & & & & & & & \\
\hline$T-38$ & 6 & $8 / 4 / 59$ & Bata & Green & PUC & $\operatorname{cs}$ & 112 & 36.59 & 0.72 & 1.95 & & & & & & & & \\
\hline$T-47$ & 7 & $8 / 2 / 99$ & Bata & Green & PVC & $\operatorname{cs}$ & 125 & 37.39 & 0.14 & 0.38 & & & & & & & & \\
\hline$T-\$ T$ & 8 & $8 / 9 / 99$ & Bata & Green & PVO & CS & 127 & 37.57 & 0.30 & 0.81 & & & & & & & & \\
\hline$T-72$ & 12 & 8/16/92 & Bata & Green & PVC & CS & 86 & 37.43 & 0.05 & 0.14 & & & & & & & & \\
\hline$T-86$ & 12 & $7312 / 99$ & Bata & Green & PVC & CS & 130 & 37.41 & 0.16 & 0.43 & & & & & & & & \\
\hline$T-91$ & 13 & $7 / 29 / 99$ & Bata & Green & PVC & CS & 163 & 37.00 & 0.26 & 0.69 & & & & & & & & \\
\hline$T-12 \mathrm{~S}$ & 17 & $8 / 9 / 59$ & Bata & Green & PVC & CS & 140 & 37.75 & 0.23 & 0.61 & & & & & & & & \\
\hline$T-151$ & 20 & $7 / 19 / 90$ & Bata & Green & PVC & CS & 141 & 37.56 & 0.38 & $1.0 t$ & & & & & & & & \\
\hline$T-158$ & 21 & $7 / 29 / 99$ & Bate & Green & PVC & CS & 27 & 38.32 & 0.06 & 0.15 & & & & & & & & \\
\hline$T-166$ & 23 & 8/12/99 & Bata & Green & PVC & CS & 128 & 38.13 & 0.24 & 0,82 & & & & & & & & \\
\hline$T-170$ & 24 & 8/SV99 & Bata & Green & PVC & CS & 144 & 37.46 & 0.25 & $0 . \overline{8}$ & & & & & & & & \\
\hline$T-178$ & 25 & $8 / 2 / 59$ & Bata & Green & PVC & CS & 132 & 37.10 & 0.10 & 0.27 & & & & & & & & \\
\hline$T-185$ & 26 & $7119 / 99$ & Bata & Green & PVC & CS & 167 & 37.44 & 0.29 & 0.79 & & & & & & & & \\
\hline$T-7$ & 1 & 8/9/53 & Bata & Green & PVC & Pit & 1147 & 37.25 & 0.12 & 0.32 & & & & & & & & \\
\hline T. 25 & 2 & $8 / 2 / 99$ & Bata & Green & PVC & Pit & 128 & 37.27 & 0.29 & 0.77 & & & & & & & & \\
\hline$T-31$ & 5 & $7 / 29 / 90$ & Bata & Green & PVC & Pit & 98 & 35.90 & 0.33 & 0,92 & & & & & & & & \\
\hline$T-42$ & 6 & $8 / 4 / 99$ & Bata & Green & PVC & Pit & 145 & 36.73 & 0.38 & 1.03 & & & & & & & & \\
\hline $7-50$ & 7 & $7 / 29 / 99$ & Bata & Green & PVC & Pit & 132 & 37.31 & 0.17 & 0.47 & & & & & & & & \\
\hline$T \in \infty$ & 8 & E/S/99 & Bata & Green & PVC & Pit & 123 & 37.33 & 0.29 & 0.78 & & & & & & & & \\
\hline T.73 & 12 & $8 / 16 / 99$ & Bata & Green & PVC & Pit & 130 & 37.40 & 0.05 & 0.14 & & & & & & & & \\
\hline$T-87$ & 12 & $7119 / 99$ & Bata & Green & PVC & Pit & 164 & 37.43 & 0.03 & 0.08 & 15 & 37.19 & 0.43 & 1.15 & & & & \\
\hline T-94 & 13 & $8 / 2 / 99$ & Bata & Green & PVC & Pit & 359 & 36.92 & 0,03 & 0,09 & & & & & & & & 32 \\
\hline$T-111$ & 14 & $8 / 9 / 99$ & Bata & Green & PVC & Pit & 140 & 37.56 & 0.08 & 0.20 & & & & & & & & \\
\hline$T-128$ & 17 & U/9/99 & Bata & Green & PVC & Pit & 134 & 37.72 & 0.10 & 0.27 & & & & & & & & \\
\hline$T-161$ & 21 & $7 / 28 / 99$ & Bata & Green & PVC & Pit & 165 & 37.15 & 0.10 & 0.27 & & & & & & & & \\
\hline$T-173$ & 24 & $7 / 29 / 99$ & Bata & Green & PVC & Pit & 112 & 36.96 & 0.50 & 1.35 & & & & & & & & \\
\hline$T-181$ & 25 & $7 / 29 / 99$ & Bata & Green & PVC & Pit & 130 & 37.26 & 0.25 & 0.68 & & & & & & & & \\
\hline$T-186$ & 26 & $7 / 19 / 99$ & Bate & Green & PVC & Pit & 150 & 37.59 & 0.14 & 0.37 & & & & & & & & \\
\hline$T+1$ & 1 & $8 / 9 / 99$ & Bata & Green & PVC & WB & 138 & 37.19 & 0.17 & 0.47 & & & & & & & & \\
\hline$T+10$ & 2 & $7 / 29 / 99$ & Bata & Green & PVC & WB & 128 & 37.78 & 0.06 & 0.16 & & & & & & & & \\
\hline$T-26$ : & 5 & $7 / 22 / 99$ & Bata & Green & PVC & WB & 102 & 36.27 & 0.10 & 0.27 & & & & & & & & \\
\hline$T \cdot 36$ & 6 & $8 / 4 / 99$ & Bata & Green & PVC & WB & 56 & 37.10 & 0.49 & 1.32 & & & & & & & & \\
\hline$T-45$ & 7 & $7 / 29 / 99$ & Beta & Green & PVIC & WB & 124 & 37.53 & 0.25 & 0.65 & & & & & & & & \\
\hline$T .54$ & $B$ & $89 / 99$ & Bata & Green & PVC & WB & 122 & 37.86 & 0.09 & 0.75 & & & & & & & & \\
\hline$T-71$ & 12 & $8 / 16 / 99$ & Bata & Green & PVC & WB & 122 & 37.30 & 0.05 & 0.13 & & & & & & & & \\
\hline$T-83$ & 12 & $7 / 19 / 92$ & Bata & Green & PVC & WB & 156 & 37.52 & 0.15 & 0.61 & & & & & & & & \\
\hline$T-8 B$ & 12 & $7 / 19 / 92$ & Bata & Green & PVC & WB & 147 & 37.31 & 0.11 & 0.31 & 17 & 37.22 & 0.47 & 1.27 & & & & \\
\hline$T \cdot 90$ & 13 & $7 / 29 / 99$ & Bata & Gieen & PVC & WB & 154 & 37.49 & 0.05 & 0.14 & & & & & & & & \\
\hline$T-105$ & 14 & $8 / 9 / 99$ & Bato & Green & PVC & WB & 141 & 37.38 & 0.06 & 0.17 & & & & & & & & \\
\hline$T-122$ & 17 & 8/9/99 & Bata & Green & PVC & WB & 135 & 37.30 & 028 & 0.75 & & & & & & & & \\
\hline$T-153$ & 20 & $7 / 12 / 90$ & Bata & Green & PVC & WB & 146 & 37.18 & 0.10 & 0.27 & & & & & & & & \\
\hline$T-155$ & 21 & $7 / 29 / 99$ & Bato & Green & PVC & WB & 118 & 37.42 & 0.15 & 0.40 & & & & & & & & \\
\hline T-167 & 24 & $8 / 9 / 99$ & Bata & Green & PVO & WE & 144 & 37.12 & 0.09 & 0.25 & & & & & & & & \\
\hline$T-176$ & 25 & $7 / 28 / 98$ & Bata & Green & PUC & WB & 34 & 35.87 & 037 & 1.04 & & & & & & & & \\
\hline$T-167$ & 26 & $7 / 19 / 99$ & Bate & Green & PVC & WB & 145 & 37.11 & 0.35 & 0.98 & & & & & & & & \\
\hline
\end{tabular}


Table S-TyvekW: Subjects' core body temperature while wearing Tyveke suit.

\begin{tabular}{|c|c|c|c|c|c|c|c|c|c|c|c|c|c|c|c|c|c|c|}
\hline \multirow{2}{*}{$\begin{array}{l}\text { Taskik } \\
\text { Set No. }\end{array}$} & \multirow{2}{*}{$\begin{array}{c}\text { Subject } \\
\text { No. }\end{array}$} & \multirow{2}{*}{$\begin{array}{l}\text { Task } \\
\text { Date }\end{array}$} & \multicolumn{3}{|c|}{ Outer Sul } & \multirow{2}{*}{$\begin{array}{l}\text { Task } \\
\text { Pert. }\end{array}$} & \multicolumn{4}{|c|}{ Task Set Data (TSD) } & \multicolumn{4}{|c|}{ TSD: Sult and Task } & \multicolumn{4}{|c|}{ TSD: Sult } \\
\hline & & & Mif. & Colos & Material & & n & Avi: & 30 & CVF & $n$ & Avg. & $S D$ & CV\% & $n$ & Avg. & So & $c \sqrt{6}$ \\
\hline T.5 & 1 & $8 / 9 / 99$ & $K C$ & White & Tyreis & CS & 100 & 37.67 & 0.47 & 1.25 & \multirow{16}{*}{16} & \multirow{16}{*}{37.40} & \multirow{16}{*}{0.48} & \multirow{16}{*}{1.30} & & \multirow{50}{*}{37.24} & \multirow{50}{*}{0.45} & \\
\hline$T \cdot 13$ & 2 & $a / 2 / 99$ & KC & White & Tyvelsb & Cs & 90 & 37.39 & 0.04 & 0.12 & & & & & & & & \\
\hline$T-29$ & 5 & $8 / 2 / 99$ & KC & White & Tyveke & $\operatorname{cs}$ & 165 & 38.01 & 0.11 & 0.31 & & & & & & & & \\
\hline$T-30$ & 6 & $8 / 4 / 99$ & KC & White & Tyweids & $\operatorname{cs}$ & 151. & 3728 & 0.10 & 0.27 & & & & & & & & \\
\hline T-4s & 7 & $8 / 4 / 99$ & KC & White & Tyneibs & $\operatorname{cs}$ & 140 & 3742 & 025 & 0.66 & & & & & & & & \\
\hline T.58 & 8 & $8 / 12 / 99$ & $K C$ & White & Tyreks & CS & 116 & 3750 & 028 & 0.74 & & & & & & & & \\
\hline T-89 & 12 & $7 / 19 / 99$ & KC & White & Tyreide & $\operatorname{cs}$ & 154 & a) 35 & 0.54 & 1.45 & & & & & & & & \\
\hline$T-100$ & 13 & $6 / 2499$ & KC & White & Tyveid & CS & 75 & 37.01 & 0.45 & 1.21 & & & & & & & & \\
\hline T. .02 & 13 & $8 / 2 / 90$ & $K C$ & Whits & Tyreks & Cs & 139 & 37.08 & 026 & 0.75 & & & & & & & & \\
\hline$T-100$ & 14 & $8 / 9 / 99$ & $K C$ & Whits & Tyreise & $\operatorname{cs}$ & 120 & 37.35 & 0.07 & 0.20 & & & & & & & & \\
\hline$T-126$ & 17 & $8 / 9 / 99$ & KC & White & Tyvoib & $\operatorname{cs}$ & 105 & 3738 & 0.52 & 138 & & & & & & & & \\
\hline$T-159$ & 21 & $7 / 29 / 99$ & $K C$ & White & Tyveks & Cs & 202 & 37.67 & 0.44 & 1.17 & & & & & & & & \\
\hline$T-171$ & 24 & $8 / 9 / 90$ & KC & White & Tymeise & CS & 123 & 37.47 & 0.37 & 1.00 & & & & & & & & \\
\hline$T-179$ & 25 & $8 / 2199$ & KC & White & Tymek6 & $\operatorname{cs}$ & 135 & 3737 & 0.35 & 0.33 & & & & & & & & \\
\hline$T-188$ & 28 & $7 / 1999$ & KC & White & Tyneks & $\operatorname{cs}$ & 156 & 38.52 & 0.38 & 0.99 & & & & & & & & \\
\hline$T-203$ & 26 & $6 / 24 / 90$ & $\mathrm{KC}$ & White & Tyneido & $\operatorname{cs}$ & 287 & 37.72 & 0.12 & 0.32 & & & & & & & & \\
\hline$T-8$ & 1 & $8 / 9 / 99$ & $\mathrm{KC}$ & White & Tyneiss & Pit & 139 & 37.12 & 0.70 & 0.26 & & & & & & & & \\
\hline$T=16$ & 2 & $8 / 499$ & $K C$ & White & Typeks & Pit & 128 & 37.01 & 0.36 & 098 & & & & & & & & \\
\hline$T-32$ & 5 & $8 / 4 / 90$ & KC & White & Tynelos & Pit & 81 & 36.79 & 0.05 & 0.13 & & & & & & & & \\
\hline T-33 & 5 & $8 / 2 / 99$ & $\mathrm{KC}$ & White & Tymelob & Pit & 132 & 36.31 & 0.16 & 0.44 & & & & & & & & \\
\hline$T-43$ & 6 & $7 / 29 / 99$ & $\mathrm{KC}$ & White & Tyvek & Pit & 113 & 37.13 & 0.50 & 157 & & & & & & & & \\
\hline T.51 & 7 & $7 / 2999$ & KC & White & TyNeisD & Pit & 140 & 37.72 & 0.10 & 0.26 & & & & & & & & \\
\hline T.52 & 7 & 72999 & KC & White & Tyveks & Pit & 114 & 37.13 & 0.58 & 1.55 & & & & & & & & \\
\hline$T-61$ & 8 & $7 / 2899$ & KC & White & Tywekd & Pit & 286 & 38.87 & 0.24 & 0.66 & & & & & & & & \\
\hline$T-101$ & 13 & $6 / 24 / 99$ & KC & White & Tyweice & Pit & 154 & 37.09 & 0.20 & 0.55 & 19 & 3704 & 0.46 & 1.24 & 5 & & & $1 n$ \\
\hline T-SS & 13 & $2 / 4 / 99$ & KC & White & Tywekd & Pit & 124 & 38.75 & 0.17 & 0.86 & 18 & 37.01 & 0.46 & 1.24 & 50 & & & 1.22 \\
\hline$T-98$ & 13 & $7 / 28199$ & $K C$ & White & Tyweks & Pit & 121 & 37.33 & 052 & 3.40 & & & & & & & & \\
\hline$T-112$ & 14 & $8 / 2 / 99$ & KC & White & Tywekb & Pit & 128 & 37.18 & 0.07 & 0.18 & & & & & & & & \\
\hline$T-146$ & 20 & $7 / 19199$ & KC & White & Tywekb & Pit & 157 & 37.12 & 0.10 & 0.28 & & & & & & & & \\
\hline$T-162$ & 21 & $7 / 29 / 99$ & $\mathrm{KC}$ & White & Tywekd & Pit & 130 & 37.26 & 0.18 & 0.49 & & & & & & & & \\
\hline$T-174$ & 24 & $7 / 2999$ & KC & Whito & Tyvekd & Pit & 130 & 37.19 & 0.00 & 0.17 & & & & & & & & \\
\hline$T-182$ & 25 & $7 / 29 / 99$ & KC & White & Tyweks & Pit & 153 & 37.01 & 0.12 & 0.34 & & & & & & & & \\
\hline$T-183$ & 25 & $8 / 2 / 29$ & KC & White & Tywekt & Pit & 134 & 36.90 & 0.00 & 025 & & & & & & & & \\
\hline$T-204$ & 26 & $6 / 24 / 99$ & KC & White & Tyuebe & Pit & $14 t$ & $37.7 \mathrm{a}$ & 0.23 & 0.52 & & & & & & & & \\
\hline$T=2$ & 3 & 81299 & KC & White & Tyueks & WB & 140 & 37.46 & 0.11 & 029 & & & & & & & & \\
\hline T-18 & 2 & $8 / 2 / 99$ & KC & White & Tyuelde & WE & 131 & 37.34 & 0.14 & 0.37 & & & & & & & & \\
\hline$T .36$ & 5 & $8 / 2 / 99$ & KC & White & Tyueko & WE & 147 & 38.70 & 0.32 & 0.38 & & & & & & & & \\
\hline 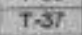 & 8 & $8 / 4 / 99$ & $\mathrm{KC}$ & While & Tyvelde & WB & 140 & 3739 & 0.04 & 0.10 & & & & & & & & \\
\hline$T-53$ & 7 & $8 / 2 / 99$ & KC & White & Tyreko & WE & 137 & 37.11 & 0.05 & 0.15 & & & & & & & & \\
\hline$T<5$ & 8 & 8/9ve9 & KC & White & Tyveks & WB & 137. & 3750 & 0.05 & 0.14 & & & & & & & & \\
\hline$T-102$ & 13 & $6 / 24 / 59$ & KC & White & Tyueko & WB & 147 & 37.52 & 005 & 0,14 & & & & & & & & \\
\hline$T-104$ & 13 & B/2/D2 & KC & White & Tyuelds & WB & 328 & 37.23 & 0.31 & 0.83 & 16 & 37.34 & 0.28 & 0.75 & & & & \\
\hline$T=106$ & 14 & $8 / 9 / 99$ & KC & White & Tyueko & WB & 131 & 37.47 & 0.21 & 0.55 & 16 & 31.34 & 0.20 & 0.75 & & & & \\
\hline$T-123$ & 17 & 8/12/99 & KC & White & Tyvelde & WB & 109 & 37.67 & 0.13 & 0.35 & & & & & & & & \\
\hline$T-1<9$ & 20 & $7 / 1999$ & KC & White & Tyueko & WB & 163 & 37.49 & 0.12 & 0.32 & & & & & & & & \\
\hline$T-154$ & 20 & $7 / 19 / 99$ & KC & White & Tyueke & WB & 37 & 36.93 & 0.06 & 0.09 & & & & & & & & \\
\hline$T-156$ & 21 & $7 / 29 / 99$ & KC & Whits & Tyreite & WE & 87 & 37.69 & 0.21 & 0.57 & & & & & & & & \\
\hline$T-160$ & 24 & $B / O / S A$ & KC & White & Tyreke & WB & 151 & 37,38 & 0.00 & 0.24 & & & & & & & & \\
\hline$T-184$ & 25 & $7 / 29199$ & KC & White & Tyredelo & WB & 135 & 36.95 & 0.06 & 0.17 & & & & & & & & \\
\hline$T-205$ & 26 & $6 / 24 / 90$ & $K C$ & White & Tynebe & WB & $18 ?$ & 37.67 & 020 & 0.54 & & & & & & & & \\
\hline
\end{tabular}


Table S-MTR: Subjects' core body temperature whlle wearing MTR suit.

\begin{tabular}{|c|c|c|c|c|c|c|c|c|c|c|c|c|c|c|c|c|c|c|}
\hline \multirow{2}{*}{$\begin{array}{c}\text { Task: } \\
\text { Set No }\end{array}$} & \multirow{2}{*}{$\begin{array}{c}\text { Subject } \\
\text { No. }\end{array}$} & \multirow{2}{*}{$\begin{array}{l}\text { Task } \\
\text { Date }\end{array}$} & \multicolumn{3}{|c|}{ Outer Suit } & \multirow{2}{*}{$\begin{array}{l}\text { Taskik } \\
\text { Perf. } \\
\end{array}$} & \multicolumn{4}{|c|}{ Task Set Data (ISD) } & \multicolumn{4}{|c|}{ TSD: Suit and Task } & \multicolumn{4}{|c|}{ TSD: Suli } \\
\hline & & & Mefr. & Color & Material & & $n$ & Avg. & so & CVE & $n$ & Ayg. & SD & CV\% & $n$ & Avg & SD & CVh \\
\hline$T-14$ & 2 & $8 / 4 / 99$ & KC & Yellow & MTR & CS & 91 & 37.68 & 0.36 & 095 & \multirow{16}{*}{16} & \multirow{16}{*}{37.37} & \multirow{16}{*}{0.46} & \multirow{16}{*}{1.22} & \multirow{46}{*}{49} & \multirow{49}{*}{37.31} & & \\
\hline$T=30$ & 5 & $8 / 4 / 99$ & KC & Yellow & MTR & cs & 142. & 35.82 & 025 & 0.71 & & & & & & & & \\
\hline$T-41$ & 6 & $8 / 4 / 99$ & $\mathrm{KC}$ & Yellow & MTR & cs & 122 & 3738 & 0.30 & 0.80 & & & & & & & & \\
\hline T.49 & 7 & $8 / 4 / 99$ & KC & Yellow & MTR & cs & 123 & 37.49 & 0.26 & 0.69 & & & & & & & & \\
\hline T. 59 & 8 & 89999 & $\mathrm{KC}$ & Yellow & MTR & cs & 142 & 37.43 & 0.10 & 0.26 & & & & & & & & \\
\hline$T-79$ & 12 & $7 / 19 \mathrm{~s} 99$ & KC & Yellow & MTR & cs & 128 & 37.35 & 0.37 & 0.98 & & & & & & & & \\
\hline$T-93$ & 13 & $8 / 4 / 99$ & KC & Yellow & MTR & Cs & 132 & 37.48 & 0.10 & 0.28 & & & & & & & & \\
\hline$T-98$ & 13 & $6 / 24 / 99$ & $\mathrm{KC}$ & Yellow & MTR & Cs & 205 & 37.57 & 0.25 & 0.67 & & & & & & & & \\
\hline$T-110$ & 14 & $7 / 28 / 09$ & $\mathrm{KC}$ & Yeliow & MTR & $\operatorname{cs}$ & 143 & 37.10 & 0.22 & 0.60 & & & & & & & & \\
\hline$T-114$ & 15 & $7 / 19 / 99$ & KC & Yellow & MTR & $\operatorname{cs}$ & 154 & 37.40 & 0.36 & 0.96 & & & & & & & & \\
\hline$T \cdot 127$ & 17 & $8 / 9 / 99$ & $\mathrm{KC}$ & Yellow & MTR & cs & 62 & 38.04 & 0.24 & 0.63 & & & & & & & & \\
\hline $7-145$ & 20 & $7 / 19199$ & KC & Yellow & MTR & CS & 128 & 37.64 & 0.16 & 0.43 & & & & & & & & \\
\hline $\mathrm{T} \cdot 172$ & 24 & 7/29:99 & KC & Yellow & MTR & cs & 71 & 37.18 & 0.17 & 0.45 & & & & & & & & \\
\hline T. 180 & 25 & $8 / 499$ & KC & Yellow & MTR & CS & 113 & 37.30 & 025 & 0.69 & & & & & & & & \\
\hline T.195 & 26 & $7 / 1999$ & KC & Yellaw & MTR & $\operatorname{cs}$ & 162 & $37 . \pi$ & 0.31 & 0.83 & & & & & & & & \\
\hline$T-201$ & 26 & $6 / 24 / 99$ & KC & Yellow & MTR & CS & 147 & 37.53 & 031 & 0.83 & & & & & & & & \\
\hline$T-9$ & 1 & $7 / 2969$ & $\mathrm{KC}$ & Yelow & MTR & Pit: & 141 & 37.80 & 0.23 & 0.61 & & & & & & & & \\
\hline$T=17$ & 2 & $7 / 2999$ & $\mathrm{KC}$ & Yellow & MTR & Pit & 131 & 37.02 & 0.39 & 1.08 & & & & & & & & \\
\hline$T-44$ & 6 & $8 / 4 / 59$ & $\mathrm{KC}$ & Yellow & MTR & Pit & 211 & 37.39 & 0.14 & 0.36 & & & & & & & & \\
\hline$T-80$ & 12 & $7 / 1989$ & KC & Yellow & MTR & $\mathrm{Pht}$ & 152 & 37.54 & 0.05 & 0.14 & & & & & & & & \\
\hline$T-81$ & 12 & $7 / 19 / 99$ & KC & Yellow & MTR & Pit & 140 & 37.34 & 0.41 & 1.10 & & & & & & & & \\
\hline T.99 & 13 & $6 / 24 / 99$ & KC & Yellow & MTR & Pit & 149 & 37.21 & 0.11 & 0.31 & & & & & & & & \\
\hline$T-113$ & 14 & $8 / 9 / 99$ & $K C$ & Yellow: & MTR & Pit & 111 & 37.35 & 0.22 & 0.60 & & & & & & & & \\
\hline$T-115$ & 15 & $7 / 19999$ & KC & Yellow & MTR & Pit & 151 & 37.18 & 0.39 & 1.06 & 16 & 37.31 & 0.26 & 0.69 & & & & \\
\hline$T-130$ & 17 & $7 / 2999$ & KC & Yellow & MTR & Pit & 123 & 37.63 & 0.12 & 0.33 & & & & & & & 0.37 & 0.99 \\
\hline$T-147$ & 20 & $7 / 1999$ & $K C$ & Yellaw & MTR & Pit & 136 & 37.22 & Q 19. & 0.50 & & & & & & & & \\
\hline$T-160$ & 21 & $8 / 4 / 99$ & $\mathrm{KC}$ & Yellow & MTR & Pit & 120 & 37.69 & 0.22 & 0.50 & & & & & & & & \\
\hline$T-163$ & 21 & $7 / 29199$ & KC & Yolow & MTR & Pt & 138 & 37.05 & 0.44 & 1.18 & & & & & & & & \\
\hline T-175 & 24 & 88899 & KC & Yellow & MTR & P: & 139 & 36.95 & 0.27 & 0.74 & & & & & & & & \\
\hline$T-196$ & 26 & $7 / 19 / 99$ & KC & Vellow & MTR & $P_{R}$ & 154 & 37.09 & 0.10 & 0.28 & & & & & & & & \\
\hline$T-190$ & 26 & $7 / 19 / 99$ & $\mathrm{KC}$ & Yellow & MTR & Pit & 159 & 36.96 & 0.28 & 0.76 & & & & & & & & \\
\hline$T-202$ & 26 & $6 / 24 / 99$ & KC & Yellow & MTR & Pit & 135 & 37.43 & 0.35 & 0.93 & & & & & & & & \\
\hline$T-11$ & 2 & $7 / 29 / 99$ & $\mathrm{KC}$ & Yeliow & MTR & WB & 152 & 37.37 & 0.08 & 020 & & & & & & & & \\
\hline$T-27$ & 5 & $7 / 29 / 99$ & $\mathrm{KC}$ & Yellow & MTR & WB & 37 & 36.05 & 0.27 & 0.75 & & & & & & & & \\
\hline$T-40$ & 6 & $7 / 29199$ & KC & Yellow & MTR & WB & 135 & 36.99 & 0.28 & 0.76 & & & & & & & & \\
\hline$T-46$ & 7 & $7 / 28199$ & KC & Yellow & MTR & WB & 149 & 37.27 & 0.26 & 0.69 & & & & & & & & \\
\hline T.56 & 8 & $8 / 9 / 99$ & KC & Yellow & MTR & WB & 140 & 3739 & 0.09 & 0.25 & & & & & & & & \\
\hline$T-02$ & 12 & 711999 & KC & Yellow & MTR & WB & 129 & 37.04 & 0.29 & 0.79 & & & & & & & & \\
\hline$T-85$ & 12 & 76199 & $\mathrm{KC}$ & Yollow & MTR & WE & 128 & 37.44 & 0.25 & 006 & & & & & & & & \\
\hline$T=103$ & 13 & $6 / 24 / 99$ & KC & Yellew & MTR & WB & 155 & 37.39 & 0.57 & 152 & & & & & & & & \\
\hline$T-97$ & 13 & $7129 / 99$ & $\mathrm{KC}$ & Yellow & MTR & WB & 126 & 37.19 & 0.17 & 0.45 & 17 & 37.27 & 036 & 0.97 & & & & \\
\hline$T-107$ & 14 & $8 / 9199$ & $\mathrm{KC}$ & Yellow & MTR & We & 44 & 37.68 & 0.65 & 1.72 & & & & & & & & \\
\hline $\mid-138$ & 20 & $7 / 19 / 99$ & KC & Yellow & MTR & WB & 128 & 37.47 & 0.45 & 120 & & & & & & & & \\
\hline$T=148$ & 20 & $7119 / 99$ & KC & Yellow & MTR & WB & 132 & 37.33 & 0.56 & 1.51 & & & & & & & & \\
\hline$T=157$ & 21 & $7 / 29 / 99$ & KC & Yellow & MTR & WB & 91 & 37.33 & 0.58 & 1.54 & & & & & & & & \\
\hline$T \cdot 177$ & 25 & $7 / 29 / 99$ & KC & Yellow & MTR & WB & 141 & 37.33 & 0.11 & 029 & & & & & & & & \\
\hline T. +97 & 26 & $7 / 19 / 99$ & KC & Yellow & MTR & WB & 123 & $37 . \pi$ & 0.19 & 0.52 & & & & & & & & \\
\hline$T-199$ & 26 & $7 / 19 / 99$ & $\mathrm{KC}$ & Yellow & MTR & WB & 130 & 37.29 & 020 & 0.54 & & & & & & & & \\
\hline$T-200$ & 26 & $6 / 24 / 99$ & KC & Yellow & MTR & WB & 148 & 37.31 & 0.20 & 0.54 & & & & & & & & \\
\hline
\end{tabular}


Table S-PVC: Subjects' core body temperature while wearing PVC sult.

\begin{tabular}{|c|c|c|c|c|c|c|c|c|c|c|c|c|c|c|c|c|c|c|}
\hline \multirow{2}{*}{$\begin{array}{l}\text { Task } \\
\text { Set No, }\end{array}$} & \multirow{2}{*}{$\begin{array}{c}\text { Subject } \\
\text { No. }\end{array}$} & \multirow{2}{*}{$\begin{array}{l}\text { Task } \\
\text { Date }\end{array}$} & \multicolumn{3}{|c|}{ Outer Sult } & \multirow{2}{*}{$\begin{array}{l}\text { Task } \\
\text { Pert. }\end{array}$} & \multicolumn{4}{|c|}{ Task Set Data (TSD) } & \multicolumn{4}{|c|}{ TSD: Sult and Task } & \multicolumn{4}{|c|}{ TSD: Suit } \\
\hline & & & Mff. & Color & Material & & $n$ & Avg & SD & cVy & $n$ & Avg. & SD & $\mathrm{CV}$ & n & Avg. & so & CVs \\
\hline$T 4$ & & $8 / 9 / 99$ & Betas & Green & PVC & CS & 168 & 37.48 & 0.13 & 0.35 & \multirow{16}{*}{16} & \multirow{16}{*}{37.36} & \multirow{16}{*}{0.54} & \multirow{16}{*}{1.46} & & \multirow{48}{*}{37.26} & \multirow{48}{*}{0.49} & \\
\hline$T-12$ & 2 & $7 / 2999$ & Beta & Groen & PVC & cs & 123 & 37.32 & 0.45 & 1.21 & & & & & & & & \\
\hline$T-28$ & 5 & $7 / 29199$ & Bata & Green & PuC & CS & 170 & 35.89 & 0.15 & 0.43 & & & & & & & & \\
\hline T-38 & 6 & $8 / 4 / 99$ & Bata & Graen & Puc & cs & 112 & 3659 & 072 & 1.95 & & & & & & & & \\
\hline$T-47$ & 7 & $8 / 2 / 99$ & Bata & Green & PVC & CS & 125 & 37.39 & 0.14 & 0.36 & & & & & & & & \\
\hline$T=57$ & 8 & 80000 & Bota & Green & Pyc & cs & 127 & 37.57 & 0.30 & 0.81 & & & & & & & & \\
\hline$T \cdot 72$ & 12 & $8 / 16 / 99$ & Bata & Green & PVC & CS & 86 & 37.43 & 0.05 & 0.14 & & & & & & & & \\
\hline$T-85$ & 12 & 711999 & Bata & Green & PVC & CS & 139 & 37.41 & 0.16 & 0.43 & & & & & & & & \\
\hline$T .91$ & 13 & $7 / 2999$ & Bats & Green & PVC & CS & 183 & 37.00 & 0.26 & 0.69 & & & & & & & & \\
\hline$T-125$ & 17 & $8 / 9 / 99$ & Bats & Green & PVC & CS & 140 & 37.76 & 0.23 & 0.61 & & & & & & & & \\
\hline$T-151$ & 20 & 711999 & Bats & Green & PVC & CS & $14 t$ & 37.54 & 0.38 & 1.07 & & & & & & & & \\
\hline$T-158$ & 21 & $7 / 29190$ & Bata & Green & PVC & cs & 27 & 3832 & 0.06 & 0.15 & & & & & & & & \\
\hline$T-166$ & 23 & $8 / 12 / 99$ & Bata & Green & PVC & CS & 128 & 32.13 & 024 & 0.02 & & & & & & & & \\
\hline$T-170$ & 24 & $8 / 9 / 99$ & Bata & Green & PVC & CS & 144 & 37.45 & 025 & 0.58 & & & & & & & & \\
\hline$T-178$ & 25 & $8 / 2 / 99$ & Bata & Green & PVC & CS & 132 & 37.10 & 0.10 & 0.27 & & & & & & & & \\
\hline$T-185$ & 25 & $7 / 19199$ & Bata & Green & PUC & CS & 167 & 37.44 & 029 & 0.79 & & & & & & & & \\
\hline$T-7$ & 1 & $8 / 990$ & Bats & Green & PVC & Pit & 147 & 37.25 & 012 & 0.32 & & & & & & & & \\
\hline$T+15$ & 2 & $8 / 2 / 99$ & Bata & Green & PVC & Pit & 128 & 37.27 & 0.29 & 0.77 & & & & & & & & \\
\hline$T-31$ & 5 & $7 / 29199$ & Bata & Green & PVC & Pit & 98 & 35.90 & 033 & 0.92 & & & & & & & & \\
\hline$T-42$ & 6 & $8 / 4 / 99$ & Bata & Green & PVC & Pit & 145 & 36.73 & 0.38 & 1.03 & & & & & & & & \\
\hline T-50 & 7 & $7 / 29 / 99$ & Bata & Green & PVC & Pit & 132 & 37.31 & 0.17 & 0.47 & & & & & & & & \\
\hline$T-60$ & 8 & $8 / 290$ & Bata & Green & PVC & Pit & 123 & 37.33 & 029 & 0.78 & & & & & & & & \\
\hline T.73 & 12 & $8 / 16 / 99$ & Bata & Green & PVC & Pit & 130 & 37,40 & 0.05 & 0.14 & & & & & & & & \\
\hline$T-87$ & 12 & $7119 / 99$ & Bata & Green & PVC & Pit & 164 & 37.43 & 0.03 & 0.08 & 15 & 37.19 & 0.43 & 1.15 & 48 & & & 1.32 \\
\hline$T=4$ & 13 & $8 / 2 / 99$ & Beta & Green & PVC & Pit & 159 & 36.92 & 0.03 & 0.00 & & & & & & & & \\
\hline$T-111$ & 14 & $8 / 9 / 99$ & Bata & Green & PVC & Pit & 140 & 37.56 & 0.08 & 0.20 & & & & & & & & \\
\hline$T-128$ & 17 & 8/9/99 & Bata & Green & PVC & Pit & 134 & 37.72 & 0.10 & 0.27 & & & & & & & & \\
\hline T.161 & 21 & $7 / 29 / 90$ & Bate & Green & PVC & Pit & 165 & 37.16 & 0.10 & 0.27 & & & & & & & & \\
\hline$T-173$ & 24 & $7 / 29 / 99$ & Bata & Green & PVC & Pit & 112 & 36.96 & 0.50 & 1.35 & & & & & & & & \\
\hline$T-181$ & 25 & $7 / 29 / 99$ & Beta & Green & PVC & Pit & 130 & 37.26 & 0.25 & 0.80 & & & & & & & & \\
\hline$T-186$ & 26 & $7119 / 90$ & Bats & Green & PVC & Pit & 150 & 37.69 & 0.74 & 0.37 & & & & & & & & \\
\hline$T-1$ & 1 & $8 / 9 / 99$ & Bata & Green & PVC & WB & 136 & 37.19 & 0.17 & 0,47 & \multirow{17}{*}{17} & & & & & & & \\
\hline$T-10$ & 2 & $7 / 29 / 99$ & Bata & Green & PVC & WB & 128 & 37.78 & 0.06 & 0.16 & & & & & & & & \\
\hline$T-28$ & 5 & $7 / 28 / 99$ & Bata & Green & PVC & WB & 102 & 36.27 & 0.10 & 0.27 & & & & & & & & \\
\hline$T-36$ & 6 & $8 / 4 / 99$ & Bata & Green & PVC & WB & 56 & 37.10 & 0.49 & 1.32 & & & & & & & & \\
\hline$T-45$ & 7 & $7 / 29 / 99$ & Bata & Green & PVC & WB & 124 & 37.53 & 0.25 & 0.65 & & & & & & & & \\
\hline T.54 & 8 & $8 / 9: 99$ & Bata & Green & PVC & WB & 122 & 37.86 & 0.09 & 0.25 & & & & & & & & \\
\hline$T-71$ & 12 & 8/16/59 & Bata & Green & PVO & wo & 122 & 37.30 & 0.05 & 0.13 & & & & & & & & \\
\hline$T-83$ & 12 & $7119 / 99$ & Bata & Green & PVC & WB & 156 & 37.52 & 0.15 & 0.41 & & & & & & & & \\
\hline$T-88$. & 12 & $7 / 19 / 99$ & Bata & Green & PVC & WB & 147 & 37.31 & 0.11 & 0.31 & & 37.22 & 0.47 & 1.27 & & & & \\
\hline$T-90$ & 13 & $7 / 29 / 90$ & Bata & Green & PVC & WE & 154 & 37.49 & 0.05 & 0.14 & & & & & & & & \\
\hline$T-105$ & 14 & $8,9,99$ & Bata & Green & PVC & WB & 141 & 37.38 & 006 & 0.17 & & & & & & & & \\
\hline T.122 & 17 & $8 / 9199$ & Bata & Green & PVC & WB & 135 & 37.30 & 0.20 & 0.75 & & & & & & & & \\
\hline T. 153 & 20 & $7 / 19 / 90$ & Bata & Green & PVC & WB & 146 & 37.18 & 0.10 & 0.27 & & & & & & & & \\
\hline$T-155$ & 21 & $7 / 29 / 99$ & Bata & Green & PVC & WB & 113 & 37.42 & 0.15 & 0.40 & & & & & & & & \\
\hline T-167 & 24 & 8/9199 & Bata & Green & PVC & WB & 144 & 37.12 & 0.09 & 0.25 & & & & & & & & \\
\hline$T-176$ & 25 & $7 / 29 / 99$ & Bata & Green & PVC & WB & 34 & 35.87 & 0.37 & 104 & & & & & & & & \\
\hline$T-187$ & 26 & $7 / 19 / 99$ & Bata & Green & PVC & WB & 145 & 37.11 & 0.36 & 0.98 & & & & & & & & \\
\hline
\end{tabular}


Table S-Tyvek@: Subjects' core body temperature while wearing Tyvek@ suit.

\begin{tabular}{|c|c|c|c|c|c|c|c|c|c|c|c|c|c|c|c|c|c|c|}
\hline \multirow{2}{*}{$\begin{array}{c}\text { Task } \\
\text { Set No. }\end{array}$} & \multirow{2}{*}{$\begin{array}{c}\text { Subject } \\
\text { No. }\end{array}$} & \multirow{2}{*}{$\begin{array}{l}\text { Task } \\
\text { Date } \\
\end{array}$} & \multicolumn{3}{|c|}{ Outer Suit } & \multirow{2}{*}{$\begin{array}{l}\text { Taski } \\
\text { Pert. }\end{array}$} & \multicolumn{4}{|c|}{ Task Ser Data (TSD) } & \multicolumn{4}{|c|}{ TSD: Sult and Task } & \multicolumn{4}{|c|}{ TSD: Sult } \\
\hline & & & Mifr. & Color & Material & & $n$ & Avg & SD & cVm & $\pi$ & Avg & SD & CV\% & $n$ & Avg. & SD & CVX \\
\hline$T-5$ & 1 & 89199 & $\mathrm{KC}$ & White & Tymales & $\mathrm{CS}$ & 108 & 37.67 & 0.47 & 125 & \multirow{16}{*}{16} & \multirow{16}{*}{37.40} & \multirow{16}{*}{0.48} & \multirow{16}{*}{1.30} & & \multirow{50}{*}{37.24} & \multirow{50}{*}{0.45} & \\
\hline$T \cdot 13$ & 2 & $8 / 2 / 99$ & KC & Whise & Tywoles & CS & 9 & 37.69 & 0.04 & 0.12 & & & & & & & & \\
\hline$T-29$ & 5 & $8 / 2 / 99$ & KC & White & Tyveles & cs & 165 & 36.01 & 0.11 & 031 & & & & & & & & \\
\hline$T-39$ & 6 & $8 / 4 / 99$ & KC & White & Tyveka) & cs & 151 & 37.28 & 0.10 & 027 & & & & & & & & \\
\hline$T-48$ & 7 & a/4/99 & KC & Whise & Tymenas & CS & 140 & 37.42 & 0.25 & 0.56 & & & & & & & & \\
\hline$T-58$ & 8 & $8 / 12 / 99$ & KC & Whise & Tyweko & cs & 116 & 37.60 & 0.28 & 0.74 & & & & & & & & \\
\hline$T-29$ & 12 & $7 / 19 / 99$ & KC & White & Tyvele & cs & 154 & 37.35 & 0.54 & 1.45 & & & & & & & & \\
\hline$T-100$ & 13 & $6 / 24 / 99$ & KC & Whise & Tyelate & CS & 75 & 37.01 & 0.45 & 121 & & & & & & & & \\
\hline$T+92$ & 13 & $8 / 2 / 99$ & KC & Whice & Tywekd & cs & 139 & 37.08 & 020 & 0.71 & & & & & & & & \\
\hline$T-100$ & 14 & 89999 & KC & White & Tyenel & cs & 120 & 37,35 & 0.07 & 0.20 & & & & & & & & \\
\hline$T-125$ & 17 & $8 / 9199$ & KC & Whice & Tymene & CS & 106 & 37.38 & 0.52 & 138 & & & & & & & & \\
\hline$T-159$ & 21 & $7 / 29 / 99$ & KC & White & Tyeike & CS & 202 & 37.67 & 0.44 & 1.17 & & & & & & & & \\
\hline$T-171$ & 24 & $8 / 9 / 99$ & KC & White & Typelos & cs & 123 & 37.47 & 0.37 & 1.00 & & & & & & & & \\
\hline$T-179$ & 25 & $8 / 2 / 99$ & KC & White & Tyeneso & CS & 135 & 37.37 & 0.35 & 0.93 & & & & & & & & \\
\hline$T-188$ & 26 & $7 / 19 / 99$ & KC & White & Tyene & CS & 156 & 38,52 & 0.38 & 0.99 & & & & & & & & \\
\hline$T-203$ & 26 & $6 / 24 / 99$ & $K C$ & White & Tyeke & CS & 287. & 37.72 & 0.12 & 0.32 & & & & & & & & \\
\hline T-8 & 1 & 8999 & $K C$ & White & Twehs & Fit & 839 & 37.12 & 0.10 & 0.26 & & & & & & & & \\
\hline$T-16$ & 2 & $8 / 4 / 99$ & $K C$ & While & Tyueks & Pit & 126 & 37.01 & 0.36 & 0.98 & & & & & & & & \\
\hline$T-32$ & 5 & $8 / 4 / 99$ & KC & White & Tyveke & Pit & 81 & 35.79 & 0.05 & 0.13 & & & & & & & & \\
\hline$T-33$ & 5 & $8 / 290$ & KC & White & Tweiks & Pit & 132 & 38.31 & 0.16 & 0.44 & & & & & & & & \\
\hline$T-43$ & 6 & $7 / 29 / 99$ & $K C$ & White & Tyelks & Pit & 113 & 37.13 & 0.58 & 157 & & & & & & & & \\
\hline T.51 & 7 & 7/29/99 & KC & White & Tyeks & Pit & 140 & 37.72 & 0.10 & 0.26 & & & & & & & & \\
\hline$T-52$ & 7 & $7 / 29: 99$ & KC & White & Tyeks & Pit & 114 & 37.13 & 0.58 & 1.55 & & & & & & & & \\
\hline$T-81$ & 8 & $7 / 29.99$ & $K C$ & White & Tweks & Pit & 288 & 36.87 & 0.24 & 0.66 & & & & & & & & \\
\hline$T-101$ & 13 & $6 / 24 / 99$ & KC & White & Tweks & Pit & 154 & 37.03 & 0.20 & 0.55 & 18 & 37.01 & 0.46 & 124 & 50 & & & 1.22 \\
\hline$T-95$ & 13 & $8 / 4 / 99$ & KC & White & Tyveke & Pit & 124 & 36.35 & 0.17 & 0.4 ह & & & & & & & & \\
\hline$T-98$ & 13 & $7 / 29199$ & KC & White & Tyeke & Pit & 121 & 37.33 & 0.52 & $1.40^{\circ}$ & & & & & & & & \\
\hline$T-112$ & 14 & $8 / 9 / 99$ & KC & White & Tyekes & Pit & 128 & 37.18 & 0.07 & 0.18 & & & & & & & & \\
\hline$T-146$ & 20 & $7 / 1999$ & KC & White & Tyohe & Pit & 157 & 37.12 & 0.10 & 028 & & & & & & & & \\
\hline T-162 & 21 & $7 / 20190$ & KC & White & Tyweke & Pit & 130 & 37.26 & 0.18 & 0.49 & & & & & & & & \\
\hline T-174 & 24 & $7 / 29199$ & $\mathrm{KC}$ & White & Tyels & Pn & 130 & 37.19 & 0.06 & 0.17 & & & & & & & & \\
\hline$T-182$ & 25 & $7 / 29 / 99$ & $K C$ & White & Tyoek & Pit & 153 & 37.01 & 0.12 & 034 & & & & & & & & \\
\hline $7-183$ & 25 & $8 / 2 / 99$ & KC & White & Tyvek & Pit & 134 & 36.90 & 0.09 & 0.25 & & & & & & & & \\
\hline$T-204$ & 26 & $6 / 24,99$ & $\mathrm{KC}$ & Whitte & Tyweke & PIt & 148 & 37.78 & 0.23 & 0.62 & & & & & & & & \\
\hline$T-2$ & $T$ & $8 / 12 / 99$ & $\mathrm{KC}$ & White & Tywek & WB & 100 & 37.46 & 0.11 & 0.29 & & & & & & & & \\
\hline$T-18$ & 2 & $8 / 2 / 99$ & KC & White & Tyneke & WB & 131 & 37.34 & 0.14 & 037 & & & & & & & & \\
\hline$T-35$ & 5 & $8 / 2 / 99$ & KC & White & Tyrekt & WE & 147 & 36.70 & 0.32 & 0.86 & & & & & & & & \\
\hline$T-37$ & 6 & $8 / 4 / 99$ & KC & White & Tyeke & WB & 140 & 37.39 & 0.04 & 010 & & & & & & & & \\
\hline$T-53$ & 7 & $8 / 2 / 90$ & $\mathrm{KC}$ & White & Tyolese & WB & 132 & 37.11 & 0.05 & 0.15 & & & & & & & & \\
\hline T.SS & 8 & $8 / 9 / 99$ & KC & White & Tyeke & we & 137 & 37.50 & 0.05 & 0.14 & & & & & & & & \\
\hline T.102 & 13 & $6 / 24 / 99$ & KC & White & Tyeke & WB & 147 & 3752 & 0.05 & 014 & & & & & & & & \\
\hline$T-104$ & 13 & $8 / 2 / 99$ & KC & White & Tyule & WB & 128 & 3723 & 031 & 0.83 & 16 & 3734 & 0.28 & 0,75 & & & & \\
\hline$T-106$ & 14 & $80 / 60$ & KC & White & Tyoles & WB & 131 & 37.47 & 0.21 & 055 & & & & & & & & \\
\hline T-123 & 17 & $8 / 12 / 99$ & KC & White & Tyene & WB & 109 & 37.67 & 0.13 & 0.35 & & & & & & & & \\
\hline T-149 & 20 & $7 / 19 / 99$ & KC & White & Tyedo & WB & 163 & 37.49 & 0.12 & 0.32 & & & & & & & & \\
\hline$T-154$ & 20 & $7 / 19 / 99$ & KC & Whine & Tyveice & WB & 37 & 36.93 & 0.03 & 009 & & & & & & & & \\
\hline$T-156$ & 21 & $7 / 29 / 99$ & KC & White & Tyweike & WB & 97 & 37.69 & 0.21 & 0.57 & & & & & & & & \\
\hline T-168 & 24 & $8 / 9 / 99$ & $\mathrm{KC}$ & White & Tyvolet & WB & 151. & 37,38 & 0.09 & 0.24 & & & & & & & & \\
\hline$T-184$ & 25 & $7 / 29199$ & KC & White & Tyveiks & WB & 135 & 36.95 & 0.06 & 0.17 & & & & & & & & \\
\hline$T-205$ & 26 & $6 / 24 / 99$ & $\mathrm{KC}$ & White & Tyyek0 & WB & 167 & 37.67 & 0.20 & 0.54 & & & & & & & & \\
\hline
\end{tabular}


Table S-MTR: Subjects' core body temperature while wearing MTR suit.

\begin{tabular}{|c|c|c|c|c|c|c|c|c|c|c|c|c|c|c|c|c|c|c|}
\hline \multirow{2}{*}{$\begin{array}{l}\text { Task } \\
\text { set No. }\end{array}$} & \multirow{2}{*}{$\begin{array}{c}\text { Subject } \\
\text { No. }\end{array}$} & \multirow{2}{*}{$\begin{array}{l}\text { Task } \\
\text { Date }\end{array}$} & \multicolumn{3}{|c|}{ Outer sult } & \multirow{2}{*}{$\begin{array}{l}\text { Task } \\
\text { Perf. }\end{array}$} & \multicolumn{4}{|c|}{ Task Set Data (TSD) } & \multicolumn{4}{|c|}{ TSD: Suit and Task } & \multicolumn{4}{|c|}{ TSD: Sult } \\
\hline & & & Mfr. & Color & Material & & $n$ & Avg. & 50 & CVF & $\mathrm{n}$ & Avg. & SD & CV\% & $n$ & Avg. & SD & CVS \\
\hline T.14 & 2 & $8 / 4 / 99$ & $\mathrm{KC}$ & Yellow & MTR & CS & 91 & 3758 & 0.38 & 095 & \multirow{16}{*}{16} & \multirow{16}{*}{37.37} & \multirow{16}{*}{0.46} & \multirow{16}{*}{1.22} & \multirow{49}{*}{49} & \multirow{49}{*}{37.31} & & \\
\hline$T \cdot 30$ & 5 & $8 / 4 / 99$ & KC & Yellow & MTR & $\operatorname{cs}$ & 142 & 35.82 & 0.35 & 0.71 & & & & & & & & \\
\hline$T-41$ & 6 & $3 / 4 / 99$ & KC & Veliow & MTR & $\operatorname{cs}$ & 122 & 3728 & 0.30 & 0.80 & & & & & & & & \\
\hline$T-49$ & 7 & $8 / 4 / 99$ & KC & Yellow & MTR & CS & 123 & 37.49 & 0.26 & 0.69 & & & & & & & & \\
\hline$T .99$ & 8 & $8 / 9 / 99$ & $\mathrm{KC}$ & Yellow & MTR & CS & 142 & 37.43 & 0.10 & 0.26 & & & & & & & & \\
\hline$T \cdot 79$ & 12 & $7 / 19 / 99$ & $K C$ & Yellow & MTR & CS & 128 & 3735 & 0.37 & 099 & & & & & & & & \\
\hline$T-93$ & 13 & a/4/99 & $K C$ & Yellow & MTR & CS & 132 & 3748 & 0.10 & 028 & & & & & & & & \\
\hline$T=96$ & 13 & $6 / 24 / 59$ & KC & Yeliow & MTR & CS & 205 & 3757 & 0.25 & 0.67 & & & & & & & & \\
\hline$T-110$ & 14 & $7 / 29199$ & KC & Yollow & MTR & $\mathrm{CS}$ & 148 & 37.10 & 0.22 & 0.60 & & & & & & & & \\
\hline$T-114$ & 15 & $7 / 19 / 59$ & KC & Yellow & MTR & $\operatorname{cs}$ & 154 & 3740 & 0.35 & 0.86 & & & & & & & & \\
\hline$T=127$ & 17 & a/9/99 & $\mathrm{KC}$ & Yeliow & MTR & CS & 62: & 28.04 & 0.24 & 0.63 & & & & & & & & \\
\hline$T-145$ & 20 & $7 / 19 / 99$ & KC & Yellow & MTR & $\operatorname{cs}$ & 128 & 37.54 & 0.16 & 0.43 & & & & & & & & \\
\hline $\mathrm{T}-172$ & 24 & $7 / 29 / 99$ & KC & Yellow & MTR & CS & 71 & 37.15 & 0.17 & 0.45 & & & & & & & & \\
\hline$T-180$ & 25 & $8 / 4 / 90$ & $\mathrm{KC}$ & Yallow & MTR & CS & 113 & 37.30 & 0.25 & 0.68 & & & & & & & & \\
\hline T.195 & 26 & $7 / 19 / 99$ & $\mathrm{KC}$ & Yellow & MTR & CS & 182 & 37.7 & 0.31 & 0.83 & & & & & & & & \\
\hline$T-201$ & 26 & $6 / 24 / 99$ & $K C$ & Yellow & MTR & CS & 147 & 37.63 & 0.31 & 0.83 & & & & & & & & \\
\hline$T-9$ & 1 & $7 / 29199$ & $K C$ & Yellow & MTR & Pit & 141 & 37.80 & 0.23 & 0.61 & & & & & & & & \\
\hline$T-17$ & 2 & $7 / 29 / 99$ & KC & Yellow & MTR & Pit & 131 & 37.02 & 0.39 & 1.08 & & & & & & & & \\
\hline$T-44$ & 6 & $3 / 4 / 99$ & $K C$ & Yellow & MTR & Pit & 211 & 37.39 & 0.74 & 0.35 & & & & & & & & \\
\hline 7280 & 12 & $7 / 19 / 99$ & KC & Yellow & MTR & Pit & 152 & 37.54 & 0,05 & 0.14 & & & & & & & & \\
\hline$T-8 T$ & 12 & $7 / 19 / 99$ & KC & Yellow & MTR & Pit & 140 & 37,34 & 0.49 & 1.10 & & & & & & & & \\
\hline$T-80$ & 13 & $6 / 24 / 99$ & $K C$ & Yellow & MTR & Pit & 149 & 37.21 & 0.11 & 0.31 & & & & & & & & \\
\hline$T-113$ & 14 & $8 / 9 / 90$ & KC & Yeliow & MTR & Pit & 111 & 37.35 & 0.22 & 0.60 & & & & & & & & \\
\hline$T-115$ & 15 & $7 / 19 / 99$ & KC & Yellow & MTR & Pit & 151 & 37.18 & 0.39 & 1.06 & 16 & 37.31 & 0.26 & 0.60 & & & & \\
\hline$T .130$ & 17 & 7129199 & $K C$ & Yellow & MTR & Pi & 123 & 37.63 & 0.12 & 0.33 & 16 & 31.31 & 0.26 & 0.69 & & & 0.37 & 0.99 \\
\hline$T-147$ & 20 & $7 / 1999$ & KC & Yellow & MTR & Pit & 136 & 37.22 & 0.19 & 0.50 & & & & & & & & \\
\hline$T-160$ & 21 & $8 / 4 / 99$ & KC & Yellow & MTR & $P_{R}$ & 120 & 37.69 & 0.22 & 0.59 & & & & & & & & \\
\hline$T=183$ & 21 & $7 / 2999$ & KC & Yellow & MTR & $P$ in & 138 & 37.05 & 0.44 & 1.18 & & & & & & & & \\
\hline$T-175$ & 24 & $8 / 9 / 99$ & KC & Yeliow & MTR & $P_{h}$ & 139 & 35.95 & 0.27 & 0,74 & & & & & & & & \\
\hline$T-196$ & 26 & $7 / 1999$ & KC & Yellow & MTR & Pit & 154 & 37.09 & 0.10 & 0.25 & & & & & & & & \\
\hline$T-198$ & 26 & $7 / 19 / 99$ & KC & Yellow & MTR & Pit & 159 & 35.98 & 0.28 & 0.76 & & & & & & & & \\
\hline $\mathrm{T}-202$ & 26 & $6 / 24 / 99$ & KC & Yellow & MTR & $P_{t}$ & 131 & 37.43 & 0.35 & 0.93 & & & & & & & & \\
\hline T-19 & 2 & $7 / 29199$ & $\mathrm{KC}$ & Yellow & NTR & WB & 152 & 37.37 & 0.08 & 0.20 & & & & & & & & \\
\hline$T-27$ & 5 & $7 / 28199$ & KC & Yellow & MTR & WE & 37 & 36.06 & 0.27 & 0.75 & & & & & & & & \\
\hline$T-40$ & 6 & $7 / 29 / 99$ & KC & Yellow & MTR & WB & 135 & 3693 & 0.28 & 0.76 & & & & & & & & \\
\hline$T-46$ & 7 & $7 / 29 / 99$ & $K C$ & Yoliow & MTR & WE & 149 & 37.27 & 0.26 & 0.69 & & & & & & & & \\
\hline 7.56 & 8 & $8 / 9 / 90$ & KC & Yeliow & MTR & WE & 140 & 27.39 & 0.09 & 0.25 & & & & & & & & \\
\hline$T-82$ & 12 & $7 / 19 / 99$ & KC & Yellow & MTR & WB & 129 & 37.04 & 0.29 & 0.79 & & & & & & & & \\
\hline$T-35$ & 12 & $7 / 18 / 99$ & KC & Yeliow & MTR & WB & 128 & 37.44 & 0.25 & 066 & & & & & & & & \\
\hline$T \cdot 103$ & 13 & $6 / 24 / 99$ & $K C$ & Yellow & MTR & WB & 155 & 39.39 & 0.57 & 1.52 & & & & & & & & \\
\hline $7-87$ & 13 & $7 / 29 / 99$ & KC & Yellow & MTR & WB & 126 & 37.19 & 0.17 & 0.45 & 17 & 37.27 & 0.36 & 0.97 & & & & \\
\hline T.107 & 14 & $8 / 9 / 99$ & KC & Yellow & MTR & WB & 44 & 37.00 & 0.65 & 1.72 & & & & & & & & \\
\hline $\mathrm{T}-138$ & 20 & $7119 / 99$ & $K C$ & Yellow & MTR & WB & 128 & 3747 & 0.45 & 120 & & & & & & & & \\
\hline T.148 & 20 & $7 / 19 / 99$ & KC & Yellow & MTR & WB & 132 & 37,33 & 0.56 & 1.51 & & & & & & & & \\
\hline$T-157$ & 21 & $7 / 29 / 99$ & $K C$ & Yellow & MTR & WB & 91 & 37.33 & 0.58 & 1.54 & & & & & & & & \\
\hline$T \cdot 177$ & 25 & $7 / 29 / 99$ & KC & Yellow & MTR & WB & 141 & 37.35 & 0.11 & 0.29 & & & & & & & & \\
\hline$T-197$ & 26 & $7 / 19 / 99$ & $K C$ & Yellow & MTR & WB & 123 & 37.77 & 0.19 & 0.52 & & & & & & & & \\
\hline$T-190$ & 26 & $7 / 19 / 99$ & KC & Yellow & MTR & WB & 130 & 37,29 & 0.20 & 0.54 & & & & & & & & \\
\hline$T-200$ & 26 & $6 / 24 / 99$ & $K C$ & Yellow & MTR & WB & 148 & 37.31 & 0.20 & 0.54 & & & & & & & & \\
\hline
\end{tabular}


Table S-PVC: Subjects' core body temperature while wearing PVC suit.

\begin{tabular}{|c|c|c|c|c|c|c|c|c|c|c|c|c|c|c|c|c|c|c|}
\hline \multirow{2}{*}{$\begin{array}{c}\text { Task } \\
\text { Set No. }\end{array}$} & \multirow{2}{*}{\begin{tabular}{|c|} 
Subject \\
$\mathrm{No}$.
\end{tabular}} & \multirow{2}{*}{$\begin{array}{l}\text { Task } \\
\text { Date }\end{array}$} & \multicolumn{3}{|c|}{ Outer Suit } & \multirow{2}{*}{$\begin{array}{l}\text { Task } \\
\text { Perf. }\end{array}$} & \multicolumn{4}{|c|}{ Task Set Data (ISD) } & \multicolumn{4}{|c|}{ TSD: Sult and Task } & \multicolumn{4}{|c|}{ TSD: Sult } \\
\hline & & & Mfr. & Color & Material & & $\pi$ & Avg & SD & CV: & $n$ & Avg. & SD & CV\% & $n$ & Avg. & $S D$ & CV\% \\
\hline$T-4$ & $\overline{1}$ & $8 / 2 / 99$ & Bata & Green & PVC & CS & 760 & 3748 & 0.13 & 0,35 & \multirow{16}{*}{16} & \multirow{16}{*}{37,36} & \multirow{16}{*}{0.54} & \multirow{16}{*}{1.46} & & \multirow{48}{*}{37.26} & \multirow{48}{*}{0.49} & \multirow{48}{*}{1.32} \\
\hline$T-12$ & 2 & $7 / 29 / 99$ & Bata & Green & PVC & CS & 123 & 37.32 & 0.45 & 121 & & & & & & & & \\
\hline$T-28$ & 5 & $7 / 29 / 99$ & Bata & Green & PVC & CS & 170 & 3589 & 0.15 & 0.43 & & & & & & & & \\
\hline$T=38$ & 6 & $8 / 4 / 99$ & Bata & Green & PVC & CS & 112 & 36.59 & 0.72 & 195 & & & & & & & & \\
\hline$T-47$ & 7 & $8 / 2 / 98$ & Bata & Green & PVC & CS & 125 & 37.39 & 0.14 & 0.38 & & & & & & & & \\
\hline$T-57$ & 8 & 8/9/99 & Bata & Green & PVC & CS & 127 & 3757 & 0.30 & 081 & & & & & & & & \\
\hline$T-72$ & 12 & $8 / 16 / 99$ & Bata & Green & PVC & CS & 86 & 37.43 & 0.05 & 0.14 & & & & & & & & \\
\hline$T-36$ & 12 & $7 / 19 / 99$ & Bata & Green & PVC & CS & 139 & 37.41 & 0.16 & 0.43 & & & & & & & & \\
\hline$T=91$ & 13 & $7 / 29 / 99$ & Bata & Green & PVC & CS & 163 & 37.00 & 0.26 & 069 & & & & & & & & \\
\hline$T-125$ & 17 & $8 / 9 / 99$ & Bata & Green & PVC & CS & 140 & 37.75 & 0.23 & 0.61 & & & & & & & & \\
\hline$T=15 t$ & 20 & $7 / 19 / 99$ & Bata & Green & PVC & CS & 141 & 37.54 & 0.38 & 1.03 & & & & & & & & \\
\hline$T-158$ & 21 & $7 / 28199$ & Bata & Green & PVC & CS & 27 & 38.32 & 0.06 & 0.15 & & & & & & & & \\
\hline$T-166$ & 23 & $8 / 12 / 99$ & Bata & Green & PVC & Cs & 128. & 38.13 & 0.24 & 0.62 & & & & & & & & \\
\hline$T-170$ & 24 & $8 / 9 / 99$ & Bata & Green & PVC & CS & 144 & 37.46 & 0.25 & 0.68 & & & & & & & & \\
\hline$T-178$ & 25 & $8 / 2 / 99$ & Bata & Green & PVC & CS & 132 & 37,10 & 0.10 & 0.27 & & & & & & & & \\
\hline$T=185$ & 26 & $7 / 19 / 99$ & Bata & Green & PVC & CS & 167 & 37.44 & 0.29 & 0.79 & & & & & & & & \\
\hline$T-7$ & 1 & $89 / 99$ & Bata & Green & PVE & Pit & 147 & 37.25 & 0.12 & 032 & & & & & & & & \\
\hline$T-15$ & 2 & $8 / 2 / 99$ & Bata & Green & PVC & Pit & 128 & 37.27 & 0.29 & 0.77 & & & & & & & & \\
\hline$T-31$ & 5 & $7 / 29 / 99$ & Bata & Green & PVC & Pit & 98 & 35.90 & 0.33 & 0.92 & & & & & & & & \\
\hline$T-42$ & 6 & $8 / 4 / 99$ & Bata & Green & PVC & Pit & 145 & 36.73 & 0.35 & 1,03 & & & & & & & & \\
\hline 7.50 & 7 & $7 / 28 / 99$ & Bata & Green & PVIC & Pit & 132 & 37.31 & 0.17 & 0.47 & & & & & & & & \\
\hline$T-60$ & 8 & $8 / 9 / 99$ & Bata & Green & PVC & Pit & 123 & 37.33 & 0.29 & 0.78 & & & & & & & & \\
\hline $7-73$ & 12 & $8 / 16 / 99$ & Bata & Green & PVC & Pit & 130 & 37.40 & 0.05 & 0.14 & & & & & & & & \\
\hline$T-37$ & 12 & $7 / 19 / 99$ & Bata & Green & PVC & Pit & 164 & 37.43 & 0.03 & 0.08 & 15 & 37.19 & 0.43 & 1.15 & 48 & & & \\
\hline$T-94$ & 13 & $8 / 2 / 99$ & Bata & Green & PVC & Pit & 159 & 36.92 & 0.03 & 0.09 & & & & & & & & \\
\hline$T-111$ & 14 & $8 / 9 / 99$ & Bata & Green & PVC & Pit & 140 & 37.56 & 0.08 & 0.20 & & & & & & & & \\
\hline$T=128$ & 17 & $8 / 9 / 92$ & Bata & Green & PVC & Pit & 134 & 37.72 & 0.10 & 0.27 & & & & & & & & \\
\hline$T-161$ & 21 & $7 / 29 / 99$ & Bata & Green & PVC & Pit & 165 & 37.15 & 0.10 & 0.27 & & & & & & & & \\
\hline$T-173$ & 24 & $7 / 29 / 99$ & Bata & Green & PVC & Pit & 112 & 36.96 & 0.50 & 1.35 & & & & & & & & \\
\hline$T-181$ & 25 & $7 / 29 / 99$ & Bata & Green & PVC & Pit & 130 & 37.26 & 0.25 & 0.68 & & & & & & & & \\
\hline$T=186$ & 26 & $7119 / 99$ & Bata & Green & PVC & Pit & 150 & 37.59 & 0.14 & 0.37 & & & & & & & & \\
\hline$T-1$ & 7 & 89999 & Bata & Green & PVC & WB & 136 & 37.19 & 0.17 & 0.47 & & & & & & & & \\
\hline$T=10$ & 2 & $7 / 29 / 99$ & Bata & Green & PVC & WB & 128 & 37.78 & 0.06 & 0.16 & & & & & & & & \\
\hline$T-26$ & 5 & $7 / 29 / 99$ & Bata & Green & PVC & WB & 102 & 36.27 & 0.10 & 0.23 & & & & & & & & \\
\hline T-36 & 6 & $8 / 4 / 99$ & Bata & Green & PVC & WB & 56 & 37.10 & 0.49 & 1.32 & & & & & & & & \\
\hline$T-45$ & 7 & $7 / 29 / 90$ & Bata & Green & PVC & WE & 124 & 37.63 & 0.25 & 0.65 & & & & & & & & \\
\hline T-S4 & 8 & $8 / 9 / 89$ & Bata & Green & PVC & WB & 122 & 37.86 & 0.09 & 0.25 & & & & & & & & \\
\hline$T-71$ & 12 & $8 / 16 / 99$ & Bata & Green & PVC & WB & 122 & 37.30 & 0.05 & 0.13 & & & & & & & & \\
\hline$T-83$ & 12 & $7 / 19 / 99$ & Bata & Green & PVC & WB & 156 & 37.62 & 0.15 & 0.41 & & & & & & & & \\
\hline$T-88$ & 12 & $7 / 19199$ & Bata & Green & PVC & WB & 147 & 37.31 & 0.11 & 0,31 & 17 & 37.22 & 0.47 & 1.27 & & & & \\
\hline$T=90$ & 13 & $7 / 29 / 99$ & Bata & Green & PVC & WB & 154 & 57.49 & 0.05 & 0.14 & & & & & & & & \\
\hline$T-105$ & 14 & 8/9/99 & Bata & Green & PVC & WB & 141 & 37.38 & 0.06 & 0,17 & & & & & & & & \\
\hline$T-122$ & 17 & $8 / 9 / 99$ & Bata & Green & PVC & WB & 135 & 37.20 & 0.28 & 0.75 & & & & & & & & \\
\hline T-153 & 20 & $7 / 19 / 99$ & Bata & Groen & PVC & WB & 146 & 37.18 & 0.10 & 0.27 & & & & & & & & \\
\hline$T, 155$ & 21 & $7 / 29 / 99$ & Bata & Green & PVC & WB & 118 & 37.42 & 0.15 & 0.40 & & & & & & & & \\
\hline$T-167$ & 24 & $8 / 9199$ & Bata & Green & PVC & WB & 144 & 37.12 & 0.09 & 0.25 & & & & & & & & \\
\hline$T-176$ & 25 & $7 / 29 / 99$ & Bata & Green & PVC & WB & 34 & 35.87 & 0.37 & 1.04 & & & & & & & & \\
\hline T-187 & 26 & $7 / 19 / 99$ & Bata & Green & PVC & WB & 145 & 37.11 & 0.36 & 0.98 & & & & & & & & \\
\hline
\end{tabular}


Table S-Tyvek?: Subjects' core body temperature while wearing Tyvekib suit.

\begin{tabular}{|c|c|c|c|c|c|c|c|c|c|c|c|c|c|c|c|c|c|c|}
\hline \multirow{2}{*}{$\begin{array}{l}\text { Task } \\
\text { Set No: }\end{array}$} & \multirow{2}{*}{$\begin{array}{c}\text { Subject } \\
\text { No. }\end{array}$} & \multirow{2}{*}{$\begin{array}{l}\text { Task } \\
\text { Date }\end{array}$} & \multicolumn{3}{|c|}{ Outer suit } & \multirow{2}{*}{$\begin{array}{l}\text { Task } \\
\text { Perf. }\end{array}$} & \multicolumn{4}{|c|}{ Task Set Dsta (TSD) } & \multicolumn{4}{|c|}{ TSD: Sult and Task } & \multicolumn{4}{|c|}{ rso: Suit } \\
\hline & & & Mifr. & Color & Material & & $\mathrm{n}$ & $\mathrm{Ang}$ & 50 & $\mathrm{crs}$ & $n$ & Avg & so & $\mathrm{CV} \mathrm{x}$ & $n$ & Avg & SD & CV: \\
\hline T.S & 1 & $8 / 9 / 99$ & $\mathrm{KC}$ & White & Tyrek0 & $\mathrm{cs}$ & 108 & 37.67 & 0.47 & 1.25 & \multirow{16}{*}{16} & \multirow{16}{*}{37.40} & \multirow{16}{*}{0.48} & \multirow{16}{*}{1,30} & \multirow{50}{*}{50} & \multirow{50}{*}{37.24} & & \\
\hline$T-13$ & 2 & $8 / 2 \sqrt{99}$ & $K C$ & White & Tyeid & CS & 99 & 37,39 & 004 & 0.12 & & & & & & & & \\
\hline T. 29 & 5 & $8 / 2 / 99$ & KC & White & Tyvelos & CS & 165 & 36.01 & 011 & 0.31 & & & & & & & & \\
\hline$T-30$ & 6 & $8 / 4 / 99$ & KO & White & Tymeles & CS & 151 & 37.28 & 0.10 & 027 & & & & & & & & \\
\hline$T-43$ & 7 & $8 / 4 / 99$ & KC & White & Tyreles & CS & 140 & 37.42 & 0.25 & $0 \theta E$ & & & & & & & & \\
\hline$T-56$ & $\theta$ & $2 / 1209$ & $\mathrm{KC}$ & White & Tyrebs & $\operatorname{cs}$ & 116 & 37.50 & 0.28 & 0.74 & & & & & & & & \\
\hline$T-69$ & 12 & 711959 & $\mathrm{KC}$ & While & Tyrabes & CS & 154 & 37.36 & 0.54 & 1.65 & & & & & & & & \\
\hline$T-100$ & 13 & $6 / 24 / 99$ & $\mathrm{KC}$ & White & Tyrebs & CS & 75 & 37.01 & 0.45 & 1.25 & & & & & & & & \\
\hline $7-92$ & 13 & $8 / 2 / 99$ & KC & White & Tyreks & cs & 139 & 37.08 & 0.26 & 0.71 & & & & & & & & \\
\hline$T-109$ & 14 & $8 / 9 / 99$ & KC & White & Tyweko & CS & 120 & 37.35 & 007 & 020 & & & & & & & & \\
\hline$T-128$ & 17 & $8 / 9189$ & KC & White & Tywent & cs & 105 & 37.38 & 0.52 & 1.38 & & & & & & & & \\
\hline T.159 & 21 & $7 / 29 / 90$ & $\mathrm{KC}$ & White & Tywalos & CS & 202 & 37.67 & 0.44 & 1.17 & & & & & & & & \\
\hline$T \cdot 171$ & 24 & $8 / 9 / 99$ & KC & White & Tyveles & CS & 123 & 37.47 & 037 & 100 & & & & & & & & \\
\hline$T-179$ & 25 & $8 / 2 / 9 \theta$ & $\mathrm{KC}$ & White & Tyweks & CS & 135 & 37.37 & 0.35 & 0.93 & & & & & & & & \\
\hline$T-188$ & 26 & $7 / 19 / 99$ & $\mathrm{KC}$ & White & Ty wales & CS & 156 & 38.52 & 038 & 0.99 & & & & & & & & \\
\hline$T .203$ & 26 & $6 / 24 / 99$ & $\mathrm{KC}$ & White & Tyweks & $\mathrm{Cs}$ & $2 a ?$ & 37.72 & 0.12 & 0.32 & & & & & & & & \\
\hline $\mathrm{T}=\mathrm{B}$ & 1 & $8 / 999$ & KC & White & Tyweks & $P t$ & 139 & 37.12 & 0.10 & 0.26 & & & & & & & & \\
\hline$T-16$ & 2 & $8 / 4 / 99$ & $\mathrm{KC}$ & White & Tyvekes & $P=$ & 126 & 37.01 & 036 & 0.96 & & & & & & & & \\
\hline$T-32$ & 5 & $8 / 4 / 99$ & $\mathrm{KC}$ & White & Tyweke & $P_{l}$ & 31 & 35.79 & 0.05 & 0.13 & & & & & & & & \\
\hline$T-33$ & 5 & $8 / 2 / 29$ & KC & White & Tyvele & $P_{A}$ & 132 & 35.31 & 0.16 & 0.44 & & & & & & & & \\
\hline$T-43$ & 6 & $7 / 20900$ & $\mathrm{KC}$ & White & Tyveis & Pit & 113 & 37.13 & 0.58 & 157 & & & & & & & & \\
\hline 7.51 & 7 & $7 / 29199$ & $K C$ & White & Tyweks & Pit & 140 & 37.72 & 0.10 & 0.26 & & & & & & & & \\
\hline$T \leqslant 2$ & 7 & $7 / 2999$ & KC & White & Tyveld & Pit & 114 & 37.13 & 0.50 & 1.55 & & & & & & & & \\
\hline$T-61$ & 8 & $7 / 29 / 99$ & KC & White & Tyveks & Pit & 286 & 35.07 & 0.24 & 0.68 & & & & & & & & \\
\hline$T=10 t$ & 13 & $6 / 24,99$ & KC & White & Tyweives & Pit & 154 & 37.03 & 0.20 & 0.55 & 18 & 37.01 & 0.46 & 1.24 & & & 0.45 & 1.22 \\
\hline$T-86$ & 13 & $8 / 4 / 90$ & KC & White & Tyones & Pit & 124 & 36.35 & 0.17 & 0.46 & 10 & & 0.40 & & & & & \\
\hline $7-96$ & 13 & $7 / 29 / 89$ & KC & White & Tyvelos & Pit & 121 & 37.33 & 0.52 & 1.40 & & & & & & & & \\
\hline$T-112$ & 14 & $8 / 9 / 99$ & KC & White & Tyreice & Pit & 126. & 37.18 & 0.07 & 0.18 & & & & & & & & \\
\hline$T-146$ & 20 & $7 / 19 \mathrm{ge}$ & KC & White & Tyreke & Pit & 157. & 37.12 & 0.10 & 0.28 & & & & & & & & \\
\hline$T-162$ & 21 & $7 / 29199$ & $\mathrm{KC}$ & White & Tyroks & Pit & 130 & 37.26 & 0.18 & 0.42 & & & & & & & & \\
\hline$T+174$ & 24 & $7 / 29 / 99$ & KC & White & Tyreno & Pit & 130 & 37.19 & 0.06 & 0.17 & & & & & & & & \\
\hline T-182 & 25 & $7 / 29 / 59$ & $\mathrm{KC}$ & White & Tyreno & Pit & 153 & 37.01 & 012 & 0.34 & & & & & & & & \\
\hline$T-183$ & 25 & $3 / 2 / 99$ & KC & White & Tyenes & Pit & 134 & 36.90 & 009 & 025 & & & & & & & & \\
\hline$T-204$ & 26 & $6 / 24 / 99$ & $\mathrm{KC}$ & White & Tywene & Pit & 148 & 37.78 & 0.23 & 0.62 & & & & & & & & \\
\hline$T-2$ & 1 & 81299 & $\mathrm{KC}$ & Whate & Tywek & WB & 146 & 3746 & 0.11 & 0.29 & & & & & & & & \\
\hline$T-10$ & 2 & $8 / 2 / 89$ & $\mathrm{KC}$ & White & Tymake & WB & 131 & 37.34 & 0.14 & 0.32 & & & & & & & & \\
\hline T. 35 & 5 & $8 / 2 / 99$ & KC & White & Tyeht & WB & 147 & 36.70 & 0,32 & 0.86 & & & & & & & & \\
\hline T.37 & 6 & $8 / 4 / 99$ & $\mathrm{KC}$ & White & Ty weise & WB & 140 & 3739 & 0.04 & 0.10 & & & & & & & & \\
\hline$T-53$ & 7 & $8 / 2 / 99$ & $K C$ & White & Ty weks & WB & 137 & 37.11 & 005 & 0.15 & & & & & & & & \\
\hline TSS & 8 & $8 / 9 / 99$ & KC & White & Tyweks & WB & 137 & 37.60 & 005 & 0.14 & & & & & & & & \\
\hline T-102 & 13 & $6 / 24 / 99$ & KC & Whits & Tyuelds & WE & 147 & 37.52 & 0.05 & 0.14 & & & & & & & & \\
\hline $7-104$ & 13 & $8 / 290$ & KC & White & Tyweks & WB & 128 & 37.23 & 031 & 0.83 & 15 & & & & & & & \\
\hline T-106 & 14 & $8 / 9 / 99$ & Ko & Whits & Tyvek & WE & 131 & 37.47 & 021 & 0.55 & 16 & 36.34 & 0.28 & 0.75 & & & & \\
\hline$T-123$ & 17 & $8 / 12 / 99$ & KC & White & Tyueks & we & 109 & 37.67 & 0.13 & 0.35 & & & & & & & & \\
\hline T-149: & 20 & 717999 & KC & White & Tyveke & WE & 163 & 37.49 & 0.12 & 0.32 & & & & & & & & \\
\hline$T-154$ & 20 & 7119199 & KC & White & Tweke & WB & 37 & 35.93 & 003 & 0.09 & & & & & & & & \\
\hline$T-156$ & 21 & $7 / 29199$ & $K C$ & White & Tyveke & WE & 97 & 37.69 & 0.21 & 057 & & & & & & & & \\
\hline$T-160$ & 24 & 89190 & KC & White & Tywede & WB & 151 & 37.38 & 0.09 & 024 & & & & & & & & \\
\hline THed & 25 & $7 / 29 / 99$ & $K C$ & White & Tyweke & WB & 135 & 35.95 & 006 & 0.17 & & & & & & & & \\
\hline$T-205$ & 26 & $6 / 24 / 99$ & $K C$ & White & Tyreko & WB & 167 & 37.67 & 0.20 & 0.54 & & & & & & & & \\
\hline
\end{tabular}

